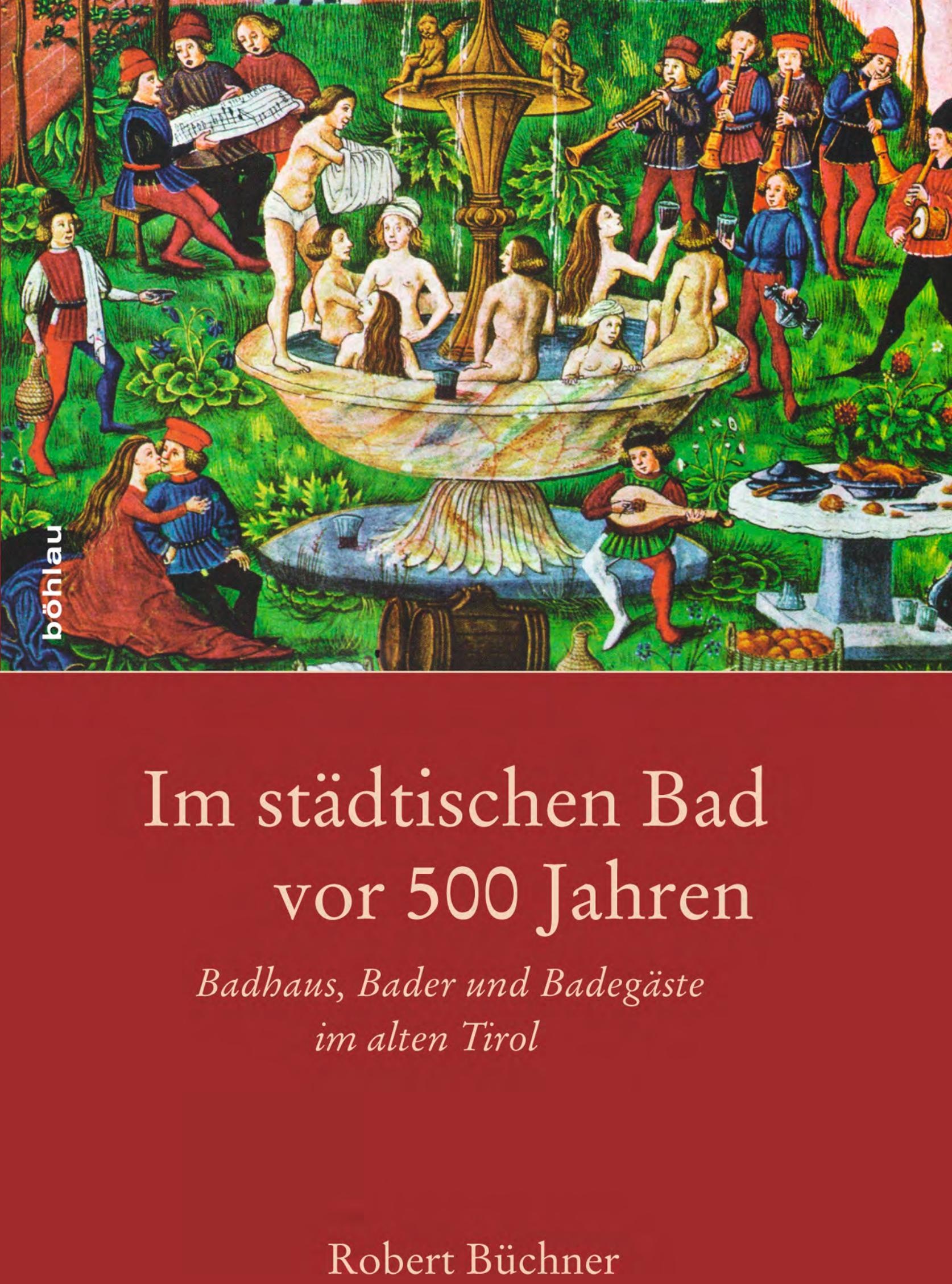


böhlau 

Robert Büchner

\section{IM STÄDTISCHEN BAD VOR 500 JAHREN}

Badhaus, Bader und Badegäste im alten Tirol

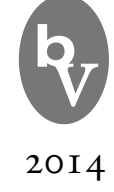

Böhlau Verlag Wien Köln Weimar 


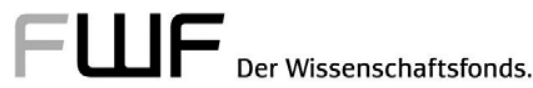

\section{Veröffentlicht mit der Unterstützung des Austrian Science Fund (FWF): PUB 91-V18}

Bibliografische Information der Deutschen Nationalbibliothek:

Die Deutsche Nationalbibliothek verzeichnet diese Publikation in der Deutschen Nationalbibliografie; detaillierte bibliografische Daten sind im Internet über http://dnb.d-nb.de abrufbar.

Umschlagabbildung: Miniatur aus Johannes de Sacrobosco, De Sphaera, um 1470, Biblioteca Estense, Modena, MS lat. 209 (X.2.14), fol. 10. @ Su concessione del Ministero per i Beni e le Attività Culturali

(C) 2014 by Böhlau Verlag Ges.m.b.H \& Co. KG, Wien Köln Weimar

Wiesingerstraße 1, A-1010 Wien, www.boehlau-verlag.com

Alle Rechte vorbehalten. Dieses Werk ist urheberrechtlich geschützt.

Jede Verwertung außerhalb der engen Grenzen des Urheberrechtsgesetzes ist unzulässig.

Korrektorat: Katharina Krones, Wien

Umschlaggestaltung: Michael Haderer, Wien

Satz: Michael Rauscher, Wien

Druck und Bindung: Balto print, Vilnius

Gedruckt auf chlor- und säurefrei gebleichtem Papier

Printed in Lithuania

ISBN 978-3-205-79509-4 


\section{Inhalt}

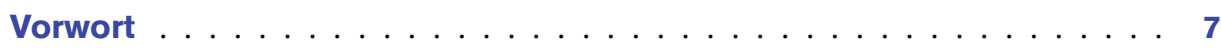

1. Das Badewesen bis ins 16. Jahrhundert . . . . . . . . . . . . . . 9

I. I Das Badhaus . . . . . . . . . . . . . . . . . . . 12

I.2 Der Betrieb im Schwitzbad . . . . . . . . . . . . . . . . . 16

I.3 Wannenbad und Baderof . . . . . . . . . . . . . . . . . . . . 22

r.4 Der Bader . . . . . . . . . . . . . . . . . . . . . . . . 24

I.5 Die Gehilfen des Baders . . . . . . . . . . . . . . . . . . 33

r.6 Die Trinkstube . . . . . . . . . . . . . . . . . 38

г.7 Badebordelle . . . . . . . . . . . . . . . . . . . 40

2. Das Badewesen vom 16. bis zum 19. Jahrhundert . . . . . . . . . . . 46

2.r Private Bäder, Badezimmer . . . . . . . . . . . . . . . 47

2.2 Gutes Wasser, böses Wasser . . . . . . . . . . . . . . . . . . . 52

2.3 Neues Baden, neue Bäder . . . . . . . . . . . . . . . . . . 57

3. "Gemainer Stat Pad" zu Rattenberg . . . . . . . . . . . . . . . . . . 66

3. I Vorhäusl und Umkleideräume . . . . . . . . . . . . . . . . . . . . . . . 66

3.2 Die beiden Badestuben . . . . . . . . . . . . . . . 68

3.2.I Gitter, Trog, Badekessel und -ofen . . . . . . . . . . . . . . . 68

3.2.2 Heizraum und Knechtskammer . . . . . . . . . . . . . . 71

3.2 .3 Boden und Bänke . . . . . . . . . . . . . . . . . . . 72

3.2 .4 Vertäfelte Wände . . . . . . . . . . . . . . . . . . . . . . 73

3.2 .5 Fenster . . . . . . . . . . . . . . . . 75

3.2 .6 Wasserversorgung . . . . . . . . . . . . . . . . . . . . . . . . . . . 76

3.3 Die Trinkstube . . . . . . . . . . . . . . . . 78

3.4 Der Abtrittserker . . . . . . . . . . . . . . . . . . . . 80

3.5 Das Holzkämmerl . . . . . . . . . . . . . . . . . . 81

4. Bader, Badknechte, Reiberinnen und Gewandhüterinnen

zu Rattenberg . . . . . . . . . . . . . . . . . . . . 82

4. I Erste Namen, Michael Hueber d. Ä. . . . . . . . . . . . . . . . . . . . . . . . . . . . . 8

4. I. I Bader im Kloster und Umland . . . . . . . . . . . . . . . . . . . . 84

4.2 Heinrich Öttinger . . . . . . . . . . . . . . . . . 87 
4.2. I Das Maibad . . . . . . . . . . . . . . . . . . 90

4.3 Gabriel Freytag $\ldots \ldots \ldots . \ldots \ldots 2$

4.3. I Krankheiten . . . . . . . . . . . . . . . . . 94

4.4 Hans Kentler . . . . . . . . . . . . . . . . . . . . . . . . 98

4.5 Michael Hueber d. J. . . . . . . . . . . . . . . . . . . . . . . . . . . 99

4.5. I Private Bäder . . . . . . . . . . . . . . . . 103

4.5.2 Das Hochzeitsbad . . . . . . . . . . . . . . . . . 105

4.6 Hans Püchler . . . . . . . . . . . . . . . . . . . . . . 107

4.6. I Reiberin und Gewandhüterin . . . . . . . . . . . . . . . . 111

4.7 Michel Schwegler . . . . . . . . . . . . . . . . . . . . 116



4.8 Matheus Paungartner . . . . . . . . . . . . . . . . . . . . . . . . . . . . . . . 12

4.9 Hans Fäler d. Ä. . . . . . . . . . . . . . . . . . . . . . . . . . 124

4. ı . Hans Fäler d. J. . . . . . . . . . . . . . . . . . . . . . 132

Zusammenfassung . . . . . . . . . . . . . . . . . 139

Anmerkungen ........................ 143

Sigeln ........................... 174

Archivalien ......................... 175

Quellen und Literatur . . . . . . . . . . . . . . . . . . . 177

Register . . . . . . . . . . . . . . . . . . . . 184

a) Orte . . . . . . . . . . . . . . . . . . . . . . . 184

b) Personen . . . . . . . . . . . . . . . . . . . . . . 187

c) Sachen . . . . . . . . . . . . . . . . . . . . . 191

Bildnachweis . . . . . . . . . . . . . . . . . 195 


\section{Vorwort}

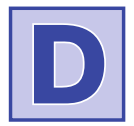

ass in den Städten des Deutschen Reiches seit dem Spätmittelalter das öffentliche Badeleben aufblühte, bis ihm privates Baden sowie Sauerbrunnen, Kur-, Thermal-, Mineral-, Kalt- und Seebäder den Rang abliefen, ist längst bekannt und in vielen Bereichen gut erforscht, namentlich seit Alfred Martins grundlegendem Werk »Deutsches Badewesen in vergangenen Tag« (Jena I906). Nimmt man eine moderne Studie zum Thema wie die von Birgit Tuchen ${ }^{1}$ zur Hand, findet man eine Fülle von Material über Badhäuser, Bader und Badewesen in süddeutschen und schweizerischen Städten (z.B. Wimpfen, Chur, Eberbach, Kulmbach, Ulm, Winterthur) ausgebreitet, auch zur Architektur. ${ }^{2}$ Einen Historiker, der sich mit Bädern in Tiroler Städten befasst, kann da nur der blanke Neid packen, weil er resigniert feststellen muss: Vergleichbares gibt es hier nicht, weder fürs Mittelalter noch für die Neuzeit. Es scheint fast, um im Bild zu bleiben, dass die Forscher bei diesem Thema kalte, nasse Füße bekommen hätten.

Zwar findet man genügend kleinere und größere Darstellungen zu Bauernbadln, Kur-, Thermal-, Mineral- und Wildbädern, wie immer man sie nennen mag (Altprags, Brennerbad, Häring, Innichen, Maistatt ${ }^{3}$ usw.), sogar zu Heubädern, doch eine eindringliche Arbeit über öffentliche Bäder in Tiroler Städten der frühen Neuzeit sucht man vergebens. Man hat sich mit kleinen, eher bescheidenen Artikeln in Zeitungen oder lokalen Zeitschriften, mehr journalistisch als historisch, und mit flüchtigen Bemerkungen in diversen Stadtgeschichten zufriedenzugeben. Das war's. Die einzige rühmliche Ausnahme bilden Heinz Mosers Ausführungen über »Bader, Barbiere, Chirurgen und Wundärzte« in der Stadt Hall. ${ }^{4}$

Was bislang an Schrifttum über das Rattenberger Bad existiert, reiht sich nahtlos in die Forschungsmisere ein. Ein kurzer Artikel in einer Zeitung, ${ }^{5}$ ein paar Seiten in einer Geschichte der Stadt am Inn, ${ }^{6}$ und damit hat es sich. Alles andere ist unerheblich, das Vorhandene zudem in mancher Beziehung fragwürdig oder falsch, wie schon an Bachmann und Stops gezeigt werden kann. Dabei ist die Quellenlage für Rattenberg durchaus als günstig anzusehen. Trotz gewaltiger Verluste ermöglichten es die Ratschlagbücher ${ }^{7}$ und Baumeisterrechnungen ${ }^{8}$ aus dem Stadtarchiv Rattenberg eine geschlossene Reihe der Bader von ca. I 482 bis I 58 I, dem zeitlichen Ende der vorliegenden Untersuchung, zu erstellen und sie biographisch abzuhandeln, mal mehr, mal weniger, je nach Quellenbefund. Dabei ergaben sich Einblicke in die Arbeitsweise der Bader und ihres Personals, in gewissem Maße auch in ihre sozioökonomischen Lebensumstände, Erkenntnisse, die häufig tiefer greifen, als es bisher in anderen thematisch relevanten Studien der Fall war. Die so oft nötigen Reparaturen, wovon 
die Raitungen der städtischen Baumeister übervoll sind, vermitteln auch ohne baugeschichtliche Untersuchung ein einigermaßen zutreffendes Bild vom Badhaus und seinen Einrichtungen.

Gemessen an den erwähnten Quellen sind andere wie die nur in Einzelstücken erhaltenen Rechnungen des Spitals, der St. Virgilkirche, der städtischen und Bergwerksbruderschaft genauso wenig ergiebig gewesen wie die Raitbücher und -hefte der Stadt, brachten aber doch in dem einen oder anderen Fall eine erfreuliche Ergänzung, namentlich was die wundärztliche Tätigkeit der Bader betrifft. Nur vereinzelt waren Kopialbücher, Urkunden, Handschriften aus dem Tiroler Landesarchiv, aus der Bibliothek des Landesmuseums und aus dem Stadtarchiv Rattenberg eine Hilfe, etwas häufiger die Verfachbücher (Gerichtsbücher) des Stadt- und Landgerichts Rattenberg. Im Gegensatz zu diesen Archivalien erwiesen sich die Rechnungsbücher des ehemaligen Augustinerklosters Rattenberg über die Jahre 1482 bis $1539^{9}$ als sehr wertvoll, besonders für jene Jahre, die nicht durch die Ratschlagbücher und Baumeisterrechnungen abgedeckt werden.

Da die benutzten Quellen offiziellen oder kirchlichen Charakter tragen und nicht dem privaten Bereich entstammen, findet man in ihnen kaum Angaben über die "Badewonnen«, die seinerzeit die Rattenberger gern genossen. Vereinzelt dastehende Hinweise auf Hochzeitsbad, Maibad, Trinkstube lassen aber erkennen, dass sich Rattenberg in seiner Badekultur nicht von anderen Städten unterschied. Um sie deutlich zu machen, musste vergleichsweise auf die Literatur zu anderen Bädern und zum Baden überhaupt zurückgegriffen werden, namentlich in den einleitenden Kapiteln über das Badewesen im Mittelalter und in der Neuzeit bis ins I9. Jahrhundert.

Die eingefügten Zeichnungen, Miniaturen, Holzschnitte, Kupferstiche, Radierungen, Lithographien, Gemälde sollen den Text illustrieren. Die Bildunterschriften sind in der Regel kurz gehalten, ausführlicher lediglich dann, wenn der Inhalt einer Illustration über den zugehörigen Text hinausgeht, wenn z.B. ganze Badeszenen erfasst werden, das Innere einer Badestube genauer dargestellt ist, es sich um wichtige Einzelheiten in Städteansichten handelt, der Zweck eines abgebildeten Gerätes nicht ohne weiteres zu erkennen ist oder eine Badeprozedur in ihrem Ablauf wiedergegeben wird. 


\section{Das Badewesen bis ins 16. Jahrhundert}

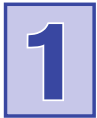

6 Io schrieb der Arzt Hippolyt Guarinoni in seinen "Grewel der Verwüstung Menschlichen Geschlechts« von den Schweiß- und Dampfbädern, dass »darauff der gemein Böffel und vil ansehenliche Burger aller Stätten dermassen steiff und starck halten, daß sie vermeyneten, viel verloren und verabsaumbt zu haben, wann sie nit alle Sambstag vor dem Sonntag oder alle Feyrabend vor den Fest- und Feyrtägen in das gemeine feil oder besondere Schweißbad gehen, schwitzen, sich reiben, fegen, butzen und abwaschen lassen sollten«. Es sei »kein Stadt, kein Marckt, kein Dorff so gering, welches nicht sein Bad habe.« Hinzu kämen noch die Bäder, welche »die ansenlichen selbsten in ihren Häusern besonders haben ${ }^{10}{ }^{10}$ Mögen auch noch um I60o in der Salinenstadt Hall, wo Guarinoni lebte, die "gemeinen« Bäder eifrig besucht worden sein, ${ }^{11}$ für viele andere Städte traf das nicht mehr zu. Die Blütezeit ihrer öffentlichen Bäder war damals vorbei, der Zulauf hatte schon mehr oder weniger stark nachgelassen. In früherer Zeit sah das jedoch ganz anders aus.

Als im r 2. Jahrhundert die öffentlichen Dampf- oder Schwitzbäder in den Städten aufkamen, ${ }^{12}$ war das nicht ein Wiederaufleben der alten römischen Thermenherrlichkeit, stellte auch nicht ein Anknüpfen an die Baderäume des Adels und der Klöster mit ihren Sitzbädern und Zubern dar, sondern bedeutete in unseren Breiten eine Übernahme der Hofbadestuben des bayerischen Alpen- und Voralpenlandes, deren Tradition bis ins Frühmittelalter zurückreicht. Sie waren einfache Holzhütten mit einer Feuerstelle oder einem Ofen, in dem Steine geschichtet und mit Wasser übergossen wurden, um Dampf zu erzeugen. Die öffentlichen Bäder, die meist auch Vollbäder in Wannen anboten, breiteten sich mit dem Aufblühen der Städte rasch aus, bald gab es keine Stadt, die nicht mehrere Bäder besaß, lediglich die kleinen Orte begnügten sich mit nur einer Badstube. So zählte Paris I 292 bereits 26 Bäder, Mainz hatte im I4.Jahrhundert vier, im I 5 . Jahrhundert fand man in Würzburg acht, in Ulm elf, in Schwäbisch Hall vier und in Nürnberg zwölf gemeine Badstuben. Sie waren aus dem alltäglichen Leben nicht mehr fortzudenken. ${ }^{13}$

Tirol stand nicht zurück. Für Brixen werden schon zu I 2 I 8 ein Bader und seine Söhne erwähnt, ${ }^{14}$ in Bozen sind zu 1237 ein Bader und zu I 242 eine Badstube dokumentiert, ${ }^{15}$ für Hall eine solche zu I335. ${ }^{16} \mathrm{Im}$ I 4 . Jahrhundert waren noch Bader und öffentliche Bäder in Innsbruck, Meran und Sterzing anzutreffen, ${ }^{17}$ um I $400 \mathrm{zu} \mathrm{Kitz-}$

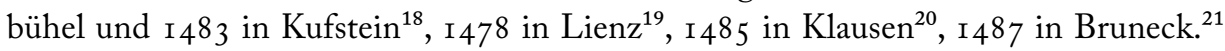
In Süddeutschland, Österreich und der Schweiz drangen die gemeinen Badhäuser ins ländliche Gebiet, in die Dörfer, zumindest in größere, vor. ${ }^{22}$ I 506 hatte z.B. schon Auer 

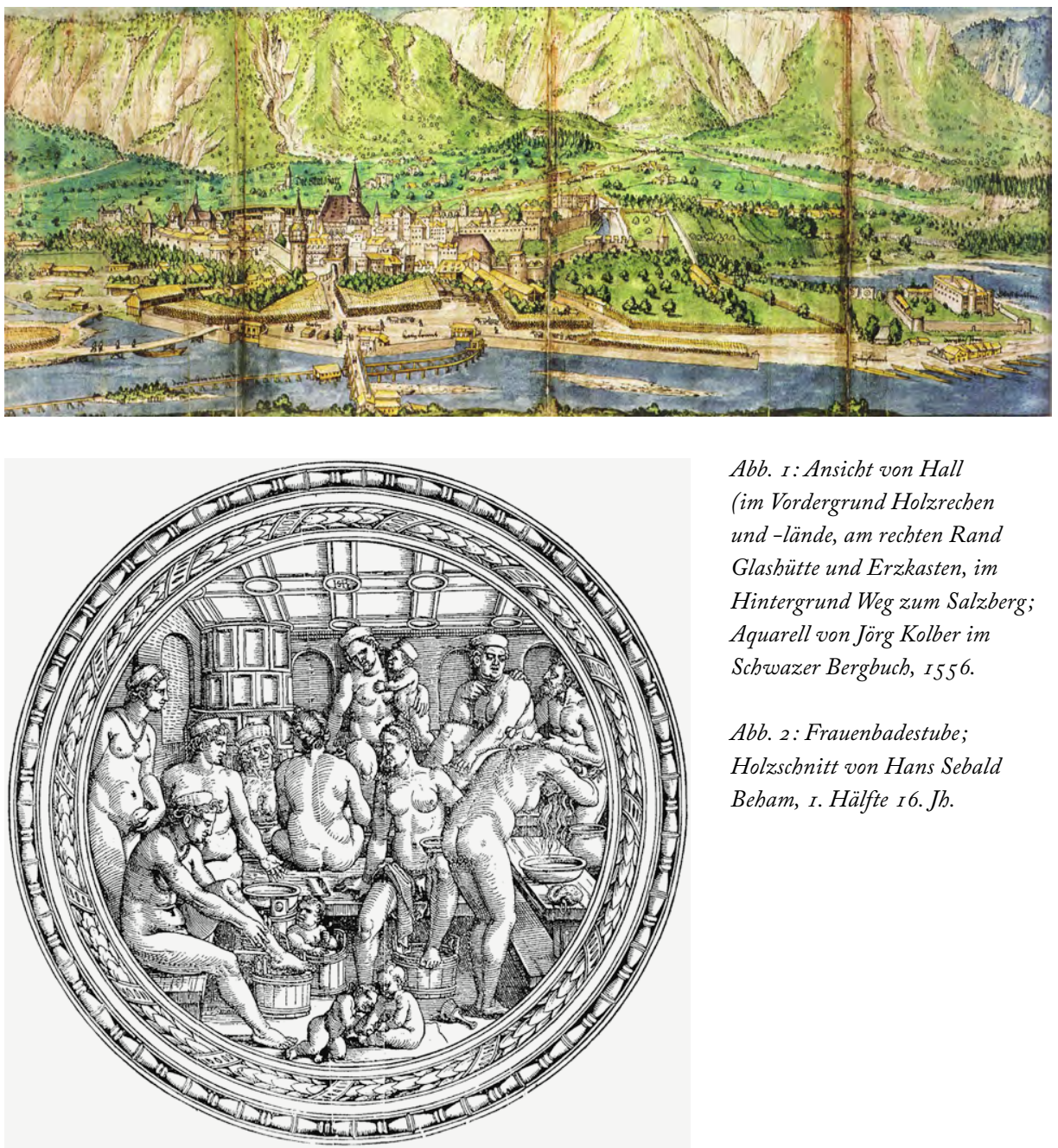

Abb. I: Ansicht von Hall

(im Vordergrund Holzrechen

und-lände, am rechten $R$ and

Glashütte und Erzkasten, im

Hintergrund Weg zum Salzberg;

Aquarell von Jörg Kolber im

Schwazer Bergbuch, ${ }_{55} 6$.

Abb. 2: Frauenbadestube;

Holzschnitt von Hans Sebald

Beham, I. Hälfte I6. Jh.

ein solches, das 1708 eingestellt wurde. ${ }^{23}$ Allerdings dürften sich öffentliche Bäder in Tiroler Dörfern nicht immer rentiert haben. Denn nach den Urkunden und Katastern zu urteilen gehörte häufig zu einem Bauernhof nicht nur Haus, Stadl, Stall und Kasten, sondern auch ein Backofen und eine »Padstuben«. Sie lag in einem separaten Häuschen, das im Erdgeschoss eine Feuerstelle besaß und wo man Schwitz- und Wannenbäder nehmen oder Wäsche waschen konnte. ${ }^{24}$ In Bayern gehörten die Badstuben neben den Schmieden, Mühlen und Tavernen zu den »ehaften« Institutionen, waren also rechtlich privilegiert und an Genehmigung durch den Stadt- oder Landesherren 
Abb. 3: Der Dichter Jakob von Warte badet unter einem Baum, bedient von zwei Jungfrauen mit Blumenkranz und Kelch, eine dritte massiert ihn, links ein Warmwasserkessel mit Heizerin; Miniatur aus der Heidelberger Manesse-Handschrift, um 1320.

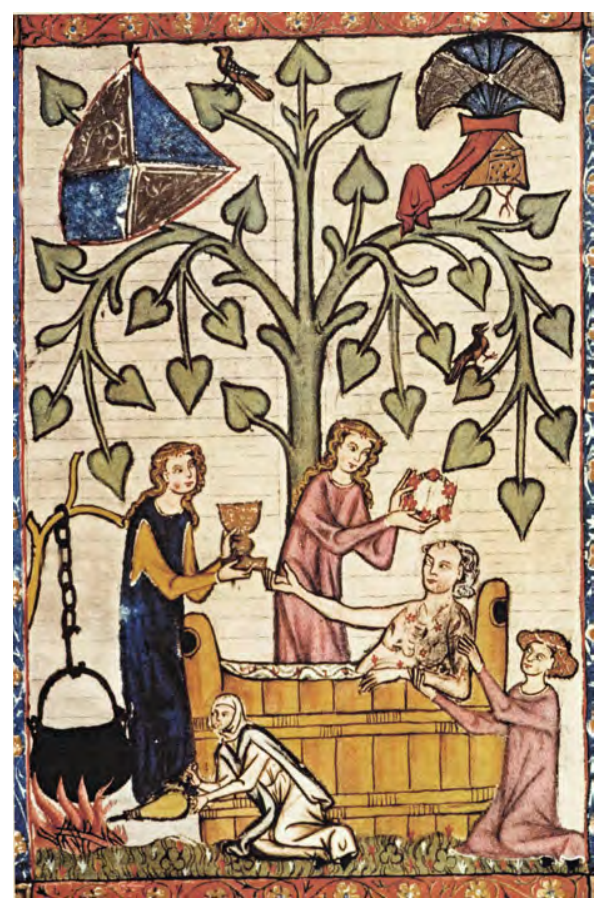

gebunden. Um den dörflichen Bädern ihr Publikum zu sichern, verbot die bayrische Regierung die "sonderbaren Padstuben« der "Paursleut» in ihren »Hausswohnungen" und gestattete solche nur Leuten, die in Einöden im Gebirge wohnten und einen weiten Weg zu den »eehaft Pädern « hatten. ${ }^{25}$ Es ist möglich, dass hinter dieser Verordnung nicht nur das Gewinnstreben der Herrschaft und Badstubenbesitzer steckte, sondern dabei auch wie in Württemberg das kommunale Selbstverständnis eine Rolle spielte, das sich in der Existenz gemeinnütziger Einrichtungen wie einer Badestube ausdrücken konnte. ${ }^{26}$

Adel und Klöster, die lange Zeit Wannenbäder vorgezogen hatten, wählten im Spätmittelalter mehr und mehr Schwitzbäder. ${ }^{27}$ Dampfbäder hat es schon früher auf einzelnen Burgen gegeben, doch lassen sie sich dort - wie Badestuben überhaupt nur selten durch Grabungen nachweisen. ${ }^{28}$ Heißluftbäder, die man durch Erhitzen eines (Kachel-)Ofens nahm und wozu noch Dampf aus einem Kessel kam, waren in Deutschland kaum gebräuchlich. ${ }^{29}$ 


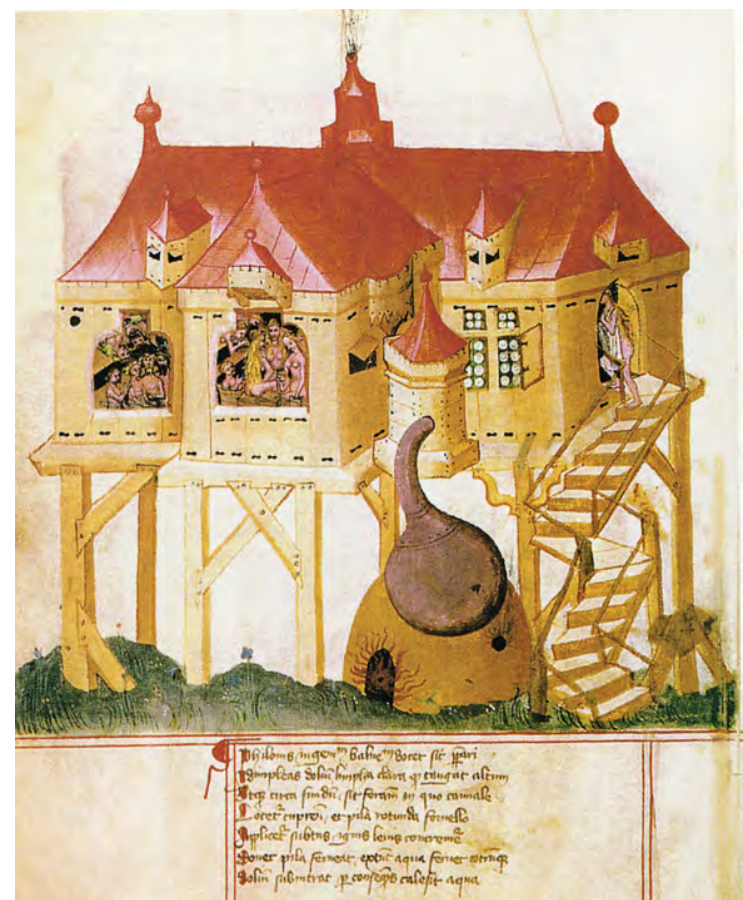

Abb. 4: Badhaus (gemauerter

Kuppelofen mit kupferner Sudblase,

Frauen-und Männerstube, auf

der Treppe eine kaum bekleidete

Badbesucherin); kolorierte Zeichnung aus dem »Bellifortis « des Konrad Kyeser, I 405 .

\subsection{Das Badhaus}

In der Frühzeit entnahm man häufig das Wasser für das Bad fließenden Gewässern, weshalb man gern die Badstuben in ihrer Nähe errichtete. Das konnten auch abgeleitete Gewerbekanäle oder künstlich in die Stadt geführte Bäche sein. Nicht selten lagen die Badhäuser an der Peripherie oder den Toren einer Stadt. Dabei bedingten sich Randlage und Fließgewässer gegenseitig. Ein Zusammenhang zwischen dem Standort eines Bades am Stadtrand und der Feuergefahr ist im Allgemeinen nicht zu erkennen. Wasser bezogen die Bäder aus einem Grundwasserbrunnen im oder beim Bad, manchmal aus einer hauseigenen Quelle und, wie erwähnt, aus natürlichen oder künstlichen Gewässern. Ende des Mittelalters lenkte man meist fließendes Wasser (von einem Laufbrunnen) durch eine Röhrenleitung ${ }^{30}$ zu einem Becken im Bad, eine wesentliche Erleichterung, mussten doch nun nicht mehr Träger oder Badknechte mühsam das Wasser aus einem Gewässer oder einem Ziehbrunnen, die mancherorts fortbestanden, herbeischleppen. Außerdem bekam man so wirkliches Frischwasser, waren doch inzwischen die städtischen oder stadtnahen Flüsse, Bäche und Kanäle oft stark verschmutzt. ${ }^{31}$

In der Regel war ein Badhaus nicht unterkellert und hatte zwei Geschosse. Im Erdgeschoss befanden sich die Baderäume, im Obergeschoss hatte der Bader seine Woh- 
nung (Stube, Küche, Kammern, Abtritt). Das Haus war meist ein Massivbau, doch gab es auch Bäder mit einem Obergeschoss aus Fachwerk. Öffentliche Badhäuser in reiner Holzbauweise traf man nur sehr selten an. ${ }^{32}$

Zentraler und größter Raum eines jeden Badhauses war die Badstube. Gab es nur eine für beide Geschlechter, dann badeten Männer und Frauen zu unterschiedlichen Tageszeiten oder an verschiedenen Tagen. War Platz für zwei Baderäume, wurde die Männer- von der Frauenstube durch eine hölzerne, seltener durch eine massive Trennwand geschieden. In diesem Fall wurde der Badeofen an die Trennwand zwischen beiden Stuben gesetzt und die Schwitzbänke unmittelbar vor den Ofen gestellt. Oder der Ofen stand im größeren Raum direkt an der Trennwand und wurde zu beiden Stuben geöffnet. Damit die heiße Luft sich gleichmäßig in beiden Badstuben ausbreiten konnte, wurde die Trennwand nicht bis zur Decke hochgezogen, sondern im oberen Teil nur mit einem Gitter (»Gätter «) versehen. ${ }^{33}$

Die Badegäste saßen auf unterschiedlich hohen Holzbänken, meist in drei Stufen voneinander geschieden. Den besten Schwitzeffekt erreichte man auf der höchsten Bank dicht unter der Decke, wo die heißeste Luft war und wo sich mit einem Blick durch das Gitter die erfreuliche Möglichkeit bot, seine anatomischen Kenntnisse über das andere Geschlecht zu vervollständigen. Kein Wunder, dass die oberste Bank sehr beliebt war und gern benutzt wurde, bisweilen zu lange, so dass schon einmal einer ohnmächtig herabsank. Kein Wunder auch, dass ein strenger Moralist wie Guarinoni sich über die Gitter empörte. Er schreibt:

»Und ob gleichwol hültzene dinne Wänd entzwischen unnd Mann von Weib underschieden, so ist doch in gemein die ober halbe Wandt gegättert, damit die Hitz hindurch möge, das Holtz erspart und Unzucht gemehrt, und wer der Höhe zusteigt, im Ansehen der Weiber und die Weiber der Männer ergetzt werden. Unnd ist uber diß stets die Thür offen und die Bader und Schandknecht hin und wider auß unnd ein lauffen, daß eins das ander gar wol sehen kann, und gleich wie mit einer Badhitz beede Zimmer gehitzt werden, also wirdt beedes Geschlecht mit einer Unzucht verstrickt. ${ }^{34}$

Es ist bekannt, dass Guarinoni zu Übertreibungen neigte, namentlich dann, wenn er sich über die herrschende Sittenverderbnis entrüstete, aber er war auch ein scharfer, genauer Beobachter seiner Umwelt, so dass man ihn nach gewissen Abstrichen als korrekten Chronisten seiner Zeit ansehen darf. Einige seiner Bemerkungen zum (Haller) Badewesen sind sicher überzeichnet, aber kommen trotzdem der Wirklichkeit nahe. Ein »Gitterfenster« im Bad hatte übrigens auch Rattenberg.

Der meist bis zur Raumdecke aufgemauerte Badeofen hatte eine vertiefte Brennkammer und wurde von einem Nachbarraum aus beheizt. Im Oberbau des Ofens lagen in einer Bogenöffnung locker geschichtete Steine. Sie dienten dazu, die Wärme über 


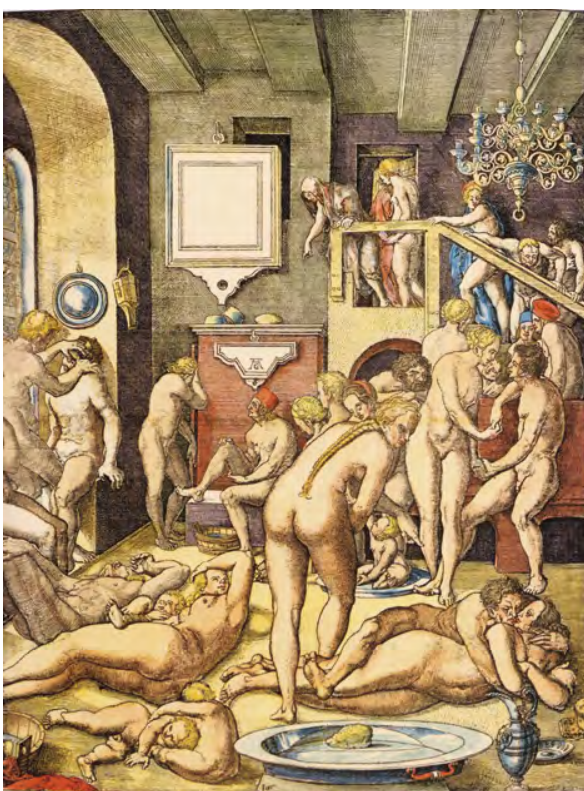

Abb. 5: Badestube mit gemischtem Publikum; kolorierter Kupferstich von Heinrich Aldegrever nach einer Zeichnung von Virgil Solis, um I55․

eine längere Zeit zu speichern und den Saunadampf zu erzeugen, indem man sie mit Wasser übergoss. Erst wenn das Holz im Ofen ausgebrannt war und man die Rauchgase durch Lüften nach außen geleitet hatte, konnte das Bad aufgesucht werden. Die anfangs üblichen Balkendecken in Badstuben wurden später fast immer durch ein nachträglich eingebautes Gewölbe ersetzt. ${ }^{35}$

Die Wände der Badstube konnten mit Holz verkleidet sein. Da aber eine Vertäfelung teuer war und unter der Feuchtigkeit litt, hatten die meisten Schwitzstuben nur glatt verputzte Wände, die regelmäßig getüncht wurden. ${ }^{36}$ Das Wasser, das unvermeidlich auf den Boden floss oder geschüttet wurde, war der Grund, weshalb die Böden der Badstuben aus Ziegelsteinen oder Steinplatten bestanden. Fußböden aus Dielen waren sehr selten. Rinnen im Boden sorgten dafür, dass das Schmutzwasser abgeleitet werden konnte. ${ }^{37}$ Die Badstube enthielt mehrere Fenster, um den Raum mit Licht zu versorgen und durch ausgiebiges Lüften den Dampf abziehen zu lassen. Nahm man anfänglich zur Verglasung Butzenscheiben, so findet sich seit dem I6. Jahrhundert rechteckiges oder rautenförmiges Flach- oder Waldglas. ${ }^{38}$

Solange einem Badhaus kein Fließwasser zugeführt wurde, enthielt seine Schwitzstube einen Trog für kaltes Wasser. In ihr stand, falls kein Vorbad existierte, ein beheizter Kessel für warmes Wasser, womit man die Wannen für ein Vollbad füllte oder sich vor dem Bad abgoss und nach der Schwitzkur den Körper von Schmutz und Schweiß reinigte. Nicht alle Badhäuser verfügten über ein Vorbad als Hauptzugang zum Bad, 
Abb. 6: Badestubenszene: Die Gäste stellen ibre Füße in warmes Wasser, damit das Blut »kliog und dünn "werde, bevor ihnen der Bader die Schröpfköpfe ansetzt; Schröpfköpfe am Kinn sollen gegen Zahnweh helfen, solche auf der Brust sind gut für die Leber; Holzschnitt aus Georg Bartischs "Ophthalmodouleia", 1583 .

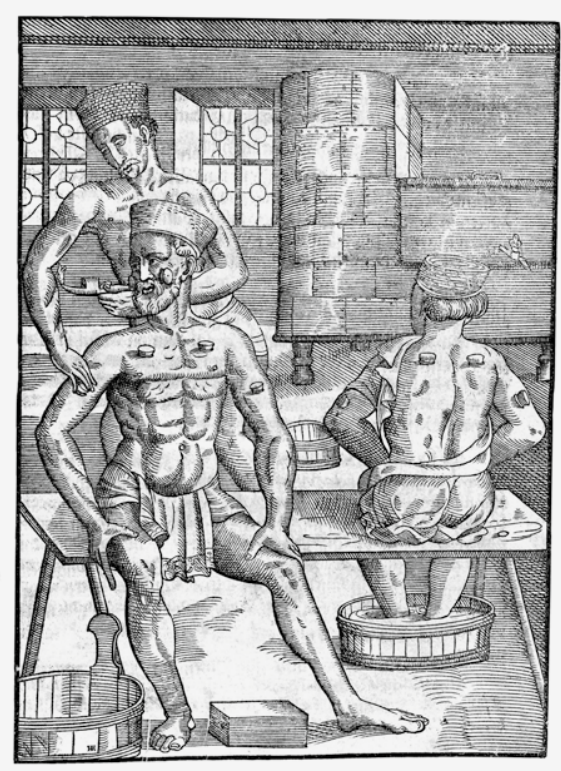

von wo aus man in die Badstube und in den Umkleideraum gelangte. Außerdem war das Vorbad so etwas wie eine Wärmeschleuse. ${ }^{39}$ Hygienische oder medizinische Tätigkeiten verrichtete der Bader hinten in der Schwitzstube, wenn kein gesonderter Raum für Kopfwaschen, Haarschnitt, Rasur, Aderlass und Wundbehandlung vorhanden war. Dann befand sich auch das nötige Mobiliar wie Scherbank, Tisch, Schemel, Stühle in der Badstube, gleichfalls die zugehörigen Geräte. ${ }^{40}$

Eine wichtige Räumlichkeit im Bad war der Umkleide- und Ruheraum, häufig als »Abziechstube« bezeichnet. Er diente zum Ablegen des Straßengewandes und Anziehen der Badekleidung sowie zum Ausruhen nach dem Bad. Es war ja empfehlenswert, sich nach dem Schwitzbad nicht gleich der kälteren Außenluft auszusetzen, sondern sich allmählich abzukühlen. Im Umkleideraum, der sich meist zu ebener Erde, seltener im Obergeschoss befand, standen Betten oder Bänke, er wurde durch einen Kachelofen beheizt. Gab es zwei Badestuben, getrennt für Männer und Frauen, lassen sich auch zwei Umkleideräume nachweisen. Wo die Abziehstube fehlte, zog man sich schon daheim um oder tat das in der Badstube selbst. Kleinere Bäder hatten nicht selten nur eine bescheidene Garderobe und kamen darin ohne Ruhebetten bzw. -bänke aus. $^{41}$ 


\subsection{Der Betrieb im Schwitzbad}

Ging ein mittelalterlicher Mensch ins Bad, dann machte er sich keine Gedanken über das Wasser in seinen Symbolfunktionen, z.B. als magisches Zeichen der Erneuerung und Wiedergeburt, in der Taufe als sakramentales Sinnbild der geistlichen Neugeburt, er sann nicht über die Macht des Wassers nach, Leben und Kraft zu verleihen, es schien ihm auch nicht als heilig. ${ }^{42}$ Solche Überlegungen lagen ihm normalerweise fern. Das Bad war für ihn ein Ort der Hygiene, Entspannung, Regeneration des Körpers und, saß er allein in einer Wanne oder Privatsauna, der Meditation. Wasser galt zudem weithin als heilkräftig und gesundheitsfördernd, ${ }^{43}$ nicht nur solches in Mineral- und Kurbädern. Man eilte nicht nur der Reinigung wegen ins Bad, sondern auch zum Vergnügen, zur Kurzweil, zum Essen und Trinken, der Geselligkeit wegen. Jedes Bad war ein wichtiger Ort der Sozialkontakte. Man feierte im Bad Feste und Jubiläen, erwies fremden Gästen oder Gesandten die Ehre eines kostenlosen Badbesuchs. ${ }^{44}$

Baden galt dem Mittelalter als eine der sieben Seligkeiten, ${ }^{45}$ wurde so sehr als ein Grundbedürfnis angesehen, dass Handwerker und Gesellen normalerweise für den Samstag oder nach Abschluss ihrer Arbeit ein Badgeld erhielten. Mancherorts räumte man ihnen während der Arbeitszeit Stunden für den Badbesuch ein. Auch Knechten, Mägden und Beamten hat man ein Badgeld verehrt. ${ }^{46}$ Ein typisches Zeichen christlicher Karitas waren die sogenannten Seelbäder, d.h. fromme, meist letztwillige Verfügungen, um Armen ein kostenloses Bad zu ermöglichen. Als Gegenleistung mussten sie für das Seelenheil des verstorbenen Stifters beten. Bisweilen gewährte auch der Rat einer Stadt den Armen ein einfaches Bad. ${ }^{47}$

Die öffentlichen Badstuben auf dem Lande waren nur ein- bis zweimal in der Woche geöffnet, in der Stadt wurde meist an drei Wochentagen gebadet, und zwar in der Regel am Montag, Mittwoch und Samstag. Als der Badbesuch seit dem I6. Jahrhundert nachließ, fiel zuerst der Montag, dann auch der Mittwoch als Badetag aus und es blieb nur noch der Samstag übrig. An Sonn- und Feiertagen sowie am Freitag war fast überall das Bad verboten. ${ }^{48}$

War das Feuer im Badeofen erloschen, waren die Rauchgase aus der Schwitzstube abgezogen, wurde die Öffnung des Bades den Besuchern bekannt gegeben. Das konnte ein Badejunge oder -knecht sein, der in Vers oder Prosa das Bad ausrief und dabei ein Messingbecken, eine Eisen- oder Kupferpfanne schlug. In manchen Orten, besonders in der Schweiz, signalisierte ein Horn- oder Trompetenstoß, dass die Badstube bezogen werden konnte. Wieder anderswo wurde ein bestimmtes Zeichen, z.B. ein Badequast, am Bad ausgehängt. ${ }^{49}$ Nun eilten die Gäste herbei.

Aber wie? Wenn man Guarinoni glaubt: schamlos. Er hält dem Stadtrichter und Bürgermeister vor: 
Abb. 7: Badeszene und Badhaus in Augsburg; Ausschnitt aus dem Augsburger Monatsbild AprilJuni, um I530.

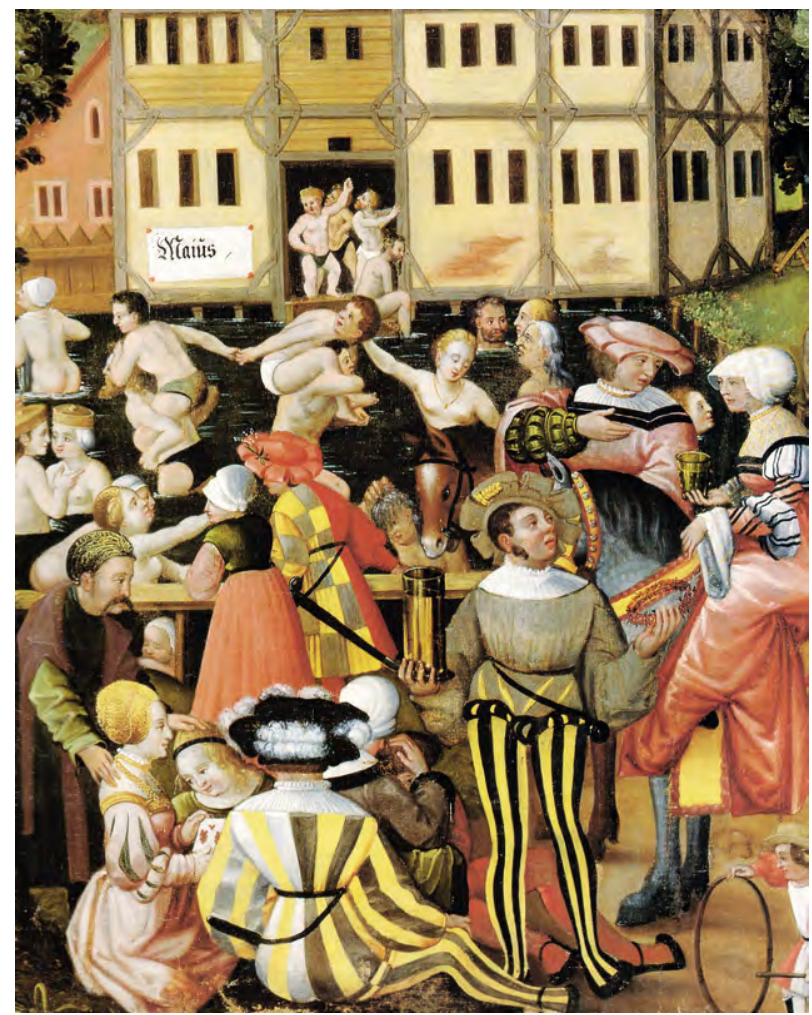

»Besinn dich, ob du nicht bißher gesehen hast und alle Wochen noch sihest, daß deine wol erzogne Burger und Burgerinnen sich in ihren Häusern entblössen und also nackend uber die offentliche Gassen biß zum Bad- oder Schandhauß vor aller fürgehenden Augen gehen dörffen? Ja damit diese lustige Zucht nicht abgehe, auch ihre junge Knaben und Töchter fein zeitlich darzu abrichten, damit sie fein früe die Geschämigkeit verlieren. Dann welche Töchter ins Luderhauß kommen sollen, die müssen ja fein zeitlich der Geschämigkeit abkommen und abgewohnen. Wie vil mal sihe ich (ich nenn darumb die Stadt nicht) die Mägdlein von ro, I2, I 4, I6 und I 8 Jaren gantz entblößt unnd allein mit einem kurtzen leinen, offt schleussigen und zerrißnen Badmantel oder wie mans hier zu Land nennt mit einer Badehr allein vornen bedeckt und hinden umb den Rucken Dieher unnd Füssen offen und die eine Hand mit gebür in dem Hindern haltend, von ihrem Hauß auß über die lang Gassen bey mitten Tag biß zum Bad lauffen? Wie vil laufft neben ihnen die gantz entblößten zehen-, zwölff-, viertzehen und sechtzehen järigen Knaben her und begleit das erbar Gesindel einander ins Schand- und Wüsthauß hinein? Ja wie vil mal laufft der Vatter bloß von Hauß mit einem eintzgen Niderwad uber die Gassen sambt seinem entblößten Weib und blossen Kindern dem Bad zu? ${ }^{50}$ 
Wer da meint, hier habe Guarinoni wieder maßlos übertrieben, sei auf den unbekannten niederösterreichischen Autor des Seifried Helbling verwiesen, der bereits Ende des I 3. Jahrhunderts in einem Gedicht vermerkte:

"Ich hôrte, daz der bader blies und sach mit niugebürstem hâr barfüez ân gürtel slîchen dar unser nâchgebûren drî巛. ${ }^{51}$

Barfuß und ohne Gürtel: Diese drei Nachbarn eilten offenkundig auch nur im Hemd zum Bad. Es gibt noch andere Nachrichten, dass Leute, selbst Standespersonen, schon im Badegewand auf den Gassen zu sehen waren. ${ }^{52}$ Man sollte sich nicht wegen der wenigen Zeugnisse, die von halbnackten oder leicht geschürzten Badegästen auf der Straße sprechen, täuschen lassen und meinen, das seien eben Ausnahmefälle gewesen. Viel wahrscheinlicher ist, dass die städtischen Obrigkeiten nur seltsame Praktiken und krasse Missbräuche rügten und im Übrigen luftig gekleidete Badbesucher als nicht auszurottendes Übel hinnahmen.

Der Grund dazu dürfte in der räumlichen Enge der vielen Kleinstädte des Mittelalters $^{53}$ gelegen haben. Man brauchte nur eben über eine Gasse, Straße, einen Platz oder kurz um die Ecke gehen und schon stand man vor dem Bad. Wozu dann sich erst darin umziehen, das konnte man schon gut und bequem zu Hause erledigen. Als Beispiel diene Rattenberg, eine kleine Stadt am Inn, in der zu Beginn des r6. Jahrhunderts rund 750 Leute wohnten. ${ }^{54}$ Kein Einwohner der Stadt war mehr als ca. $250 \mathrm{~m}$ vom Bad entfernt, ${ }^{55}$ die meisten hatten es wesentlich näher. Was Guarinoni über Halls Badbesucher sagt, wird auch auf Rattenberg zugetroffen sein, nur erfährt man nichts davon. Es war halt so üblich. Lediglich ein einziger Eintrag in den Ratsprotokollen des i6. Jahrhunderts lässt erkennen, dass sich auch die Rattenberger wenig um den Anstand scherten, wenn es um den Gang zum oder vom öffentlichen Bad ging. ${ }_{5} 6_{3}$ hielt der Rat Herrn Wolfgang (Antzinger), dem Frühmesser, und Meister Hans Fäler, dem Bader, vor, sie sollten den Leuten gegenüber "geschmeidig“ (höflich, konziliant) sein und nicht "zunässt « unter das Volk gehen. Meister Hans solle überhaupt nicht ins Bad gehen. ${ }^{56}$ Wenn Wolfgang Antzinger nass, also ohne sich abzutrocknen, aus dem Bad die ca. Ioo $\mathrm{m}$ zu seiner Wohnung eilte, kann er nicht in der Straßenkleidung oder Priestertracht gewesen sein, sondern dürfte nur ein Badehemd getragen haben. ${ }^{57}$ Was man an den einfachen Leuten durchgehen ließ und nicht für erwähnenswert hielt, tadelte man am Kleriker Antzinger als Standesperson. Wenigstens er sollte auf gutes Benehmen achten.

Hall hatte eine zweieinhalb- bis dreimal so große Bevölkerung wie Rattenberg, besaß eine wesentlich größere bebaute Fläche und verfügte über vier öffentliche Bäder und nicht nur über eines wie Rattenberg. Doch auch in Hall werden die meisten Bewohner nur einen kurzen Weg zum gemeinen Bad gehabt und sich deshalb das Umkleiden im 




Abb. 8: Badestube (Heißluftbad, Kachelofen, Wannenbad, Schröpfen, Badehüte und -mützen), Spruch: "Die Welt ist ain Badhauß, die Jung gath ein, der Allth gath aus"; Deckfarbenmalerei auf Papier, um 1580 .

Abb. 9: Kopfwäsche, Reiben, Schwitzen im Bad, leicht bekleidet und barfuß aus dem Bad, ausgehängter Badequast als Zeichen für den Badebetrieb; Titelholzschnitt zu Philipp Allendorfs "Der Juden Badstub", I535.

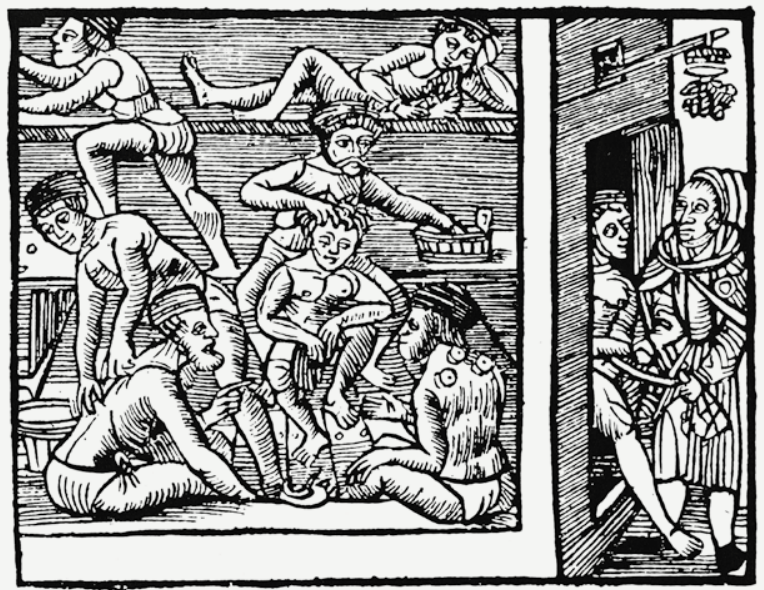

Badhaus erspart haben. Als hauptsächliche Benutzer erwähnt Guarinoni Handwerker und Bergleute, doch kamen auch Bürger und Bürgerinnen mit ihren Kindern, und zwar halbnackt, wie Guarinoni entrüstet feststellt, zum Bad. Möglicherweise war es nicht nur bloße Bequemlichkeit, wenn man sich schon zu Hause umkleidete, sondern zudem eine reine Vorsichtsmaßnahme, um sich gegen den Kleiderdiebstahl zu schützen. Denn der war in den Bädern weit verbreitet, selbst in bewachten Garderoben. ${ }^{58}$ Langfinger moch- 
ten die Badegäste selbst gewesen sein, doch genauso oft kamen wohl Badeknecht und -magd dafür in Frage, wie die Baderordnung Freiburgs aus dem Jahr I 477 zeigt. Darin heißt es, habe ein Meister von einem Diebstahl durch sein Gesinde erfahren, dann dürfe weder er noch sonst ein Meister eine solche diebische Person beschäftigen und anderes Badevolk solle sich weigern, mit ihr zusammenzuarbeiten. ${ }^{59}$

Im Allgemeinen legten angesehene Leute der Stadt ihre Straßenkleidung erst in der Abziehstube ab und brachten ihr Badegewand von zu Hause mit ${ }^{60}$. Bei Frauen war es ein kurzes ärmelloses Hemd, die »Badehr « ${ }^{61}$, bei Männern eine »Bruch» (Badehose), Unterhose, ein Hemd oder Kittel. Ob man mit einem Hemd immer sittsam bekleidet war ist zweifelhaft. Im spätmittelalterlichen Wiesbaden z.B. wurde darüber geklagt, dass man bei manchen Männern im Bad den Hintern, bei einigen Frauen die bloße Brust sehen könne. ${ }^{62}$ Da war wohl das Hemd zu kurz, der Ausschnitt zu groß. Wer es sich leisten konnte, brachte seine eigene Badewäsche, einen Bademantel, zumindest ein Badetuch oder Badelaken, auch eine Badekappe (Bademütze) oder einen Badehut (aus Stroh) und Quast mit. ${ }^{63}$

Ehe der Bader die Gäste einließ, wurden die Dielen und Bänke abgewaschen, weil sich während des Anheizens Ruß ${ }^{64}$ auf ihnen abgesetzt hatte. Gleichzeitig begoss man den Fußboden zur Abkühlung mit Wasser, da er heiß geworden war. ${ }^{65}$ Die eintretenden Besucher erhielten vom Bader oder seinem Knecht einen Badewedel, auch Quast genannt. Dies war ein Büschel aus belaubten Birken- oder Eichenzweigen und führte zu erhöhter Blutzirkulation und vermehrter Schweißabsonderung, wenn der Knecht damit den Körper des Gastes schlug und rieb. Um die Poren zu öffnen und Schmutz zu entfernen, wurde zuvor der Schwitzbadbesucher aus einem Schaff ${ }^{66}$ mit lauwarmem Wasser übergossen. Saß er auf der Bank, fächelte er sich mit dem Quast Dampf zu, rieb und schlug mit ihm seinen Leib, um den Schweißausbruch zu steigern. Waren die Geschlechter unter sich und badeten nackt, bedeckte man mit dem Wedel die Scham. ${ }^{67}$

Um sich an die Temperatur zu gewöhnen, war es empfehlenswert, sich erst auf die unterste Schwitzbank zu setzen oder legen und erst später auf die oberste zu steigen. Wer sich gleich zu Anfang der größten Hitze aussetzte, lief Gefahr, von oben ohnmächtig herabzufallen oder gar »todt wie das Viech auß dem Bad hinauß getragen [zu] werden«, meint Guarinonius, der gleich als guten Rat hinzufügt:

»Wiltu ohne grossen Schaden schwitzen, Fleuch die grosse Hitz, thu nicht z'hoch sitzen, Sonst fällst herab auf allen Viern, Ligst da wie todt, kanst dich nicht rührn«. ${ }^{68}$

Der Bader musste dann die in Ohnmächtigen durch Überschütten mit kaltem Wasser wieder zur Besinnung bringen, was gar nicht so selten vorkam, auch bei Männern, die fasziniert vom Blick durch das »Gätter« in die Frauenstube, oben zu wenig auf die 


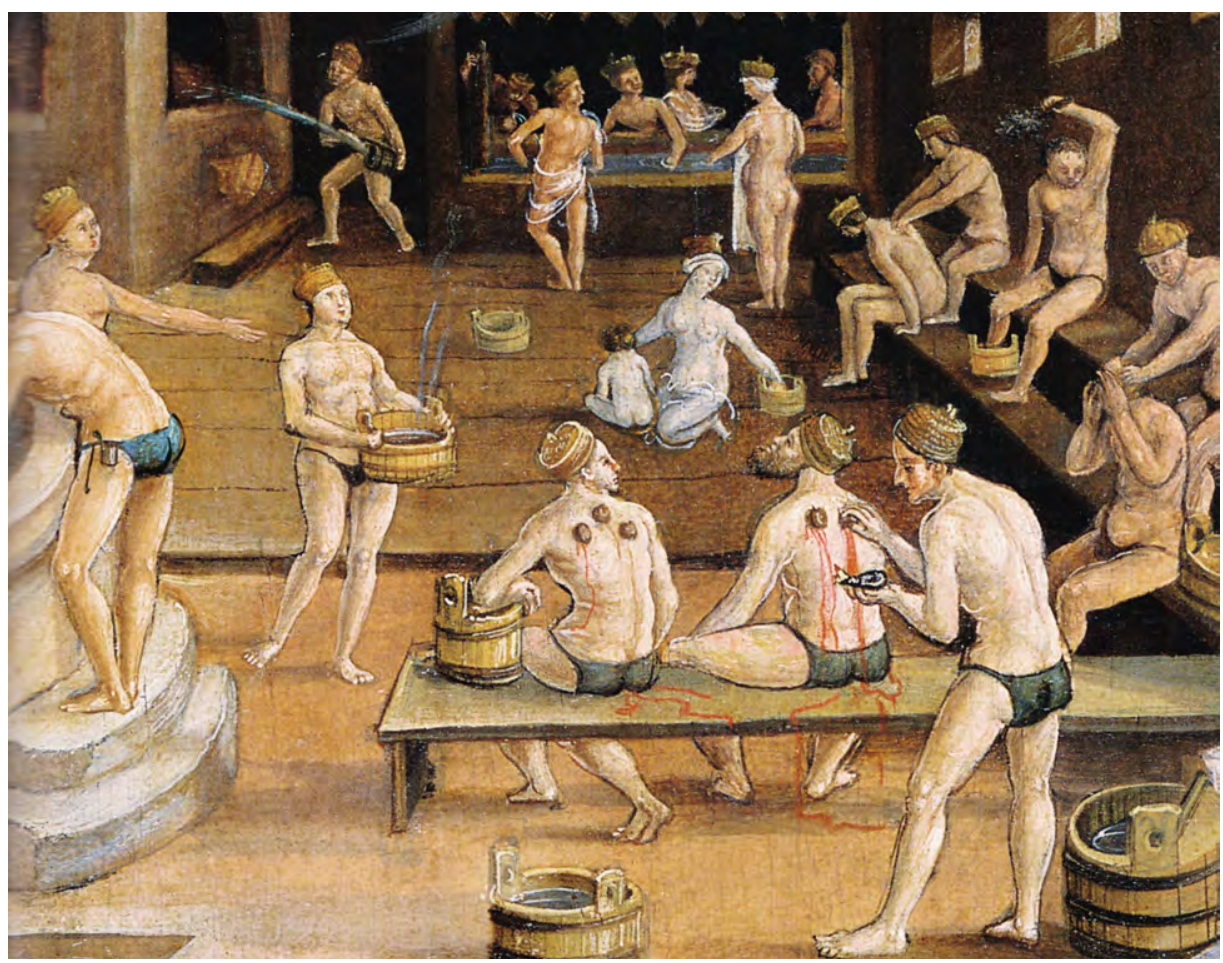

Abb. ro: Badeszene: Die Gäste tragen Badebüte aus Stroh, die Frauen eine Badehre, die Männer eine Bruch (Badebose), die seitlich gebunden wird (vgl. den Mann links am Brunnen), im Vordergrund Schröpfen, rechts Abreiben und Kopfwaschen, im Hintergrund links übergießt ein Knecht die heißen Steine, in der Mitte wäscht eine Frau ihrem Kind die Haare; Detail aus einem Tafelbild von Hans Wertinger, $15 \pm 6 / 25$.



Abb. I I: Badehut aus Stroh, hier in einer kostbaren Ausfertigung (mit Seide, Gold-und Silberfäden durchzogen, mit Nelken und Perlen besteckt; Schloss Ambras, Innsbruck - ${ }_{1} 6 . \mathrm{Jh}$. 
Hitze achteten und dann ohnmächtig zu Boden sanken. Das Problem stellte sich kaum in kleinen Badstuben, die keine drei abgestuften Bänke hatten, sondern nur eine. ${ }^{69}$

War die Luft zu trocken geworden, gossen der Bader oder seine Knechte Wasser auf die heißen Steine, bis der aufsteigende Dampf die Stube erfüllte. Solche Aufgüsse wurden mehrmals wiederholt. Hatte man das Schwitzen beendet, stieg man von der Bank herab und ließ sich auf dem Boden oder im Vorbad den Schweiß mit lauem oder kaltem Wasser abgießen. Danach erfolgte mit Schwamm, Lauge oder Seife, die aber teuer war, das Waschen und Abreiben (Massieren). ${ }^{70}$

\subsection{Wannenbad und Baderof}

Guarinoni meint, die Obrigkeiten sollten allen schwer arbeitenden Menschen, den Handwerkern, "starcken« Arbeitern und besonders den Knappen die Schweißbäder untersagen, weil ihnen dadurch »die ubrigen Kräffte unnd die natürlich Hitz gar auß dem Leib« getrieben werde, und sie, »wann es ihnen umb die Säuberung der Leiber zu thun ist, im warmen Wasserbad sitzen lassen, davon sie nicht allein gesäubert und gereinigt, sonder auch an abgearbeiten Kräfften und allen Glidern fürtrefflich ergetzt, gestärckt unnd befeichtigt werden«. Doch die Habgier der Bader lasse es nicht dazu kommen. Denn sie verlangten von einem Armen wie einem Reichen »umb ein Wasserbad ein Groschen, das ist drey Kreutzer « [ = I 5 Vierer]. Deshalb sollten die Obrigkeiten den unverschämten Badern »ein gewises Zil einsetzen«, also einen Höchstpreis für ein Wasserbad vorschreiben. ${ }^{71}$

In der Tat war ein Bad in der Wanne gemessen an einem solchen in der Schwitzstube keineswegs wohlfeil und für einen einfachen Menschen eigentlich zu teuer. Die Preise in den vier Badhäusern Halls sind nicht bekannt, doch zahlten ${ }_{4} 45$ ein Bürger oder eine Bürgerin in Klausen und I609 jede Person, gleich ob Mann oder Frau, in Kaltern nur zwei Vierer für ein Schwitzbad. ${ }^{72}$ Die Differenz in Bamberg war noch größer. Dort kostete 1480 ein Wasserbad zwölfmal so viel wie ein Schweißbad. ${ }^{73}$ So verwundert es nicht, wenn nur wenige Wannen in den Bädern auf Kunden warteten. Nach den Inventaren zweier Haller Bader aus den Jahren I 570 und I 602 besaß der eine fünf, der andere vier große hölzerne Badewannen. ${ }^{74}$ Sie waren meist aus Tannenholz gemacht, wie Walter Hermann Ryff in seiner »Badenfart" (I 549) bemerkt ${ }^{75}$. Andere erwähnen Eichen-, Kastanien oder Wacholderholz, weil diese Hölzer länger der Feuchtigkeit standhalten. ${ }^{76}$

Wannen- wie Schwitzbäder dienten nicht nur der Entspannung, der körperlichen Reinigung und Regenerierung, sie galten auch nach damaliger Ansicht als wirksame Mittel, Krankheiten vorzubeugen oder zu behandeln, sollten z. B. bei Lähmungen, Steinen, Bauchgrimmen, Hautjucken und anderem helfen. ${ }^{77}$ Man gab in das Badewasser 
Abb. I2: Begießen im Bad; Kupferstich aus Thomas Murners "Nebulo nebulonum«, I663.

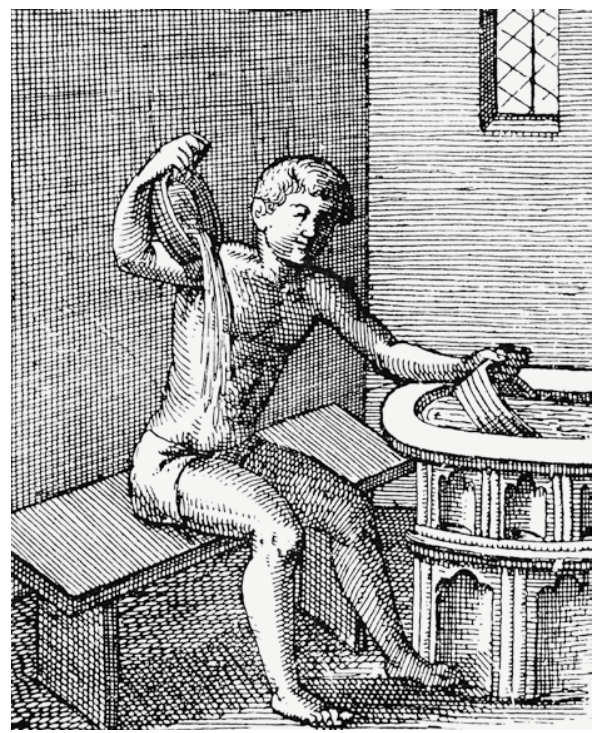

nicht nur Duftstoffe und Blütenblätter von Rosen hinein, sondern reicherte es auch mit Essenzen, ätherischen Ölen und Absuden von Heilkräutern ${ }^{78}$ an, um eine belebende, gesundheits- und schönheitsfördernde oder heilende Wirkung zu erzielen. Schon Arnald von Villanova († I3 I I) wusste um die Vorteile von Kräuterbädern und empfahl sie alten Leuten viermal im Jahr. ${ }^{79}$

Es fehlte auch nicht an ungewöhnlichen Zusätzen. Pictorius hält es in seinem »Badenfahrtbüchlein« (I 560) für recht nützlich, wenn man dem Wasser Baumöl zufüge, am besten solches, in dem zuvor ein Fuchs oder Dachs gesotten worden sei. Es helfe bei Krämpfen, Darmgicht, Nierensteinen und stille Schmerzen. Milchbäder nützten besonders Ausgemergelten oder von schwerer Arbeit Erschöpften, Bäder aus Wein, vor allem aus starkem Rotwein, seien eine große Hilfe für Erlahmte und alle, die über Nervenschmerzen klagten. Doch, tröstlich zu wissen, waren Bäder in Ö1, Milch und Wein bei den Deutschen nicht in Gebrauch, schreibt Ryff. ${ }^{80}$

Durchaus üblich im Reich aber war es, dem Wasser einen Sud von heilkräftigem Holz beizugeben und das Holzwasser zu trinken. ${ }^{81}$ Der Südtiroler Freiherr Jakob von Boimont zu Pairsberg (I527-r 58I) litt viele Jahre an Gicht (Fuß, Hand, Arm). Zur Linderung seiner Schmerzen suchte er öfter seit I 556 zunächst mit seiner Mutter, dann mit seiner Frau das Thermalbad in Bormio auf, das in ganz Oberdeutschland berühmt war, später als »Weiberbad« galt. ${ }^{82}$ I 56 I legte er sich zur Kur gegen die Gichtanfälle auf Schloss Schwanburg (Nals) ins Holzwasser und trank es I 5 bzw. I 578 noch einmal 26 Tage lang. ${ }^{83}$ 


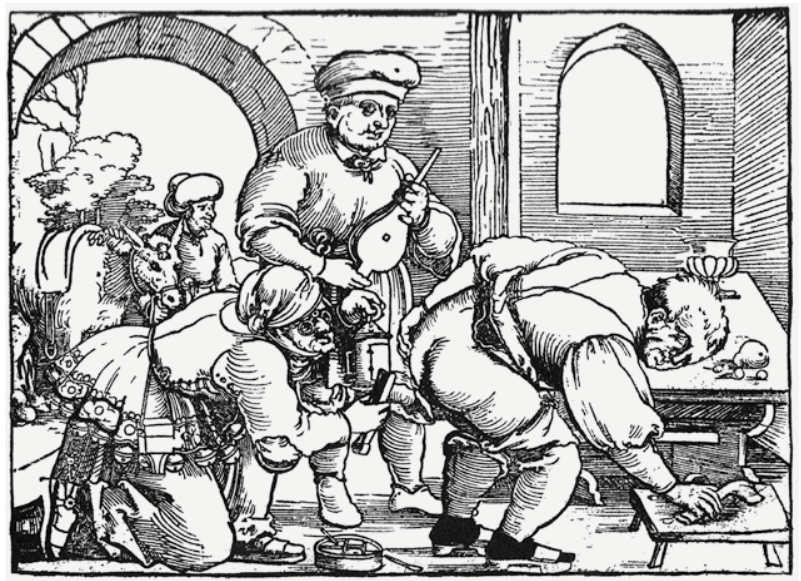

Abb. 13: Ansetzen eines Klistiers; Holzschnitt eines unbekannten Meisters, ca. I55O.

Sicher richteten die Bader medizinische Bäder, bei Gelegenheit (Hochzeit, Frühling, Mai) auch Duft- oder Kräuterbäder her, doch im Allgemeinen nahm man solche Vollbäder in Wohnungen der Bürger, in Burgen und Schlössern des Adels, nicht in eigenen Badezimmern - die gab es kaum -, sondern in einem Stübchen, in Wohn- oder Schlafzimmern, auch schon einmal im Garten. ${ }^{84} \mathrm{Um}$ ein solches Wannenbad, in dem man gern zu zweit saß, in ein »Zimmerdampfbad « zu verwandeln, wurde der Zuber ringsum mit einem Baldachin von Leinen ${ }^{85}$ umschlossen. Das Baderof, wie man den Aufbau nannte, sollte ein rasches Abkühlen des Wassers verhindern, weniger die Blicke Unberufener fernhalten - so prüde war man im Mittelalter nicht. Ein richtiges kleines Schweißbad entstand dann, wenn man in den Zuber erhitzte Steine, Kiesel, Ziegel legte und sie »mit abgesottenem Wasser von guten und wol riechenden Kräutern« begoss. In so verhängten Wannen konnte man auf einem Stühlchen sitzen, mit einem Schemel unter den Füßen, um sich nicht an den heißen Steinen zu verbrühen. In Seuchenzeiten wurde zu solchen Schwitzbädern im Haus geraten. ${ }^{86}$

\subsection{Der Bader}

Es hat genug Badeknechte gegeben, die sich, ohne von einem Meister ausgebildet zu sein, allein durch Praxis und Lernen von älteren Gesellen die nötigen Kenntnisse in diesem Metier angeeignet haben, doch zu behaupten, das Baderhandwerk sei kein wirklicher Lehrberuf gewesen und habe vielfach beruflich Gescheiterten einen Unterschlupf geboten, ${ }^{87}$ geht wohl zu weit. Schon im I 5. Jahrhundert lassen einige Statuten von Baderbruderschaften und -zünften das Gegenteil erkennen. Die Ordnung der 
Abb. I4: Transport

eines an der

Podagra (Fußgicht)

Erkrankten;

Holzschnitt des

Petrarca-Meisters

aus "Von der artzney

bayder Glück,

des guten und

widerwertigen « des

Franciscus Petrarca,

1532 .

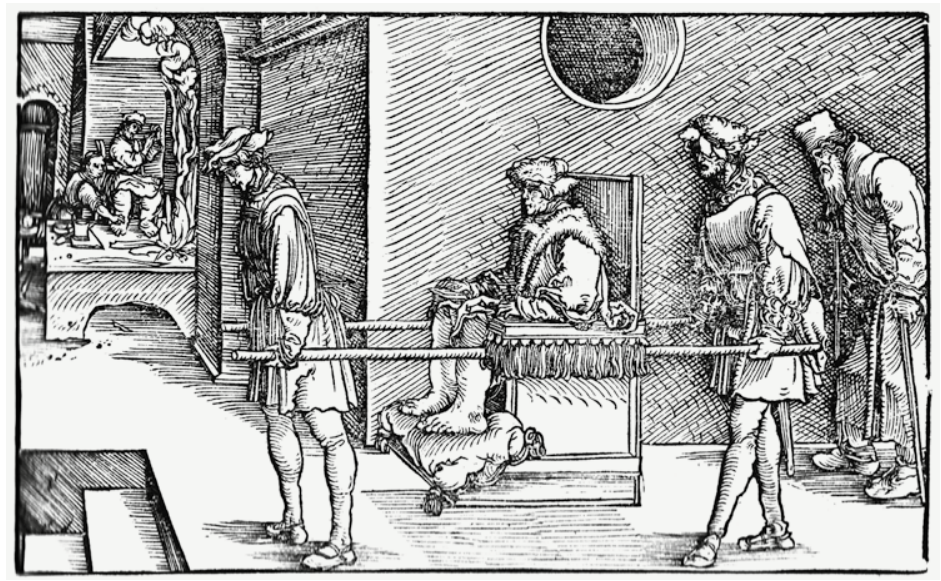

Baderbruderschaft zu Innsbruck und Hall von ca. I450/6o z.B. schreibt den Knechten als Pflichten vor, den Meistern zu heizen, binden, flechten ${ }^{88}$ und Holz zuzutragen, die Badstube, Gläser und alles, was zum Handwerk gehöre, zu versehen. Habe der Meister einen Lehrjungen, dann solle ihn der Knecht anweisen, die Gläser ${ }^{89}$ zu waschen und die Badstube zu reinigen. Solange der Knabe noch in der Lehrzeit sei, solle er »des Hauses warten ${ }^{90}{ }^{90}$ Diese Aufgabe treffe auch jeden Badknecht, wenn er Wochendienst habe. ${ }^{91}$ Es gab wohl in früheren Zeiten in keinem Handwerk Lehrlinge, denen man nicht Besen und Wischlappen in die Hand gedrückt hat, zumal für den Haushalt der Meisterin.

Über Dauer der Lehre und Meisterwerden eines Badknechts schweigen sich die Innsbruck-Haller Statuten aus. Ein Junge dürfte im Alter von ungefähr I 4 Jahren ${ }^{92}$ seine zwei- bis vierjährige Lehrzeit als Bader und Wundarzt ${ }^{93}$ begonnen haben. Ein Geselle musste drei Jahre lang ${ }^{94}$ auf Wanderschaft gegangen sein, bevor er zur Meisterprüfung antreten konnte. Die Anforderungen dafür waren anfänglich sehr bescheiden. Nach einem Nürnberger Ratserlass von I 456 bestand das ganze Examen nur im Scheren- und Messerschleifen. Bald aber verlangte man wirkliche Meisterstücke. Vor einem Kollegium von Badermeistern und Ärzten hatte der Bewerber Salben, Pflaster und Wundtränke zuzubereiten und »Fragstücke von allen Leden « (Hamburger Rat I 468) $\mathrm{zu}$ beantworten, also seine (Buch-)Kenntnis von verschiedenen Leiden zu beweisen. ${ }^{95}$

Dass im Laufe der Zeit immer höhere Ansprüche an die Handwerkerchirurgen ${ }^{96}$ gestellt wurden, verdeutlicht das 7755 abgelegte Examen Jakob Lochgruebers, Sohn eines Kirchbichler Barbiers und Wundarztes. Das Prüfungsgremium bestand aus einem Professor für Anatomie und Geburtshilfe der Universität Innsbruck, aus dem Regierungsphysikus Dr. Winkler und zwei Barbieren. Man befragte den Kandidaten, wie 


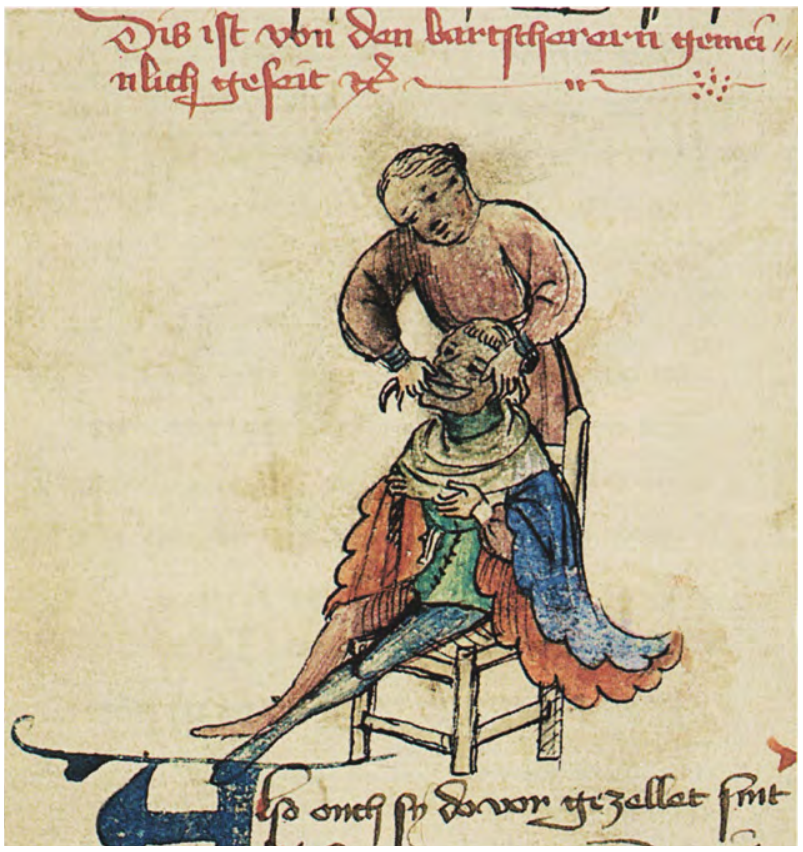

Abb. 15: Bartscherer; Miniatur aus einer Handschrift des Schachzabelbuchs von Konrad von Ammenhausen, I4I4.

Beinbrüche, eine Lähmung nach einem Fall, ein verrenkter Unterkiefer, Quetschungen nach Schlägen und Angina zu behandeln seien, wann man »Incisionen« (Schnitte) machen solle, welche Ingredienzien für ein Klistier bei Windgrimmen zu wählen seien, welche Heilmethode man bei »verwundeten Gäder oder Flächsen« (d.h. Adern oder Sehnen) anwenden solle. Lochgrueber wurde einstimmig für tauglich befunden, doch legte ihm der Universitätsprofessor nahe, sich in einschlägigen Werken der Chirurgie und Anatomie weiterzubilden. Ohne Bücherstudium ging schon lange bei Wundärzten nichts mehr. ${ }^{97}$

Seit wann in Tirol Meisterstücke von Badern und Barbieren verlangt wurden, ist unbekannt. In Hall war dies erst seit I648 der Fall, in Rattenberg vermutlich auch nicht früher. Man stellte dafür in Tirol lange keine hohen Anforderungen. I708 verlangte man von den Innsbrucker Badern als Meisterstück lediglich die Herstellung von dreierlei Hauptpflastern und Salben, wozu dem Kandidaten vier Wochen Zeit eingeräumt wurden. ${ }^{98}$

Die Badstuben waren Eigentum einer Gemeinde, einer Institution, eines Stadt- bzw. Landesherren oder des Baders selbst. Traf Letzteres zu, musste er für sämtliche Bauund Reparaturkosten aufkommen, im anderen Fall übernahm der Eigentümer solche Lasten oder teilte sie sich mit dem Bader. Wurde ihm das Bad verpachtet, fand er nur die allernotwendigsten Einrichtungen (Badeofen, Heißwasserkessel, Kaltwassertrog, 


\section{Der Saber.}

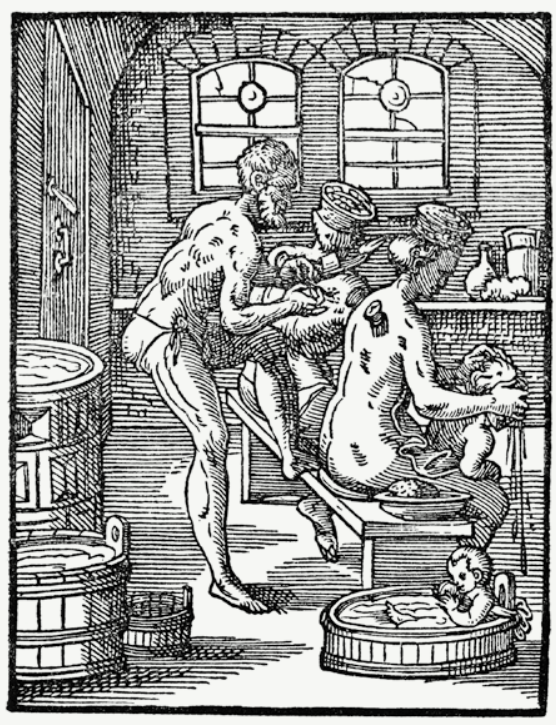

Abb. I6: Bader; Holzschnitt aus Jost Ammans "Ständebuch«, ${ }_{5} 68$.

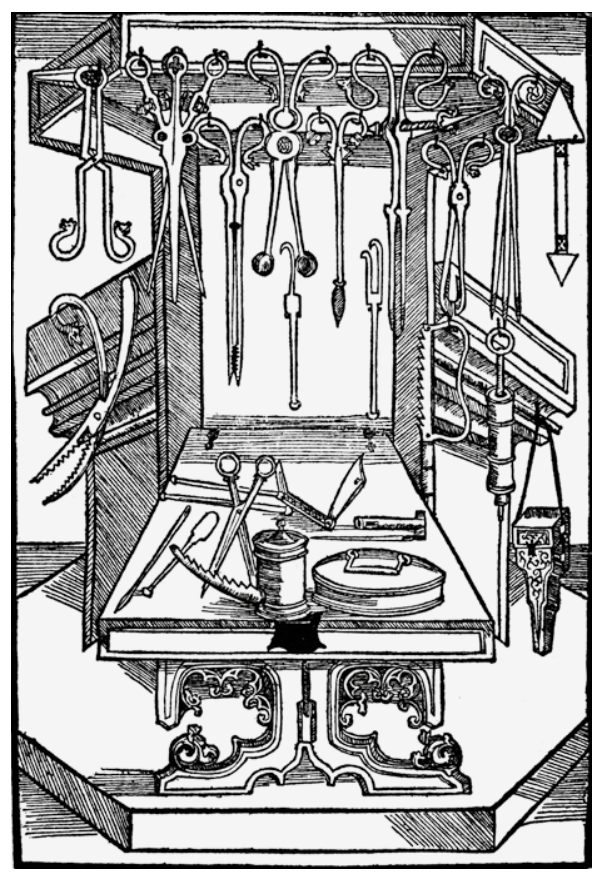

Abb. I7: Chirurgische Instrumente; Holzschnitt aus

Hieronymus Brunschwigs"Buch der Cirurgia", 1497.

Brunnenbecken, Wasserleitung, Bänke, Schemel, Tische, evtl. Ruhebetten) vor, alles andere hatte er selbst bereitzustellen, und das war viel, wenn er gut ausgestattet sein wollte: Barbierzeug vom Becken und Rasiermesser bis zu Schere, Spiegel und Kamm, Bestecke für Aderlass, Schröpfköpfe, chirurgische Instrumente, Arzneimittelbehälter, gebrannte Wässer, Öle, Verbandszeug, Arznei- und Kräuterbücher, Bademäntel und Tücher, Waschstuhl oder -bank, bisweilen sogar ein drehbarer Barbiersessel, vor allem aber die vielen Holzgefäße zum Waschen, Abgießen und Schöpfen, für den Wassertransport, für ein Wannen-, Fuß- oder Schenkelbad, ob sie nun Gelten, Eimer, Kübel, Schaffe oder Badewannen, Zuber, Kufen hießen. ${ }^{99}$

Wurde ein Bad neu vergeben, schlossen die Gemeinden mit dem Meister einen Vertrag. Die wesentlichen Punkte darin glichen sich fast überall. Ihm wurden Badetage, Öffnungszeiten und Preise vorgeschrieben, er hatte für Ordnung und Sauberkeit, für Brennholz, rechtzeitiges Heizen und ausgiebiges Lüften, für genügend Wasser und Lauge zu sorgen, jedermann gleich zu behandeln, taugliche, möglichst auch für den Aderlass und das Schröpfen geeignete Badeknechte anzustellen und darauf zu achten, dass sich Badeknechte und -mägde gebührlich benahmen. ${ }^{100}$ 
Schon die altindische Sammlung medizinischer Texte, einem Susruta (vielleicht I. Jh. n. Chr.) zugeschrieben, weiß wie die griechisch-römische Antike um die Vorteile einer Massage. Sie »erfrischt den Körper«, heißt es, »die Adern, Haut und Gelenke, fördert den Kreislauf, stärkt auch die Nerven und erweckt wohltuende Gefühle der Gesundheit, Reinheit und des Glücks«. ${ }^{101}$ Dies Glück wollte man auch nicht im abendländischen Schwitzbad missen. Das Reiben, wie man früher das Massieren nannte, überließ jedoch der Meister seinen Badeknechten, -mägden und -frauen, die gleichfalls für das Über- und Abgießen ihrer Gäste, das Waschen mit Lauge oder Seife zuständig waren. Der Bader widmete sich anderen Aufgaben.

Da waren zunächst einmal das Kopfwaschen ${ }^{102}$, Haareschneiden und Rasieren, was zusätzlich zum Badgeld bezahlt werden musste. Der Dampf und die Wärme machten das Haar weicher, die Barthaare geschmeidiger, so dass man gern diese Prozeduren in der feuchten Badstube vornehmen ließ. Trotzdem war das Rasieren lange Zeit ein schmerzhafter Vorgang. Erst seit Ende des I 5. Jahrhunderts verwendeten die Barbiere Rasierschaum, geschlagen von »balbierer kugelin«, wodurch das Brennen der Haut erträglicher wurde.

Lästige Haare wurden einzeln mit einer Pinzette ausgezupft oder sie sollen, handelte es sich um größere Flächen (z.B. in den Achselhöhlen), angeblich mit Hilfe einer »har fressend arzney«, d.h. einer Paste, die aus gelöschtem Kalk, Meerschaum, Blut von Fröschen und Schnecken, Ameiseneiern oder Eidechsenöl bestand, entfernt worden sein. ${ }^{103}$ Hatte diese Prozedur wirklich Erfolg, dürfte er wohl eher auf Aberglauben als auf die Ingredienzien dieser merkwürdigen Salbe zurückzuführen sein. Vermutlich half sie aber nicht und man musste auf ein Rasiermesser zurückgreifen.

Regelmäßiges Kopfwaschen mit Seife oder einer Aschenlauge, alle ein bis zwei Wochen, mindestens einmal im Monat, galt als unerlässlich. Kopfwaschen diente nicht nur der Sauberkeit, sondern es sollte auch das Wohlbefinden des Gehirns fördern. ${ }^{104} \mathrm{Gab}$ es einen eigenen Barbier im Ort, waren Auseinandersetzungen mit ihm unvermeidlich. Oft einigte man sich darauf, dass der Bader nur in der Badestube die Haare schneiden und den Bart scheren durfte, dies ihm aber außer Hauses untersagt wurde. ${ }^{105}$

Mehr Gewinn als das Baden versprach das Aderlassen und besonders das Schröpfen. Nach der Lehre von den vier Körpersäften (Blut, Schleim, gelbe und schwarze Galle) geriet ihre Zusammensetzung immer wieder in ein Ungleichgewicht, was zu korrigieren war, um Krankheiten zu vermeiden. Der Aderlass bot eine Möglichkeit, die »schlechten Säfte« zu entfernen. Dabei wurde das Blut am Arm durch eine Binde gestaut und die hervortretende Vene mit einem Schnepper, Lasseisen oder einem Messerchen (Lanzette) angeschnitten. Das entweichende Blut, zwischen 90 und I 20 Milliliter ${ }^{106}$, fing man in einem Schälchen oder Becken auf. Lasskalender, -zettel und -tafeln unterrichteten über die günstigste und ungünstigste Zeit zum Aderlass, wobei man Gestirnskonstellationen zu Grunde legte. 



Abb. I8 (l.): Aderlass; Miniatur aus dem Luttrell-Psalter, um 1340.

Abb. Ig (r.): Ansetzen von Schröpfköpfen, Schwitzbank, Badequast; kolorierter Holzschnitt aus einer böhmischen medizinischen Handschrift, um 1500.

Einerseits beliebter, andererseits schonender war das Schröpfen, weil dabei weniger Blut entzogen wurde. Die Schröpfköpfe, auch »Hörnlin« genannt, kleine Gefäße aus Keramik, Glas oder Metall, wurden erwärmt, so dass beim Aufsetzen ein Unterdruck entstand und sie sich leichter an der Haut festsaugten, die vorher an der betreffenden Stelle mit einem Messer geritzt worden war. Die Köpfe, gefüllt mit etwas Blut, fielen von selbst ab oder wurden abgelöst. Die Wärme der Badestube erweiterte die Blutgefäße und erleichterte das Abzapfen des Blutes. „Das Schröpfen wirkt nicht nur blutentziehend, sondern auch ableitend, krampflösend und krampfstillend«(Jütte). Im Durchschnitt ließ man sich vier bis fünf Schröpfköpfe ansetzen, einmal bis mehrere Male im Jahr. Da das Schröpfen in der Regel nicht im Badepreis inbegriffen war und der Bader nach der Zahl der gesetzten Köpfe bezahlt wurde, tat er manchmal des Guten zu viel, was mit einer Ohnmacht des Geschröpften enden konnte. Unmäßiges Aderlassen war allerdings häufiger als übertriebenes Schröpfen. Nicht umsonst gibt es die sprichwörtlichen Redensarten, dass jemand zur Ader gelassen oder geschröpft wird, wenn man meint, er wird übervorteilt. ${ }^{107}$

In der Badstube entfaltete der Bader auch seine medizinische Tätigkeit, unterstützt von versierten Badknechten: Zahnwässer wurden verabreicht, Zähne gezogen, von Ka- 
ries befallene Zähne ausgebrannt und die entstandenen Hohlräume mit Blattgold oder Blei gefüllt, Klistiere gesetzt, Abführmittel gegeben, Wunden verarztet oder neu verbunden, Knochen geschient, Knochenverrenkungen behoben, Geschwüre und Hautkrankheiten (sehr häufig) behandelt, Medikamente ausgegeben, sogar Amputationen vorgenommen. Doch das galt nur für die besten der Wundärzte. Das allgemeine medizinische Niveau der Handwerkschirurgen lag im I6. Jahrhundert niedriger, ihr Besitz an chirurgischen Instrumenten war lange Zeit bescheiden. ${ }^{108}$ In Seuchenzeiten erwartete man von den Badern, dass sie sich der Infizierten annahmen, ${ }^{109}$ falls nicht eigene »Totenlässl« bestellt wurden (s.u.). Anscheinend standen manche Bader den Damen mit allerlei Schönheitsmittelchen auch als Kosmetiker zu Diensten. ${ }^{110}$ Neben der Zahnpflege übten die Bader auch die Mundhygiene aus. Dazu diente ein Zungenschaber. Wer an die Säftelehre glaubte, glaubte auch daran, dass das Gehirn Schleim absonderte. Durch Abhusten, Ausspucken und Schaben der Zunge am Morgen sollte das Stocken des Schleims vermieden werden. Man konnte das auch durch den Bader nachholen lassen. So wurde der Zungenschaber ein Kennzeichen des Baders bzw. Wundarztes. ${ }^{111}$

Jeder Bader war auf die Einkünfte aus Körperpflege und Wundarznei angewiesen, ob er nun im Badhaus tätig wurde oder in den Wohnungen der Kunden bzw. Patienten. Vom Badebetrieb allein, der oft mehr Unkosten als Einnahmen brachte, ${ }^{112}$ hätte er nicht existieren können. Das war ein reines Pfenniggeschäft, wohin man auch blickt. In der Regel belief sich der Preis für ein einfaches Schwitzbad nur auf ein bis zwei Pfennig, in Bamberg I 480 gar nur auf einen Heller, für Vermögende auf das Doppelte, also auf einen Pfennig. Häufig wurden beim Geld Alters- oder Standesunterschiede gemacht, besondere Dienstleistungen mussten extra bezahlt werden, das Badgeld konnte auch

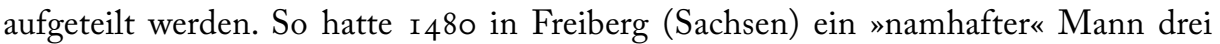
Pfennig für sich und sein Gesinde zu zahlen, wovon anderthalb Pfennig der Bader, einen Pfennig das Stubenpersonal und einen Heller die »Schurin« (Heizerin) erhielten, ein Handwerksmann und ein lediger Geselle gaben dem Bader zwei Pfennig, die Frauen zwei Pfennig für sich, einen Pfennig für ihre Magd, dem Bader und der Bademagd einen Pfennig. ${ }^{113}$

Kinder kamen auch nicht ungeschoren davon. In Mosbach (Baden) mussten Jungen und Mädchen im Alter von I 2 bis I 4 Jahren zwei Pfennig Badgeld geben, also so viel, wie Knechte und Mägde, die nur badeten, aber sich nicht schröpfen ließen. Ein Kind, das schon einen Kübel tragen konnte (ca. neun bis zehn Jahre alt), hatte einen Pfennig zu entrichten, zwei jüngere kleine Kinder zusammen einen Pfennig. ${ }^{114}$ Bestanden in größeren Städten wie Wien komfortablere Badeeinrichtungen, schnellten die Preise in die Höhe. Dort kostete ein Schwitzbad vier, ein Wannenbad sechs Kreuzer, der Haarschnitt eines Dienstboten drei Kreuzer. ${ }^{115}$ Als im I6. Jahrhundert die Holzpreise stark anstiegen und der Besuch der Bäder zurückging, konnten die Bader nicht mehr ihre Preise halten. Die Obrigkeiten bewilligten ihnen deshalb fast überall eine Erhöhung 
Abb. 20: Einrenken eines

Kiefers; Miniatur aus einer norditalienischen Handschrift der»Chirurgia" des Roland von Parma, um Iзоо.

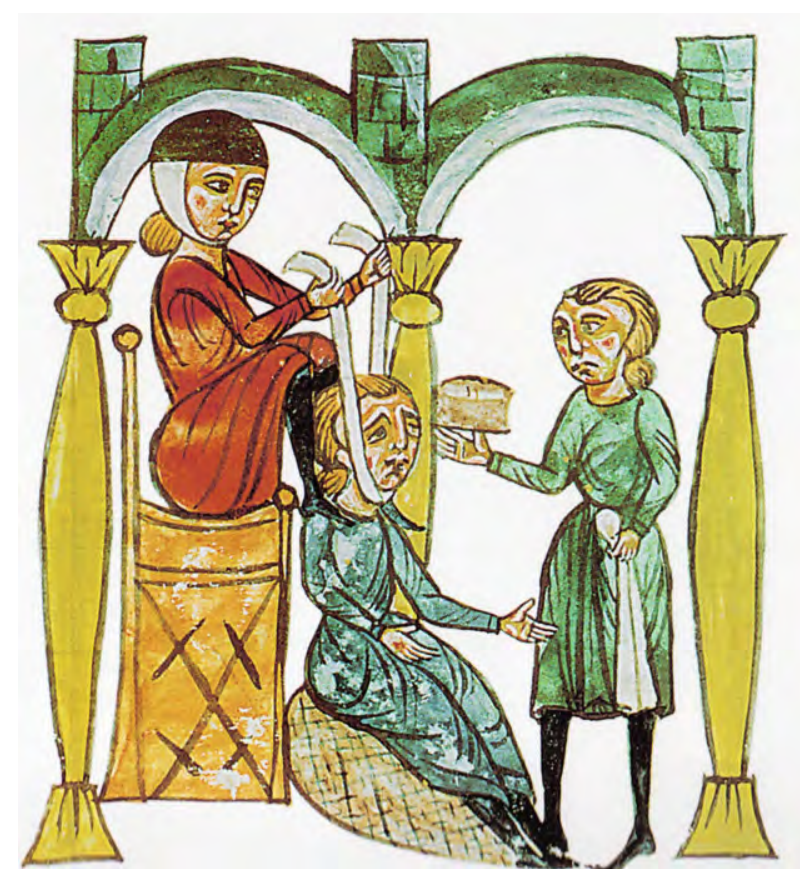

der Badgelder. In Esslingen z.B. durften nun die Bader von den Männern drei, von den Frauen zwei und von den Kindern einen Pfennig nehmen ( 547 ), Nürnberg ${ }^{116}$ erhöhte die Preise auf drei Kreuzer für Männer und Frauen, auf einen halben Batzen für Jugendliche und Kinder (I622), Stuttgart bewilligte ein Badgeld von drei Pfennig für einen erwachsenen Mann, drei Heller für eine Frau und ledige Personen, I Heller für Dienstboten und Kinder (I 547 ). ${ }^{117}$

Sofern genauere Nachrichten aus Tirol vorliegen, reiht es sich in dies Preisgefüge ein. In Klausen nahm I 485 der Bader von einem Bürger oder einer Bürgerin zwei Vierer, von dem Knecht eines Bürgers drei Vierer und von einer Hausmagd zwei Vierer. Ließ man sich Schröpfköpfe ansetzen, mussten sie extra bezahlt werden. In Kaltern sollte I 602 jede Person, die nur ein einfaches Bad nehmen wollte (»slechtiglich paden«), nicht mehr als zwei Vierer geben. Wollte ein Mann sich noch dazu scheren lassen, sollte er drei Vierer zahlen, für jeden Schröpfkopf (»hörnli«) einen Vierer, für den Aderlass einen Vierer. Ließ man sich in der Stube von einem Badeknecht bedienen mit Reiben, Waschen und anderem, sollte man ihm einen Vierer schenken. Einen Anspruch darauf habe er allerdings nicht. ${ }^{118}$

Neben den genannten Tätigkeiten übten die Bader, teils im Auftrag der Obrigkeit, noch andere Arbeiten aus, die nicht immer in einem Bezug zu ihrem Beruf standen. 
So stellten sie Seife her, fertigten und verkauften Badehüte aus Stroh, auch schon einmal geflochtene breite Strohhüte gegen die Sonne, sie schliffen Scheren und Messer, nicht nur die eigenen, sondern auch fremde, sehr zum Unwillen der Schmiede und Schleifer. Sie reinigten Brunnen und Öfen, die sie auch setzten, waren mancherorts Kaminkehrer, bisweilen auch Glaser und Kannenreiniger. Wenn man in der ehemaligen Badstube von Zwettl einen Destillierhelm entdeckt hat - ein solcher Fund ist für Badehäuser einmalig -, so ist anzunehmen, dass der Bader den Hut zur Herstellung von gebrannten Wässern für Heilzwecke verwendet hat, doch ist auch eine Produktion von Branntwein nicht ausgeschlossen. Denn ein Zwettler Bader hatte Ende des I 7. Jahrhunderts auch eine Lizenz zum Alkoholausschank. ${ }^{119}$ Die Bader wurden vom Gericht zum Beschauen von tödlichen und nichttödlichen Wunden, sogar zum Öffnen von Leichen herangezogen, die ihnen in Ulm vorgeschriebene Leichenwäsche leisteten sie aber - verständlicherweise - unwillig. ${ }^{120}$ Wollte allerdings ein Bader zu geschäftstüchtig sein und schädigte dadurch ein städtisches Gewerbe, dann stieß er auf Widerstand. So lehnte r66o der Rat dem Haller Bader Jakob Mayr sein Ansuchen, im Bad auch Bier ausschenken zu dürfen, mit der Begründung ab, niemand dürfe in Hall gleichzeitig zwei Gewerbe ausüben und im Übrigen habe die Stadt schon fünf Bierschenken. ${ }^{121}$

Wie andere Handwerker wurden auch die Bader und ihre Knechte zum Löschen eines Feuers herangezogen. Sie hatten, was die Verordnungen vieler Städte erkennen lassen, mit Eimern, Badeschaffen und Zubern herbeizueilen und bei der Brandbekämpfung zu helfen. Während die Münchner Stadtväter I420 zwölf auf eigene Kosten angeschaffte Löschzuber in den Badestuben bereithalten ließen, weil dort stets reichlich Wasser zur Verfügung stand - I 42 I waren es weitere ${ }_{5}$ Zuber -, stellte der Wiener Rat 534 jedem der elf noch in der Stadt vorhandenen Bader zehn Ledereimer zu, I 639 und r 688 befahl er seinen Badern, ihre »Ganter« (Bottiche) stets voller Wasser zu halten, um für den Notfall gewappnet zu sein. Würzburg forderte im I6. Jahrhundert sogar den Einsatz des weiblichen Badepersonals, während sonst zur Feuerbekämpfung nur die Meister, ihre Knechte und die Lehrjungen genannt werden. ${ }^{122}$

Anhaltende Hitze und Dampf machen durstig. So verwundert es nicht, dass man den Badern nachsagte, sie schauten gern zu tief ins Glas. ${ }^{123}$ Dieser Vorwurf wird sie weniger getroffen haben - schließlich galten die Deutschen überhaupt als sehr trinkfreudig, als dass man sie regional mit dem Makel der Unehrlichkeit belegte und an den Rand der Gesellschaft drängte, indem man ihnen verbot, Waffen zu tragen, sie von einzelnen Bruderschaften und Zünften ausschloss, sie nicht in den städtischen Rat aufnahm. Eine solche Diskriminierung der Bader lässt sich für einzelne Orte im Norden, Westen und in der Mitte des Reiches nachweisen, aber bislang nicht im Süden, auch nicht in Österreich und Tirol.

Die Gründe für die Stigmatisierung der Bader (und Chirurgen) sind nicht völlig geklärt. Ihr oft schamloses Auftreten in leichter Bekleidung schadeten ihnen ebenso 
Abb. 2 I: Der Nürnberger Barbier Peter von Hausen; Wasserfarbenmalerei aus dem "Geschworenenbuch der Nürnberger Barbiere", Mitte I6.Jh.

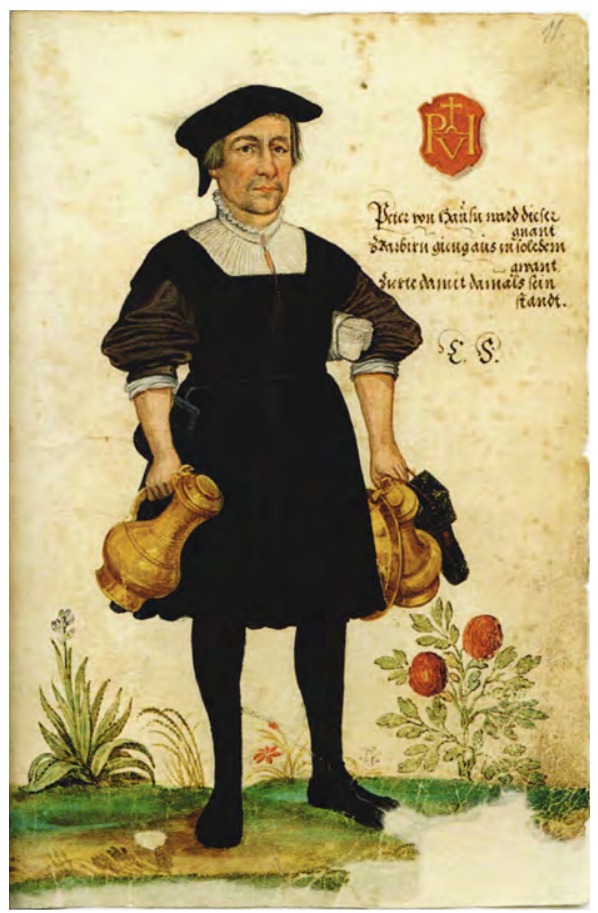

wie dass sie mit ihren Frauen, Töchtern und dem Badepersonal im Ruf standen, zur Unzucht zu neigen, namentlich in den Badestuben, die nicht wenige als Sündenpfuhl ansahen. Der hauptsächliche Grund der Ausgrenzung dürfte aber in ihrer Beschäftigung mit tabuisierten (Blut) oder ekligen (Eiter, Ausflüsse, Schleim) Körperflüssigkeiten und Geschwüren bestanden haben, für jemanden, der zur Ader ließ, schröpfte oder als Wundarzt tätig war, unvermeidlich. Dabei dürften die Diskriminierung und das Vorurteil sich gegenseitig beeinflusst und hochgetrieben haben. Zwar beschloss der Augsburger Reichstag von I 548, Bader, Barbiere, Leineweber, Schäfer, Müller, Zöllner, Pfeifer und Trompeter dürften nicht mehr benachteiligt werden, sondern seien wie andere redliche Handwerker in die Zünfte, Gaffeln, Gilden und Ämter aufzunehmen, doch der Vorwurf der Unehrlichkeit ließ sich nicht so schnell beseitigen. ${ }^{124}$

\subsection{Die Gehilfen des Baders}

Für den reinen Badebetrieb waren mehr die Badeknechte und -mägde als der Bader selbst zuständig. Bei den Männern wird man im Allgemeinen nicht streng zwischen 

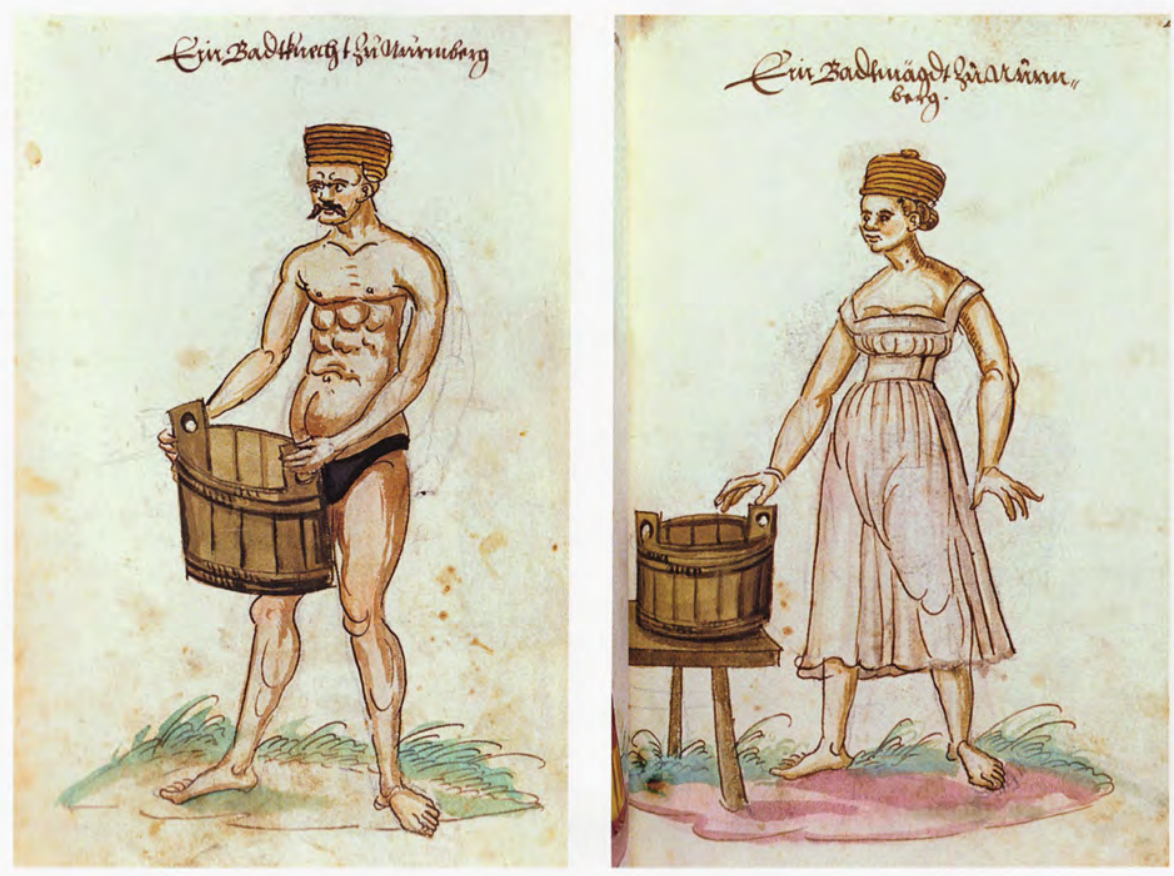

Abb. 22: Nürnberger Badeknecht und Bademagd mit Wasserschaff, Badehut, schwarzer Badehose (Knecht) und Badekleid (Magd); kolorierte Zeichnung aus Sigmundt Heldts »Trachtenbuch», I560-I680.

einfachen, ungelernten Helfern, die lediglich niedrige Dienste wie Wasserholen, Holzschleppen, Heizen, Übergießen, Reiben verrichteten, und ausgebildeten Fachkräften, die sich auf Scheren, Schröpfen, Aderlassen, Wundarznei verstanden, unterscheiden dürfen. ${ }^{125}$ Gerade in den Badstuben kleinerer Orte, aber auch vielfach sonst wird man die Knechte zu allen Tätigkeiten herangezogen haben, gleich ob sie ihr Metier richtig erlernt oder sich nur erarbeitet hatten. Umfangreiches Personal konnten sich die wenigsten Meister leisten. Es sei nur an die Innsbruck-Haller Ordnung der Baderbruderschaft von I 450/6o erinnert, wonach ein Knecht heizen, binden, flechten, Holz zutragen, Gläser waschen und die Badstube reinigen solle.

Durch den Badedienst allein erwarb kein Geselle genug Lohn, der zum Leben reichte. Es waren nur Pfennige, die in der Badestube anfielen, um 554 in Böblingen für einen Reiber ein Heller fürs Reiben und ein Pfennig fürs Baden, I480 in Freiberg (Sachsen) ein Pfennig für den Bader und die Bademagd. ${ }^{126}$ Und nicht einmal diese geringen Beträge flossen ständig. Die erwähnte Innsbruck-Haller Ordnung vermerkt nämlich, wenn ein Gast (Herr) ins Bad komme und die Landessitte, dem Knecht ein 
Abb. 23: Obrlöffelchen (links und Mitte) und Zungenschaber (rechts). Die Löffelchen wurden zur Säuberung der Obren, zur Entnahme von Riechessenzen, Salben oder Schminke, manchmal auch zur Reinigung von Wunden benutzt. Hatten sie an einem Ende eine Spitze, dienten sie zudem als Zahnstocher (Mitte). Die Zungenschaber hatten die Form einer scharfkantigen Schlaufe (bier) oder eines kleinen Spatels; Tirol- I4. bis I6. Jh.



Trinkgeld zu geben, nicht kenne, solle der Meister nach Belieben dem Knecht »ain Erung« tun.

Er musste also ein anderes Einkommen haben, vermutlich wie der Bader aus der Körperpflege an den Besuchern (Kopf waschen, Haare schneiden, Bart scheren) und aus der Wundarznei. Außerdem stand er in einem festen Lohnverhältnis zum Bader, wie wieder die Innsbruck-Haller Statuten lehren. Werde ein Knecht krank, heißt es, habe ihm der Meister I 4 Tage zu essen und zu trinken zu geben, dazu seinen Wochenlohn. Die anderen Knechte sollten ihn mittlerweile am Trinkgeld beteiligen. Liege er länger danieder und habe selbst keine »zerung « mehr, sollten ihm aus der Büchse zwei oder drei Pfund geliehen werden, die er, sobald er gesund geworden sei, abzudienen oder sonst der Bruderschaft zu vergelten habe. ${ }^{127}$ Dass erkranktes oder bedürftiges männliches oder weibliches Badepersonal aus der Büchse einer Zunft oder Bruderschaft, in die es einzahlen musste, unterstützt wurde, war auch sonst üblich. ${ }^{128}$

Interessant an der Innsbruck-Haller Ordnung ist noch der Passus, jeder Knecht solle sein Handwerkszeug außerhalb des Badhauses aufbewahren, ausgenommen (Bade-)Tü- 




Abb. 24: Bademagd; Miniatur aus der Wenzelsbibel, Ende I4. Jh.

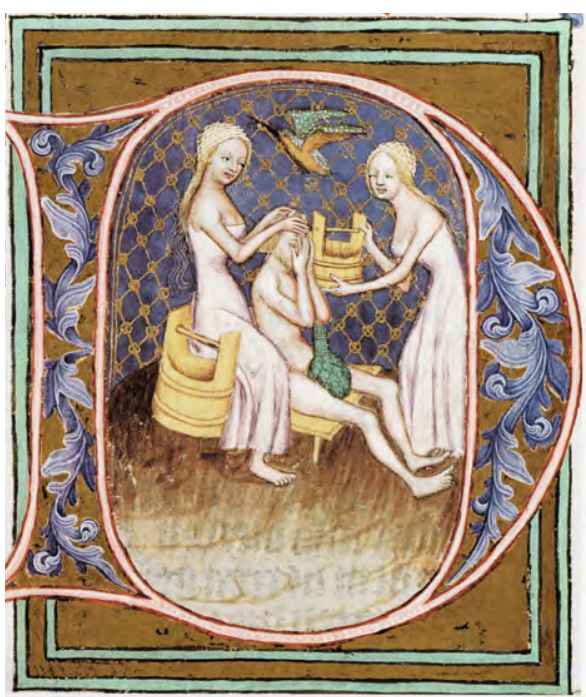

Abb. 25: Zwei Mägde waschen König Wenzel die Haare, in seinem Schoß liegt ein Badequast. Der über dem König schwebende Eisvogel, ein Symbol der ehelichen Treue, war sein Leibzeichen; Miniatur aus der Wenzelsbibel, Ende des 14. Jh.

cher und Becken. ${ }^{129}$ Die Badeknechte hatten also eigenes Werkzeug, nichts Ungewöhnliches im Mittelalter. Maurer und Steinmetzen z.B. mussten selbst Hammer, Kellen, Spitzeisen, Meißel, Flächen, Setzeisen usw. auf die Baustelle mitbringen. Der Bauherr zahlte nur fürs Schärfen und Spitzen der Geräte. ${ }^{130}$ Die Pflicht der Badeknechte, ihr Werkzeug mit nach Hause zu nehmen, war eine reine Vorsichtsmaßnahme gegen Diebstahl. Schermesser, Schröpf- und Lasseisen, Schnepper, Lanzetten, chirurgische Instrumente waren teuer und reizten gewissenlose Kollegen dazu, lange Finger zu machen. Deshalb verfügte die Ulmer Ordnung von I346 für Badhüter, Reiber und Schröpfer, wer beim Diebstahl ertappt werde, »der soll der dienst und des handtwercks gentzlich verstossen sein «. ${ }^{131}$

Bademägde und -frauen, meist Reiberinnen genannt, und Gewandhüterinnen waren ungelerntes Personal. Wie die Knechte als Reiber mussten die Badefrauen die Besucher mit Quasten, Hüten und vielseitig verwendbaren Kübeln (Eimern, Schaffen) versorgen und ihnen beim Baden behilflich sein. In der Durlacher Baderordnung von I 536 wurden die Reiberinnen eigens angehalten, sich ausreichend mit Hüten und Kübeln (je 30) zu versehen, damit keiner der Gäste, die alle ohne Rücksicht auf Rang und Namen freundlich zu behandeln seien, zu kurz komme. ${ }^{132}$ Die Vergütung für die Badefrauen fiel, wie bereits vermerkt, bescheiden aus. In Höxter waren um I 500 die bekannt 
gewordenen Bademägde arm, wohnten in abgelegenen Winkeln oder im Armenviertel der Stadt, zum Teil in einer Häusergruppe, die vermutlich als Bordell gedient hat. ${ }^{133}$ Nimmt man Rattenberg her, dann stellte man zumindest in Kleinstädten gesetzte Matronen als Reiberinnen an, Frauen oder Witwen armer oder verarmter Handwerker, die sich zu einem solchen schlecht bezahlten Dienst gezwungen sahen (s.u.). Nicht besser stand es um die Gewandhüterinnen (Badhüterinnen), die bei Verlust oder Diebstahl der von ihnen beaufsichtigten Kleidung für den Schaden aufkommen mussten. Konnten sie nicht zahlen, hielt man sich an dem Bader, sofern ihm eine Schuld nachgewiesen werden konnte, schadlos. ${ }^{134}$

Das Wunschbild, von einer jungen, reizenden, in durchsichtiges Gewand gekleideten oder gar nackten Magd im Bad bedient zu werden, wie es die Bilder der Wenzelsbibel (um 1400) den Männern vorgaukelten, hatte keinen realen Hintergrund, wenn es sich nicht gerade um ein Badebordell handelte (s.u.). Bader, Knechte und Mägde waren bekleidet, die Männer mit einer Badehose, zumindest mit einem Vortüchel, seit dem I 7. Jahrhundert häufiger mit einem Schurz. Die Mädchen und Frauen bedienten im Bad in einem leichten, ärmellosen Hemd, das die Brust bedeckte. Lediglich in Frauenstuben kam es vor, dass eine Badmaid mit entblößten Brüsten ihren Dienst versah. ${ }^{135}$

$\mathrm{Da}$ es der Moral abträglich war, untersagten Obrigkeiten den Knechten das Arbeiten in Frauenbädern. In Eberbach wurde I6 1o der Bader ernstlich aufgefordert, den Knecht in der Weiberstube abzuschaffen, "anderst vor der thür sein lohn sein solle«. ${ }^{136}$ Anderswo war man nicht ganz so streng. In Straßburg ließ man schon einmal einen Badeknecht im Frauenbad zu, doch musste er »hinden und fornen« mit einem »breittem mider bedeckt« sein, also ein breites Tuch um die Hüfte geschlungen haben. ${ }^{137}$ Wenn Guarinoni grollt:

»Ich rede hier nichts von der Badmeister unnd der Gesellen Unzucht und Ungeschämigkeit, so vor den Weibern unnd Jungkfrawen nackend da stehen, sich recken unnd strecken, unnd ob sie schon mit der Niderwad bedeckt, dieselb (damit ich Teutsch rede) öffters zu sonderm Fleiß also richten, als hetten sie keine vor ihnen oder als wer es ihnen ohn gefahr entfallen etc. Wann man erst von den uppigen und unlautern worten hie handlen wolt, so in den Bädern fürüber gehen, hette man vil zuschaffen « ${ }^{138}$

hat er maßlos übertrieben. Selbst wenn die Knechte die Frauenstube aufgesucht haben, um Wasser zu bringen, werden sie schon ihre Badehose getragen haben. Dass sie und ihre Meister in diesem »Kostüm» barfuß und »barschenkelig", nicht "gehost«, wie es heißt, über die Straße gingen, war allerdings eine Unsitte, die man ihnen lange Zeit nicht austreiben konnte. ${ }^{139}$ 


\subsection{Die Trinkstube}

Johannes Cramer spricht von Gesellschaftsräumen im Obergeschoss der Badhäuser, in denen es zu »allerlei Ausschweifungen und Gelagen« kam. Birgit Tuchen stellt diese Behauptung in Frage, weil die Baubefunde und Schriftquellen nichts von Gesellschaftsräumen in öffentlichen Badhäusern erkennen lassen. Wohn-, Schlaf- und Gesellschaftsräume für Gäste hätten wir nur in Kurbädern zu erwarten, meint sie ${ }^{140}$, und sie ist zum Teil im Recht. Alle Bilder (Stiche, Radierungen, Gemälde), die fröhliches Schmausen und Zechen sowie geselliges Treiben in Bädern zeigen, beziehen sich auf Kur-, Wild- und Thermalbäder ${ }^{141}$, Badebordelle ${ }^{142}$ oder private Bäder der gehobenen Gesellschaft in Haus und Garten. ${ }^{143}$ Sieht man wirklich einmal Besucher eines öffentlichen Bades, in diesem Fall Frauen, in drei Zubern sitzen, über die sich eine breite Planke mit Speisen und Getränken zieht, ${ }^{144}$ dann handelt es sich um ein besonderes Ereignis, nämlich um eine Brautbad, ein Hochzeitsbad (s.u.).

Doch ist nicht zu bestreiten, dass auch in städtischen Badhäusern getrunken und gegessen wurde, manchmal auf sehr primitivem Niveau. Ein Schwitz- oder Wannenbad konnte sich Stunden hinziehen, Hitze macht durstig, so dass dann einer »etwan mit seinem Weib oder sonsten einem guten Freund sitzet und ein Kändele drey/vier Wein neben guten Sträublen außleeret, damit in seinem Leib innen nicht etwan das Vacuum rusticum entstehe«, schreibt Guarinonius und meint damit, der Wein müsse den abgegangenen Schweiß an Flüssigkeit ersetzen. ${ }^{145}$ So manierlich er sich hier noch äußert, einige Seiten später zieht er gegen das Fressen und »ungehewre, lasterhaffte unnd bestiälische Vollsauffen« in den Statdbädern vom Leder. In ihnen, grollt er, lasse man alle Zurückhaltung fallen,

»in dem man in den Schweißbädern nach der Bauß frißt und trinckt, und einer nicht wol underschiden kan, ob das Schwitzbad ein Bad- oder aber ein Freß- oder Sauff- oder Unzuchtund Luderhauß sey, darauß eben die größten Suchten und Ungelegenheiten den thorechten Menschen widerfahren ${ }^{146}$

Hundert Jahre früher urteilte Antonio de' Costabilis, ein Gesandter Ferraras zu König Maximilian, nicht besser über die Zustände in deutschen Bädern. Die Männer, schreibt er, die genauso übel riechen wie die Frauen, zechen an Festtagen (auch davor und dazwischen) in stinkenden Schwitzbädern, grölen darin so herum, dass es von den Wänden widerhallt, würfeln, verschütten dabei den Wein und fordern lauthals jeden Eintretenden zum Mittrinken auf. ${ }^{147}$

Beide Autoren übertreiben gewaltig, wenn sie nur Unmäßigkeit und schlechte Sitten sehen, ${ }^{148}$ doch es entspricht den Tatsachen, dass auch in den gemeinen Bädern gegessen und getrunken wurde, ${ }^{149}$ oft schon während des Badens, sonst in der Regel 


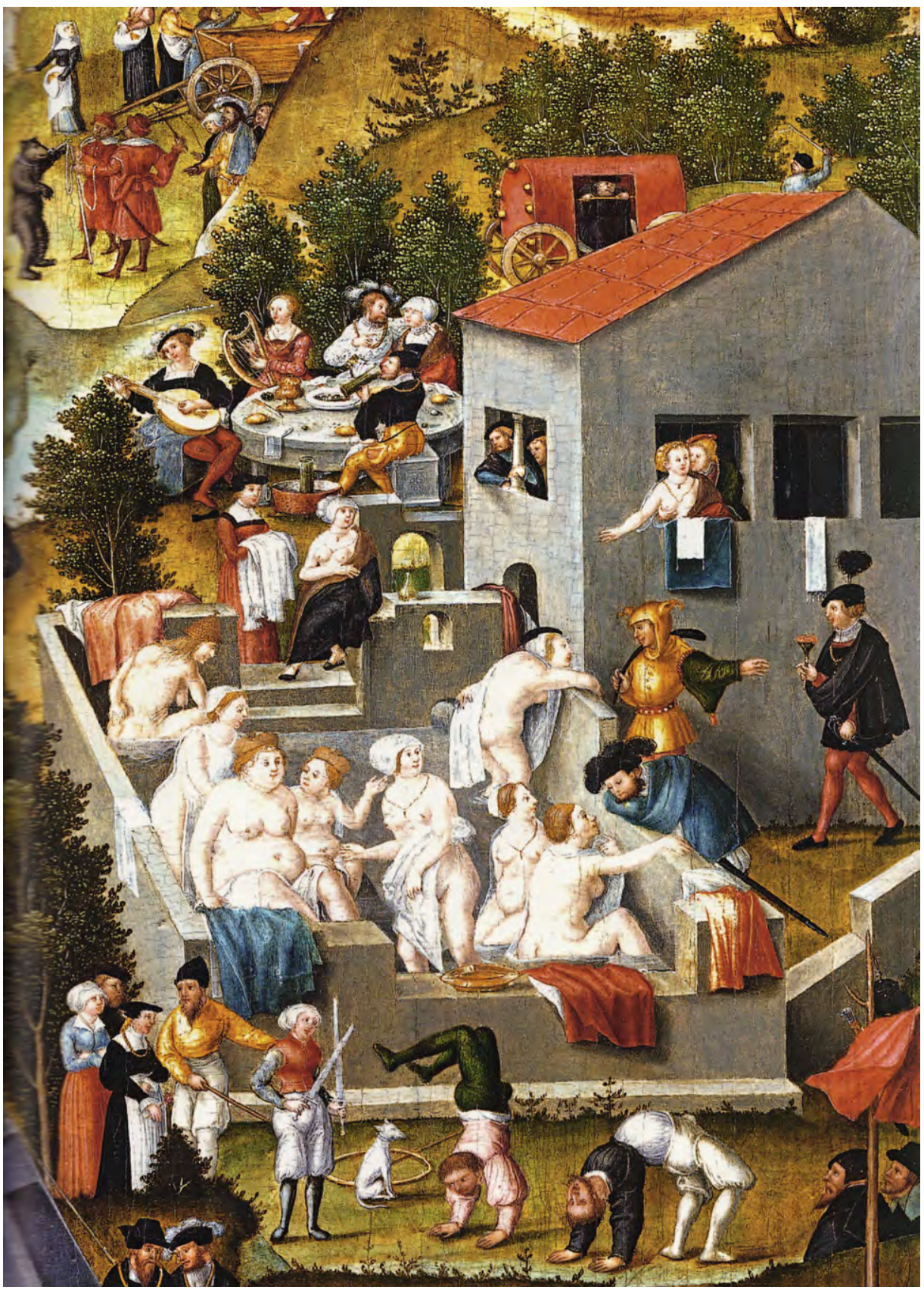

Abb. 26: Wildbadszene; Detail aus Mattbias Gerungs Tafelbild "Die Melancholie im Garten des Lebens«, 1558. 
nach dem Bad in einer eigenen Trinkstube, die sich fast immer wie in Eberbach $^{150}$ und in Rattenberg (s.u.) im Obergeschoss des Badhauses befand. Dort haben der Bader und seine Frau den Gästen Wein ${ }^{151}$ und Gebäck oder Brot mit Beilagen (Speck, Wurst, Käse), vielleicht auch Milchsuppe, Brei, Mehlspeisen und andere Gerichte (die Küche war ja nahe) serviert, ein erfreulicher Nebenverdienst. Mag auch keine Quelle direkt den Bader mit dieser Tätigkeit erwähnen, so ist das doch viel wahrscheinlicher als die Annahme, die Badbesucher und -besucherinnen hätten selbst eine Jause und vielleicht auch den Wein mitgebracht. Das dürfte zwar in Einzelfällen vorgekommen sein, war aber sicher nicht die Regel.

\subsection{Badebordelle}

Guarinoni erkannte durchaus den Nutzen des Badens für Hygiene und Gesundheit an, warnte aber eindringlich die Ehemänner und Väter davor, ihre Frauen und Töchter ins öffentliche Bad zu lassen. Kein ehrliches Weib, kein Mädchen sollte ins gemeine Bad gehen, weil dort nur Bubenwerk, Unzucht und Schamlosigkeit herrschten, die Frauen Ehre und Zucht, die Mädchen ihre Unschuld verlören. Etliche Badmeister vermieteten die Betten, die zum Ruhen nach dem Bad dienen sollten, gegen Geld und machten sie so zu »bübischen unnd hürischen Ligerstätten«, andere hielten sich »schöne Metzen und Baddürnen darzu, welche die Badenden reiben, zwagen unnd zu Uppigkeit anzünden etc. «,ja wieder andere liehen gar die eigene Frau für so schändliche Dinge her. Das Päperle-Bad in Böhmen - den Ort nennt er nicht - sei zu seiner Zeit in ganz Böhmen und Österreich »von so schöner Badzucht beschreyt « gewesen. ${ }^{152}$

Guarinoni war nicht der Einzige, der sich über laszives Gebaren und Unzucht in Bädern entrüstete. Schon anderthalb Jahrhunderte vor ihm beklagte der Arzt und Gelehrte Giovanni Michele Savonarola († I 468), die Schwitzbäder seien nun bei den Italienern $\mathrm{zu}$ lupanaria (Bordellen) verkommen, ${ }^{153}$ der bereits erwähnte Ryff behauptet in seiner »Badenfart« ( I 5 49), in einigen deutschen Ländern, besonders in niederländischen Städten seien die Badstuben hauptsächlich der Unkeuschheit wegen erbaut worden, so dass darin mehr Mutwillen und Schande geübt werde als in den öffentlichen Frauenhäusern, Ulrich von Hutten rügt I 52 I an den (Würzburger) Domherren, sie verbrächten oft ganze Nächte voll Prasserei mit ihren schönen Metzen im Bad, ${ }^{154}$ das zur Zeit des Konstanzer Konzils entstandene satirische Lehrgedicht »Des Teufels Netz« stellt lakonisch fest: »Der bader und sin gesind / Gern huoren und buoben sind «. ${ }^{155}$

Dass es sich hier nicht nur um ein gängiges literarisches Thema handelt, lässt sich leicht zeigen, besonders an Burgund, Frankreich, England, den Niederlanden. Mit der Zunahme der öffentlichen Bäder im Spätmittelalter wuchs offensichtlich auch die Zahl der Badebordelle an. Sie fanden sich z.B. in Besançon, Dijon, Mâcon, Nevers, 

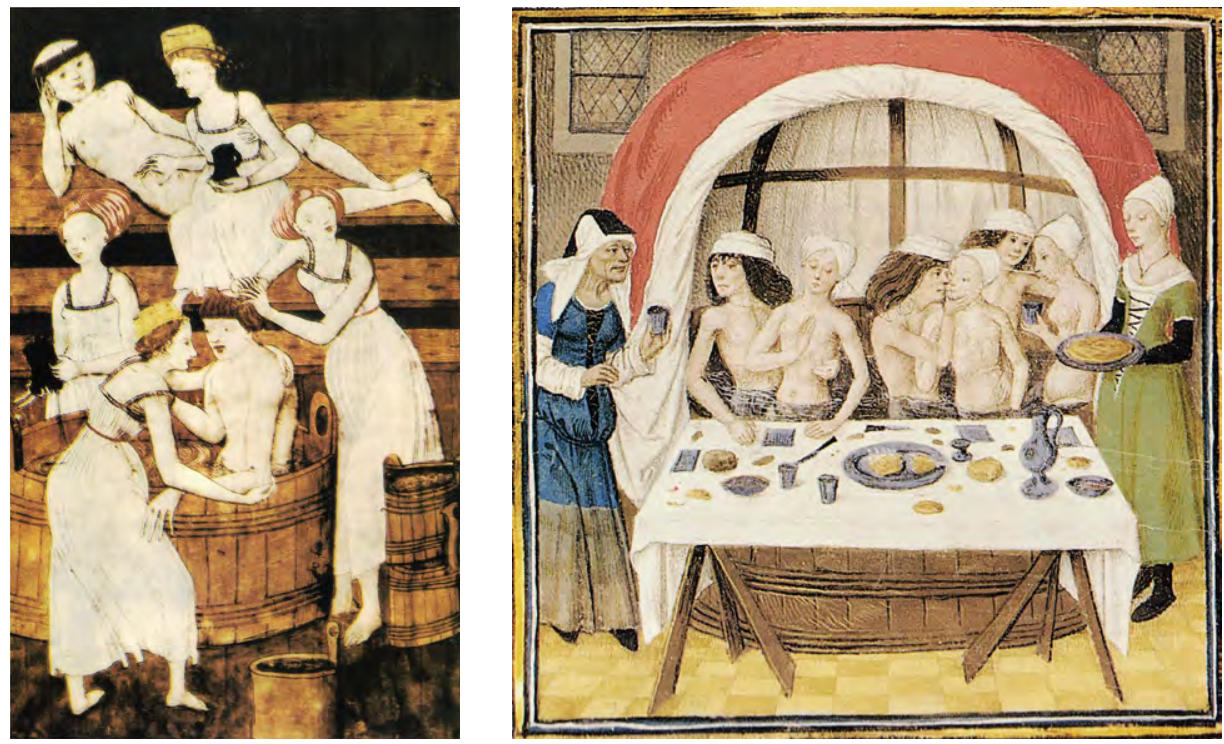

Abb. 27 (l.): Mönche und Bademädchen; Illustration aus dem sogenannten Jenaer Codex, I490-I5 IO.

Abb. 28 (r.): Burgundische Badegesellschaft; Miniatur aus "Faits et dits mémorables des romains «es Valerius Maximus, um 1470 .

Brügge, Antwerpen, Paris, Toulouse, Avignon, Lyon und London, wo sie fast alle am rechten Themseufer außerhalb der Londoner Stadtmauer lagen. Es waren einträgliche Etablissements, zur großen Freude ihrer Besitzer, worunter sich auch Äbte und Bischöfe befanden. Der Bischof von Winchester beaufsichtigte die englischen »hothouses«, weshalb man »seine« Damen des horizontalen Gewerbes in den Bädern "Winchestergänse« nannte..$^{156}$

Solche »lustvollen« Badeanstalten lagen häufig in Straßen, wo Kaufleute und Reisende Quartier bezogen. In Avignon befanden sich die türkischen Bäder in derselben Straße wie alle Gasthäuser an der Brücke. In Lille konzentrierte sich das Rotlichtmilieu ebenfalls um die Gasthäuser. In Southwark lagen vollends Gasthäuser, Bäder und Bordelle eng beieinander. ${ }^{157}$ Die cleveren Stadtväter wussten sehr wohl, was Männer wünschten und wie man Fremden den Aufenthalt so angenehm wie möglich machte.

Das laszive Verhalten von Badehuren wie denen in Montpellier brachte leicht alle Bademägde in Verruf. In Montpellier, wo es I 477 zwei Badebordelle gab, lenkten sie nicht nur die Studenten vom Studium ab, wie es heißt, sondern sie kletterten manchmal auf die Mauer zu einem angrenzenden Kloster und präsentierten den Mönchen ihre "pudibunda« (Scham). ${ }^{158}$ Geschah so etwas, konnte man andere Bademägde 
schnell und grundlos der Hurerei verdächtigen, ihnen unterstellen, einst Prostituierte gewesen zu sein und sich gelegentlich weiterhin zu preiszugeben. Es gab aber auch übel beleumdete Bäder, ohne dass sie schon Bordelle waren, in denen sich die Bademägde zu Liebesdiensten verschiedener Art bereitfanden oder in denen sich mit Billigung des Baders Huren aufhielten. ${ }^{159}$

Zum Konzil von Konstanz z. B. sollen 700 gemeine Frauen gekommen sein, von denen viele in Badstuben wohnten. ${ }^{160}$ Wenn I 486 den Badern in Breslau geboten wurde, keine Dirnen zu beherbergen, in Straßburg der Rat Ende des Mittelalters verfügte, kein Bader dürfe eine ehemalige Prostituierte als Magd anstellen, es sei denn, sie habe sich gebessert, wenn die Badestuben in Brünn am Fuße des Spielbergs und zu St. Leonhard in Basel besonders verrufen waren, Luzern das Spielen und Übernachten von Fremden in Badestuben verbot, I 5 I 4 ein Würzburger Bader entfernt werden musste, weil er viele Uneheliche und »verleumutte« Frauen ihr unziemliches Wesen im Bad hatte treiben lassen, wenn bereits im I3. Jahrhundert behauptet wurde, fast alle Wiener Badstuben seien Winkelbordelle, ${ }^{161}$ dann wirft das kein gutes Licht auf die Bader.

Doch ein verallgemeinerndes negatives Urteil über solche Zustände wäre zu einseitig. Betrachtet man die erwähnten Orte in Deutschland und im Ausland, in denen es Badebordelle gab, stellt man fest, dass es sich nur um einige wenige mittlere und größere Städte handelt. ${ }^{162}$ Und was ist mit den Kleinstädten unter 2.00o Einwohnern, die im Reich fast $95 \%$ aller Städte ausmachten? Man hört so gut wie nichts über Unsittlichkeit in ihren städtischen Bädern, geschweige denn über Hurerei und andere Liebesdienste. Das vermerkt auch Moser zu Hall, obgleich hier reiche Quellen vom Stadtrat vorliegen. ${ }^{163}$ Dasselbe Ergebnis liefert Rattenberg.

Obgleich die Ratsherren rasch bei der Hand waren, ungebührliches Benehmen (Randalieren, nächtliche Ruhestörung, Ungehorsam gegen Rat und Bürgermeister, Trunkenheit, Übertreten der Sperrstunde, Beleidigungen, Prügeleien usw.) mit ein, zwei oder mehr Gulden und Einsitzen auf dem Tor oder im Turm zu bestrafen - das verraten die Ratsprotokolle und Stadtrechnungen - , findet sich nicht ein einziger Eintrag, der moralisch ärgerliche Zustände im Bad, schon gar nicht sexuelle Ausschweifungen betrifft. Das lässt nur den Schluss zu, dass es im Rattenberger Badhaus nicht zu schwer wiegenden Verstößen gegen die Sittlichkeit gekommen ist. ${ }^{164}$

Wenn es vermutlich auch darin fröhlich, laut und locker zugegangen ist, sah offensichtlich der Rat keinen Grund zum Einschreiten, solange sich alles in erträglichen Grenzen hielt. Eine gewisse Ungezwungenheit gehörte eben zum Badevergnügen, man war ja schließlich nicht auf einer Beerdigung. Außerdem hätte zumindest die männliche Jugend keine große Freude an den Bademägden gehabt, denn die Reiberinnen im Rattenberger Frauenbad wurde von gesetzten Matronen gestellt, gemischte Badestuben kannte man hier wie anderswo auch nicht und in der Männerstube bediente sowieso kein weibliches Personal. ${ }^{165}$ 


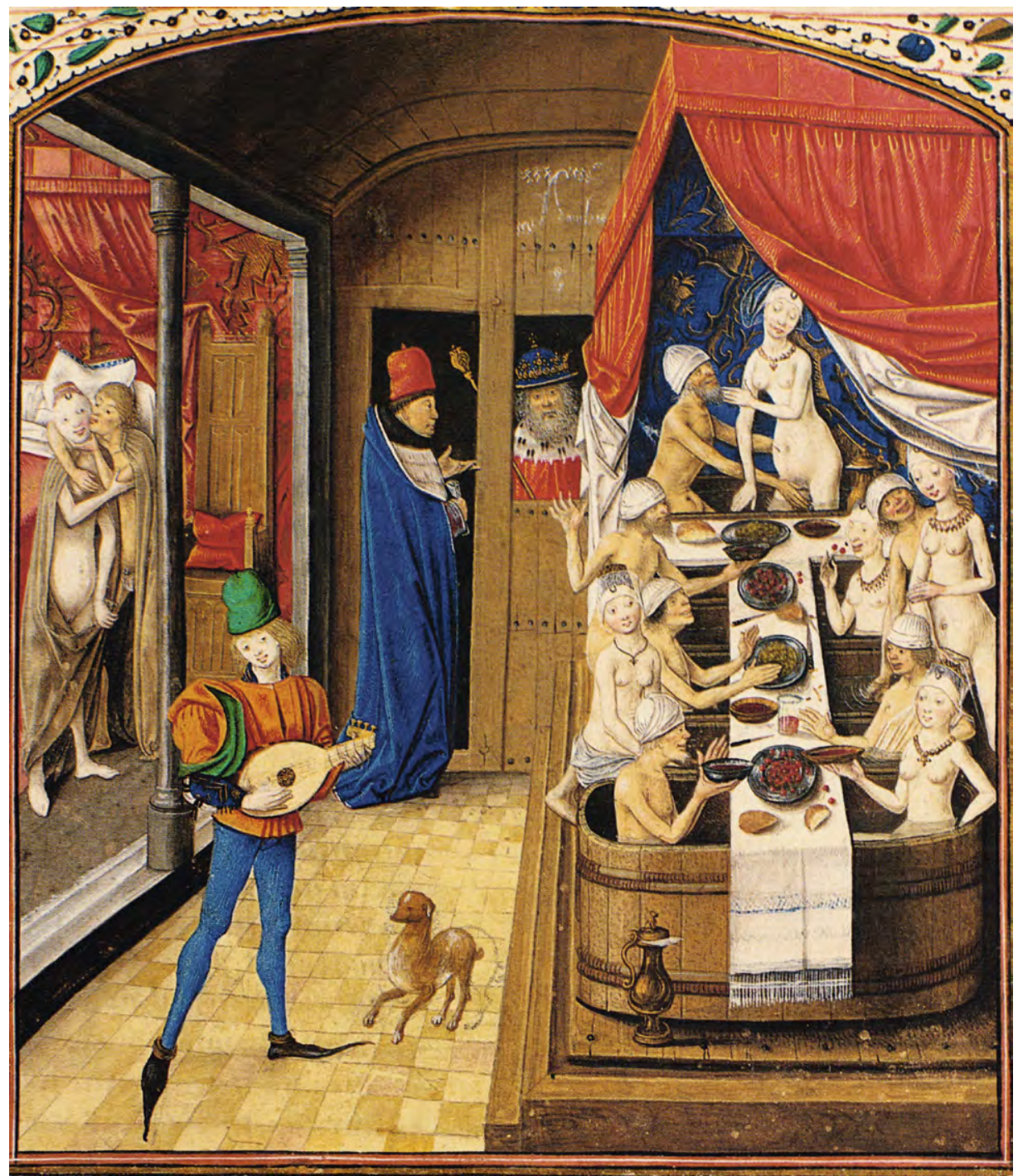

Abb. 29: Szene in einem burgundischen Bad; Miniatur Meister Antons von Burgund aus "Faits et dits mémorables des romains" des Valerius Maximus, um I 470. 
Weitaus den meisten städtischen Badhäusern konnte man hinsichtlich der Sittlichkeit nichts vorwerfen, ihre Bader, Knechte und Mägde waren ehrbare Leute. Wenn einige »schwarze Schafe« unter ihnen ihren Betrieb zu einem Badebordell gemacht haben, heute würde man wohl Massagesalon sagen, dann darf man das nicht dem ganzen Berufsstand zum Vorwurf machen. ${ }^{166}$

Der Hinweis auf viele Kupferstiche, Radierungen, Holzschnitte und Gemälde, auf denen man angeblich in öffentlichen Bädern Männer und Frauen zusammen nackt baden, speisen und kurz vor sexuellen Aktivitäten sieht, geht ins Leere. Zum einen handelt es sich um Badebordelle, nicht um städtische Bäder, ${ }^{167}$ zum anderen sind es Kur-, Wild- oder Thermalbäder, wo man sich ausufernden Gastereien und moralisch verwerflichen Lüsten hingab. ${ }^{168}$ Außerdem trifft die Behauptung von »vielen« Abbildungen nicht zu. Bei genauerem Hinsehen ergibt sich, dass es sich immer um die wenigen selben Bilder handelt, vor allem um die leicht geschürzten Bademägde aus der Wenzelsbibel und um schlüpfrige Badeszenen in den »Faits et dits mémorables des romains«, einer französischen Übersetzung der »Facta et dicta memorabilia« des Valerius Maximus.

Anton, der »Große Bastard« von Burgund († I 504), ein illegitimer Sohn Herzog Philipps des Guten und somit ein Halbbruder Karls des Kühnen, war ein eifriger Büchersammler und hat Illustrationen zu einem Manuskript des Valerius bei einem unbekannten Maler, der um I 470 in Brügge wirkte und als Meister des Anton von Burgund bezeichnet wird, in Auftrag gegeben. Eine Miniatur aus diesem künstlerisch hervorragenden Zyklus, die in moderner Zeit wieder und wieder als Beispiel sexueller Freizügigkeit im Spätmittelalter abgebildet wird, ${ }^{169}$ sollte, wie auch Buchmalereien in anderen »Faits«-Handschriften zeigen, eine Geschichte illustrieren, mit der Valerius die Neigung der Menschen zu sinnlichen Genüssen charakterisieren will. Als der Autor von Hannibals Heer vor Capua erzählt, führt er unter den lasterhaften Vergnügungen, denen sich die Soldaten hingeben, auch den Umgang mit Prostituierten an. Das Bild illustriert also in erster Linie einen Abschnitt des Textes. In die Ausgestaltung ist natürlich das Wissen des unbekannten Meisters um die eigene Welt eingeflossen. Die Miniatur vereinigt beide Elemente, Textillustration und Lebenserfahrung des Künstlers, in sich und ist so ein »verzerrter Blick durch das Schlüsselloch auf das mittelalterliche Leben «. ${ }^{170}$ Mit anderen Worten: Die Szene voller Lust und Völlerei in einem burgundischen Badebordell, die der Meister des Anton von Burgund uns präsentiert, entspricht nicht genau der damaligen Wirklichkeit, zumal er als einfacher Buchillustrator wohl nie ein so nobles Haus mit derart weitgehenden Diensten von innen gesehen und darüber etwas nur vom Hörensagen gewusst hat. Das bedeutet natürlich nicht, dass es solche exklusiven Etablissements, die allen möglichen Komfort boten, nicht gegeben hat. Noch Casanova zeigte sich von Londoner Bädern beeindruckt, in denen man zu "Abend speisen, baden und für nur sechs Guineen mit einer Kurtisane die Nacht verbringen konnte«. ${ }^{171}$ 
Wenn der Theologe, Naturwissenschaftler und Prediger Heinrich von Langenstein ( $\dagger_{\text {I } 397)}$ in einem Brief an den Mainzer Stadtkämmerer und Domherren Graf Johann von Eberstein ( I $_{3} 87$ ) sich über ein Wandgemälde entrüstet, das er bei ihm gesehen hatte, es zeige allzu laszive Szenen fleischlicher Lust eines Wiesbadener Badefestes, es säßen Männer und Weiber im Bade "nackt mit Nackten beisammen, nackt mit Nackten tanzen sie«, man "geht ins Bad, wäscht den Leib, befleckt die Seele«, ${ }^{172}$ so hört man hier zwar die Stimme eines eifernden Moralpredigers, doch ist wohl kaum zu bezweifeln, dass es in den bereits von den Römern aufgesuchten Thermalbädern Wiesbadens, von denen es im I4. Jahrhundert schon wieder elf gab, ${ }^{173}$ recht locker herging. Aber es waren keine normalen Stadtbäder, sondern eben Thermalbäder, in denen wie in anderen Kur- und Wildbädern die größte Freiheit herrschen konnte. Bekannt und immer wieder zitiert ${ }^{174}$ ist der Bericht Poggios von I4I 7 in einem Brief an seinen Freund Niccolò Niccoli über das fröhliche, ungezwungene Leben, Lieben und Treiben in den Thermalbädern zu Baden im Aargau. 


\section{Das Badewesen vom 16. bis zum 19. Jahrhundert}

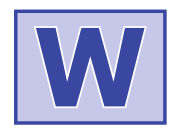

annenbäder schoben sich im I6. Jahrhundert mehr und mehr in den Vordergrund und drängten das gemeine Schwitzbad allmählich zurück, bis es im I7. und I 8. Jahrhundert ganz oder fast ganz von der Bildfläche verschwand. Zählte Wien im Mittelalter 2 I Badestuben, waren es I 534 noch elf, Anfang des I 8. Jahrhunderts lediglich sieben. Speyer, das im I4. Jahrhundert neun öffentliche Bäder hatte, besaß im I 7. Jahrhundert nur noch eins. Ähnlich in Frankfurt am Main. Um I 500 gab es dort I 5 städtische Bäder, I 555 nur noch zwei, die letzte Stube stellte I 809 ihren Betrieb ein. ${ }^{175}$ Zwar sah es nicht überall so schlimm um das Überleben der Schwitzbäder aus, ${ }^{176}$ doch der Trend zu ihrem Untergang zeigte sich in fast allen größeren und mittleren Städten. Die vornehmen Leute mieden sie. Eine Dame solle zu Hause baden, nur »Weibesbilder von schlechtem Stande« besuchten noch das gemeine Bad, verkündete das Leipziger Frauenzimmerlexikon von I 7 I $5 .{ }^{177}$

In der Tat ließ sich das Volk von der lieb gewordenen Gewohnheit, man mochte gegen das Baden sagen was man wollte, nicht abbringen. Es war ihm zum unerlässlichen Bedürfnis geworden. Die städtischen Unterschichten und vor allem die Landbevölkerung hielten an den Dampfbädern fest, sie überdauerten in kleinen Städten bis ins I 8. Jahrhundert, auf dem Lande noch länger. ${ }^{178}$ Die vier Haller Bäder z.B. schlossen erst um I 760, I770 und I800, ${ }^{179}$ also zu einer Zeit, als andernorts unter geänderten Voraussetzungen bereits neue Bäder entstanden.

Man hat Gründe für den Niedergang geltend gemacht, die das Problem nur zum Teil oder gar nicht betreffen. Ein moralischer Druck der (protestantischen) Kirche, der, wie behauptet, das Ende der Bäder besiegelt hätte, lässt sich nicht nachweisen. ${ }^{180}$ Zwar trug eine Verknappung und Verteuerung des Brennholzes im I6. Jahrhundert dazu bei, dass die Eintrittspreise stiegen und die Badetage von durchschnittlich drei auf einen verringert wurden, doch der Besucherschwund war schon vorher eingetreten. ${ }^{181}$ Zudem machte sich eine wahre Explosion der Brennholzpreise erst Ende des I6. Jahrhunderts bemerkbar. ${ }^{182}$ Der Dreißigjährige Krieg hat sicherlich Deutschland schwer verwüstet, aber der Rückgang der Bäder ist nicht seine unmittelbare Folge. Außerdem wurden zerstörte Bäder wieder aufgebaut, z.B. I66o in Allensbach um 300 Gulden, wenn die Gemeinde das Bedürfnis danach hatte. Leipzig leistete sich gar nach dem großen Krieg ein gewölbtes schönes Badhaus aus Stein mit Kupferwannen und Zubern, deren jede (jeder) frisches Wasser aus einem eigenen Messinghahn erhielt. Andere Badstuben befanden sich an der Thomaser Pforte. ${ }^{183}$

Dass zu Zeiten der Pest und anderer Seuchen die Ansteckungsgefahr in Badhäusern besonders groß war und es sich deshalb empfahl, sie wenigstens zeitweise zu schließen, 
war den Obrigkeiten sehr wohl bewusst. Solche Maßnahmen beeinträchtigten natürlich bei lang anhaltenden Infektionskrankheiten die Rentabilität des Bades und verstärkten die Schwierigkeiten des Baders, aber sie waren nicht hauptverantwortlich für die Schließungen, zumal nicht wenige Badestuben selbst bei Epidemien den Betrieb weiterführten. ${ }^{184}$ Ansteckung hin oder her, die Leute wollten auf ihr wöchentliches Bad nicht verzichten. Bezeichnend für ein solches Verhalten sind die Quellenzeugnisse aus Rattenberg.

Wie andere Tiroler Orte litt Rattenberg immer wieder unter Infektionskrankheiten, die um die Stadt grassierten oder in sie eindrangen. Nimmt man die Jahre I $_{5}$ I $_{2} /$ I $_{3}$, I $526 / 28$ und I 543/45, als es hier zu länger anhaltenden Seuchenzügen kam, traf der Rat, in Absprache mit dem Stadthauptmann und der Regierung oder auf ihre Weisung hin, folgende Vorsichts- oder Abwehrmaßnahmen. Es wurden Sondertorhüter bestellt, Schiffe durfte nicht mehr an der städtischen Arche anlegen und Schiffsleute nicht mehr die Stadt betreten, niemand, der aus einem verseuchten Gebiet kam, durfte eingelassen werden. Infizierte Personen kamen in das Spital, das mit zusätzlichem Bettzeug versehen wurde, oder in ein Haus außerhalb der Stadt, in anderen Fällen wurden sie in ihrem Haus, das mit Wachs und Schnüren versiegelt wurde, eingesperrt und nicht vor vier Wochen hinausgelassen. Der Rat bezahlte Leute, die den Seuchenkranken aufwarteten, ihnen Lebensmittel zutrugen, die Toten einnähten und begruben. Ein eigens angestellter Totenlässl ließ die Erkrankten zur Ader und versorgte sie medizinisch. Kirchtage, Prozessionen und Märkte wurden abgesagt. ${ }^{185}$

Nicht ein einziges Mal wird erwähnt, dass während einer Seuche das städtische Bad geschlossen wurde. Der Rattenberger Bader erhielt nach wie vor seinen vollen Jahreslohn von I6 Gulden, der Badebetrieb lief, wie viele Hinweise in den Quellen erkennen lassen, einfach weiter. Lediglich bei akuten Fällen, wenn z. B. Syphilis auftrat, wurde das Bad kurzzeitig geschlossen. Zu behaupten, der »tatsächliche Schlag gegen die Badestuben« sei durch die Syphilis gekommen, ${ }^{186}$ stimmt nicht. Sie war immer bloß ein vorübergehender Störfaktor, mehr nicht.

\subsection{Private Bäder, Badezimmer}

Nicht nur störend, sondern finanziell geradezu bedrohlich konnten für einen Bader die privaten Bäder werden, die seit dem Ende des Mittelalters beim vornehmen Leuten mehr und mehr in Mode kamen und eine gewichtige Ursache für den Niedergang der öffentlichen Bäder wurden. Dem Bader ging die zahlungskräftige Kundenschicht verloren. ${ }^{187}$ Bei privaten Bädern denkt man unwillkürlich an eigene Badezimmer im Wohnbereich und liegt damit gründlich daneben. Noch lange Zeit verzichtete man fast immer darauf und begnügte sich bei Adel wie Bürgertum mit einer in den Raum gestellten Wanne, mit oder ohne Baderof. 


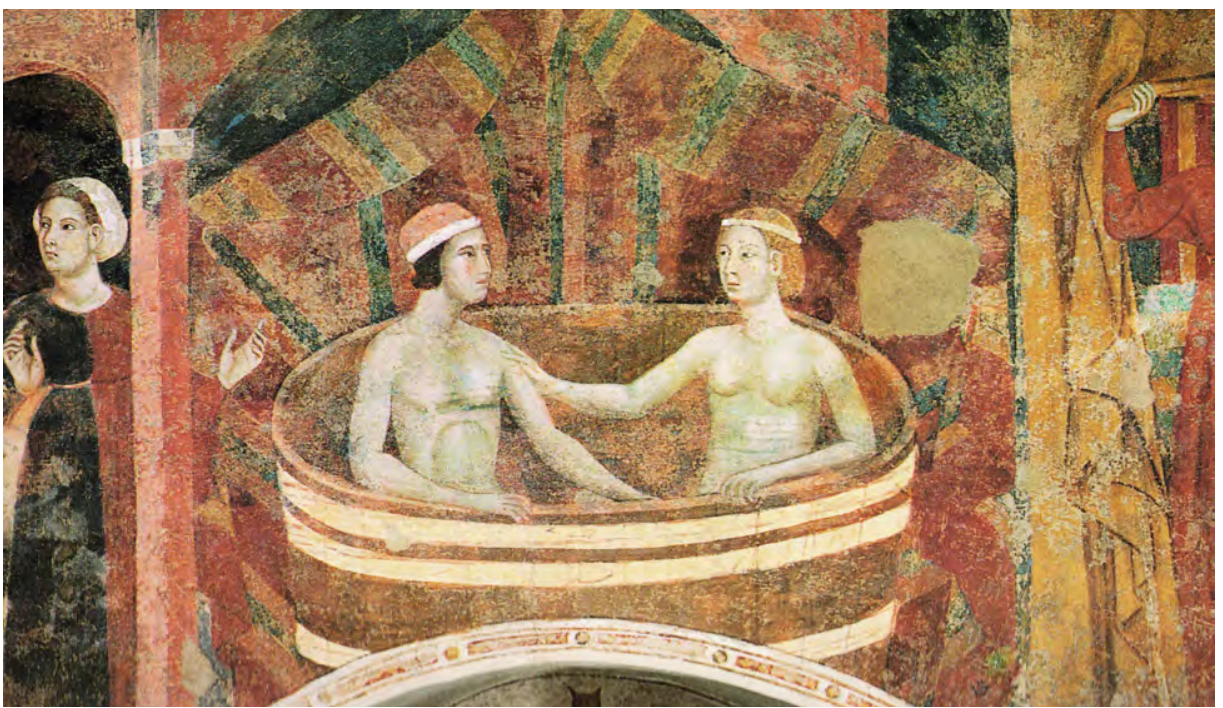

Abb. 3o: Paar in einer Wanne mit Baderof; Fresko von Memmo di Filippuccio im Palazzo Comunale zu San Gimignano, I3I7.

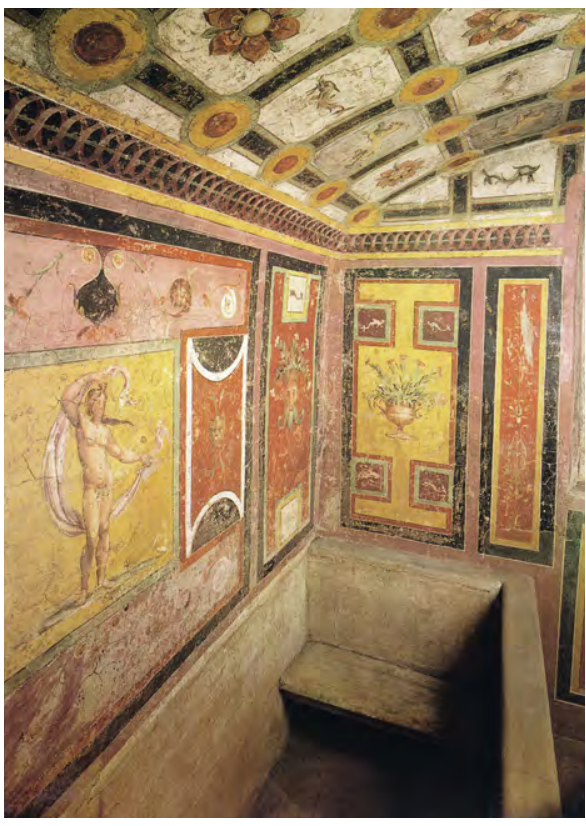

Abb. 3 I: Kleines Dampfbad (Stufetta) Papst Clemens VII. (1523-1534) im Vatikan

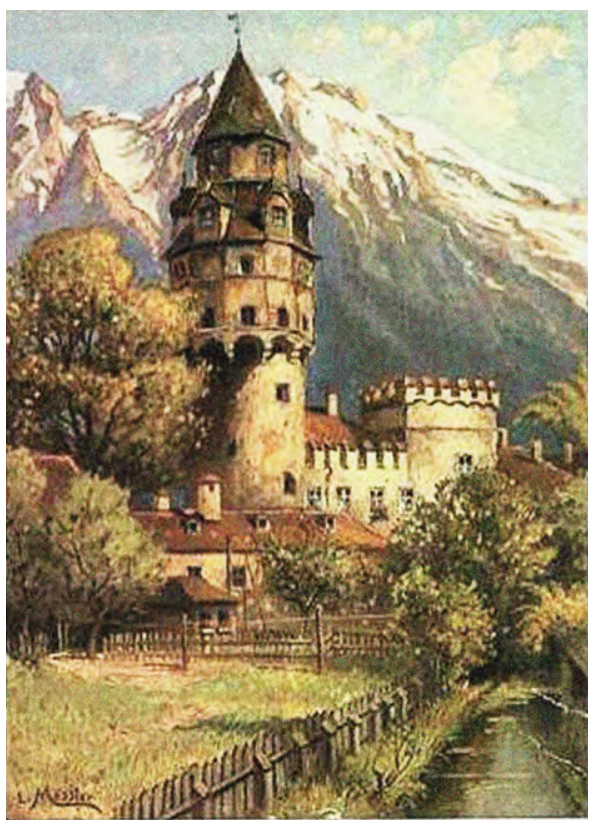

Abb. 32: Münzerturm zu Hall (Ansichtskartenmalerei von Ludwig Mössler, I940 - Privatbesitz. 
Selbst aus dem Florenz des I 5. Jahrhunderts sind lediglich zwei private Bäder bekannt geworden, eines davon im Palast der Medici. Leistete man sich allerdings ein eigenes Bad, konnte die Anlage großartig ausfallen wie die des Markgrafen Philipp II. von Baden. Zwischen I 575 und I588 im Schloss Baden-Baden errichtet, enthielt sie ein vertieft liegendes, mit Zinn ausgeschlagenes Bassin, auf deren umlaufenden Sitzstufen sich eine ganze Badegesellschaft niederlassen konnte. Das Becken war mit Thermalwasser gefüllt. ${ }^{188}$ Vergleichbares in Tirol, wenn auch aus Holz, konnte nur das herzogliche Bad in der Burg Hasegg zu Hall bieten, I 466 fertig gestellt und ${ }_{5} 567$ für die in die Burg verlegte Münze aufgehoben.

Agostino Patrizzi, der I 47 I den Kardinallegaten Todeschini-Piccolomini zum Regensburger Reichstag begleitete, beschreibt die einzigartige Anlage wie folgt:

»Kaltes und warmes Wasser steigt von unten bis ganz nach oben empor. Das Badehaus ist im Innern vollständig mit Tannen- und Fichtenholz ausgetäfelt. Die Bedienungsräume und Badebecken sind ebenfalls aus Holz. Zudem ist hier für allerhand Verstellungskünste gesorgt, die Lachen hervorrufen sollen. So kann es geschehen, dass beim Durchschreiten der Baderäume plötzlich der Boden unter den Füßen weicht und man ins Wasser fällt. Andere, die in einem Badebecken sind, werden unversehens von empor geschleuderten Wasserstrahlen von allen Seiten nass gespritzt, wie von einem Regenguss. Jemand, der sich an die Zwischenwände anlehnt, um über sie hinweg den Badenden im benachbarten Becken zuzuschauen (die Zwischenwände der größeren Becken sind ziemlich hoch), verliert plötzlich den Halt, weil die Wand weggezogen wird, und stürzt kopfüber in das Becken. Wer sich im Badebecken aufhält, kann sich unverhofft im Trockenen wiederfinden. So ist mit feiner Erfindungsgabe alles zur Erheiterung getan. ${ }^{189}$

Man könnte glauben, man hätte es mit einem barocken Wasserspiel zu tun.

$\mathrm{Ob}$ allerdings die prächtigen, schon einmal mit einer Wanne oder einem Bassin aus Marmor ausgestatteten Baderäume von den hohen Herrschaften rege benutzt wurden ist fraglich. ${ }^{190}$ In den deutschen Schlössern des I6. Jahrhunderts fanden sich immer weniger Badestuben, die seit Mitte des I7. Jahrhunderts unter französischem Einfluss errichteten neuen Bäder waren teilweise nur Schau- und Prunkbäder. ${ }^{191}$ Bezeichnend ist das Verhalten Ludwigs XIV. Er ließ in Versailles ein Badezimmer mit einer Wanne aus Marmor einbauen, um es einige Jahre später dem Grafen von Toulouse als Wohnung zu überlassen. ${ }^{192}$ Baden war nicht (mehr) unbedingt notwendig. Das meinte auch schon im I 5. Jahrhundert der burgundische Herzog Philipp der Gute. Nach Ausweis seiner Rechnungsbücher hat er nur alle vier bis fünf Monate gebadet. ${ }^{193}$ Ihre Fürstliche Gnaden dürfte zeitweise etwas streng gerochen haben.

Dass, wie erwähnt, seit Ende des Mittelalters unter den begüterten Schichten die Tendenz bestand, ein Bad zu Hause zu nehmen, ist nicht zu bezweifeln, wie lange 
allerdings das Bestreben anhielt, steht auf einem anderen Blatt (s.u.). Nur meinte man damit nicht schon ein separates Badezimmer. In der Literatur werden als Zeugen dafür immer wieder die prächtigen Renaissancebäder der Fugger und des Ambrosius Höchstetter in Augsburg sowie die Badstuben des Mainzer Domherrn von Hattstein und des wohlhabenden Nürnberger Patriziers Anton Tucher genannt. ${ }^{194}$ Das alles war die Ausnahme. Ein privates Bad bedeutete in dieser und späterer Zeit meist nichts anderes als Baden zu Hause in einem Zuber. Das vorhin erwähnte Frauenzimmerlexikon von I 7 I 5 erklärt als Badstube: »Ist dasjenige Behältnis unten im Hause, worinnen sich das Frauenzimmer zu baden pfleget «. ${ }^{195}$

Das »Behältnis«, die Wanne bestand schon längst nicht mehr allein aus Holz, die sich feine Damen mit Tuch auslegen ließen, um sich keinen Splitter einzuziehen. Beliebt waren verzinkte Kupferwannen, die zwar teuer waren, aber gut die Wärme hielten. Es gab Wannen aus Marmor oder verbleitem Holz, für Ärmere aus Blech, die man anstrich, um Email vorzutäuschen. Im I 8. Jahrhundert pflegte man vor der Gesellschaft im Salon, im Schlafzimmer in kunstvoll gefertigten Möbeln mit Polstern oder aus Rohrgeflecht zu baden, die geschickt das Blechbecken verbargen. Karl der Kühne hatte eine Wanne aus Silber, die er sogar auf das Schlachtfeld mitgenommen haben soll. ${ }^{196}$

Keine eigene Badestube, ja manchmal nicht einmal ein eigener Zuber war ratsam, wenn man zudringliche Nachbarn fernhalten wollte, wie das Beispiel des Kölner Ratsherrn Hermann Weinsberg lehrt. Sein Vater hatte ihm geraten, keine eigene Badestube zu errichten, sonst kämen Freunde und Nachbarn zum Baden, erwarteten einen gedeckten Tisch und Wein, von weiteren Kosten ganz abgesehen. Hermann schlug den Rat in den Wind, ließ sich heißes Wasser in die Badebütte einfüllen und bald hatte er die Nachbarn am Hals. Er wusste sich nicht anders zu helfen, als I 579 einige Jahre mit dem Badebetrieb auszusetzen. ${ }^{197}$ Separate Badezimmer in Kölner Bürgerhäusern waren eben sehr selten, ${ }^{198}$ anderswo auch, und das noch lange Zeit. Sie galten bis ins 20. Jahrhundert als ein »außergewöhnlicher Luxus der Wohnungsausstattung «. ${ }^{199}$

Der Durchschnittsbürger Frankreichs z.B. begnügte sich um I 800 mit einer tragbaren Badewanne, oft im Flur vor dem Wohnzimmer aufgestellt, nahe der Eingangstür, um das Wasser nicht so weit schleppen zu müssen. In Deutschland wie Frankreich ließ man sich seit Anfang des I 9. Jahrhunderts das Bad ins Haus liefern, mit warmem oder kaltem Wasser in Behältern, mit Bademantel und Tuch. ${ }^{200}$ Oder man lieh sich wie Goethe eine Wanne. I 809 wies er aus Jena seine Frau an, sie solle mit der Schubkarre die geliehene Badewanne zum Eigentümer zurückbringen. ${ }^{201}$

Im I 9. Jahrhundert wuchs in der feinen Gesellschaft, besonders bei den Damen, das Bedürfnis nach einer privaten Badesphäre, nach einem Raum, wohin man sich zur Körperpflege zurückziehen konnte. Die neben den Privatgemächern aufkommenden Badekabinette enthielten zwar einfache Möbel, einen Waschtisch, Wasserkrug, eine Schüssel, manchmal ein Bidet und einen Eimer für das Schmutzwasser, aber keine 




Abb. 33: Mit Leinen ausgeschlagene Badewanne; Miniatur Meister Antons von Burgund aus "Faits et dits mémorables des romains" des Valerius Maximus, um 1470.



Abb. 34: Badewanne in Form einer Liege aus Rohrgeflecht, mit Blechdeckel, ; Ende I 8. Jh. 
Badewanne, und wenn, dann wurde sie von Fall zu Fall ins Kabinett gebracht. Fließendes Wasser gab es nicht. Nur in wenige Herrenhäuser baute man schon richtige Badezimmer ein. ${ }^{202}$ Als man seit 1 870/ I880 daran ging, Wasser- und Abwasserleitungen in die Räume zu legen, fanden mehr und mehr Badezimmer Eingang in die (Miet-)Wohnungen gehobener Qualität, zunächst in den größeren, später auch in den kleinen Städten. Der Prozess verlief aber langsam. Noch um I 900 enthielten in Paris nur die teuersten Wohnungen ein Badezimmer, gab sich die gutbürgerliche Pariserin mit gelegentlichen Fußbädern zufrieden, bis zum Ersten Weltkrieg konnten sich die Arbeiter und der größte Teil der Mittelschicht den Luxus eines Badezimmers nicht leisten. $^{203}$

\subsection{Gutes Wasser, böses Wasser}

Selbst Befürworter des Badens, die seinen Wert für Hygiene, Gesundheit, Entspannung, Regeneration anerkannten, warnten davor, zu oft und zu lange Badestuben, Thermal- und Mineralbäder aufzusuchen. ${ }^{204} \mathrm{Zu}$ häufige Dampfbäder, hieß es, verursachten Kopfschmerzen, verstopften die Leber, riefen Geschwüre und Fieber hervor, schädigten die Augen, Lunge und Nerven, begünstigten Podagra und Infektionskrankheiten, verweichlichten die Jugend. ${ }^{205}$ Schon die Kirchenväter hoben, wenn auch eher aus moralischen Gründen, warnend den Finger. Nach Augustinus sollten Nonnen nur einmal im Monat, Kranke nach Maßgabe der Ärzte, nach dem hl. Benedikt sollten gesunde und namentlich jüngere Mönche nur wenig, nach Wilhelm von Hirsau (I r. Jh.) gar nur zweimal im Jahr (Weihnachten und Pfingsten) baden, der hl. Hieronymus riet überhaupt vom Bad ab. Den Jungfrauen legte er nahe, ganz darauf zu verzichten, damit nicht der Anblick ihres nackten Körpers unzüchtige Gedanken in ihnen erwecke. Nähmen sie doch ein Bad, solle das in finsterer Nacht und bei dicht verschlossenen Fensterläden geschehen. ${ }^{206}$ Wie sie im Dunkeln Schwamm und Seife finden sollten verrät er nicht.

Solche gelehrten Ansichten erreichten das Volk nicht oder kaum, vergraultem ihm nicht die Freude am Badevergnügen. Aber die Ärzte taten dies. Seit dem ausgehenden I 5. Jahrhundert wurden sie nicht müde, immer wieder vor der Gefährlichkeit des Wassers und Badens zu warnen. Hieß es bislang nach humoralpathologischen Vorstellungen, die Wärme und Feuchtigkeit eines Schwitzbades öffneten die Poren für den Schweiß, um den Körper von überflüssigen, schädlichen Körpersäften zu reinigen, namentlich von kalter Materie, die das Gehirn verstopfe, ${ }^{207}$ Baden sei also gesund, galt nun, dass »das Baden, außer aus dringenden medizinischen Gründen, nicht nur überflüssig, sondern auch sehr schädlich für die Menschen« sei, dass es den Menschen die Lebenskraft entziehe, den Körper erschlaffen lasse, den Organismus verweichliche. ${ }^{208}$ 




Abb. 35: Thermalbad zu Plombières; Holzschnitt aus Konrad Gesners »De balneis«, I553. 


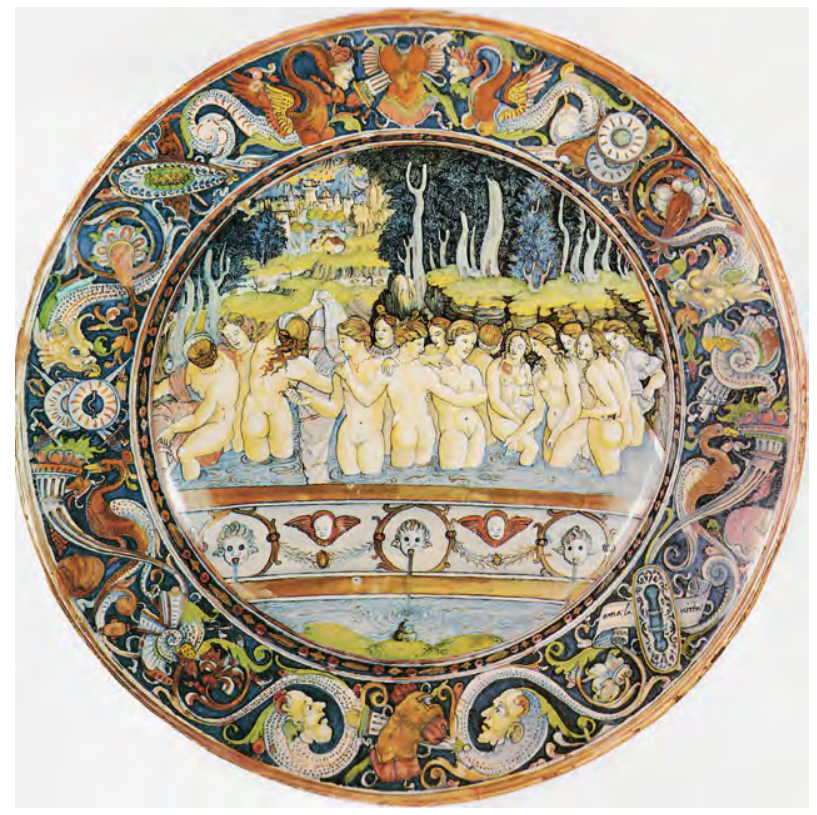

Abb. 36: Badende Frauen im

Freien; Majolika des Maestro

Giorgio da Gubbio, I525.

Der Vorwurf, den die Ärzte gegen Dampfhitze, warmes oder heißes Wasser richteten, war, dass sie die Poren öffneten und Risse in der Haut verursachten, wodurch die Körpersäfte geschwächt und die Organe allen möglichen Gefahren ausgesetzt würden. Verseuchte Pestluft und andere Krankheitserreger könnten sich ungehindert einnisten, mit dem Wasser schleiche sich die Syphilis ein. Baden, besonders die eindringenden Dämpfe schädigten Nerven und Sehnen, schwächten die Brust, verursachten Wassersucht und andere Leiden, förderten den Schwachsinn, töteten die Frucht im Leib der Mutter, auch wenn das Wasser warm sei, führten zu ungewollter Empfängnis, wenn zuvor Männer im Wasser gebadet hätten, kann man lesen. ${ }^{209}$ Sogar die Ansicht, Schmutz beuge Krankheiten vor, wurde hoffnungsvoll geäußert. ${ }^{210}$

Wie sollten die Bader gegen diese Meinungsmache der Mediziner und Gelehrten bestehen? Das gebildete Publikum blieb aus, scheute auch daheim vor dem Wasser zurück. Als 1798 der reiche Quäker und Kaufmann Henry Drinker zu Philadelphia seiner Frau Elizabeth eine Duschkabine in den Garten stellte, vermerkte sie nach der ersten Benutzung in ihrem Tagebuch, sie sei nach 28 Jahren erstmals wieder am ganzen Körper nass geworden. ${ }^{211}$ Königin Margarete von Navarra (I 492-I 549), Schwester Franz' I. von Frankreich und Autorin des berühmten »Heptameron«, hatte eine solche Scheu vor dem Kontakt mit Wasser, dass sie sich gegenüber ihrem Liebhaber rühmte, sie habe seit acht Tagen ihre schönen Hände nicht mehr gewaschen. ${ }^{212}$ Dass Herzog 


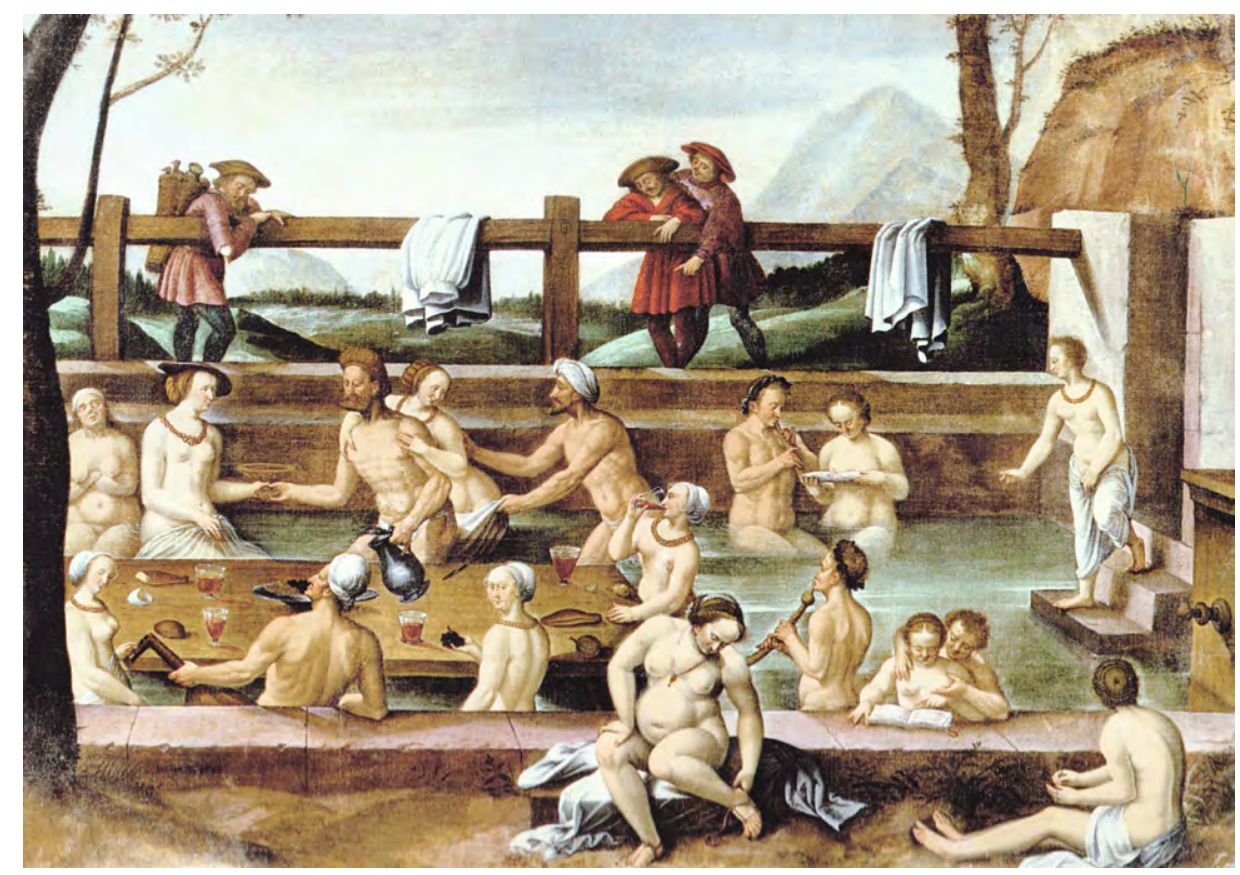

Abb. 37: Leukerbad im Wallis; Gemälde von Hans Bock d. Ä., I597.

Philipp der Gute im Jahr nur zwei bis drei Bäder nahm, wurde schon erwähnt. Ludwig XIV. rieb sich morgens nur die Hände mit Branntwein ab. ${ }^{213}$

Höchst seltsam ist die Meinung eines gewissen Herrn von Buswy, des Leiters der kaiserlichen Reitbahn. Als Graf Wolrad von Waldeck I 548 in Rudolstadt, der Residenz der Grafen von Schwarzburg, erstaunt feststellte, dass hierzulande die Frauen häufig badeten, bekam er »auf gelehrte Weise« vom Reitchef zu hören, ein Bad für sie sei fast jeden Tag nötig. Denn im höher gelegenen Deutschland - dazu zählte er offensichtlich schon den Thüringer Wald - zögen die Frauen unvermeidlich weit mehr Schmutz an als die Frauen in Brabant oder Niederdeutschland. »Unsere« wüschen ihren Körper kaum ein- oder zweimal im Jahr. ${ }^{214}$ Wenn das stimmt, sollte man über die Duftnote dieser Damen besser nicht diskutieren.

Zwar verabschiedeten sich die Angehörigen der Oberschicht (Adel, reiches Bürgertum) im Allgemeinen vom Bad daheim, doch mieden sie das Wasser nicht völlig. Die schon im Mittelalter frequentierten Thermal-, Mineral- und Wildbäder erlebten seit dem r6. Jahrhundert einen starken Zulauf, vielerorts kam es zu neuen Heilbädern, weil die Mediziner nun nicht nur Thermen, sondern auch kalten Mineral-, Sole- und Schwefelquellen eine Heilkraft, zumindest eine Linderung der Leiden zusprachen. 
Thermalwasser könne Gallen- und Nierensteine aufösen, hieß es, Menschen mit ausgemergelten und abgemagerten Körpern kämen durch Bäder wieder zu Kräften, sie könnten auch bei Gelbsucht und Verstopfung helfen und sich positiv auf die Mischung der Körpersäfte auswirken. Kalte Bäder oder Übergießungen seien manchmal bei Podagra (Gicht) und Lähmungen zu empfehlen, Quellwasser überhaupt fördere die Gesundheit. ${ }^{215}$

Das in Italien zusammengetragene balneologische Wissen fand seit dem I 5 . Jahrhundert in deutschen Bäderbüchlein und -traktaten seine Fortsetzung. Erwähnt sei das I 562 erschienene »Bäderbüchlein« des Paracelsus. Für ihn ist nicht nur die Zusammensetzung des Wassers (Mineralien) von Bedeutung, sondern auch sein Ursprungsort, seine Temperatur und das Gestein, worüber es fließt, um die Heilwirkung jeden Wassers bestimmen zu können. ${ }^{216}$ Oft schlugen die Badekuren nicht so an, wie man wollte. Einerseits mussten die Ärzte übertriebene Hoffnungen auf eine Heilung der verschiedenen Krankheiten und Gebrechen dämpfen, andererseits ist zu bezweifeln, ob Leute, die regelmäßig Badefahrten mehr um des Vergnügens willen als zu therapeutischen Zwecken unternahmen, ernstlich gewillt waren, Badekonsilia, ärztliche Ratschläge, medizinische Indikationen und diätetische Anweisungen zu befolgen.

Da man kalte Quellen schnell zur Hand hatte, um ein Wildbad mit natürlichem Wasser (künstlich gewärmt) zu eröffnen, schossen solche Bäder ins Kraut und ermöglichten auch den einfacheren Bürgern den Besuch eines Wildbades, da die Reisekosten zu einem solchen in der Nähe gering ausfielen. Städtische Bader des I6. und I 7. Jahrhunderts suchten an dieser Entwicklung teilzuhaben und wollten plötzlich überall in den Städten heilkräftige Quellen entdeckt haben, um nicht noch mehr Kundschaft $\mathrm{zu}$ verlieren. ${ }^{217}$ Die Landesherren förderten die Kurbäder. Die alte Schwefel- und Eisenquelle zu Schgums (zwischen Laas und Tschengls im Vinschgau) war schon den Römern bekannt. Herzog Sigmund hatte das dortige Bad seinem Rat Balthasar von Liechtenstein, Hauptmann zu Trient, und dessen Vetter als Lehen überlassen. Weil es an einem »mos (Sumpfland) lag, »daraus vil ungesunthait den leuten in demselben bad, als uns furbracht wirdet, aufersteen müge«, erlaubte I 470 der Tiroler Landesfürst den beiden Liechtensteinern, zwei Gräben durch das Moos bis in die Etsch zu ziehen, um dem Übelstand abzuhelfen und das Bad zu verbessern. ${ }^{218}$

Die Scheu vor dem Baden und dem Wasser überhaupt darf nicht dazu verleiten, die Damen und Herren der frühen Neuzeit als »Dreckspatzen« anzusehen. Sie hatten nur eine andere Ansicht von der Hygiene als wir, ihre Kriterien für Sauberkeit und morgendliche Toilette entsprechen nicht den unsrigen. War es im I 5./I 6. Jahrhundert noch ein Gebot des Anstands, sich jeden Morgen Hände und Gesicht zu waschen, ließ man im I7. Jahrhundert nur noch das Händewaschen zu. Dass, wie früher die Mediziner meinten, kaltes Wasser die Sehkraft stärke, davon wollte man nichts mehr wissen. Eine achtbare Person, hieß es nun, solle ihr Gesicht nur trocken abreiben, um den Talg zu 
Abb. 38: Schmausen im Wildbad; kolorierter Titelholzschnitt zum "Tractat der Wildbäder« von Lorenz Fries, 1519 .

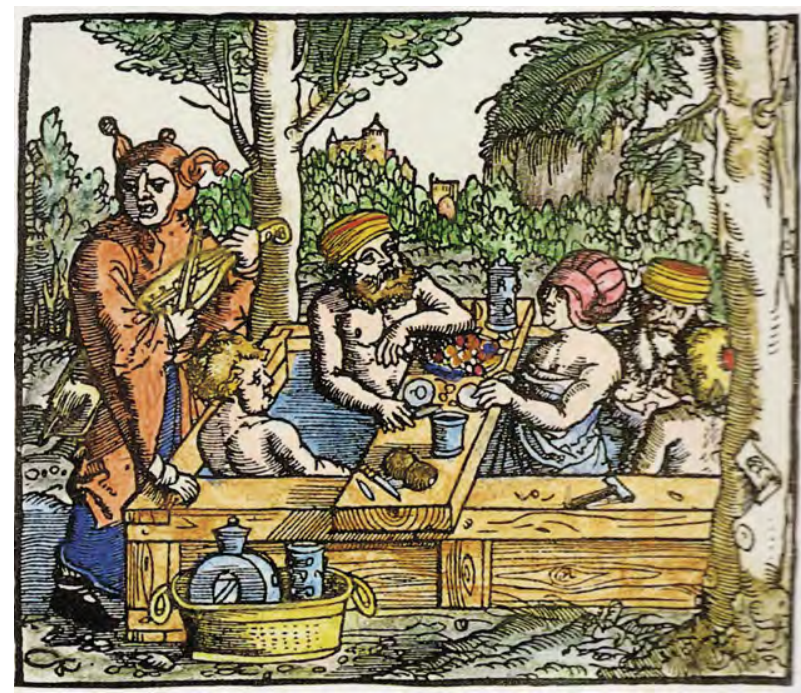

entfernen, nicht waschen, denn Wasser mache die Haut im Winter gegen Kälte und im Sommer gegen Sonnenlicht empfindlicher. Das Gesicht mit Wasser zu waschen schade den Augen, verursache Zahnschmerzen und bewirke einen bleichen Teint. Besser als Wasser sei Mandelkleie für die Gesichtsreinigung. Auch sonst sei der Körper abzuwischen und abzureiben, nicht zu waschen. Wasser war nur noch für die Mundhygiene vorgesehen. Üble Körpergerüche wurden durch Parfümieren und Duftsäckchen unter den Achseln oder in den Kleidern überdeckt. Die »trockene« Toilette der Höflinge entsprach dem Sauberkeitsempfinden der Zeit, das nicht Hygieniker, sondern Verfasser von Anstandsschriften bestimmten. ${ }^{219}$

Ergänzt wurde das Abreiben durch häufigen Wechsel der Leibwäsche. Das bildete das Kriterium für Sauberkeit schlechthin. Weiße Unterwäsche aus Leinen absorbiert den Schweiß, beseitigt den Schmutz und reinigt so die Haut, hieß es. Die Leibwäsche zu wechseln bedeutete so viel, als ob man sich gewaschen oder gebadet hätte, ja war besser, weil man die schädlichen Wirkungen des Wassers vermied. Um die Mitte des I 7. Jahrhunderts wechselten Adlige täglich ihr Hemd, die betuchten Bürger alle drei bis sieben Tage. Französische Höflinge hatten durchschnittlich 30 Hemden. ${ }^{220}$

\subsection{Neues Baden, neue Bäder}

Während vielerorts das Baden in Schwitzstuben zurückging oder gänzlich aufhörte, es sei denn, Ärzte verordneten zu Heilzwecken Dampfbäder, gelangte das Baden im 
Freien, in Flüssen, in Seen zu großer Popularität, von den Medizinern wärmstens empfohlen "wegen der kräftigenden und adstringierenden ${ }^{221}$ Wirkung kalten Wassers« (Bonneville). Verbote dagegen - z.B. in Wien I633, I643 und I 7 I w wegen Badens in der Donau - wurden aus Gründen der Schicklichkeit und wegen der Gefahr des Ertrinkens in größeren und reißenden Flüssen erlassen, fruchteten aber wenig, zumal auch höchste Damen und Herren sich ein solches Vergnügen gönnten. König Heinrich IV.von Frankreich liebte es, in der Seine zu schwimmen, sein Hof nicht minder. Es kam zu regulären Flussbadeanstalten mit Umkleidekabinen, Verleih von Badehemden und Handtüchern. ${ }^{222}$

Ein Schritt nach vorn war die Erfindung von Flussbadeschiffen. Man verdankt sie dem königlich-französischen Leibbader Jean-Jacques Poitevin, der I 760 von Ludwig XIV. die Erlaubnis erhielt, auf eigene Kosten zwei Schiffe zu bauen. Das größere von beiden, zweistöckig, fest auf der Seine bei der Vorstadt St-Germain-en-Laye verankert, hatte insgesamt 33 Badezimmer für Männer und Frauen, meist mit Betten versehen. Das Wasser wurde mit zwei Handpumpen aus dem Fluss gepumpt, durch drei mit Sand gefüllte Gefäße gefiltert, bevor es in die Röhren kam und in einer Kesselanlage erhitzt wurde. Man konnte aber auch vom Schiff aus im Fluss baden oder schwimmen lernen. Die besten Badeschiffe in Paris wurden immer luxuriöser und komfortabler, hier verkehrte die Pariser Oberschicht, namentlich die Jugend, in extravaganter Kleidung und pflegte einen exzentrischen Lebensstil. Nicht ganz so prächtige Badeschiffe befanden sich auch außerhalb Frankreichs, z.B. in Frankfurt am Main, Mannheim und Wien. ${ }^{23}$

Das »Flussschiff « in Wien war allerdings nicht mehr als ein schwimmendes Floß. Es handelt sich um das I 78 I eröffnete Ferrobad im Donauarm in der Nähe des Augartens am Tabor. Das Floß hatte in der Mitte ein offenes Becken zum Strom hin. Rundherum waren Umkleidekabinen angebracht. I 8 3 I wurde ungefähr an der Stelle des Ferrobades eine komfortable Damenschwimmschule (offizieller Titel: Ferdinand-Marien-DonauSchwimm- und Bade-Anstalt am Tabor nächst dem k. k. Augarten) errichtet, der bald eine Männerabteilung folgte. Durch einen Brand I 848 zerstört, wurde das Bad wieder aufgebaut und führte nun den einfacheren Namen »Marienbad«. ${ }^{224}$

Vertreter der Aufklärung wie Rousseau, Diderot und Voltaire sprachen sich für ein natürliches Leben, für die Naturverbundenheit aus. Dem Motto »Zurück zur Natur« kamen die kalten Bäder entgegen, die vermutlich in erster Linie dafür verantwortlich waren, dass das Badewesen eine Renaissance erlebte. In diesem Sinne typisch war das Entstehen von Seebädern, zunächst in England (Brighton, Margate, Deal, Harwich), bald auch in Deutschland (Doberan I 794, Norderney I797, Travemünde I 800, Wangerooge I 804, Rügenwalde I 8 I 5 usw.). Seebäder wurden rasch beliebt, besonders beim Adel. Wie die mondänen Thermalbäder im Binnenland (Bad Pyrmont, Baden-Baden, Karlsbad, Wiesbaden) entwickelten sie sich rasch zu Luxusbädern und entfalteten ein reiches Kulturleben (Buchhandlungen, Bibliotheken, Theater, Konzerte, Casinos, Bälle, 




Abb. 39: Pariser Badeschiff (links der Mitteltreppe die Badekabinen für Frauen, rechts die der Männer); Holzschnitt aus "Perruquier" von d'Alembert und Diderot, 1765 .

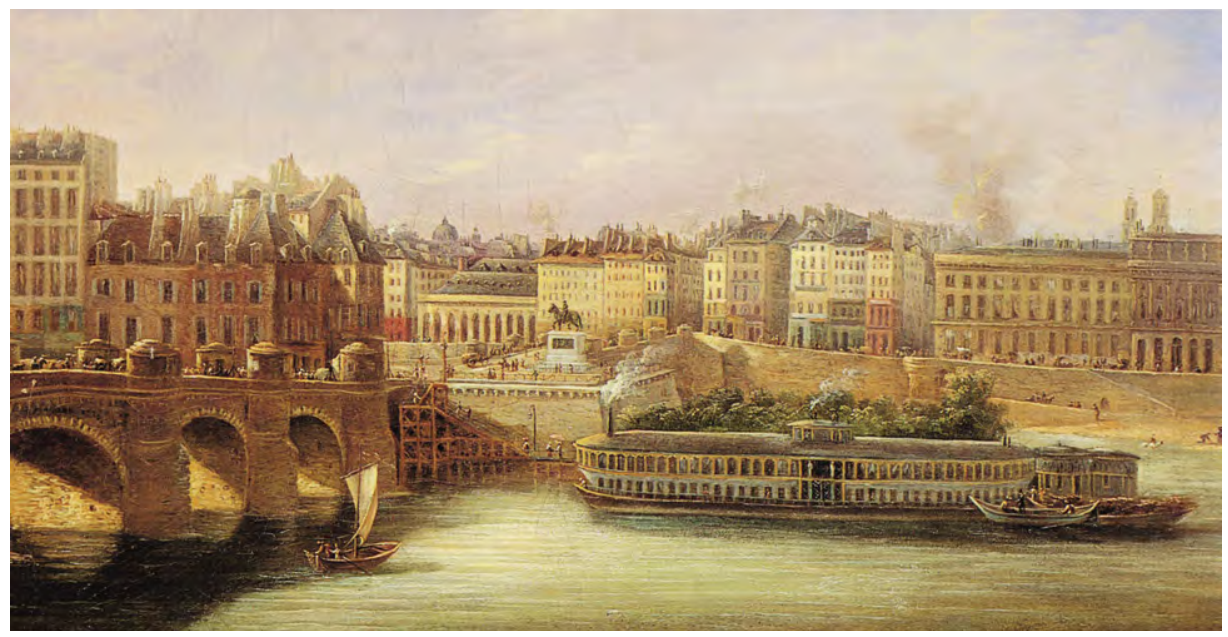

Abb. 40: Badeschiff (Vigier-Bad) am Pont-Neuf zu Paris; Gemälde von I 830. 

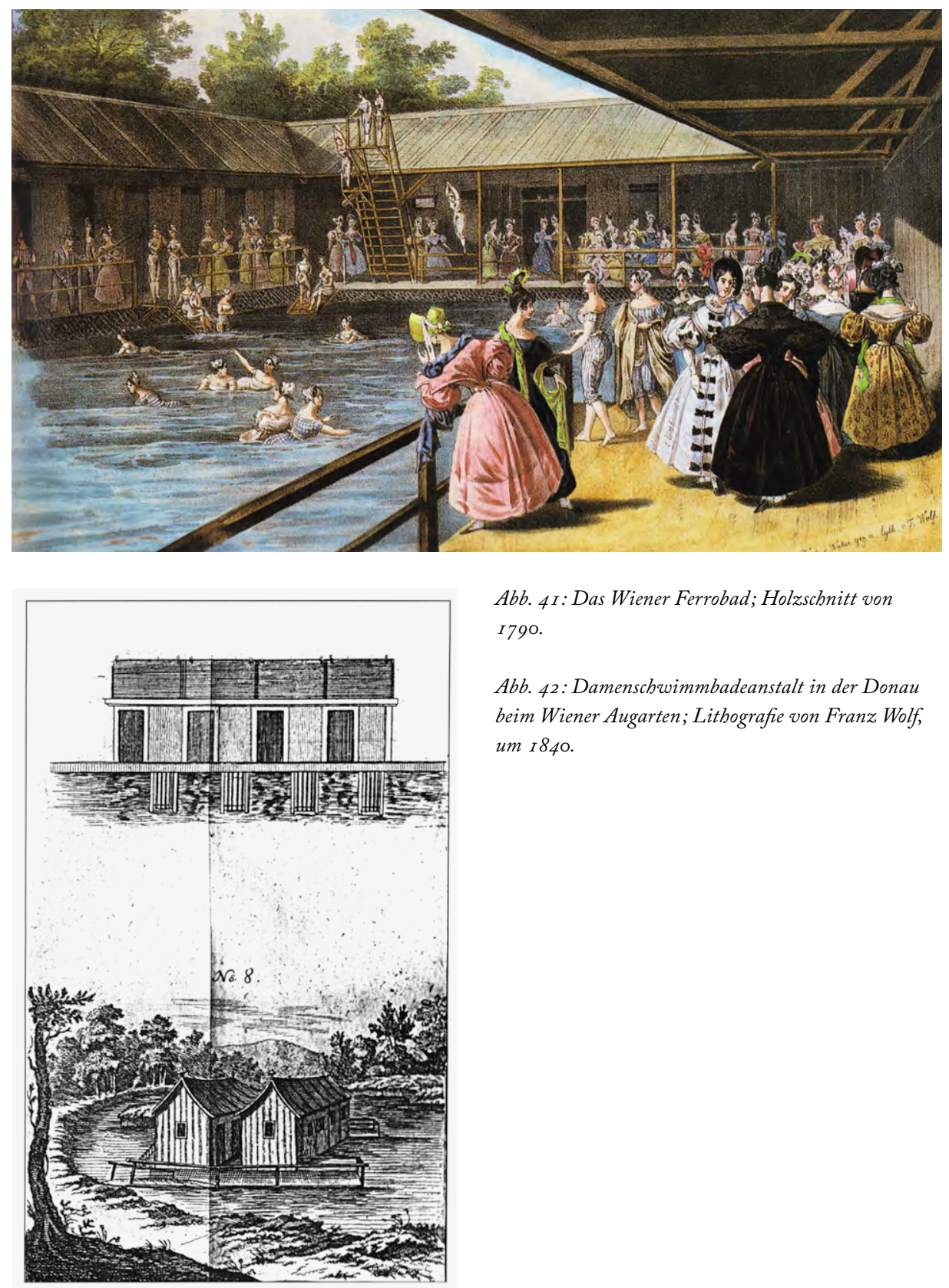

Abb. 4I: Das Wiener Ferrobad; Holzschnitt von I790.

Abb. 42: Damenschwimmbadeanstalt in der Donau beim Wiener Augarten; Lithografie von Franz Wolf, um $184 \mathrm{O}$. 


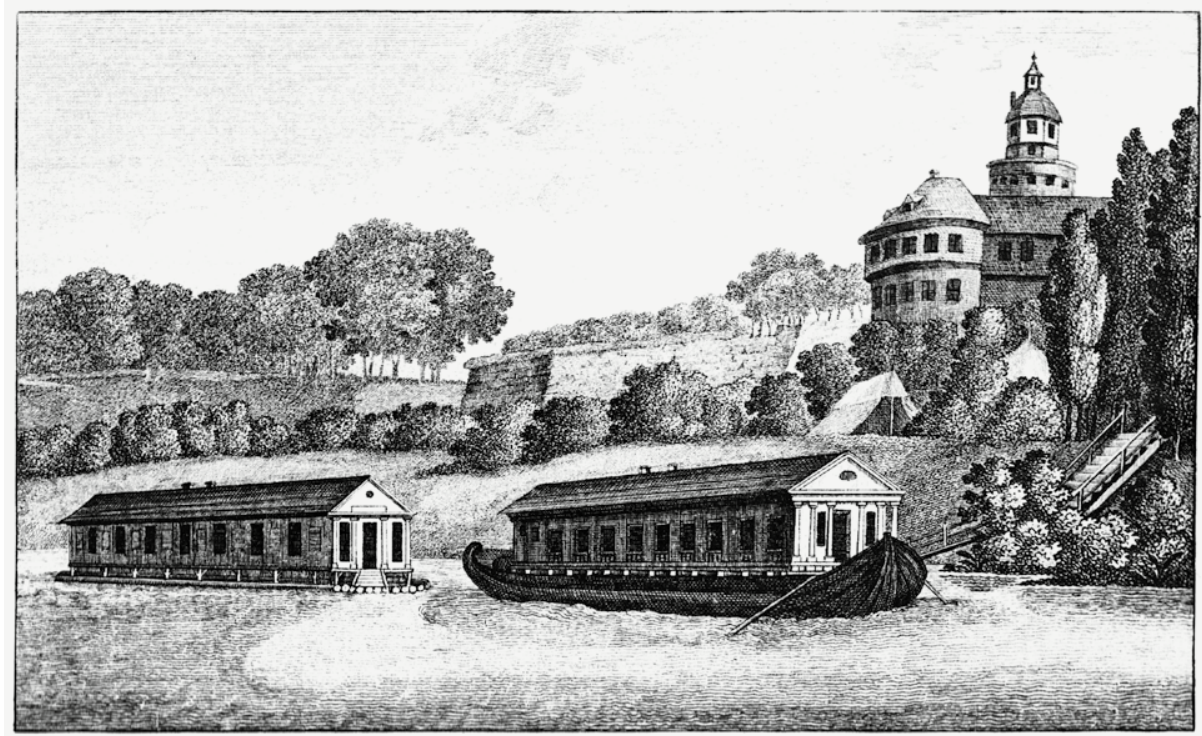

Abb. 43: Die beiden ersten Frankfurter Badeschiffe; Holzschnitt, um 1774.

Tees, Ausflüge, Sport). So manche Dame in einem exklusiven Bad hat nie oder nur selten ihren Fuß ins Wasser getaucht, sondern sie suchte wie schon die alten Römerinnen das Bad mehr zu ihrem Vergnügen auf. Baden war ein gesellschaftliches Ereignis geworden, Badeorte des i 8. und I 9. Jahrhunderts wurden Zentren der Geselligkeit und zugleich Heiratsmärkte. ${ }^{225}$

Mit der Wiederentdeckung der Natürlichkeit in der zweiten Hälfte des I 8. Jahrhunderts verteufelten die Ärzte nicht mehr generell das Wasser. Sie plädierten nunmehr für regelmäßige kalte und warme Bäder und verlangten eine verstärkte hygienische Pflege des Körpers. Nachdem Antoine Laurent de Lavoisier I 777 nachgewiesen hatte, dass die Haut atmet, Wasser und Luft braucht, gerieten Schminke, Puder und allerlei Sälbchen bei den feinen Damen in Verruf. Strahlend weißer, schimmernder Teint war nun das Schönheitsideal. Es galt, den Körper von seiner »fauligen Dreckschicht zu befreien « und gemäß der neuen Ästhetik regelmäßig seine sichtbaren Teile zu waschen. Viel mehr aber nicht. Vor dem warmen Vollbad schreckte man noch immer zurück. Nur wenige Mediziner rieten zu mehr als einem Bad im Monat. Als der Arzt Christoph Wilhelm Hufeland (I 762-I 836) sich für ein wöchentliches Bad aussprach, sah man das für einen verwegenen Vorschlag an, erst recht Michael Friedländers I8 5 geäußerte Meinung, Kinder solle man zwei- oder dreimal in der Woche baden. Gegen maßloses Baden war 


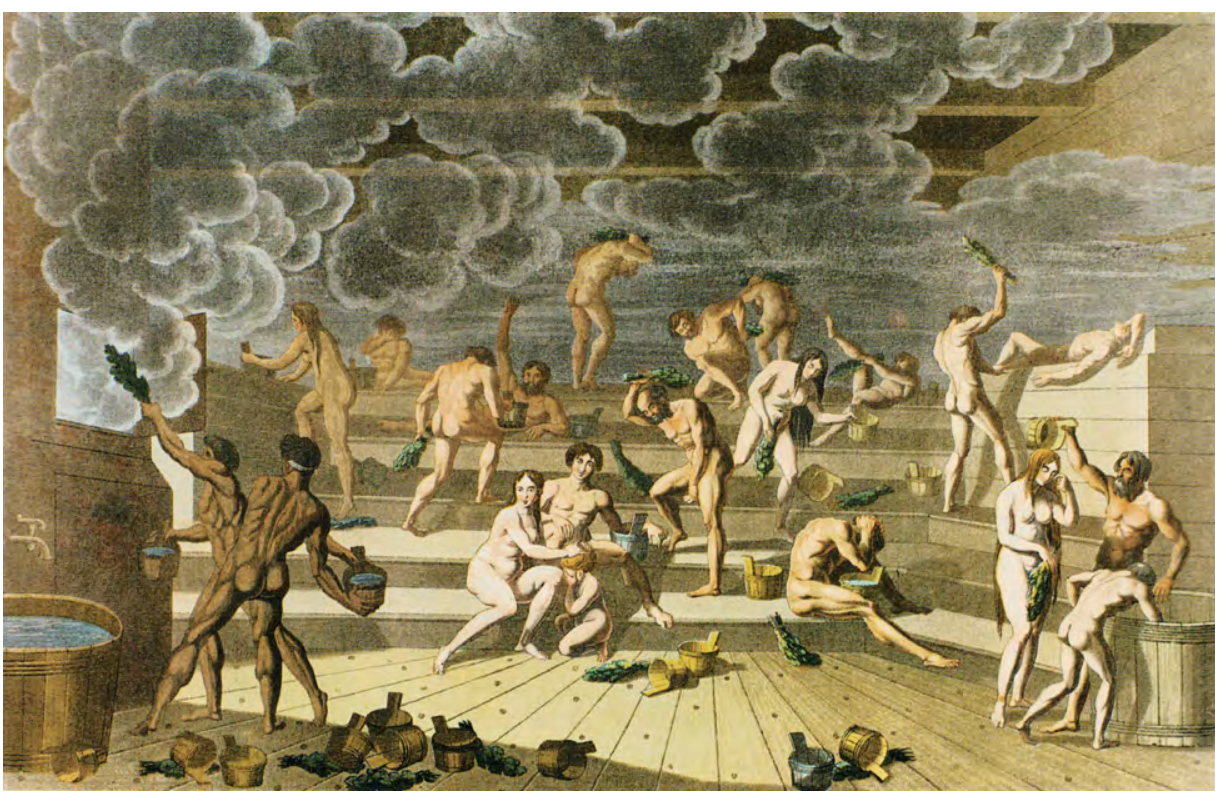

Abb. 44: Im russischen Bad; Aquatintazeichnung von Efim Karnejew, I8I2.

allerdings auch er. Stattdessen kamen Teilbäder (Fuß-, Hand-, Sitz- und Halbbäder) in Mode, und saubere Wäsche sowieso. ${ }^{226}$

$\mathrm{Zu}$ häufiges Baden hielt man für riskant, es rufe Unfruchtbarkeit hervor, gefährde die Schönheit, mache farblos und dickleibig. Junge Mädchen könnten vom vielen Baden sogar debil werden, wurde behauptet. Nach wie vor sah man das Bad für einen äußerst gefährlichen Ort im Hinblick auf die Sittlichkeit an, namentlich für junge Mädchen. Doktor Marie de Saint-Ursin reicht über die Jahrhunderte dem hl. Hieronymus die Hand, wenn er I 804 über die Verwirrung eines Mädchens, das nackt ins Bad steigt, schreibt: „Die Unerfahrenheit gleitet errötend in die kristallene Flut, begegnet dort dem Bild ihrer unbekannten Schätze und errötet um so mehr «. ${ }^{227}$ Jungfrauen hatten es anscheinend immer schwer.

Solche Vorbehalte machte man nicht gegen die mehr oder weniger luxuriösen römisch-irischen, chinesischen, russischen, maurischen, türkischen Dampfbäder, die als große Neuheit des I 9. Jahrhunderts gelten. Ihnen sprach man durchaus einen Nutzen für die Gesundheit, Regeneration und das Wohlbefinden zu. ${ }^{228}$ Um I 800 hatte jede einigermaßen nennenswerte Stadt in Deutschland Fluss- oder andere Badeanstalten, ${ }^{229}$ wenn nicht gar ein mondänes orientalisches Bad, aber das waren keine Einrichtungen für einfache Leute, die sich nicht einmal eine Wanne daheim leisten konnten. Wenn 


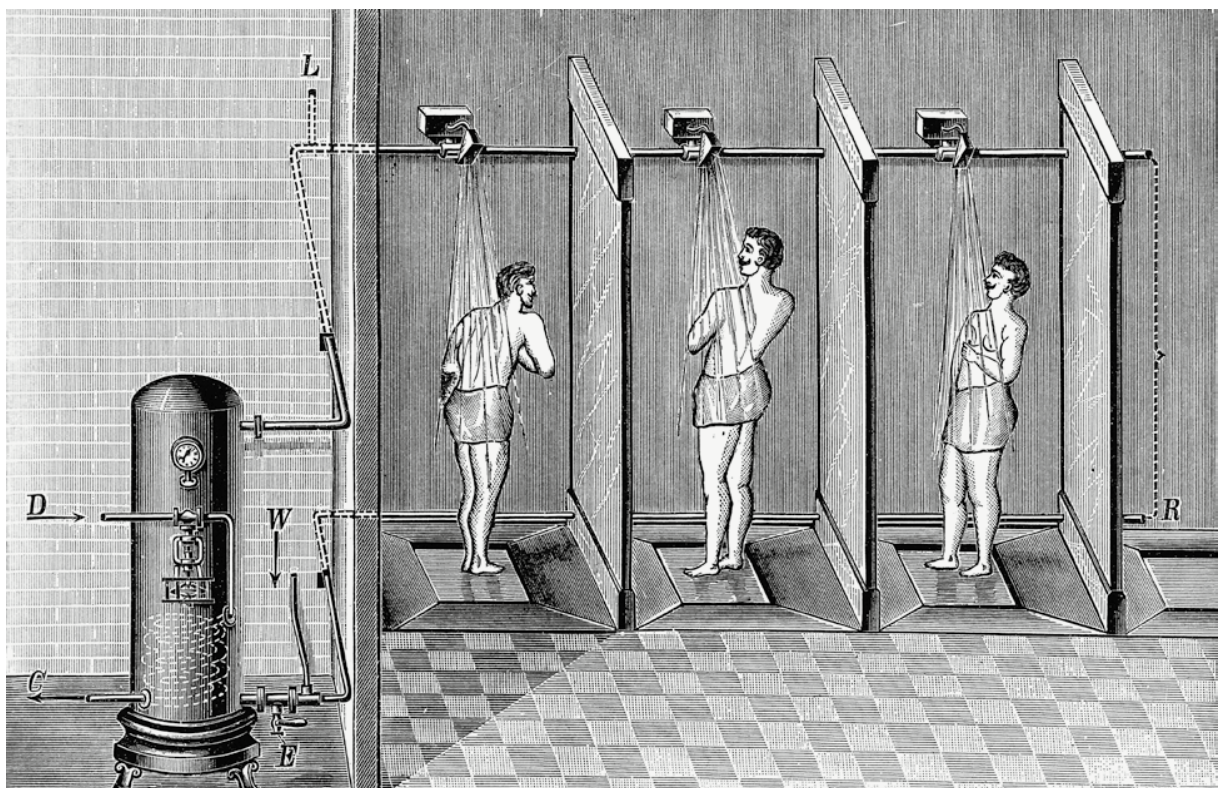

Abb. 45: Massenbrausebad (1905).

I 747 Dr. Schelhamer beklagte, durch Sorglosigkeit der Obrigkeiten seien die alten Schwitzstuben verfallen, und ihre Wiederherstellung empfahl, ${ }^{230}$ so dachte niemand ernstlich daran. Sie hatten sich überlebt. Das Industriezeitalter mit seinen Arbeitermassen verlangte nach etwas Neuem.

Liverpool ging voran. I 842 wurde hier das erste Volksbad eröffnet. Es bestand aus einer getrennten Männer- und Frauenabteilung mit insgesamt 28 Badekammern, 6 davon zusätzlich mit einer Dusche. Die Anstalt verfügte zudem über zwei kleinere Schwimmbecken. Drei Jahre später folgte London mit zwei städtischen Anstalten. Man konnte in ihnen Wannenbäder nehmen und gleichzeitig seine Wäsche waschen. Hamburg nahm nach englischem Vorbild I 855 am Schweinemarkt eine »Wasch- und Badeanstalt« mit 65 Wannenbädern in Betrieb, 49 für Männer und r6 für Frauen. Bei einer Erweiterung wurden, wie überall, zu mietende Kabinen erster und zweiter Klasse und Schwimmbecken errichtet. Im Laufe der Jahre entstanden noch größere Badeanstalten in Berlin (I 857 ), Fürth (I 857), Magdeburg (I 860), Hannover (I 865), Chemnitz ( I 868) und Leipzig (I 869). ${ }^{231}$

Sie hatten alle einen Nachteil. Trotz geringer Eintrittspreise, die den Gebrauch von Handtuch und Seife einschlossen, waren sie für die Masse des Volkes zu teuer. Es musste eine billigere Badegelegenheit geschaffen werden. Man fand sie, indem man das 
Wannenbad aufgab und in den siebziger Jahren in Deutschland zum Volksbrausebad überging. Um I 900 waren die Duschbäder zu einer beliebten Einrichtung geworden, allerdings nur in den ärmeren Vierteln. Zehn Pfennig Eintritt einschließlich Seife und Handtuch leisteten sich auch Ärmere, mochte auch die Wassermenge pro Person im Brausebad beschränkt sein. 1908 nutzten in Paris 153.285 Personen das öffentliche Duschbad, die Hälfte davon Frauen. ${ }^{232}$

Der Traum von einer eigenen Wanne oder gar von einem separaten Baderaum zu Hause erfüllte sich noch lange nicht. Erst seit dem Ersten Weltkrieg setzte sich allmählich die Vorstellung durch, dass zum Standard einer guten Wohnung ein Badezimmer mit Wanne und/oder Dusche gehörte, erst nach dem Zweiten Weltkrieg fand es auch in den sozialen Wohnungsbau Eingang, erst die moderne staatliche Gesundheitsfürund vorsorge ermöglicht es auch breiteren Bevölkerungsschichten, in den Genuss von Heil-, Kur- und Thermalbädern zu kommen. 


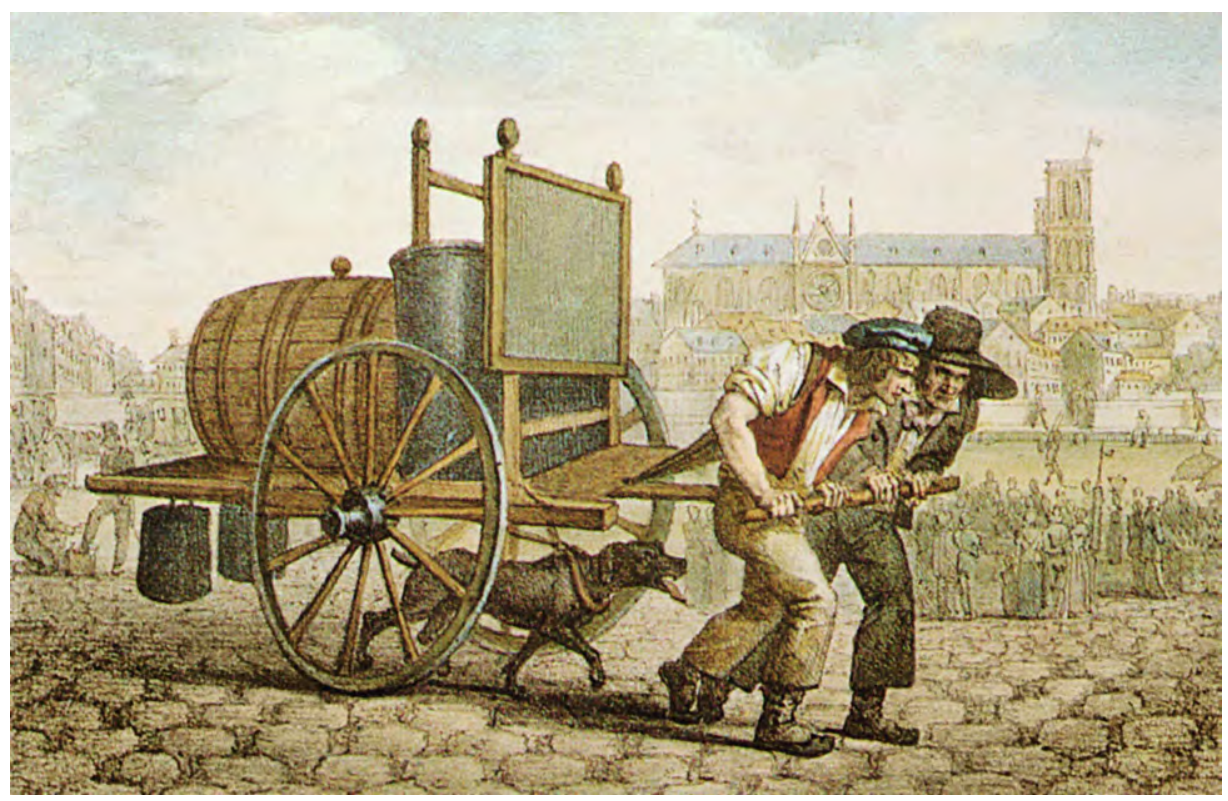

Abb. 46: Karren mit Mietwanne und Warmwasser; kolorierter Kupferstich von Jean Henri Marlet, I 830. Abb. 47: Leibwanne (um I9oo).






\section{3. "Gemainer Stat Pad« zu Rattenberg}



as heute noch erhaltene Badhaus zu Rattenberg liegt am Inn und stieß einst direkt an die westliche Seite des Brückentors. Als i 4 I 6 Herzog Ludwig VII. der Bärtige von Bayern-Ingolstadt mit der Stadt eine Übereinkunft über notwendige Straßen- und Befestigungsbauten traf, verfügte er, dass auf das Brückentor ein großer Turm (mit gedecktem Wehrgang auf der Mauer) zu setzen sei. Man nimmt an, dass damals schon das Bad existiert hat oder errichtet wurde, ${ }^{233}$ zumal seine nördliche ${ }^{234}$ Mauer zum Inn die beachtliche Wandstärke von gut $100 \mathrm{~cm}$ hat und wohl ein Teil der Stadtmauer ist. ${ }^{235}$ Das Bad ist ein zweigeschossiger, nicht unterkellerter Massivbau ländlicher Bauweise, mit einem Satteldach ${ }^{236}$ und einem gotischen Birnstabportal. ${ }^{237}$ I 547 wurde es hinten mit Schiefersteinen versehen (»verreicht«). ${ }^{238}$ Die Räume im Erdgeschoss dienten dem Badebetrieb (Vorhäusl, Männer- und Frauenbadestube, Heizraum), im Obergeschoss befand sich die Wohnung des Baders mit einer Stube, drei Kammern, einer Küche und einem Speisegewölbe. ${ }^{239}$

Wer in Rattenberg ins Badhaus ging wird nirgends aufgezählt. Wie in Hall werden es vor allem Handwerker mit ihren Frauen gewesen sein, gewiss auch die einen oder anderen besser gestellten Bürger und Bürgerinnen, Bauern aus der Umgebung, die kein eigenes »Badl« hatten, zudem Knappen und Arbeiter der umliegenden Berg- und Hüttenwerke, anscheinend auch die städtische Geistlichkeit (Vikar, Mönche).

\subsection{VorhäusI und Umkleideräume}

Man betrat das Bad von Süden durch das gotische Portal. Dahinter öffnet sich ein 3,70 $m$ breiter Vorraum, der auch als Wärmeschleuse diente und durch eine Mauer in zwei Räume geteilt ist. Durch eine Tür in der Mauer kam man links in den kleineren (nur 4,50 m langen) westlichen Teil des »Vorhäusls«, wie der Vorraum genannt wurde. Er stellte die "Abziechstube« der Frauen dar und enthielt den Eingang zur Frauenbadestube, die durch eine starke Mauer (mit Gewölbe tragenden, eingemauerten Säulen) von der Männerstube getrennt war. Ein »Türl« in der »Schidwand « ${ }^{240}$ ermöglichte dem Badepersonal den Wechsel von einer Badestube in die andere.

Am I 2. Juni I 573 beschloss der Rat, »im pad ain abziech stibl den frawen zumachen «. Zu diesem Zweck solle der an das Bad - wohl im Westen - anstoßende hölzerne Schusterladen abgebrochen, an dieser Stelle aus dem Bad oder Vorstübl mit einer Mauer herausgefahren und dadurch der Raum erweitert werden, damit sich die Frauen 




Abb. 48: Gotisches Eingangsportal des Badhauses zu Rattenberg; Foto: Eveline Büchner.

darin umziehen und ihr Gewand sauberer halten könnten. ${ }^{241}$ Wenn man sich noch I 573 bemüßigt fühlte, den kleinen Umkleideraum für die Frauen zu erweitern, kann von einem merklichen Nachlassen des Badebesuchs noch nicht die Rede sein. Das in einer Beschreibung des Badhauses von I 775 erwähnte Holzgewölbe könnte noch diese angebaute Abziechstube gewesen sein. ${ }^{242}$

Der weitaus größere östliche Teil des Vorhäusls, in dem die Wannen standen, ${ }^{243}$ diente zunächst einmal als allgemeiner Eingangsraum, wo ein Pfeiler ein Kreuzrippengewölbe trägt. ${ }^{244}$ Durch eine Tür in der Nordwand gelangten die Männer vom Vorraum in ihre Schwitzstube. Nach knapp vier Metern wurde der östliche Teil des Vorhäusls durch eine Mauer (mit Tür) abgeschlossen. Dahinter lag höchstwahrscheinlich der Umkleideraum für Männer. Auf Ruhebetten in der Frauen- und Männergarderobe findet sich kein Hinweis. Gleich rechts hinter dem Eingangsportal führt eine Wendeltreppe in das obere Geschoss. Der Vorraum erhielt Licht durch Fenster ${ }^{245}$ an der Südseite. Wo man in Wannen badet, spritzt Wasser auf den Boden oder wird ausgegossen und muss dann abfließen. Das geschah im Vorhäusl über eine Rinne. ${ }^{246}$ 


\subsection{Die beiden Badestuben}

\subsubsection{Gitter, Trog, Badekessel und -ofen}

Als I 5 Io Gabriel Freytag das städtische Bad zu Rattenberg übernahm, überantwortete ihm der Rat am 20. September folgende Mobilien:

»Von erst zwen kupffren kessl im kachlofen, ain gleser ram mit dem gäter, vor dem pad den grossen kessl, im pad ain aichen grant «. ${ }^{247}$

Bänke, Gestelle (Regale) und Badeofen, die vorhanden waren, werden nicht erwähnt, ansonsten war das alles, was der neue Bader vorfand. Er musste sein ganzes Arbeitsgerät wie Wannen, Schaffe, Becken, Tücher, Bademäntel und -hüte, Lasseisen, Schröpfköpfe, medizinische Instrumente mitbringen. Üblicherweise kaufte er sie, auch einen vorhandenen Vorrat an Holz, seinem Vorgänger oder dessen Witwe ab.

So kurz obiger Eintrag ist, er sagt doch Wichtiges über die Badestuben aus. Da wäre zunächst einmal der hölzerne Fensterrahmen (Gläserrahmen) mit einem Gitter, der anscheinend aus den Scharnieren herausgenommen werden konnte. Er schien dem Rat so wertvoll zu sein, dass er ihn unter den beweglichen Gegenständen anführte. Ohne Zweifel handelt es sich um jenes Gitter, das oben die Trennwand zwischen den beiden Badestuben abschloss und dafür sorgen sollte, dass sich Hitze und Dampf in beiden Räumen gleichmäßig ausbreiteten. ${ }^{248}$ Der Eichentrog (Grant) im Bad ${ }^{249}$ »or dem padtoffn zum angiessen« (I 54I) wird auch sonst erwähnt und musste immer wieder mit »miess (Moos) »geschoppt «, d. h. wasserdicht gemacht werden. ${ }^{250}$ Der große Kessel vor dem Bad wird nur an dieser Stelle genannt. Er war wohl überflüssig geworden, seit man das Wasser nicht mehr aus einem Ziehbrunnen holen musste, sondern durch Röhren direkt ins Bad leitete.

Besonders interessant sind die beiden Kupferkessel im Kachelofen, worunter man den Badeofen dieser Zeit verstehen soll. Man brauchte warmes Wasser für die Reinigung nach dem Schwitzbad und für die Wannenbäder. Ein Holzschnitt Hans Sebald Behams aus der ersten Hälfte des I6. Jahrhunderts ${ }^{251}$ zeigt in der Tat einen Kessel mit zwei Wasserhähnen, der in einer Wölbung des Badeofens steht. Zwar entspricht diese Darstellung der obigen Beschreibung, doch war sie außergewöhnlich. In der Regel befanden sich die beheizten Kessel direkt im Baderaum an einer Wand - das konnte auch die Trennwand sein, oder im Vorraum, oberhalb des Kessels auch schon einmal mit einer Durchreiche in die Badestube versehen. ${ }^{252}$ Es fällt schwer zu glauben, dass Rattenberg im Hinblick auf den Standort der Kessel die große Ausnahme gewesen sein soll. Viel eher ist anzunehmen, dass I 5 ro ein Versehen des Rates vorlag und er von zwei Kupferkesseln im Bad hätte schreiben sollen. Denn zwanzig Einträge aus der 
Abb. 49: Frauenbadestube

(Ofen mit Steinen und

Warmwasserkessel, Balkendecke,

getäfelte Wand, Haarwäsche,

Reiben mit Quast, Massieren

durch eine Bademagd); kolorierter

Holzschnitt von Hans Sebald

Beham, I. Hälfte I6. Jh.

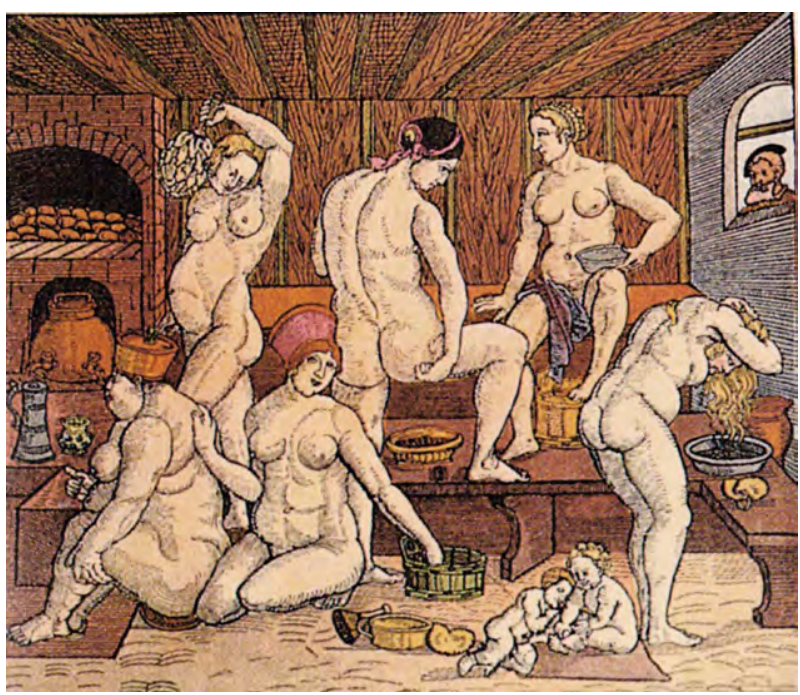

Zeit davor und danach sprechen nur von einem Kessel »in dem pad«, von zwei Kupferkesseln im Bad, von einem Kessel im Männerbad, gleich ob ein Kessel gemacht, geflickt, (mit Mörtel) gekittet, durch einen neuen ersetzt wurde oder einen Deckel ${ }^{253}$ erhielt, ob er von Maurern ausgebrochen und wieder eingesetzt wurde, ob man ihn mit Bretternägel beschlug oder um ihn eine Täfelung anbrachte usw. Besonders oft sind Maurerarbeiten am Kessel - es ging vermutlich hauptsächlich um Reparaturen an der Heizeinrichtung - vermerkt. ${ }^{254}$

Stops will im Umkleideraum (Vorraum) zwei Nischen mit ihren dicken Mauern erkannt haben, in denen die Kupferkessel eingemauert waren. ${ }^{255}$ Ein solcher Standort für die Kessel ist sonst möglich, hier aber auszuschließen. Zum einen wird im Zusammenhang mit ihnen nie das Vorhäus ${ }^{256}$ erwähnt, zum anderen spricht der eben erwähnte Vermerk aus dem Jahr I 55 I, dass ein Kessel im Männerbad stand, ${ }^{257}$ ausdrücklich dagegen. Der andere dürfte auch im und nicht außerhalb des Frauenbads gestanden sein. Wenn man 579 eine Mauer im Bad durchbrochen hat, um mit den Röhren beim Kessel durchzukommen, ${ }^{258}$ dann deutet das auch nicht auf den Vorraum hin. Legte man schon (wohl von außen) eine eigene Wasserleitung zum Kessel (darum handelt es sich anscheinend), wird man das zweckmäßigerweise durch die Außenmauer des Bades, nicht durch das Vorhäusl getan haben. Außerdem muss man sich fragen, wo denn zwei Kupferkessel noch in einem Vorhäusl Platz gefunden hätten, wenn sich dort schon Badewannen (wie üblich vermutlich vier bis fünf), zwei Umkleideräume für Frauen und Männer, im Eingangsbereich ein massiver Pfeiler, ferner zumindest ein Gestell und Haken für die Badehüte ${ }^{259}$ befanden? Und da wäre noch das Problem 




Abb. 5o (l.): Pfeiler im Vorbäusl des Badhauses zu Rattenberg, im Hintergrund Eingang zur Männerstube und (rechts) Trennwand zur

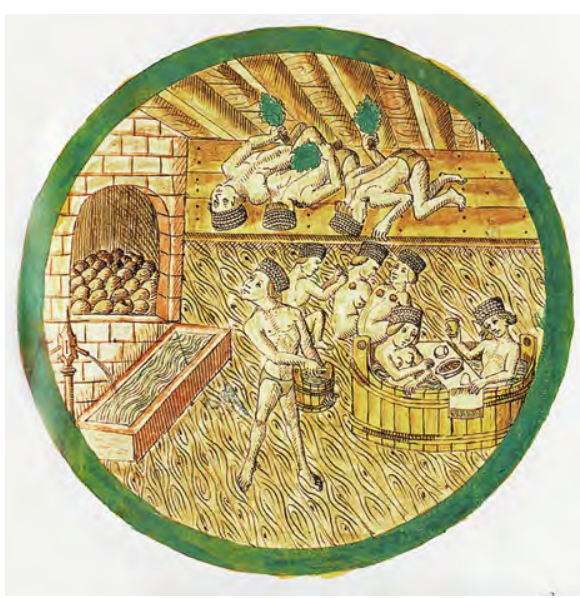

Männergarderobe, rechts unten erste Stufe der Wendeltreppe ins Obergeschoss; Foto: Eveline Büchner. Abb. 5 I (r.): Badestube (Laufbrunnen, Badeofen mit Wölbung für die Steine, Ansetzen der Schröpfköpfe, Speisen im Zuber, auf der oberen Bank drei schwitzende Gäste, die den Badequast schwingen; kolorierte Federzeichnung aus einem Kalender des I6. Jh.

der Heizung in einem Raum, dessen Dielen den Ratsherren schon zu kostbar für eine Holzlagerung waren. ${ }^{260}$

Geht man nach den erhaltenen Rechnungen des städtischen Baumeisters, so verging fast kein Jahr, ohne dass man den Badeofen reparieren, wenn nicht gar abbrechen und neu mauern musste (z.B. I 547, I 568, I 580/8 I), wobei zahllose Fuhren an Steinen, Sand, Lehm und Kalk, selten an Feuersteinen und Ziegeln ${ }^{261}$ anfielen. Ebenso zahlreich sind die Fuhren, mit denen man den beim Ofenbau angefallenen Schutt vom Bad wegbrachte. ${ }^{262}$ Als Handwerker und Helfer wurden dabei Maurer, Hafner und Tagelöhner beschäftigt, in einem Fall sogar die Badeknechte. ${ }^{263}$ Wenn es I 477 heißt, zwei Maurer hätten eine Mauer hinter dem Ofen im Bad gemacht, dann ist nur an die Rückwand des Ofens, vermutlich als zusätzlicher Feuerschutz, ${ }^{264} \mathrm{zu}$ denken, und nicht daran, dass sie die ganze Mauer im Heizraum neu gezogen hätten. ${ }^{265}$ Falls die Angelegenheit eilte, arbeitete man auch bei Kerzenlicht. ${ }^{266}$

Das Bad, besonders der Ofen war eine kostspielige Sache, leerte die städtische Kasse und brachte den Kämmerer zur Verzweiflung. So verwundert es nicht, dass der Rat einmal (1 55 I) beschloss, Reparaturen an Öfen und Fensterscheiben, die man vergangenes Jahr auf den Toren und im Bad gemacht habe, künftig zurückzustellen. ${ }^{267}$ 


\subsubsection{Heizraum und Knechtskammer}

Jede Badstube benötigt einen Heizraum oder zumindest einen besonderen Heizbereich für Badeofen und -kessel. Während sich bei einem Kachelofen ${ }^{268}$ der Feuerkasten auf der Ebene des Bodens befindet, war für Badeofen und Warmwasserkessel, die nebeneinander in den Badestuben standen, typisch, dass sie eingetiefte Brennkammern und Schüröffnungen in einem vorgelagerten Heizraum hatten, mit der Folge, dass das Bodenniveau des Heizraums mindestens $0,50 \mathrm{~m}$ bis I,20 $\mathrm{m}$ tiefer lag als das der benachbarten Stube. Die eingetiefte Brennkammer verhinderte das Ersticken des Feuers durch Rauchgase. ${ }^{269}$

Einen solchen Heizraum besaß auch das Badhaus zu Rattenberg. Es ist die Kammer, ungefähr gleich groß wie das Vorhäusl, die durch eine Mauer (mit Gewölbe tragenden, eingemauerten Säulen) die beiden Badstuben nach Norden abschloss. Licht erhielt dieser Raum durch ein Fenster ${ }^{270}$ in seiner dem Inn zugewandten Seite. Sein Bodenniveau liegt noch immer unter dem der ehemaligen Badstuben. Erst über eine Stufe erreicht man heute den Boden des Heizraums. ${ }^{271}$ Dass er früher wohl noch tiefer lag, darauf könnte folgende Nachricht hindeuten:

Im März I 553 beschwerten sich die Frauen beim Rattenberger Rat, in ihrer Badstube würde keine rechte Hitze aufkommen. Der Rat ließ den Schaden beschauen und beschloss danach, mit der Reparatur bis zum Herbst zu warten. Dann solle der Ofen abgetragen und die Feuerstelle um einen oder anderthalb Schuh (o,335 bzw. o,50 m) niedriger gesetzt werden. Feuersteine (Schamottesteine) dazu solle man auf Flößen aus dem Zillertal holen. Außerdem schrieb man vor, mit langen Stücken zu heizen. Für vier Klafter Holz habe der Baumeister zu sorgen. Als Anfang November der Ofen noch immer nicht repariert war, mahnte der Bader im Interesse der Frauen den Umbau an ${ }^{272}$. Wie tief vorher die Schüröffnung lag, erfährt man nicht.

Der Badeofen, der - wie bei zwei Stuben üblich - wohl an die Trennwand gemauert war, wahrscheinlich auch die Warmwasserkessel standen also an der Wand der Badestuben zum Heizraum. Wegen der geringen Höhe der Stuben (s.u.) wird man den Ofen vom Boden bis zur Decke hochgezogen haben. Die Rauchgase im Heizraum wurden entweder direkt in einen Kamin oder in eine Rauchabzugsöffnung geleitet, die in einen Kamin mündete. Auch eine kaminlose Ableitung seitlich aus den Badhäusern kam vor. ${ }^{273}$ Fürs Rattenberger Bad lässt sich ein Kamin nachweisen, der sich offensichtlich über dem Heizraum befand. ${ }^{274}$

Der Heizraum scheint ab I 523 nicht nur für die Befeuerung der Öfen verwendet worden zu sein, sondern seitdem auch den Badknechten als Aufenthaltsraum zur Verfügung gestanden zu haben. Denn in diesem Jahr wurde den Knechten eine Kammer »ausgesetzt« (zugewiesen). ${ }^{275}$ Dem Bader konnte man schlecht ein Zimmer aus seiner Wohnung im Obergeschoss entziehen, im Bad selbst war außer dem Heizraum kein 


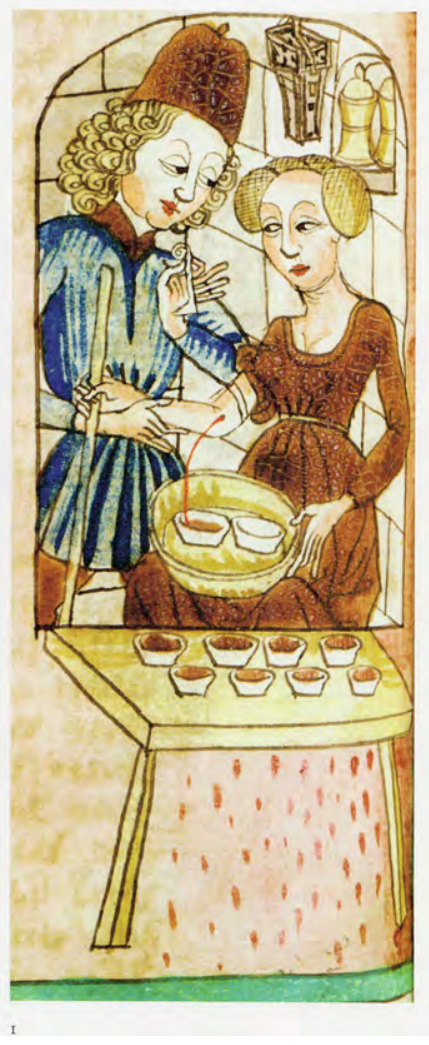

Abb. 52: Ein Bader lässt eine Frau, die ihren Arm auf einen Stab stützt, zur Ader; das Blut fließ in ein Schälchen, das in einem Becken steht, damit nicht die Kleidung der Frau beschmutzt wird; auf einem Klapptisch acht mit Blut gefüllte Schälchen; an der Wand ein Bindfutter, in einer Nische zwei Salbenbüchsen; Miniatur aus Konrad von Ammenhausens »Schachzabelbuch«, 1467
Platz mehr. Der dortige gestampfte Lehmboden wurde vermutlich erst jetzt mit Brettern belegt. ${ }^{276}$ Gewissheit darüber vermittelt ein Eintrag aus dem Jahr I55I, wonach der Boden vor dem Ofenloch ausgebessert wurde. ${ }^{277} \mathrm{Um}$ ihn vor herausfallender Glut und Asche zu verschonen, hatte man schon früher einen Schild aus Blech auf ihn genagelt. ${ }^{278}$

\subsubsection{Boden und Bänke}

Es empfahl sich von selbst, den Boden von Badstuben mit Ziegeln ${ }^{279} \mathrm{zu}$ pflastern oder mit Steinplatten zu belegen, weil sie am besten gegen das unvermeidliche Wasser resistent sind. »Nässeempfindliche Lehm- oder Estrichböden kamen nicht in Frage«, behauptet Frau Tuchen ${ }^{280}$, und sie irrt sich im Hinblick auf Rattenberg, so einleuchtend sonst ihre Aussage ist. Noch heute zeigen die offen daliegenden Böden im Rattenberger Bad nur gestampften Lehm, auch verweisen drei Rechnungseinträge darauf. ${ }^{281} \mathrm{Um}$ der nicht seltenen Überschwemmungen Herr zu werden, hat man an der Innzeile häufig die Straßen aufgeschüttet, so dass man heute die Erdgeschosse einzelner Häuser durch eine abwärtsführende Treppe erreicht. ${ }^{282}$ Stops will erkannt haben, »dass der angeblich meterdicke lehmige Fußboden im Badhaus gut I,20 m unter dem Straßenniveau liegt«. ${ }^{283}$ Davon kann keine Rede sein. Der Sockel des Gewändes am Eingangsportal liegt auf Straßenniveau und auf gleicher Höhe wie der Sockel des Pfeilers im dahinter liegenden Vorhäusl. Es gibt keinen Vermerk in den Ratsprotokollen, den städtischen und Baumeisterrechnungen, dass man je den Boden im Bad aufgeschüttet habe. Möglich ist allerdings, dass das Badhaus schon auf einer Schüttung errichtet wurde. Das Bodenniveau des Vorhäusls setzt sich in der angrenzenden Männerstube fort und steigt dort etwas an. ${ }^{284}$ Das war sinnvoll. Denn wie in anderen Badhäusernn ${ }^{285}$ konnte über das leichte Gefälle des Dielenbodens das Schmutzwasser in Rinnen ${ }^{286}$ fließen und über weitere Röhren abgelassen werden, in Rattenberg in den Inn. ${ }^{287}$ 
Statt Ziegel und Steinplatten hatte man im Bad einen Holzboden. Auf dem Lehmboden ruhten Durchzüge (Tragbalken, Unterzüge), auf ihnen das "pölster holtz« (Dielenträger) und zum Schluss kamen die Dielen selbst. Da Holz nicht gerade wasserbeständig ist, sind die Reparaturen an Boden und Bänken im Männer- wie Frauenbad seit Einsetzen der Baumeisterrechnungen eine unendliche Geschichte. ${ }^{288}$ Fast Jahr für Jahr wurde an ihnen gebessert und geflickt, wurden neue Bänke gemacht, neuer Boden verlegt, immer wieder Laden (Dielen) und Bretter herangeschafft, im Laufe der Zeit Tausende von Bretternägeln verschlagen, neue Durchzüge und neues Polsterholz angebracht. ${ }^{289}$ Gleich kostspielig waren die Türen, die repariert oder durch neue ersetzt werden mussten, für die man Bänder zu Türangeln anfertigte, auch Nägel brauchte. ${ }^{290}$ Die Zimmerarbeiten im Bad verursachten hohe Kosten, die von der Stadt nicht immer gleich aufgebracht werden konnten. Im Januar 1545 beschloss der Rat, Baumaßnahmen an der schadhaften Arche, im Bad am Boden, der »letz« (schlecht) sei, und am Brunnenbecken erst dann vornehmen zu lassen, wenn die Tage wieder länger würden, denn zur Zeit sei in der Stadtkasse kein Geld. ${ }^{291}$

$\mathrm{Da}$ die Badstuben in Rattenberg nicht hoch waren, ${ }^{292}$ ist kaum mit gestuften Schwitzbänken zu rechnen, auf denen man sich höher oder niedriger setzte, je nachdem, ob man eine starke oder mäßige Hitze wünschte. Sie werden vermutlich alle nur eine gleiche Höhe gehabt haben. Ein großer Teil der Bänke wird bloß als Sitzbank gedient haben, sei es zum Ausruhen, sei es zur Behandlung durch den Bader oder seine Knechte. Haarschnitt, Rasur, Aderlass, Schröpfen, Verarzten erfolgten in einem separaten Raum, sofern das Bad einen solchen für diese Zwecke hatte. Ansonsten übten die Bader solche Tätigkeiten in den Badstuben aus. ${ }^{293}$ So auch in Rattenberg.

Nach eindeutigen Zeugnissen befanden sich die Scherbank für Männer und die Lassbänke für Männer und Frauen im Schwitzbad selbst, ${ }^{294}$ mit ziemlicher Sicherheit hinten ${ }^{295}$ vom Badeofen aus gesehen, also gleich nach dem Eingang in die Stuben, wo Platz war und ein Fenster für Licht sorgte. Auch die Kopfwäsche wird man hier vorgenommen haben. Ebenfalls werden an dieser Stelle die nötigen Geräte (Schaffe, Becken, Lasseisen, Schröpfköpfe, chirurgische Instrumente), Lauge, Pflaster, Salben Verbandmaterial, Hand- und Badetücher usw. in Nischen oder auf Regalen untergebracht gewesen sein. ${ }^{296}$

\subsubsection{Vertäfelte Wände}

Noch Anfang des r 8. Jahrhunderts empfahl man, ein Schwitzbad rings zu täfeln, »damit die Kälte nicht durch das Mauerwerk häufig eindringe, und man an einem Ort verbrenne, und an den anderen fast erfröhre ${ }^{297}$ Schon der mehrfach erwähnte Walter Ryff wollte in seiner "Badenfart" ( 1549 ) von nackten, ungetäfelten Wänden im Bad nichts wissen, da »darauß ein schedtlicher feuchter dampf schlecht [schlägt], inn 


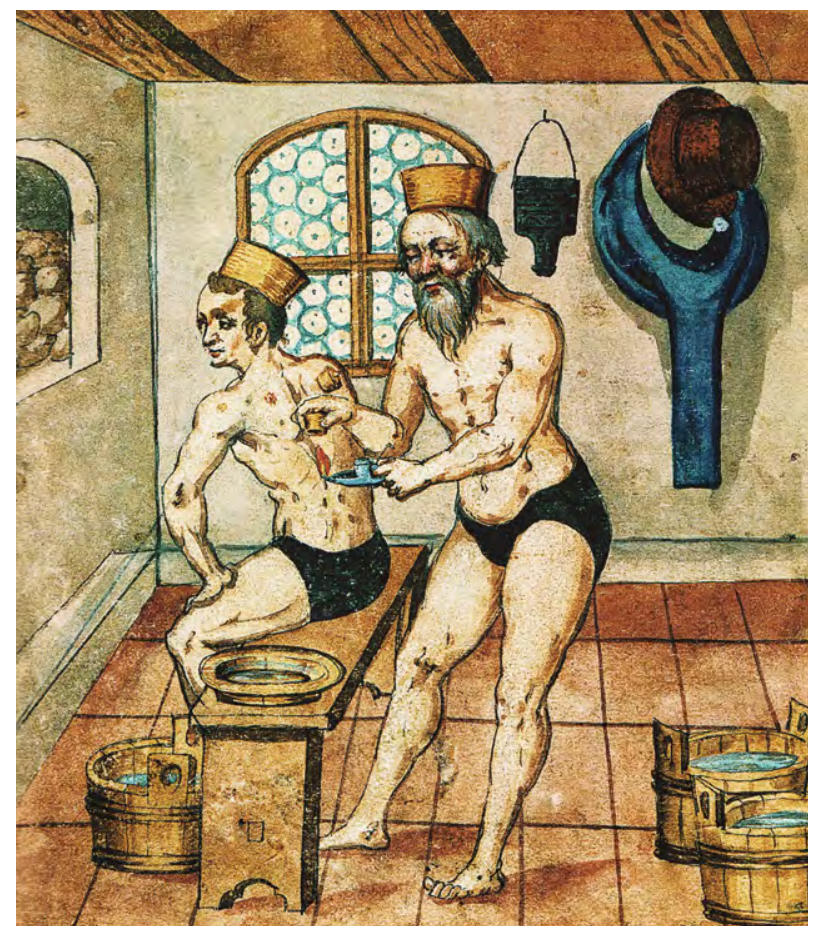

Abb. 53: Der Bader Wolff Geigen-

feindt erbitzt Schröpfköpfe

mit einer Lampe, an der Wand

ein Bindfutter, auf der Bank

ein Becken, links ein Badeofen

mit Wölbung für die Steine;

kolorierte Federzeichnung aus

dem "Hausbuch der Mendelschen

Zwölfbrüderstiftung«, $I 612$.

sonderheit aber wa solchs gemewer noch new und frisch, und der kalck ein starcken stinckenden geroch gibt, welcher inn sonderheit schedtlich und gifftig ist«. Dagegen böten die hölzernen Badstuben ein gesundes Raumklima, weil die »verschlossen lufft, dünst und dampff dermassen von holtzwerck nit alterirt werden, als von stein und kalck des gemewers ${ }^{298}$

Gekalkte Wände waren wesentlich billiger als holzvertäfelte, sie eben einmal zu weißen verursachte deutlich weniger Kosten als die Täfelung zu erneuern, weshalb sie nicht überall zur Ausstattung gehörte, aber anscheinend sehr wohl in Rattenberg, wenn auch nicht im Vorhäusl. Man erfährt nämlich zum Jahr I 547, dass in der Karwoche der Maurer Cristof Ässinger das Vorhäusl im Bad geweißt hat. ${ }^{299}$ Das ist jedoch der einzige Hinweis für Tünchen im Bad überhaupt. In gut roo Rechnungsbelegen aus der behandelten Zeit, die sich auf Reparaturen im Bad beziehen, wird keinmal das Weißen der Badstuben erwähnt. ${ }^{300}$ Das legt die Vermutung nahe, dass sie vertäfelt waren. ${ }^{301}$

Die Arbeiten an den Warmwasserkesseln machen das zur Gewissheit. Die Kupferkessel wurden mit Nägeln oder Klammern an den Umfassungswänden befestigt. ${ }^{302}$ Sind die Angaben dazu genauer, dann erfährt man etwas von einer Vertäfelung. So 
wurde $5_{523}$ ein Kessel vertäfelt, I 55 I beim Kessel ein »täfer« gemacht. ${ }^{303}$ Noch eindeutiger ist der Rechnungseintrag zum Jahr I476, wonach drei Zimmerleute im Bad ein "geschäl« in der Stube angefertigt haben. ${ }^{304}$ Dass nicht mehrere Vermerke im Hinblick auf die Holzvertäfelung in den Rechnungen aufscheinen, liegt daran, dass sie oft nur allgemein gehalten sind, dass es lapidar heißt, man habe Zimmerleute bezahlt, habe Laden (Dielen), Bretter und Bretternägel fürs Bad gekauft, ob für Boden, Bänke, Regale oder Täfelung, wird nicht gesagt.

\subsubsection{Fenster}

Noch heute zeigt das östliche Erdgeschoss des Badhauses drei alte mit schrägen Laibungen in die Wände geschnittene Fenster. Sie befinden sich an der Stelle, wo einst die Männerstube lag, und dienten offensichtlich zur Entlüftung. Das südlichste Fenster war anscheinend für den Bader und sein Personal die Lichtquelle, wenn sie hinten in der Stube ihre Kunden bedienten (Kopfwäsche, Aderlass, Schröpfen, Wundarznei usw.). Die Außenwand der Frauenstube im Westen wird jetzt von drei großen Garagentoren gebildet, doch ist anzunehmen, dass auch sie drei Fenster zum Entlüften und für das Tageslicht hatte. ${ }^{305}$

Wenn es schon I 476 heißt, in die hintere Badstube (Frauenstube) Rattenbergs seien Gläser eingesetzt worden, ${ }^{306}$ dann war das für ein Bad der damaligen Zeit keine Selbstverständlichkeit. Im I 5 . Jahrhundert galt Fensterglas noch als zu wertvoll, als dass man es überall in Badhäusern verwendet hätte. ${ }^{307}$ Rahmen mit dünn geschabten Häuten, gewachstem Leinen, ölgetränktem Papier taten es auch ${ }^{308}$. Konnte man in der zweiten Hälfte des I 5. Jahrhunderts in Städten wie Wien, Frankfurt am Main, Nürnberg, Göttingen, Hannover nicht nur öffentliche Gebäude, sondern die meisten oder viele Bürgerhäuser schon mit Glasfenstern bewundern, so kamen sie erst im I6. Jahrhundert allgemein in Gebrauch. Bürgerhäuser mit Fenstern aus Butzenglasscheiben oder Mondglas in Rautenform waren nun keine Seltenheit mehr, aber noch in der Mitte des I6. Jahrhunderts etwas Besonderes. ${ }^{309}$

In einer kleinen Stadt wie Rattenberg reichte das Glaserhandwerk allein nicht zum Auskommen. Deshalb hatten die ein bis zwei jeweiligen Glaser der Stadt noch einen zweiten Beruf, z.B. Maler oder Spengler. ${ }^{310}$ Die Glaser stellten vielfach selbst die Holzrahmen her, falls diese nicht von Tischlern gemacht wurden. ${ }^{311}$ Die Baumeisterrechnungen Rattenbergs lassen erkennen, dass ständig viel Glas zu Bruch ging und die Rahmen, die unter der Feuchtigkeit litten, immer wieder repariert oder erneuert werden mussten. ${ }^{312}$

Bevor I 534 in Hall die erste Tiroler Glashütte, die auch farblose Glasscheiben nach venezianischer Art herstellte, errichtet wurde, musste das Fensterglas importiert werden. Es war grünes Waldglas, ${ }^{313}$ das man von deutschen Waldglashütten der Mittelgebirge 
oder aus dem Bayerischen Wald bezog. ${ }^{314}$ Mondglas wie Butzenscheiben, mit Stroh in Körbe verpackt, verkauften wandernde Glasträger an Glaser oder Glashändler. ${ }^{315}$ Vermutlich war das Rattenberger Bad mit Flachglas, zum Teil mit Butzenscheiben verglast. Darauf deutet ein Eintrag zum Jahr 539 hin, wonach in beiden Badstuben Scheiben eingesetzt, Gläser gebessert und »in der kuchen 2 waldt glaß« eingesetzt wurden. ${ }^{316}$ Auf Waldglas aus Schwaben oder auf die Verglasung nach schwäbischer Art deutet ein anderer Vermerk hin, wonach I 564 der Tischler Sigmund Moser zwei neue »schwäbische fenster« und Rahmen für die Badstube lieferte. ${ }^{317}$

\subsubsection{Wasserversorgung}

Stops meint, da beim Wasserholen aus dem Inn immer wieder Todesopfer zu beklagen gewesen seien, habe man aus einer Zisterne das nötige Wasser fürs Bad geschöpft. ${ }^{318}$ Ihn hat vermutlich das Vorhandensein eines eigenen Badtürls ${ }^{319}$ in der Stadtmauer zu dieser Ansicht verleitet. Doch hatte das Türl, das vermutlich älter als das Bad war, eine ganz andere Aufgabe, wie die Ansicht Rattenbergs im Schwazer Bergbuch von ${ }_{5} 56$ zeigt. Durch das Badtürl gelangte man nämlich zu den Heftstecken (Pfählen) vor der Arche (Uferschutzbau) am Inn, wo die Schiffe festmachten. Und dass der Bader und seine Knechte gleich reihenweise in den Inn gestürzt und ertrunken sind, kann man auch nicht sagen. In über hundert Jahren bis 1580 findet sich lediglich eine Nachricht dazu, nämlich über den Bader Matheus Paumgartner, der I 549 im Inn ertrunken ist, sicher nicht beim Wasserholen (s.u.).

Mit dem Schöpfbrunnen hat Stops allerdings nicht Unrecht, nur hätte er stattdessen Ziehbrunnen sagen müssen. Erst in einer Rechnung aus dem Jahr I 5 I 3 stößt man auf ihn, als die Stadt dem Bader Gabriel Freytag zwei Mark (= 4 Gulden) »von des ziehprunnen wegn zu pesserung « zahlte. ${ }^{320}$ Der Brunnen stand etwas entfernt vom Bad ${ }^{321}$, und zwar vor dem Haus Martin Härrers (Nr. 4I), wie man zu I 548 erfährt, als man den "ziechprun« wie früher machte. Weil das "prunkhar« (Brunnenbecken, -trog) vor dem Härrer, heißt es, "gar faul und zunicht ist «, solle ein neues Becken und dabei ein Fischkalter gemacht werden. Über das Kar solle ein Dächl gesetzt, an die Brunnensäule zwei Eimer und ein "gätzl« (Schöpfkelle) gehängt werden, damit nicht immer so viel Wasser verloren gehe. ${ }^{32}$ Sechs Jahre später, I 554, konnte der Ziehbrunnen nicht benutzt werden, weil Eimer und Kette fehlten. Deshalb forderte der Rat den Baumeister auf, den "ziechprunn« zu machen und für Kette und Kübel zu sorgen. Die Brunnenkette sei von Martin Härrer, ${ }^{323}$ der nun in seinem Haus in Kramsach lebte, binnen drei oder vier Tagen zurückzuholen. ${ }^{324}$ Später, z. B. I 568 , wird wieder der Brunnen beim Härrer erwähnt. $^{325}$

$\mathrm{Zu}$ dieser Zeit hatte aber der Ziehbrunnen fürs Bad nur noch eine untergeordnete Bedeutung. Es verfügte schon längst über zwei Laufbrunnen. Der erste dürfte in den 


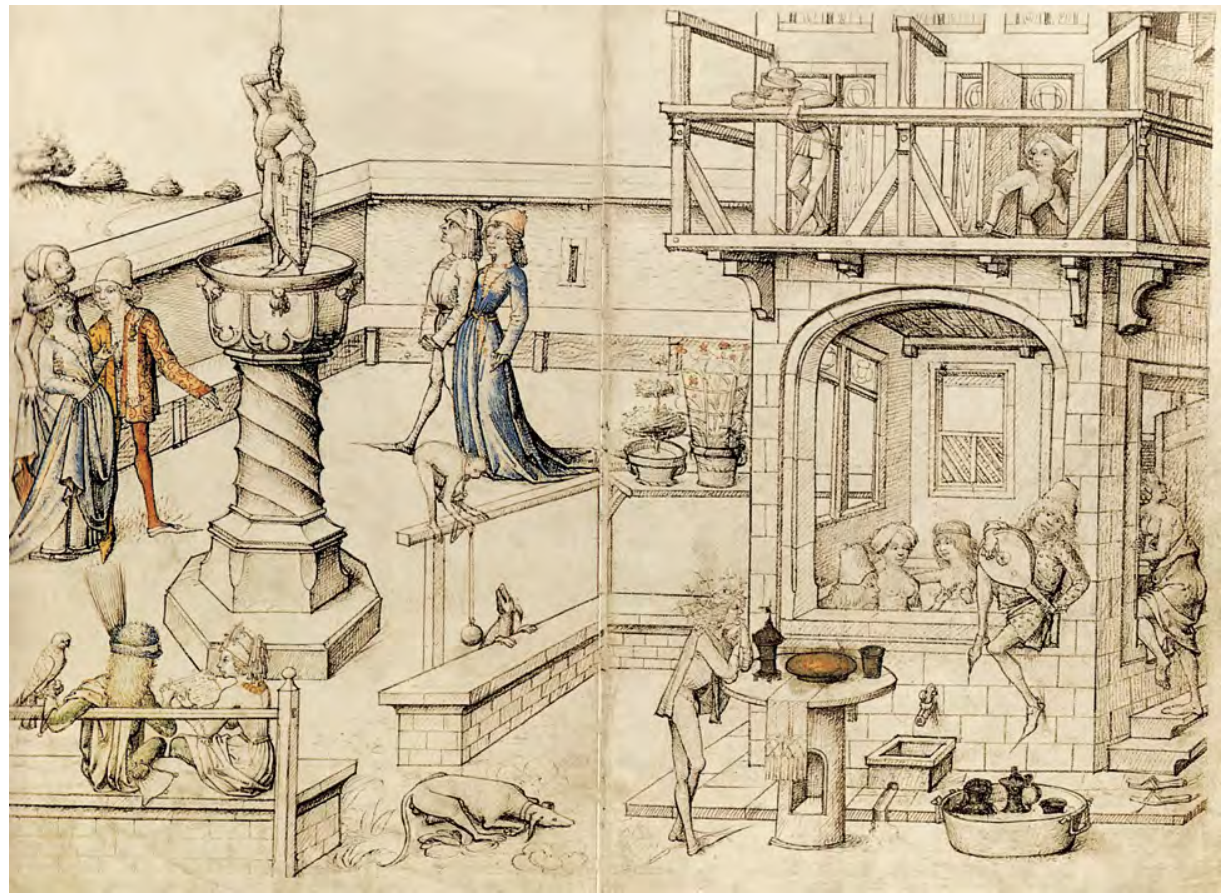

Abb. 54: Baden und Vergnügen; kolorierter Kaltnadelstich aus "Das mittelalterliche Hausbuch«, um I480.

dreißiger Jahren des I6. Jahrhunderts errichtet worden sein. ${ }^{326}$ Nach eher dürftigen Angaben, wonach I 54I im Bad einige Röhren »abprochen unnd wider mit vilczen angeslagen " worden seien ${ }^{327}$ und man I 545 das schadhafte "prunkhar" im Bad beschaute, ${ }^{328}$ wird das Rechnungsbuch zu 1547 genauer. Danach hat man damals in der Frauenstube Röhren gebohrt und gelegt sowie eine neue Brunnensäule gesetzt, ferner Brunnenröhren von Geislers ${ }^{329}$ Brunnen zum Bad geführt und wieder zugedeckt, in der Männerstube eine neue Brunnensäule ausgeschnitten, gebohrt und gesetzt, die Röhren unter der Scherbank aufgehoben und beschaut. ${ }^{330}$ Die Brunnenbecken (Wasserkästen) bestanden aus Lärchen- oder Eichenholz. ${ }^{331}$

Als es 554 im Bad wieder an Wasser mangelte, beschloss der Rat, beim Haus des Hans Vischer eine Säule oder einen Stock mit einer "pippn« zu errichten und über die Röhren das Bad mit Wasser zu versorgen, wenn Badestunden seien. Außer dieser Zeit solle man die Leitung abstellen. ${ }^{332}$ Anscheinend war das nur ein vorübergehender Notbehelf. Denn später hört man wieder von Röhren bei Inzingers (Geislers) ${ }^{333}$ Brunnen, die in das Bad geführt wurden, und von einem Pflaster vom Bad bis zu Inzingers Brunnen, das man aufriss und in das man neue Röhren legte, wonach die Erde wieder 
zugemacht und ein neues Pflaster gelegt wurde. ${ }^{334}$ Aber die Schwierigkeiten mit der Wasserzuführung scheinen nicht behoben worden zu sein. I 579 wurden zwei Brunnensäulen in das Bad und in den »Taillstockh" (Teilungsstock) beim Brückentor eingesetzt, Röhren in das Männerbad gelegt, im Bad die Mauer durchbrochen, das Pflaster aufgehoben, damit man mit den Röhren zu der Säule beim Brückentor kommen konnte. Im Bad machte man danach das Pflaster wieder zu. ${ }^{335}$ Offensichtlich stand beim Brückentor ein großer Brunnenstock, von dem man Wasser in das Männerbad abzweigte. ${ }^{336}$ Das Pflaster über den Röhren in der Badstube machte durchaus einen Sinn, brauchte man doch so nicht den ganzen Holzboden aufreißen, wenn die Röhren verstopft oder verfault waren. Die Wasserleitung und das Pflaster darüber dürften entlang einer Wand verlaufen sein, an der vermutlich auch das Brunnenbecken stand.

\subsection{Die Trinkstube}

Badhäuser waren nicht nur Orte der Gesundheit, Hygiene und Erholung, sondern auch der Begegnung, Unterhaltung, des Trinkens und Essens. Zwar lassen sich, wie oben erwähnt, in städtischen Bädern Gesellschaftsräume nur selten archäologisch oder schriftlich nachweisen, doch für Rattenberg gelingt das. "Der Stefflin und der andern gwandthu reyberin von den poden auf der trinckstubn ${ }^{337} \mathrm{zu}$ waschen $30 \mathrm{kr}$.« bezahlt, vermerkt der Baumeister kurz in seiner Rechnung für $1544 \cdot{ }^{338}$ Nun kann man rätseln, weshalb die Reiberinnen, die als Badfrauen in der Frauenstube ganz andere Aufgaben hatten und direkt von den Badbesucherinnen bezahlt wurden, zum Bodenputzen herangezogen wurden, ${ }^{339}$ zumal die Reinigung des Bades zu den Pflichten der Badknechte und Lehrjungen gehörte (s.o.), die Sauberhaltung der Trinkstube wohl der Baderin und ihrer Magd oblag. Denkbar ist, dass die Ratsherren, die wie andere das Bad besuchten, ${ }^{340} \mathrm{zu}$ ausgiebig gezecht und den Boden entsprechend beschmutzt, um nicht $\mathrm{zu}$ sagen versaut hatten, so dass sich das Badpersonal geweigert hatte, sauber zu machen. Den beiden armen Reiberinnen dagegen wird der Zusatzverdienst gerade recht gewesen sein.

Noch eindeutiger als Beleg für eine eigene Trinkstube im Rattenberger Badhaus ist folgender Nachweis. I 556 gerieten der städtische Tuchscherer Jörg Erber und der Vikar Niclas Neuhauser in einen Streit, der schließlich damit endete, dass der Vikar am I 7. Februar des Jahres den Tuchscherer erschoss. ${ }^{341}$ Der Zank ging um ein simples "Jungets« (Brotmesser). Nach Aussage der Witwe Barbara Erber habe ihr Mann um den Dreikönigstag »auf dem pad geessen und geczecht« und dabei sein Jungets vergessen. Das hätten die Leute auf dem Bad »aufbehalten und hinauf in dj wannd gesteckht«. Bald danach habe auch der Herr Vikar »auf dem pad geczecht«. Als sie ins Bad gekommen sei, um das Messer zu holen, habe man ihr gesagt, der Herr Vikar »habs 


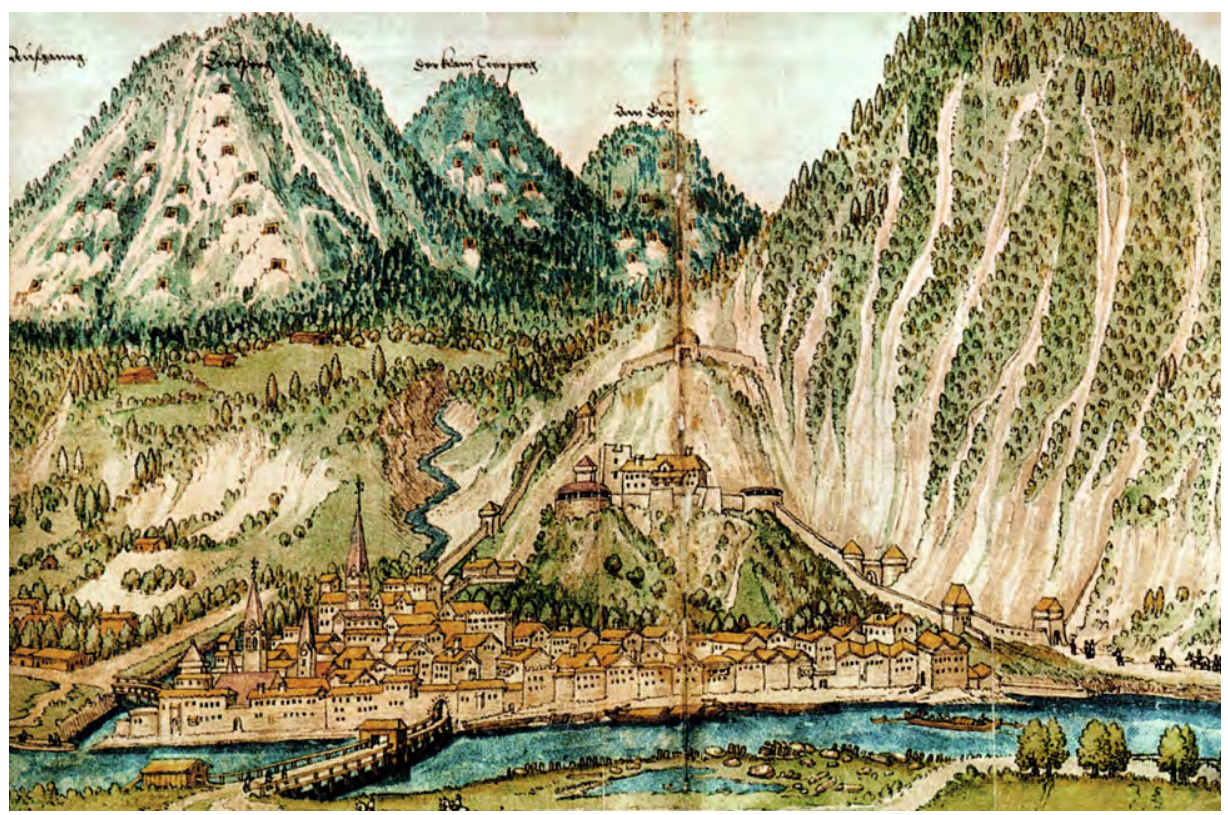

Abb. 55: Ansicht von Rattenberg (rechts vom Brückentor das Badhaus mit Abtrittserker, daneben das Badtürl mit Schiffsanlegeplatz); Aquarell von Jörg Kolber im Schwazer Bergbuch, 1556.

aufgesteckht «. ${ }^{342}$ Daraufhin beschuldigte der Tuchscherer den Geistlichen des Diebstahls, dieser leugnete immer wieder, das Messer genommen zu haben, es kam zu Handgreiflichkeiten, die letztlich dann zum Mord führten. ${ }^{343}$

Fragt man sich, wo denn die Trinkstube gewesen ist, bleibt nur das Obergeschoss übrig. Darauf deutet auch die Formulierung »auf dem pad« hin. Sie wird bis auf wenige Versehen $^{344}$ in den Dokumenten nur verwendet, wenn der erste Stock des Badhauses gemeint ist. Vermutlich befand sich die Trinkstube in der Südwestecke des Hauses. Das Mauerwerk im entsprechenden Zimmer deutet noch heute an, dass darin einst umlaufende Sitzbänke gewesen sind. Durch eine Tür in der nördlichen Mauer dieser Stube gelangte man in ein Nebenzimmer, wahrscheinlich in die Küche. Dafür spricht eine gleichzeitig vorgenommene Reparatur in beiden Räumen. I 538 wurde im Bad der Kachelofen abgebrochen, der Fuß erneut aufgemauert, der Herd in der Küche abgebrochen und wieder gemauert. ${ }^{345}$ Dass der Kachelofen wirklich in der Trink-, nicht Badestube stand, ergibt sich aus einem Rechnungseintrag zu I568, wonach der Kachelofen "auf dem Bad « repariert wurde. ${ }^{346}$ Die Trinkstube dürfte getäfelt gewesen sein. Wie wollte man sonst ein Messer in die Wand stecken, wenn sie nicht aus Holz gewesen wäre. 


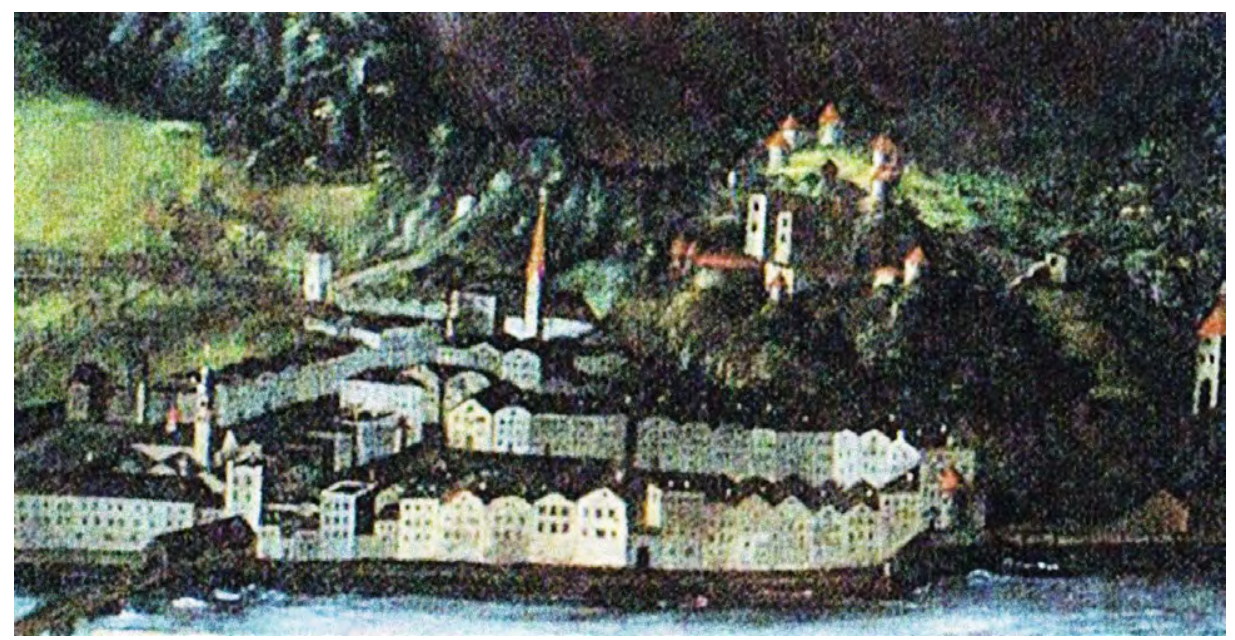

Abb. 56: Rattenberg (rechts vom Brückentor das Badhaus, daneben das Badtürl); Ausschnitt aus der NotburgaFahne von 1728 in der Pfarre Rattenberg.

So dürftig die Hinweise auch sind, sie lassen doch vermuten, dass ein Badbesuch gern mit anschließendem Trinken und Essen verbunden wurde.

\subsection{Der Abtrittserker}

Die Miniatur Rattenbergs im Schwazer Bergbuch von I 556 lässt erkennen, dass sich auf der Innseite des Badhauses im Obergeschoss ein Abtrittserker zwischen je zwei Fenstern rechts und links befand, vermutlich am Ende eines Ganges. Man kann ihn auch in den Rechnungen des Stadtbaumeisters nachweisen. Heißt es noch I 547 kurz und bündig, im Bad sei ein heimliches Gemach gemacht worden, ${ }^{347}$ so ist die Raitung I 572 anlässlich einer Erneuerung genauer. Danach wurde mit dem Maurer Rudolf Heypacher vereinbart, er solle das heimliche Gemach bei dem Bad von unten bis oben mauern, und zwar solle er unten von dem alten Steinwerk an drei Werkschuh mit gehauenen Steinen in die Höhe fahren, den Rest mit Ziegeln. Die Ziegel werde man ihm liefern, das übrige Material habe er auf eigene Kosten beizubringen. Sein Lohn solle sechs Gulden sein. Dazu kämen 24 Kreuzer Leitkauf und noch einmal dieselbe Summe für das Räumen des Gemachs. ${ }^{348}$ Noch einmal I 58 I hört man vom Abort, als Heypacher Marmorstücke (»märblstainene stückh«) bezahlt wurden, die er zum heimlichen Gemach am Bad verwendet hatte. ${ }^{349}$ Aus heutiger Sicht muss man froh sein, dass die Fäkaliengrube geräumt wurde und man nicht einfach den Unrat in den nahen Inn geleitet hat. 


\subsection{Das Holzkämmerl}

Der Heizraum im Bad scheint lange Zeit auch als Lager für Brennholz gedient zu haben. Als er aber I 523 den Knechten auch als Aufenthaltsraum zur Verfügung gestellt wurde, ${ }^{350}$ war vermutlich nur noch Platz für die Menge, die man zum Anheizen des Ofens und der Warmwasserkessel für einen Tag benötigte. Jedenfalls wird erstmals I 523 ein eigenes Holzkämmerl erwähnt. Damals erhielt die Witwe des Baders Heinrich Öttinger auf Befehl des Bürgermeisters »umb die holczhütten bei dem pad [...] und umb 8 pad schäffer, so pei der prunst, so Hupfaufs stadl verprunnen, verlorn «, eine Entschädigung. ${ }^{351}$ Drei Hinweise lassen erkennen, dass man sich auch später um das »Holzställchen« oder »Holzkämmerl«, wie es genannt wurde, gekümmert hat. I547 brach man darin ein Fensterl aus, I 55 I erhielt es ein neues Dächl und gleichzeitig wurde seine Tür gerichtet. ${ }^{352} \mathrm{Ob}$ das 1775 erwähnte Holzgewölbe ${ }^{353}$ der Anbau der Frauengarderobe oder der Holzschuppen gewesen ist, lässt sich nicht entscheiden. 


\section{Bader, Badknechte, Reiberinnen und Gewandhüterinnen zu Rattenberg}

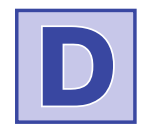

as Bad zu Rattenberg war im Eigentum der Stadt. Sie bezahlte alle Reparaturen am Gebäude, an den festen und beweglichen Einrichtungen (Badofen, Warmwasserkessel, Bänke, Stellagen usw.) und sorgte für die nötigen Neuanschaffungen. Dem Bader wurde das Bad verpachtet und dabei kostenlos überlassen, er erhielt einen Jahressold von I 6 Gulden (= 8 Mark) ${ }^{354}$ musste aber alles Werkzeug, das er als Bader, Barbier und Wundarzt benötigte, mitbringen, angefangen von den Badewannen, Schaffen, Becken, Rasiermessern bis hin zu Lass- und Schröpfeisen, chirurgischen Instrumenten, Verbandszeug. Er nahm sein Personal selbst auf, brauchte jedoch für die Anstellung von Gewandhüterinnen und Reiberinnen (Badefrauen) die Zustimmung des Rates, weil dieser mit beiden Berufen Frauen oder Witwen von einfachen Handwerkern und Krämern, die arm oder verarmt waren, ein kleines Einkommen verschaffen wollte.

Fast alle Bader besaßen nur das Inwohnerrecht. ${ }^{355}$ Bei der Aufnahme und jährlichen Wiederbestellung eines Baders schärfte ihm der Rat seine Pflichten ein. Stets wiederkehrende Punkte waren: Alle Badegäste seien gleich zu behandeln, die Badetage und Öffnungszeiten seien einzuhalten, er solle taugliche Knechte anstellen, die sich auch auf das Aderlassen, Schröpfen und Verbinden verständen, es sei stets rechtzeitig zu heizen und ausgiebig zu lüften, die Kessel dürften nicht überhitzt werden, es sei unbedingt auf Sauberkeit in den Badstuben zu achten, Kranke darin seien abzusondern oder auszuschließen und im Übrigen sollten er und sein Personal nicht so viel Wein trinken. Bader galten als starke Trinker, ${ }^{356}$ kein Wunder, Hitze und Dampf machten eben eine trockene Kehle. Steter Durst des Badepersonals war so eine Art Berufskrankheit.

\subsection{Erste Namen, Michael Hueber d. Ä.}

Angesichts des dürftigen Quellenmaterials zur Geschichte des Rattenberger Badhauses und seiner Bader im I5. Jahrhundert muss man schon froh sein, wenigstens den Namen dreier Bader in dieser Zeit anführen zu können. Da wäre zunächst »Hanns Karg von Röttemberg «, der drei Groschen Aufnahmegebühr in die Innsbruck-Haller Baderbruderschaft von I 450/6o zahlte. ${ }^{357}$ Diese Bruderschaft nahm sehr viele fremde Mitglieder auf, kaum aus Tirol, ${ }^{358}$ aber aus Vorarlberg, der Schweiz, Schwaben und besonders aus Bayern. ${ }^{359} \mathrm{Da}$ für Rattenberg im Mittelalter und in der frühen Neuzeit 
Abb. 57: Wundarzt lässt Frau zur Ader; Miniatur aus einer Handschrift von "Die sieben weisen Meister«, $147 I$.

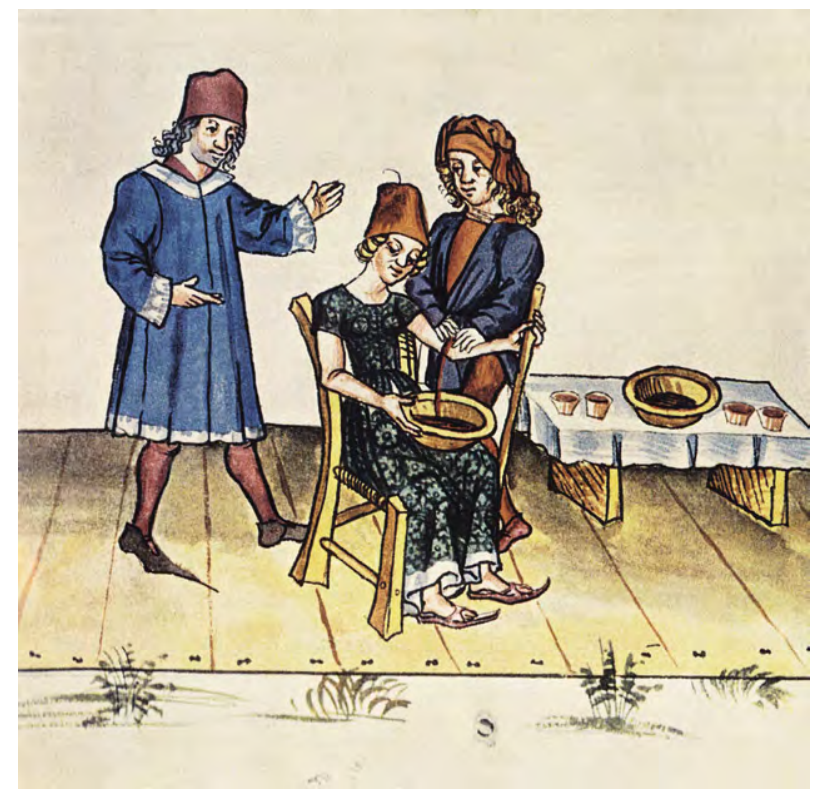

viele Schreibformen existieren, z.B. Ratemberg, Ratmperg, Ratenperch, Ratenwerg, eben auch Rot(t)enberg ${ }^{360}$, spricht vieles dafür, dass Hans Karg Bader im damals noch bayerischen Rattenberg gewesen ist.

Vom zweiten, zu I 478 genannten Rattenberger Bader kennt man auch nur den Namen: Meister Hans Plank. ${ }^{361}$ Allerdings existiert aus ungefähr seiner Zeit eine interessante Nachricht. I 470 strafte der Bergrichter von Rattenberg den Hanns Schëkl, vermutlich einen Knappen, mit einem Pfund Berner, weil er gegen Barbara, Gewandhüterin im Bad, ein »schörper ${ }^{362}$ gezückt hatte. ${ }^{363}$ Da der Übeltäter wohl ein Brotmesser in die Hand genommen hat, kann man davon ausgehen, dass er nach dem Bad in der Trinkstube essen (und zechen) wollte oder schon gezecht hatte. Der "Gesellschaftsraum« reicht also hier schon ins I 5. Jahrhundert zurück, wenn nicht überhaupt in die Entstehungszeit des Bades.

Von dem nächsten Stadtbader, Michael Hueber d. Ä., ist unklar, wie lange er in Diensten des Rattenberger Augustinerklosters stand und wann er sein Amt im städtischen Bad angetreten hat. Sicher ist, dass von $\mathrm{I}_{4} 83$ bis 1496 Meister Johannes Ranndek und sein gleichnamiger Sohn Klosterbader waren, ${ }^{364}$ ihnen in dieser Funktion von I 496 bis I 503 Gabriel Freytag folgte, ${ }^{365}$ der später Stadtbader wurde, und I 504 noch einmal Meister Johannes, vermutlich der jüngere Ranndek, mit ${ }_{5}$ Pfund Berner entlohnt wurde. ${ }^{366}$ Am I I. Dezember I 506 zahlte der Rechnungsführer des Klosters dem 
Badermeister Michael [Hueber] für die Arbeit von einigen Jahren (»de aliquibus annis«) lediglich 22 Pfund Berner. ${ }^{367}$ Da Meister Johannes allein für ein Jahr I 5 Pfund erhielt, kann es sich bei Michael nur um gelegentliche Aushilfe in einigen Jahren gehandelt haben.

Denn er war anscheinend schon selbstständiger Bader, und zwar seit längerem. Im Februar I 489 ließ sich das Kloster vom Bader Michel für eine Fuhre Holz zwölf Vierer bezahlen. ${ }^{368}$ Es wäre unsinnig anzunehmen, dass ein Klosterbader die Holzfuhren für seinen Arbeitgeber bezahlen musste. Michel - aus späteren Quellen (s.u.) erfährt man, dass er Hueber hieß - hatte I 489 vermutlich ein anderes Bad inne, nämlich das von Rattenberg, wie sich unten ergibt. Michel Hueber könnte bis I 482 Bader der Fratres gewesen sein, dann das städtische Bad übernommen und den Klosterdienst Johannes Ranndek überlassen haben. Jedenfalls zahlte ihm der Prior schon im November 1482 sechs Kreuzer für $3^{1 / 2}$ Lot eines Pulvers gegen den "gmein tod der küe «. ${ }^{369}$ Rattenberg hatte zu dieser Zeit weder einen Arzt und Apotheker ${ }^{370}$ noch einen Vieharzt. ${ }^{371}$ Es ist interessant, dass also auch ein Bader und Wundarzt bei Viehkrankheiten in Anspruch genommen wurde.

Mehr über Huebers Tätigkeit erfährt man nicht. Er ist I 507 gestorben, und zwar nach Martini. Denn am Martinsabend war er noch mit seiner Frau im Kloster zu Gast, ${ }^{372}$ aber am Nikolaustag war seine Frau bereits Witwe. Damals erlaubte der Rat der Baderin Michaelin, das Bad auf ein Vierteljahr zu versehen, und trug ihr auf, dabei "guten vleis $[\mathrm{zu}]$ thun «. Ihre Badknechte mussten Bürgermeister und Rat geloben, ebenfalls fleißig zu sein. ${ }^{373}$ Wahrscheinlich hatte es bislang allerseits am nötigen Arbeitseifer gefehlt. Sie bzw. ihre Knechte betreuten offensichtlich wie ihr verstorbener Mann auch die Mönche, denn sie erhielt Anfang I 508 für das Baden I 5 Pfund Berner Jahreslohn (für I 507) vom Kloster. ${ }^{374}$ Bald darauf heiratete sie, denn im Rechnungsbuch des Konvents liest man unter dem I4. Februar I 508, dass Bruder Andreas an der Hochzeit der Baderin (»ad nupcias balneatricis«) teilgenommen habe. ${ }^{375} \mathrm{Ihr}$ zweiter Mann, Heinrich Öttinger, wurde der neue Bader. Ihr Sohn Michael war anscheinend noch zu jung zur Übernahme des Baderamtes. Er sollte erst später zum Zuge kommen.

\subsubsection{Bader im Kloster und Umland}

I 5 I 4 und I 5 I 8 lassen sich zuletzt Verträge des Klosters mit eigenen Badern nachweisen. ${ }^{376}$ Seitdem treten alle Stadtbader auch als Klosterbader auf. Lediglich vereinzelt beschäftigten die Mönche noch fremde Bader. ${ }^{377}$ Dagegen ist nichts zu sagen, profitierten doch die Inhaber des städtischen Bades stark von den Mönchen als Auftraggebern, die sie erst recht nach I 5 I 8 zu ihren besten Kunden zählten, sowohl im Kloster selbst ${ }^{378}$ als auch im eigenen Bad. ${ }^{379}$ Aber wer garantierte dem Stadtbader, dass die auswärtigen Kollegen ${ }^{380}$ nicht in die Stadt oder ihre Bannmeile hinein arbeiteten 
Abb. 58: Barbier; Holzschnitt aus Jost Ammans »Ständebuch«, ${ }_{15} 68$.

\section{Der Balbierer.}

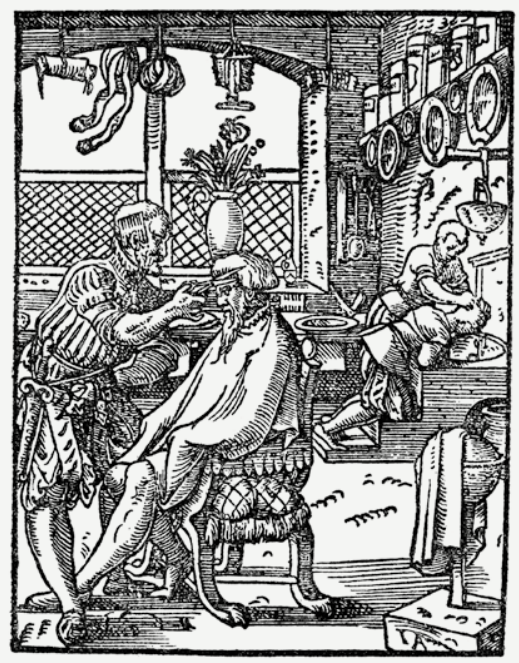

und somit ihre Einkünfte schmälerten? Viele Jahre hatten die Handwerker in Rattenberg darum gestritten, dass nur sie in der Stadt bis zur Bannmeile arbeiten dürften, ebenso viele Jahre hatten sich auswärtige Dorfhandwerker nicht darum gekümmert, bis schließlich Christoph Philipp von Liechtenstein, der Hauptmann von Rattenberg, I 52 I einen Vertrag zwischen den Stadtbewohnern und Gerichtsleuten in der Herrschaft Rattenberg aushandelte.

Die Vereinbarung beschränkte die Zahl der innerhalb der Bannmeile zulässigen Handwerker, in Reith und Kramsach: je ein Schneider, ein Schuster, ein Weber; in Brixlegg und Radfeld: je ein Schneider, ein Schuster, ein Weber, ein Schmied. Die innerhalb der Bannmeile zugelassenen Meister sollten dieselben Lasten und Steuern tragen wie die Meister in der Stadt, die Bürger waren. Andere Handwerker und Störer durften sich nicht in der Bannmeile niederlassen, die Handwerker außerhalb der Bannmeile dürfen nicht in sie hineinarbeiten. ${ }^{381}$

Es wäre naiv zu glauben, dass der Vertrag von allen Auswärtigen eingehalten wurde. Die Skepsis der städtischen Bader gegenüber unerlaubter fremder Konkurrenz war berechtigt, wie folgender Fall zeigt. Im Januar I 549 beschwerte sich Meister Matheus Paumgartner, der Rattenberger Bader, über drei auswärtige Störer, nämlich über Achaci Pfeiffer, Stefan Schick in Brixlegg und einen Knappen zu Radfeld. Der Landrichter solle dafür sorgen, dass sie ihm nicht mehr ins Handwerk pfuschten. Dieser tat offensichtlich nichts, denn im März wiederholte Paumgartner seine Klage über Pfeiffer und 
Schick. Nun wurde der Rat energischer. Man beschloss, dem Richter die »Declaration« (von I 52 I) vorzulegen. Schaffe er nicht Ordnung, werde man Herrn von Liechtenstein zum Eingreifen bitten. ${ }^{382} \mathrm{Wie}$ die Sache ausging, erfährt man nicht, doch erschien I 560 der Bader Alexander Schick, augenscheinlich ein Verwandter (Bruder, Sohn?), vor dem Rat und bat um die Erlaubnis, zu Mehrn (b. Brixlegg) das Bad zu versehen. Er wolle, was billig sei, entrichten. Der Rat stimmte zu und erlegte ihm 36 Kreuzer Steuern auf, die er auch brav bar erlegte. ${ }^{383}$ Es fragt sich nur, wie lange. Denn bereits ${ }_{5} 64$ hatte er als auswärtiger Bader 36 Kreuzer Steuerschulden, I 565 waren es schon für drei Jahre ein Gulden 48 Kreuzer. ${ }^{384}$

Die unliebsame Konkurrenz auszuschalten gab es zwar Möglichkeiten, die aber wenig fruchteten. Wählte der Bader seine Knechte unter den Badern/Badgesellen außerhalb der Stadt - das empfahl I5 49 der Rat dem neuen Bader -, ${ }^{385}$ blieben ihm noch viele andere Störer im Umkreis. Man konnte sie auch in die Stadtgemeinschaft aufnehmen, nicht ohne sie auf das aussichtslose Unterfangen, sich neben dem Stadtbader und anderen erhalten zu können, hinzuweisen. I 5 Io vertrat der Rat im Interesse seines eigenen Baders noch eine harte Linie. Obgleich sich ein Barbiergeselle für seine Bitte, eine Stube errichten zu dürfen, auf die Fürsprache Kaiser Maximilians berufen konnte, befanden Bürgermeister und Rat, man brauche derzeit keinen Barbier, zumal »sich gemainer stat pader hert erneren und entfalten mag ${ }^{306}{ }^{386}$ Zwei Jahre später gestattete man auf Bitten des Stadthauptmanns Pauls von Liechtenstein dem Barbier Thoman Zierler, eine »werchstat offen parbierung « zu errichten, obwohl die Stube unnötig sei und dem gemeinen Bad Nachteile brächte. Man wolle aber den Herrn von Liechtenstein wissen lassen, dass Zierler keinen Gewinn machen werde (»nit mit frucht erschiessen werde«), weil viele Störer um die Stadt wohnten. ${ }^{387}$ Das hat anscheinend Zierler selbst eingesehen. Man hört nie wieder etwas von ihm.

Hatte sich jemand um die Stadt verdient gemacht, gab der Rat nach, legte aber den Bewerbern Beschränkungen auf. Conrad (Kuntz) Stolz aus Kramsach wurde auf seine Bitte hin $5_{2} 7$ zum Inwohner aufgenommen. Man erließ ihm die Aufnahmegebühr wegen seiner tüchtigen Arbeit als Totenlässl in den »sterbenden leuffen« des vergangenen Jahres. Allerdings durfte er in der Stadt weder eine "palbierstat« errichten noch darin »hausirn«, d.h. in Rattenberg von Haus zu Haus seine Dienste als Barbier anbieten. Doch wurde ihm erlaubt, außerhalb der Stadt mit Aderlass und Wundarznei zu hausieren. ${ }^{388}$

Ganz aus der Reihe fällt der Badknecht Matheus Schmied aus Inckhausen ${ }^{389}$, der I 556 im Beisein des Baders Hans Fäler gegen 20 Gulden zum Bürger in Rattenberg aufgenommen wurde. Die Gebühr fiel so hoch aus, weil er die begüterte Witwe des verstorbenen Jacob Wetin, eines Wirtes und Ladenbesitzers, geheiratet hatte. Doch Schmied hatte das Pech, dass seine Frau Ursula Wetin schon im nächsten Jahr starb und er bei der Erbaufteilung leer ausging, bis auf zwölf Gulden, Leibgewand, Harnisch und Wehren. Alles andere erhielten Ursulas Kinder, Fahrnis, Kaufmannswaren, Klein- 
odien, Silbergeschirr, Haus und Garten. Schmied hat offensichtlich nie als Bader in Rattenberg gearbeitet und zog es vor, nach dem Tod seiner Frau in kaiserliche (Kriegs-) Dienste zu treten. ${ }^{390}$

Es sind gewiss nur gravierende Dinge aktenkundig geworden, der tägliche Ärger des Stadtbaders mit den auswärtigen Störern wurde nur selten vermerkt, zumal dann nicht, wenn die Dorfbader »hausieren« gingen, also ihre Dienste als Bader, Haarschneider, Barbier, Aderlasser oder gar Wundarzt von Haus zu Haus anboten. Hätte der Stadtbader nicht neben den Schwitz- und Wannenbädern noch andere Einkünfte gehabt, er wäre angesichts der dörflichen Konkurrenz schwerlich über die Runden gekommen.

\subsection{Heinrich Öttinger}

Über seine erste Amtszeit im städtischen Bad von Rattenberg liegen nur dürftige Zeugnisse vor, ${ }^{391}$ doch das Raitbuch des Klosters kann etwas aushelfen. Die Mönche zahlten am Lichtmesstag I 509 dem Badermeister Heinrich I 5 Pfund Berner als Lohn für das vergangene Jahr. ${ }^{392}$ Da oben erwähnt wurde, dass I 508 Katherina, die Witwe des verstorbenen Baders Michael Hueber, vom Kloster dieselbe Summe als Jahreslohn für I 507 erhalten hat, ist anzunehmen, dass Öttinger nach seiner Heirat mit Katherina (Februar I 508) von ihr nicht nur das städtische Bad samt allen Geräten, sondern auch den Dienst an den Mönchen übernommen hat. Im Juli I 509 schlossen die Patres und Fratres mit ihm darüber einen Vertrag.

Meister Heinrich solle jede Woche den ganzen Konvent an einem solchen Tag baden und scheren, an dem er nicht in der Stadt das Bad halte. Die gedingten Dienstboten (»ehalten«) und die Pfründner im Kloster solle er am Feierabend in seinem Bad baden, wenn ein gewöhnlicher Badtag sei. Dafür erhalte er vom Konvent als Lohn 5 Gulden (= 25 Pfund Berner), zwei Star Korn, einen Star Weizen, einen Star Gerste. Das Ansetzen der Schröpfköpfe und Aderlassen (»köpfflen und lassen«) solle ihm vorbehalten sein. ${ }^{393}$

Dass auch sein Können als Wundarzt gefragt war, zeigt folgende Episode über zwei Rattenberger Augustinermönche, die offenkundig keine friedlichen Lämmer waren. Abends gegen die neunte Stunde am Cäcilientag (22. November) I 509 verließen die beiden Fratres Andreas Schneider und Richard Kripp die klösterliche Klausur und stießen draußen auf den Weltpriester Johannes Gebhart aus Weilheim. Ob sie nun keine Bayern mochten, ob ein längerer Streit zwischen ihnen schwelte oder was sonst der Grund war, man erfährt es nicht. Jedenfalls gingen die beiden Brüder auf Gebhart los, stießen, schlugen und verwundeten ihn so schwer, dass er länger vom Wundarzt behandelt werden musste (»stare sub cirurgici manu«). Für I 7 Tage Aufenthalt, Schadenersatz an Gebhart und Arzkosten musste der Konvent über I 3 Mark aufwenden, davon 2 Mark an den »Cirurgicus « und Bader, Meister Heinrich. ${ }^{394}$ 


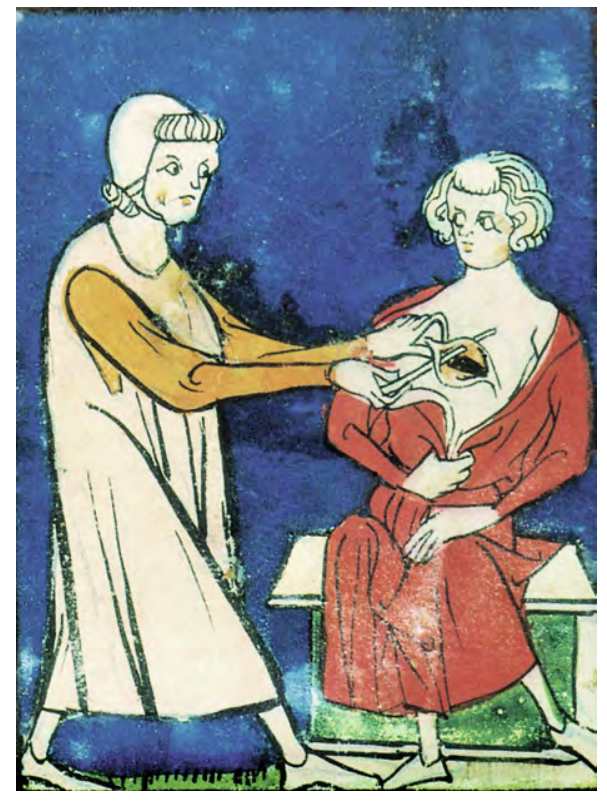

Abb. 59: Nähen einer Brustwunde; Miniatur aus einer französischen Handschrift, I4. Jh.

Als er im September I 5 I o von den Mönchen seinen letzten Lohn empfing, sagte er ihnen seinen Dienst auf. ${ }^{395}$ Er tat dies nicht, weil er mit ihnen unzufrieden war, sondern weil er die Stadt verlassen wollte. Schon im Juni hatte er den Rat um Urlaub gebeten, doch verzögerte sich die Angelegenheit bis Mitte September. Mit dem erbetenen Abschiedsbrief, in dem ihm gutes Verhalten bescheinigt wurde, machte er dem neuen Bader Platz. ${ }^{396} \mathrm{Um}$ seine Nachfolge bewarben sich drei Bader: Meister Gabriel Freytag, gefördert vom Stadthauptmann Paul von Liechtenstein, Meister Matheus, empfohlen von drei Personen zu Schwaz, und Fritz Hauser, unterstützt vom Pfarrer zu Münster, vom Hüttenmeister Rüml und vom Hüttenschreiber. Bei Hauser fehlte es anscheinend noch an einigem, denn der Rat legte ihm nahe, sich »mit petgewant und ander notturft [zu] versehen«. Der Rat entschied sich am 28. Juni für Meister Gabriel, weil die Stadt »ains gueten artzt und paders vast dürftig" sei. Er hat wohl am besten diesen Anforderungen entsprochen. Zu Quatember Michaelis (1 8. September) sollte er seinen Dienst antreten. ${ }^{397}$

Von Öttingers Arbeit im Stadtbad erfährt man nichts, außer dass ihm sein Sold von acht Mark (= I6 Gulden), für I 5 I o nur noch sechs Mark für 3 Quatember bezahlt wurde und dass er von der Stadt (Brenn-)Holz gekauft hat. ${ }^{398} \mathrm{Ob}$ es ihm außerhalb Rattenbergs nicht gefiel oder ob er in der Fremde keinen Erfolg hatte, weiß man nicht, jedenfalls war er sofort zur Stelle, als im Oktober I 5 I 3 das Baderamt in Rattenberg frei wurde, da Meister Gabriel Freytag in Brixen ein Bad gekauft hatte und dorthin ziehen wollte. Dem Rat kam seine Bewerbung gelegen, weil, wie es im Ratsprotokoll heißt, er 
eine Bürgerstochter ${ }^{399}$ geheiratet und früher schon zur vollsten Zufriedenheit das Bad versehen hat. Meister Heinrich wurde das Bad zur kommenden Fastenzeit zugesagt, doch machte man ihm zur Pflicht, dass er »sich mit guetn geselln versechen, oben und undten ${ }^{400}$ mit huet und pflicht den armen und reichen wol warten « solle. ${ }^{401}$ Gabriel wurde erst am Dreikönigstag I 5 I 4 zur Fastenquatember gekündigt und gleichzeitig dem Heinrich Öttinger aufgetragen, er solle von Freytag Zuber und Badgeschirr kaufen, wie es seinerzeit Gabriel von ihm erworben habe. ${ }^{402}$

Auch über Heinrichs zweite, bis I 523 währende Amtszeit als Stadtbader ist außerhalb der klösterlichen Überlieferung wenig bekannt. Er erhielt den üblichen Jahressold von I 6 Gulden ${ }^{403}$ und erwarb I5 5 I gegen eine mäßige Aufnahmegebühr von zwei Gulden das Bürgerrecht. ${ }^{404}$ Als Heinrich Öttinger wird er in der Folge unter den Bürgern Rattenbergs erwähnt. ${ }^{405}$ Interessant ist lediglich der Hinweis auf eine Seuche, die von Mitte Oktober I 52 I bis Ende Januar ${ }_{5} 5_{2}$ herrschte. ${ }^{406}$ Eine Diwoldin pflegte I 5 Wochen die Kranken und trug ihnen Speise zu, ein Bader namens Jacob ging zehn Wochen in den »sterbenden Läufen« zu den Kranken und ließ sie zur Ader. ${ }^{407}$ Da normalerweise in Rattenberg während einer Seuche das Bad nicht geschlossen wurde, man aber den Stadtbader vor Ansteckung bewahren wollte, bestellte der Rat in der Regel einen eigenen »Totenlässl«. So auch in diesem Fall.

Heinrich Öttinger nahm nach seiner Rückkehr wieder den Dienst als Klosterbader, sowohl für die Patres und Fratres als auch für das ganze Hausvolk (»familia«), auf und erhielt den alten Jahreslohn von fünf Gulden zuzüglich zwei Star Gerste, stattdessen einmal auch zwei Star Hafer. Der Lohn konnte mit Holz, das er vom Kloster bezog, verrechnet werden. ${ }^{408}$ Sonderleistungen wurden von beiden Seiten extra vergütet, wenn etwa der Bader Weizen und Holz vom Kloster kaufte, den Klosterknecht für sich fahren ließ $\aleph^{409}$ oder wenn das Kloster außerhalb des Vertrages die Dienste des Baders beanspruchte. ${ }^{410}$ Das Verhältnis Öttingers zu den Augustinermönchen war augenscheinlich gut. I 5 2 I war er mit seiner Ehefrau im Kloster zu Gast, ${ }^{411}$ im selben Jahr ließ sich der Rechnungsführer von Dr. Stefan Kastenbauer (Agricola), dem Prior und dem Bader sechs Kreuzer für einen gesottenen Hecht zahlen, den offensichtlich die drei im Kloster verspeist hatten. ${ }^{412}$

Während Heinrich Öttinger noch im Mai I 523 als lebend erwähnt wird, ${ }^{413}$ war er am 9. Juli bereits tot. An diesem Tag erhielt die Heinrich Baderin auf ihr und ihres Sohnes Michel Begehren hin einen Anweiser und für ihre Kinder Anna, Apollonia und Margreth zwei Vormunde. Angesichts der »clainen und unerczogen kind« wurden ihr und ihrem Sohn Michel erlaubt, mit den Knechten das Bad noch bis Weihnachten zu versehen. ${ }^{414}$ Der Jahreslohn von I6 Gulden wurden ihr I 524 und I 525 in fünf Raten ausgezahlt. ${ }^{415}$ Die Stadt zahlte ihr für eine Holzhütte bei dem Bad und für acht Schaffe, die bei einem Feuer in einem Stadl verbrannt waren, 30 Kreuzer. ${ }^{416}$ Mehr ist über sie nicht aktenkundig geworden. 
Anfang I 529 ist Katherina, Heinrich Öttingers Witwe, gestorben. Ihre drei hinterlassenen Kinder Anna, Apollonia und Margreth erhielten neue Vormunde. Bei der Erbaufteilung bekamen die drei Kinder 45 Gulden, alles andere fiel an Veronica Hueberin, die Gattin des Jacob Rasp aus »Partisgadn« (Berchtesgaden) und Michel Hueber, die davon alle Schulden ihrer Mutter und Schwiegermutter ${ }^{417}$ zu bezahlen hatten. ${ }^{418} \mathrm{Ve}-$ ronica und Michel stammen also aus ihrer ersten Ehe mit Michael Hueber. Der Nachlass muss äußerst dürftig gewesen sein. Denn zur Türkensteuer vom 23. Februar I 529 veranlagte die Stadt »Öttingers Erben« mit nur zwölf Kreuzern. Damit gehörten sie zu den $18 \%$ der Einwohner, die am geringsten belastet wurden. ${ }^{419}$

Um die Nachfolge Öttingers bewarben sich Jorig Eberl, Barbier aus Schwaz, und Hans Kentler, der eine "fürschrift « Sigmund Fiegers vorlegte. ${ }^{420}$ Die Intervention des angesehenen Schwazer Großgewerken Fieger und anderer fruchtete. Kentler erhielt das Bad ab Weihnachten I 523 (s.u.).

\subsubsection{Das Maibad}

Da es für Rattenberg im ı6. Jahrhundert keine literarischen Zeugnisse wie Chroniken, Memoiren, Tagebuchnotizen, Reisebeschreibungen gibt, die über das Alltagsleben der Bewohner unterrichten könnten, ist man auf offizielles Schrifttum wie Urkunden, Ratsprotokolle, Regierungserlässe und Rechnungen verschiedener Provenienz angewiesen. Es liegt im Charakter solcher Dokumente, dass sie äußerst selten Einblicke in das wirkliche Leben einer Stadt gewähren, es sei denn, ein Bewohner hätte sich auf die eine oder andere Art vergangen und sei deswegen gerügt oder bestraft worden. Hin und wieder fällt dann doch einmal etwas für die Alltags- und Festtagsgeschichte ab. So auch für Rattenberg im Jahr I 523, als Heinrich Öttinger noch lebte. Der städtische Baumeister notierte damals in seiner Rechnung, er habe in der Woche Quasimodogeniti ( 2 2.-I 8. April) »das vorheusl im pad zum Mayen pad ausgemacht und zugericht «. ${ }^{421}$

Maibäder sind nie Schwitzbäder, sondern immer Wasserbäder, gleich ob sie an einem Kurort, im Freien, in der Badstube oder im eigenen Haus genommen wurden. Sie fanden im Mai (namentlich in der Walpurgisnacht) oder sonst im Frühling statt und sind vielfach für die Schweiz und Deutschland, besonders Süddeutschland bezeugt. Für Tirol gibt es bislang meines Wissens keinen Nachweis für ein Maienbad in der Badstube. Man bringt diese Bäder mit dem Volksglauben, mit der wieder erwachenden Natur seien im Mai die naturwarmen oder erwärmten Quellwasser am heilkräftigsten, in Verbindung. Davon profitierten besonders jene öffentlichen Badstuben in Süddeutschland und der Schweiz, deren Brunnenbecken aus Quellen, die als heilkräftig galten, gespeist wurden.

Das warme Wasser in der Wanne, die »oben wol bedeckt" sein konnte (Baderof), wurde häufig mit guten, frischen Frühlingskräutern angereichert. Neben der Gesundheit kam auch der Magen nicht zu kurz, wenn nicht überhaupt das Essen und Trinken 


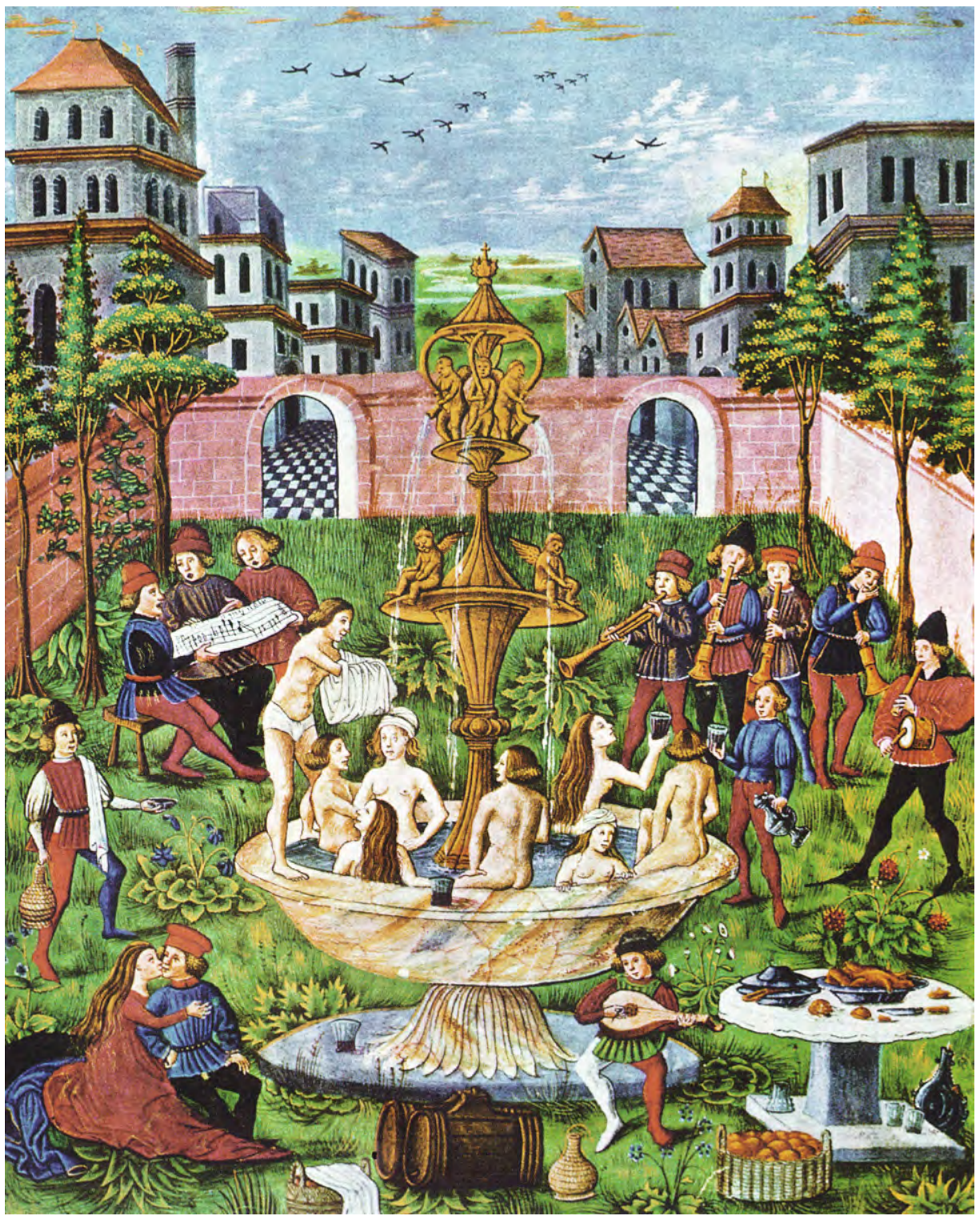

Abb. 6o: Badeszene in einem italienischen Garten; Miniatur aus Johannes de Sacroboscos »De Sphaera«, um 1470 . 
im Zuber das größte Vergnügen beim Maienbad war. Holzschnitte und Stiche des I6. Jahrhunderts zeigen in der Regel Mann und Frau, wie sie zusammen im Wasser sitzen und am quer über die Wanne gelegten Brett fröhlich schmausen und zechen. Walter Ryff behauptet in seiner »Badenfart«, man müsse zum »lieplichen Mayen Badt» Regenwasser in die Wanne füllen, das besser als Brunnen- und fließendes Wasser wirke, weil es reiner und subtiler sei, die Wärme des Sonnenscheins, den starken Einfluss und die schädliche Kraft des Gestirns verändert und gemildert habe. ${ }^{422}$ Wenn Herr Ryff wirklich diesen astrologischen Unsinn geglaubt hat, dürfte er häufiger in einer Wanne mit Regenwasser gesessen sein.

Aus der Tatsache, dass der Rattenberger Baumeister den Vorraum zum Maienbad in der Badstube Mitte April herrichtete, kann man schließen, dass es sich um ein Bad zum I. Mai (Walpurgisnacht) gehandelt haben dürfte. Man darf sicher sein, dass es dann fröhlich herging, mit Reden, Essen und Trinken, vielleicht auch mit »Venusdienst «. ${ }^{423}$

\subsection{Gabriel Freytag}

Er ist, wie bereits vermerkt, vom Rat zu Michaelis I 5 ro in der Nachfolge Heinrich Öttingers als neuer Bader aufgenommen worden, hat von ihm Zuber und Badgeschirr gekauft und ist von der Stadt mit zwei Kupferkesseln, einem Gitterfenster, großen Kessel und Eichentrog versehen worden. Es war nicht sein erstes Amt in der Stadt. Bereits von $1496^{424}$ bis 1503 war er Klosterbader. Seine Abrechnung mit dem Konvent am I . Januar I 504 ergab einen Dienst von sieben Jahren und einem Quartal (»angaria«), wofür er jährlich zwei Star Weizen und I 3 Pfund, die letzten beiden Jahre ${ }_{5}$ Pfund Berner erhielt. Sein gesamter Lohn von neun Mark und fünf Pfund wurde mit Holzfuhren (I 8 Pfund) ${ }^{425}$ und mit den Zinsen verrechnet, die er den Augustinermönchen für drei Grundstücke schuldete. ${ }^{426}$

Kaum in Rattenberg, nahm Freytag den Dienst bei den Augustinermönchen zu fünf Gulden jährlich wieder auf. I5 I3 rechnete er mit ihnen den Lohn für drei Jahre weniger einen Quatember ab. Der Gesamtbetrag von sechs Mark acht Pfund wurde mit dem Holz verrechnet, das vom Kloster bzw. seinem Knecht zum Bad gefahren worden war. Man vereinbarte neuerlich einen Jahreslohn von fünf Gulden zuzüglich zwei Star Weizen und einen Star Gerste und dass ihm das Kloster weiterhin das Holz zum Bad fahren solle, jeweils zwei Fuder zu fünf Kreuzern. ${ }^{427}$

Die üblichen r6 Gulden Jahressold wurden ihm für das Stadtbad in unterschiedlichen Raten ausgezahlt, ${ }^{428}$ während er selbst der Stadt drei Mark Darlehen ${ }_{5}$ I I zurückerstattete. ${ }^{429}$ Für die Ausbesserung des Ziehbrunnens bewilligte ihm der Rat zwei Mark, ${ }^{430}$ für die Behandlung eines Verwundeten sieben Gulden. ${ }^{431}$ Während ihn die Ratsherren noch I 5 I I gegen einen Badknecht namens Stefan unterstützten, indem 
Abb. 6I: Satan schlägt Job mit Aussatz; Miniatur aus einem französischen Stundenbuch, I500.

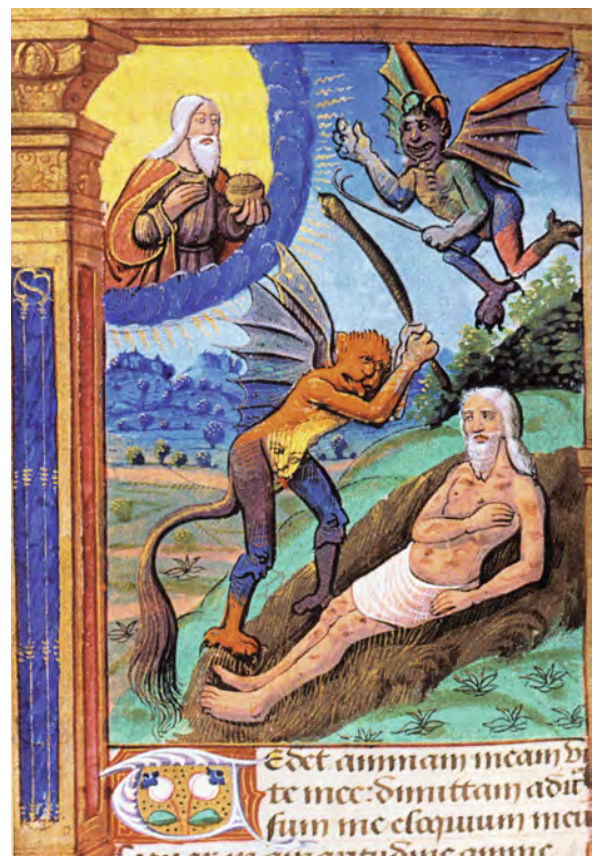

sie ihn aufforderten, »das er furter ny mer dem pader hie zu nachtayl steurn [stören] unnd arbaiten solt« ${ }^{432}$ fanden sie am Dreikönigstag I 5 I 3 bei der Neubestellung auch an ihm etwas auszusetzen. Freytag wurde aufgefordert, fleißig darauf zu achten, dass »die prechenhaftign leut nit in das pad gelassen werden«, außerdem solle er ehrbare und "gut kundig" Gesellen halten und das Bad »reichen und armen wol warten $«{ }^{433}$ Die Gewandhüterin und Reiberin, die ihm offensichtlich nicht »zu gefallen« dienten, durfte er gegen andere Frauen austauschen. ${ }^{434}$

Als der Rat im Oktober I 5 I 3 erfuhr, dass Meister Gabriel sich in Brixen ${ }^{435}$ ein anderes Bad, das er durch seine Leute mit dem Rattenberger Bad versehen ließ, gekauft hatte, befürchteten die Herren Nachteile für ihre Stadt, weil Freytag ständig hin- und herreiste. Deshalb entsprachen sie der Bitte Heinrich Öttingers, ihm das Bad am Inn zu überlassen, und sagten es ihm zur kommenden Fastenzeit zu. Gabriel sollte rechtzeitig gekündigt werden. ${ }^{436}$ Gabriel wurde am Dreikönigstag I 5 I 4 gekündigt, mit der Auflage, noch drei Wochen nach der Fastenquatember zu dienen. Zuber und Badgeschirr solle sein Nachfolger Öttinger von ihm kaufen, wie er seinerzeit die Geräte von Öttinger erworben habe. ${ }^{437}$ Nach seiner Aufstellung hatte Gabriel Freytag noch Forderungen an die Stadt, die ihm am 3 1 . März I 5 I 4 mit drei Gulden abgegolten wurden. ${ }^{438}$ Als man von ihm bei dieser Gelegenheit eine Quittung verlangte, gestand er verlegen, »er künne selb nit schreiben ${ }^{439}$ 
Das wirft natürlich die Frage nach der Bildung der Bader zu dieser Zeit auf, die sich mangels Quellen nicht beantworten lässt, zumindest nicht für Rattenberg. Freytag war offenbar weit entfernt von den höheren Ansprüchen, die man im I8., ja schon im I 7. Jahrhundert an die Bader und Wundärzte stellte (s.o.), er hatte ziemlich sicher auch nicht das Bildungsniveau des Haller Baders und Wundarztes Melchior Schlögl, der Ende I570 ein wohl ausgestattetes Bad mit Wannen, Schaffen, umfangreichem Handwerkszeug, Arzneien und acht Büchern, darunter das »Feldbuch der Wundarznei« des Hans von Gersdorff, hinterließ. ${ }^{440}$ Ende des I6. Jahrhunderts war vermutlich ein schreibunkundiger Bader wie Freytag schon seltener anzutreffen. ${ }^{441}$ Trotz zweier Bäder scheint er nicht in Geld geschwommen zu sein. Denn die Kammer ließ ihm I 5 I 4 eine Schuld von I 3 Gulden nach, die noch für Holz, das der Bader vom Hüttenwerk gekauft hatte, bestand. ${ }^{442}$

\subsubsection{Krankheiten}

Obgleich im Mittelalter und in der frühen Neuzeit Bakterien, Viren und Tröpfcheninfektion nicht bekannt waren, wusste man sehr wohl, dass an öffentlichen Orten, besonders in der Badstube, die Gefahr lauerte, sich mit unangenehmen, ja gefährlichen Hautkrankheiten anzustecken. Dabei ging es nicht um mehr oder weniger harmlose Ausschläge wie Blasen, Knoten, Schuppen, Flechten, Röteln, sondern zur Hauptsache um vier schwere Leiden. Guarinonius zählt solche »mildte Gaben«, die einer ins Bad schleppt und »den andern Mitbadenden mittheilet«, auf: starke Räude (Krätze), schorfiger Aussatz, Franzosen (Syphilis) im Anfangsstadium und schmierige Geschwüre. ${ }^{443}$

Während die Lepra seit dem I6. Jahrhundert verschwand, ${ }^{444}$ war es sicher für jeden unangenehm, ja ekelhaft, wenn in der Badestube neben ihm oder ihr Männer oder Frauen saßen, die sich an der durch Milben verursachten Krätze blutig gekratzt hatten oder mit Borken übersät waren, ${ }^{445}$ die schwärende, offene Wunden oder eitrige Geschwüre zeigten. Aber so richtig gefürchtet hat man sich vor der Syphilis, die kurz vor I 500 ihren Siegeszug durch Europa nahm. Da sie lange währte und zu abstoßenden Hautausschlägen, die unter üblem Gestank aufbrachen, und heftigen Knochenschmerzen führte, ängstigte man sich vor ihr mehr als vor der Pest, die einen wenigstens schnell dahinraffte, oder man wurde wieder gesund. Und der stinkende Atem der Syphilitiker machte sie auch nicht gerade den Mitmenschen angenehmer. ${ }^{446}$

Verfügungen der Obrigkeiten, Kranken den Zutritt zu Bädern zu verwehren, betrafen fast immer, wenn die Verbote ins Detail gingen, die Französische oder Gallische Krankheit, die bösen Pocken, die schwarze Krätze, den Mal de Naples oder wie man sonst die Syphilis nannte. Das Trinken eines Suds aus tropischem Guajakholz als Gegenmittel war teuer und wenig hilfreich, das Einschmieren mit Quecksilbersalbe 
Abb. 62:An einer

Infektionskrankheit leidende

Mönche werden gesegnet;

Miniatur aus der 2. Hälfte des I4. Jh.

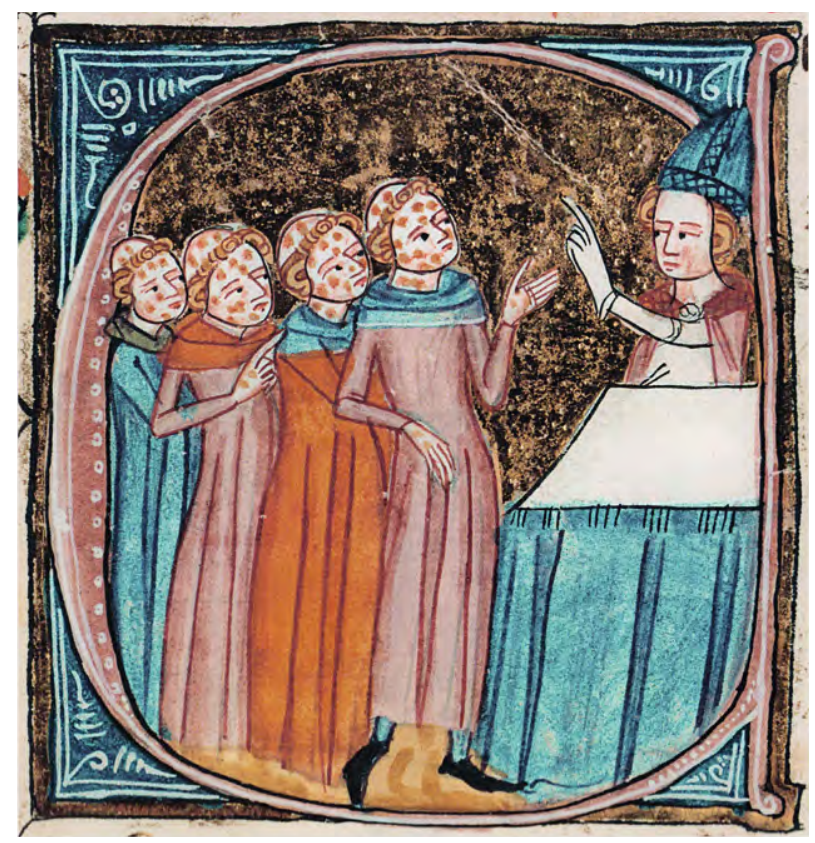

äußerst gefährlich, nicht selten tödlich (Quecksilbervergiftung). Wer mit Zahnausfall, Atemnot, Sprachstörungen davon kam, konnte sich glücklich schätzen. ${ }^{447}$

Eines der bekanntesten Opfer der Syphilis wurde der Humanist Ulrich von Hutten, der elf Quecksilberkuren über sich ergehen ließ, den hochgelobten Sud des Guajakholzes trank und trotzdem I 523 elendiglich an den Franzosen starb, wie drei Bauern, die sich mit ihm hatten schmieren lassen. In seinem Traktat »Über die gallische Krankheit« ( 5 I9) beschrieb er, wie es einem Kranken ging, nachdem er eingerieben war und neben einem heißen Ofen stark schwitzen musste:

Die Wirkung der Salbe war so stark, dass sie die Krankheit von der Oberfläche des Körpers in die Eingeweide trieb [...], in fast allen Fällen wurden Rachen, Zunge und Gaumen zu einem einzigen Geschwür, das Zahnfleisch geschwollen, die Zähne gelockert, und der ununterbrochene Speichelfluss von einem Gestank, schlimmer als ein faulendes Aas [...] Diese Art der Behandlung war so grausam, dass viele es vorzogen, eher zu sterben, als auf diese Weise kuriert zu werden ${ }^{4}{ }^{448}$

Erasmus, der den todkranken Hutten gesehen hatte, war vor dem »lebenden Leichnam« erschrocken. ${ }^{449}$ 




Abb. 63: Arzt mit Uringlas, Wundarzt bestreicht einen Syphiliskranken mit Quecksilbersalbe; kolorierter Holzschnitt aus Bartholomaeus Stebers "A malafranczos morbo Gallorum praeservatio ac cura«, 1498 .

Schon 1496 gebot Nürnberg unter Androhung einer Strafe von zehn Gulden seinen Badern, dass von ihnen »die menschen, die an der Newen krankhait malum Frantzosen beflekt oder krank sein, in iren paden nicht gepadet« werden, und dass die Bader Eisen und Messer, die sie zum Aderlassen und Rasieren solcher Kranker verwendet hätten, danach nicht mehr in den Badstuben gebrauchen dürften. ${ }^{450}$ Auch anderswo, z.B. in der Schweiz, verbot man Syphilitikern und allen mit ekelhaften Hautkrankheiten Behafteten den Besuch öffentlicher Bäder oder sonderte sie in eigene Abteilungen bzw. Stuben ab. ${ }^{451}$ Zwar erkannte schon 1499 der Humanist Jakob Wimpfeling und I 500 der päpstliche Leibarzt Torrella, dass die Infektion über den Geschlechtsverkehr (mit Dirnen) erfolgte, ${ }^{452}$ doch setzte sich erst Mitte des I6. Jahrhunderts allgemein die Ansicht durch, Syphilis werde durch Sexualkontakte verbreitet. ${ }^{453}$

Der Rattenberger Rat zeigte sich anfänglich hart gegenüber »schadhaften « ${ }^{454}$ Leuten im Bad, wurde aber später nachsichtiger. Während er noch I 5 I 3 dem Bader Gabriel Freytag gebot, keine bresthaften Leute im Bad zu dulden, ${ }^{455}$ schrieb er I 549 Meister Matheus Paumgartner vor, schadhafte Leute zur gewöhnlichen Zeit baden zu lassen, sie aber nach hinten zu setzen. ${ }^{456}$ Bei seinem Nachfolger Hans Fäler d. Ä. heißt es I 55 o, der Meister solle die kranken Leute, die schadhaft seien, nicht zuerst drannehmen. ${ }^{457}$ An seinem Sohn Hans Fäler d. J. bemängelte $5_{578}$ der Rat, dass er in der Badstube die schadhaften Leute neben und unter die anderen [Gesunden] setze. ${ }^{458}$ Rücksichtsvolle Leute wie Wolfgang Topf, seit I 5 I 9 Prior des örtlichen Augustinerklosters, der seine 
Brüder nicht anstecken wollte, waren selten. Er litt anscheinend an einer Hautkrankheit und wagte deshalb drei Jahre lang nicht, den Wärme- und Baderaum des Klosters zu betreten, sondern ließ sich separat rasieren. ${ }^{459}$ Die stumme Magd Ursula des Klosters hat es allerdings schwerer getroffen. Sie litt an der Gallischen Krankheit und wurde vom Mesner zu Mehrn (bei Brixlegg) medizinisch behandelt, ${ }^{460}$ wohl mit der berüchtigten Schmierkur.

Bürgermeister und Rat reagierten überaus vorsichtig, sobald nur der entfernteste Verdacht auf Syphilis bestand. Im April I 524 kündigten sie dem Meister Hans Kentler, weil er nicht zum Baderberuf taugte, aber noch aus einem anderen Grund. Die Herren hatten anscheinend vernommen, dass »ain knabe und villeicht er selbst auch mit der kranckhait Mala franzosa beladen sollt sein«. ${ }^{461}$

Wenn Kentler wirklich die Syphilis hatte, dürfte er sich bei der Behandlung eines seiner Badegäste oder Patienten angesteckt haben. Das war eben das Berufsrisiko eines Baders und Wundarztes, dem I 549 der Rattenberger Bader Matheus Paungartner erlag. In der Erbauseinandersetzung (April I 549) zwischen seiner Witwe und den drei verheirateten Schwestern des Verstorbenen erfährt man, dass "maister Matheus in der salbn gelegen [ist] an den frantzosen«. Wenn es nach den drei habgierigen Schwestern, die sich um ihn in seiner Krankheit

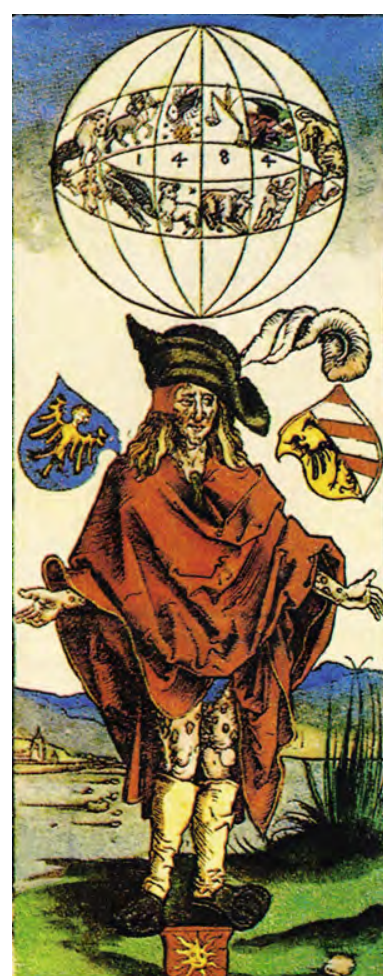

Abb. 64: Syphiliskranker; kolorierter Holzschnitt Albrecht Dürers zu einem Flugblatt des Nürnberger Stadtarztes Th. Ulsen über die Syphilis, 1496 . nicht gekümmert hatten, gegangen wäre, hätte der selige

Meister Matheus an der Franzosenkrankheit "muessn erfauln«. Nur die Witwe habe sich um ihn gekümmert, entrüstete sich ihr Rechtsbeistand. ${ }^{462}$ Demnach scheint die Quecksilberkur erfolglos geblieben zu sein und Paungartner könnte schwer unter der Syphilis gelitten haben, so schwer, dass er vielleicht den Freitod im Inn gesucht hat. Denn er ist ertrunken und seine Leiche war beim Erbvertrag noch nicht gefunden. ${ }^{463}$ Das lange Siechtum und die heftigen Knochenschmerzen haben so manche verzweifelte Syphiliskranke dazu getrieben, aus dem Fenster oder in einen tiefen Brunnen zu springen. ${ }^{464}$

I 552 gebot der Rat dem erwähnten Hans Fäler, Leute, die die Franzosen oder eine andere gefährliche Krankheit hätten, nicht aufzunehmen, um andere damit nicht anzustecken. $^{465}$ 


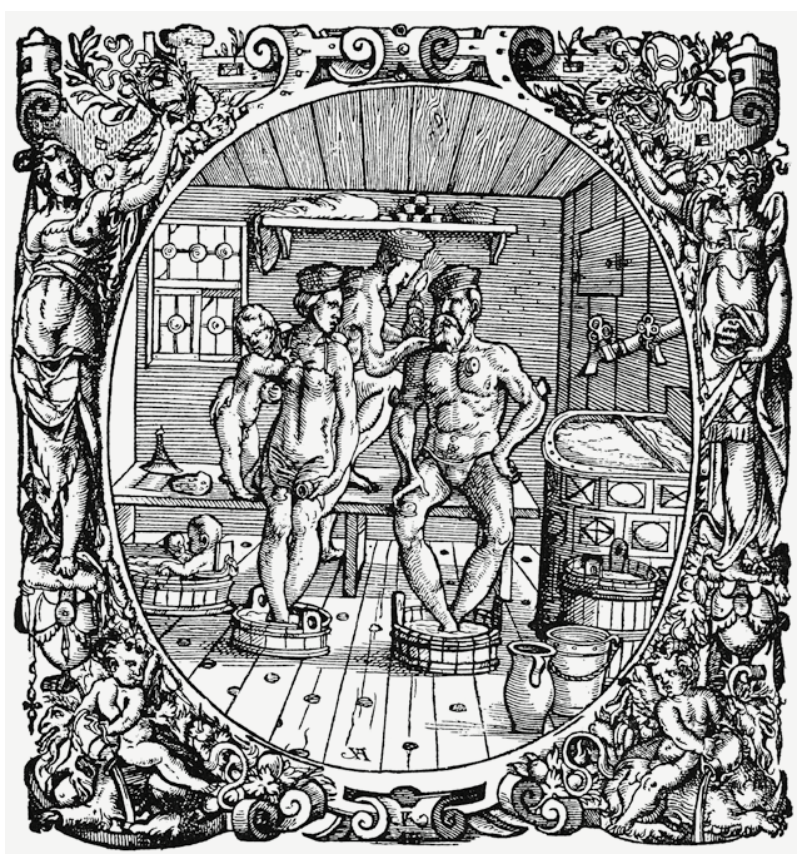

Abb. 65: Badestube; Holzschnitt von Jost Amman aus dem "Wund- und Artzney Bucbu des Paracelsus, Frankfurt/M. ${ }_{15} 65$-Titelholzschnitt zum »Bäderbüchlein«.

\subsection{Hans Kentler}

Auf ein Empfehlungsschreiben des reichen Herrn Sigmund Fieger, des Herrn Christof Philipp von Liechtenstein, Hauptmanns zu Rattenberg, und des Christof Fuchs von Fuchsberg hin bestellte ihn der Rat zum Bader ab Weihnachten I 523. ${ }^{466}$ Die Herren hätten sich das überlegen sollen. Kentler ist im behandelten Zeitraum der einzige Bader, dem man wegen Unfähigkeit den Stuhl vor die Tür gesetzt hat. Schon nach einem Vierteljahr, im März I 524, hielt der Rat Meister Hans vor, »er selbs [sei] zu solchm padwerch nicht geschickt und kundig«. Deswegen solle er sich schleunigst wieder zwei gute Knechte besorgen, nachdem seine Frau seine zwei besten Knechte ${ }^{467}$ verjagt habe. Versähen er und die Seinen das Bad nicht besser als bisher und hätte man über ihn zu klagen, werde man ihm zu Pfingsten kündigen und zu Michaelis müsse er dann gehen. ${ }^{468}$ Einen Monat später riss dem Rat die Geduld. Weil Kentler sich nach wie vor als untauglich für den Baderberuf erwies, er und ein Knabe außerdem die Syphilis haben sollten, wurde er beurlaubt und ihm mitgeteilt, dass er zu Michaelis das Bad zu räumen habe und sich nach einer neuen Stelle umsehen solle. ${ }^{469}$

Damit war für Meister Hans die Sache gelaufen. Ende September erhielt er seinen ganzen Jahressold von I6 Gulden, obwohl ein Quartal fehlte. Aber da er dem Rat 
vorgejammert hatte, dass er gar »so eilend von dem pad entseczt« worden sei, schenkte man ihm gnadenhalber vier Gulden. ${ }^{470}$ Das Augustinerkloster allerdings, für das er auch tätig geworden war, bezahlte ihm zu Michaelis I 524 nur drei Quatember. ${ }^{471}$

Aus seiner kurzen Dienstzeit ist nur ein Ereignis bekannt geworden, das aber sehr aufschlussreich ist. Mitte Juni bat Hans Kentler den Rat, man möge ihm ein Bad in der Woche erlassen. Weil die Brücke ${ }^{472}$ durch ein Getreideschiff beschädigt worden sei, entstünden ihm jetzt hohe Kosten, um das Holz zum Bad zu bringen. Der Rat bewilligte ihm, er dürfe bis auf Jacobi (25. Juli) das Bad am Montag ausfallen lassen, doch dafür müsse er die Bäder am Mittwoch und Samstag desto besser heizen und versehen. ${ }^{473}$ In Rattenberg wurden also damals noch die für Städte üblichen drei Bäder pro Woche gehalten.

Kentler ließ sich später in Hall nieder, wo er I53 I als Bruchschneider das Bürgerrecht erwarb. ${ }^{474}$ Drei Jahre später schaltete er die Innsbrucker Kammer ein, um Bürgermeister und Rat von Hall aufzufordern, sie sollten als Vormunde von Kentlers Sohn endlich sein Geld, das bei ihnen liege, anlegen. ${ }^{475}$ Vier Jahre später war Hans Kentler zu Hall verschuldet. Auf sein Ansuchen hin befahl die Innsbrucker Kammer Hans Graf, dem Bergrichter zu Hall, er solle die Gläubiger des Bittstellers vor sich fordern und sie dahin bringen, dass sie den nächsten Monat ihre Forderungen auf Bezahlung und die angedrohte Klage auf sein Bergwerksteil ruhen ließen. ${ }^{476}$

\subsection{Michael Hueber d. J.}

Als man Hans Kentler Ende April befahl, Ende September I 524 das Bad zu räumen, hatte der Rat bereits den künftigen Bader parat. Auf sein und mehrerer ehrbarer Leute Bitten hin wiesen die Herren Michel Hueber das Bad zu, auch in Anbetracht »seiner zwaier väter«, die schon früher der Stadt »erlich und wol« als Bader gedient hatten. Hueber wurde aufgetragen, sich in Kürze zu verheiraten, das Bad mit guten Knechten zu versorgen, aber seine Mutter nicht auf das Bad zu nehmen, sondern ihr auf andere Weise Gutes zu tun. ${ }^{477}$ Anscheinend hatte Katherina Öttinger, verwitwete Hueber, zum Schaden des Bades zu stark in die Geschäftsführung eingegriffen, als sie und ihr Sohn Michael von Juli bis Weihnachten I 523 den Betrieb geleitet hatten. Möglicherweise war sie aber in dieser Hinsicht auch schon zu Lebzeiten ihres zweiten Mannes als herrische Person ungut aufgefallen.

Während es zu Heiligdreikönige I 525 nur lakonisch heißt, Michel Hueber sei aufs Neue, unter vierteljährlicher Kündigungsfrist seitens der Stadt, zum Bader bestellt worden, ${ }^{478}$ schrieb man ihm I 528 bei der Ämterbesetzung vor, er solle samstags seine Knechte im Bad behalten, um »ainer gemain ausczewarten «. ${ }^{479}$ Sie hatten nämlich inzwischen, und der Bader mit ihnen, eine Möglichkeit gefunden, anderswo 
mehr Geld zu verdienen (s.u.). Um seiner Verdienste für die Stadt willen und in Anbetracht dessen, dass sein Vater selig auch Inwohner gewesen sei, hatte der Rat ihm schon das Inwohnerrecht verliehen. ${ }^{480}$ Michael Hueber d.J. erhielt den üblichen Jahressold von I 6 Gulden. ${ }^{481}$ I 527 teilte ihm der Rat mit der Peter Holtzmanin eine neue Reiberin zu, zunächst probeweise auf ein Vierteljahr. ${ }^{482}$ Weil ein Verunglückter in städtischen Diensten stand, erfährt man auch etwas von Hubers Tätigkeit als Wundarzt. ${ }^{483}$

Als ihm im Oktober I 527 ein »Knab« (Lehrjunge) gestorben war, geriet der Rat in Aufregung, da er eine Infektionskrankheit befürchtete. Auf Befragen erklärte der Bader, er wisse nicht, woran der Junge gestorben sei. Er habe ihn beschauen lassen, doch habe man an ihm nichts Verdächtiges feststellen können. Von seinen Knechten habe er gehört, der Knabe sei, als er in einer »tesen« (Blechkasten) Asche habe forttragen wollen, in die Asche gestürzt, worauf er eine Zeit lang Blut gespien habe. Aus Vorsicht ließ der Rat das Bad acht Tage nicht beheizen und für den Besuch sperren. ${ }^{484}$

Die Angst des Rates war nicht unbegründet, herrschte doch seit Herbst 1526 eine Seuche im Umkreis der Stadt, weshalb man am I 5. Oktober dieses Jahres gegen einen Gulden Wochenlohn mit Kuntz (Conrad) Stolz (Stoltz) aus Kramsach einen eigenen Totenlässl angestellt hatte, der das untere Stübl im Pfarrhof als Wohnung bekam. ${ }^{485}$ Den Stadtbader Huber wollte der Rat nicht der Gefahr, sich zu infizieren, aussetzen. Da sich die Seuche hinzog, wurde zwar später dem Totenlässl gekündigt und er auf Wartegeld gesetzt, doch letztlich bis ${ }_{5} 528$ behalten. ${ }^{486}$ Auf seine Bitte hin wurde Conrad Stolz im September 1527 zum Inwohner von Rattenberg aufgenommen. Wegen seiner treuen Dienste in den »sterbenden leuffen« erließ man ihm die Aufnahmegebühr, doch untersagte man ihm gleichzeitig, in der Stadt eine Barbierstube zu errichten. Außerhalb Rattenbergs als "palbierer", Aderlasser und Wundarzt tätig zu sein wurde ihm erlaubt. ${ }^{487}$ Die Augustiner sicherten sich schon am 5. Oktober ${ }_{5} 526$ die Dienste des Baders Kunz Stolz im Falle eines Seuchenkranken im Kloster. ${ }^{488}$

Ansonsten war Michael Hueber der Klosterbader gegen den üblichen Sold von fünf Gulden jährlich zuzüglich zwei Star Gerste ${ }^{489}$ oder sein Lohn wurde mit Forderungen bzw. Aufwendungen des Klosters für ihn verrechnet. ${ }^{490}$ Wenn man die aufgewendete Arbeit des Baders für ein ganzes Jahr berücksichtigt, ist das nicht viel. Das Kloster zählte nämlich damals I 8 Leute: einen Prior, fünf Mönche, zehn Dienstboten (Knechte, Mägde, Köchin) und zwei Schüler. ${ }^{491}$ In der Zeit der Seuche vermieden die Mönche jede Ansteckungsgefahr. Deshalb kauften sie schon im November ${ }_{5} 26$ vom Bader Michael zwei Schermesser und vier Lasseisen, die er offensichtlich nur für Klosterangehörige verwendete. ${ }^{492}$ Das Rechnungsbuch des Konvents ist es auch, das uns die eine oder andere Auskunft über seine medizinische Tätigkeit gibt. I 527 behandelte er den Klosterknecht Bernhard, irgendwelche Kranken im Kloster und lieferte um einen Gulden Latwerg, ${ }^{493}$ I 529 bekam er fünf Pfund, 


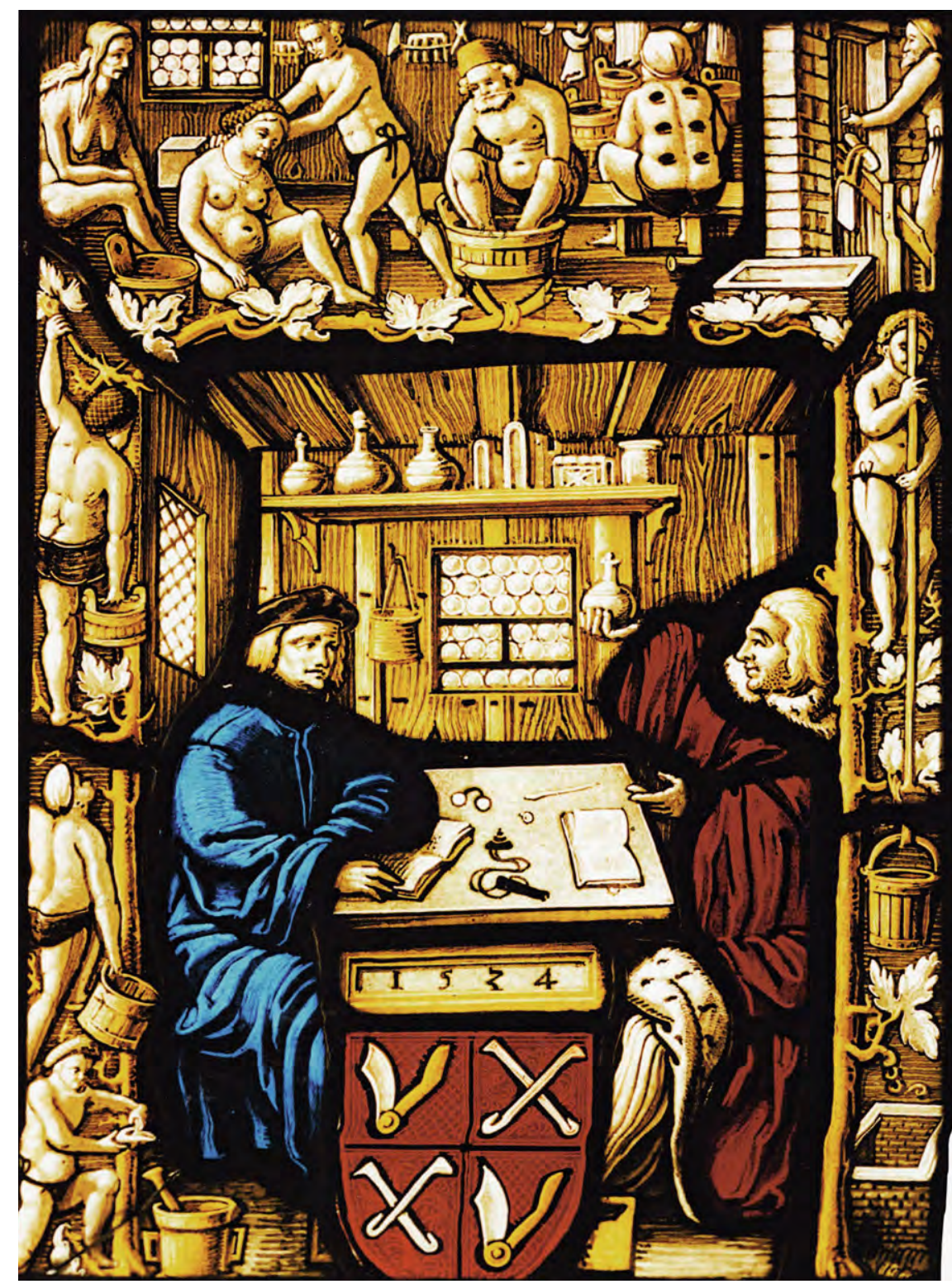

Abb. 66: Zwei Wundärzte/Bader mit Zunftwappen (geviert, I u. 4: Schermesser, 2 u. 3: schräggekreuztes Schröpf- und Lasseisen), umrahmt von Badeszenen (links und rechts Wasser holende Badeknechte und - magd, links unten ein Bader, der seine Lampe mit Öl füllt, oben ein Mann mit Schröpfköpfen, ein anderer nimmt ein Fußbad, eine Frau wird gerieben; Glasscheibe der "Gesellschaft zum Schwarzen Garten", in der die Zürcher Bader und Barbiere organisiert waren, 1534. 
weil er erkrankte Brüder gebadet hatte, ${ }^{494}$ und wenn I 528 seine Magd vier Kreuzer von den Fratres erhielt, könnte sie eine Salbe, Pflaster oder Ähnliches gebracht haben. ${ }^{495}$ Hueber nahm auch wie andere Bader die Fuhrdienste des Klosters (vermutlich für Holz) in Anspruch. ${ }^{496}$

Neben der lange währenden Seuche fiel noch ein zweites bedeutendes Ereignis in die Amtszeit des Baders Michael Hueber, die Verfolgung der Täufer. Auch er geriet deswegen in das Visier der Justiz, wie man aus einem Schreiben der Innsbrucker Regierung vom 26. März I 528 an Christof Philipp von Liechtenstein, den Hauptmann von Rattenberg, erfährt. Sollte der Bader Michel Hueber, heißt es, wegen seines Vergehens die Strafe und Buße auf sich nehmen, wie sie ihm die Regierung zu Innsbruck auferlegen werde, und sollte er sich bis kommenden Palmtag (5. April) der Regierung stellen, werde man ihm den Henker ersparen. ${ }^{497}$ Hueber war also flüchtig und vermutlich das Opfer einer falschen Beschuldigung oder Verdächtigung. Denn bereits am 7. April I 528 ließ die Regierung Bartlme Angst, Stadt- und Landrichter zu Rattenberg, wissen, Hueber sei gar nicht bei der Versammlung der Täufer in der Hagau gewesen, sondern habe nur Wiedertäufer beherbergt. Deshalb befehle man, ihn gegen Urfehde zu begnadigen. Die Begnadigung sei nichtig, wenn sich später herausstelle, dass er doch bei der Versammlung gewesen sei. ${ }^{498}$ Das war er offensichtlich nicht. Denn bis zu seinem Tod ist Michael Hueber Bader in Rattenberg und unbehelligt geblieben.

Als er am Dreikönigstag I 529 weiter zum Stadtbader bestellt wurde, geschah das nur unter der Androhung, wenn er sich nicht ändere, werde man ihn durch einen anderen ersetzen, ihm zu künftigem Reminiscere (2 I. Februar) kündigen, wonach er zu Pfingsten das Bad zu räumen habe, weil er seit einiger Zeit "gantz unfleissig« sei, selbs im pad an padtägen nicht arbait und erscheint «. ${ }^{499}$ »Wie der Herr, so’s Gescherr«, das kann man wohl von seinem Personal sagen. Denn am 30. April I 529 forderte der Rat den Bader auf, den Hänsl zu beurlauben, denn man könne weiterhin »sein und seins weibs unenndt nicht gedulden oder leiden $« .{ }^{500}$ Worin das liederliche Treiben des netten Paars bestand, wird nicht gesagt.

Beim nächsten Eintrag im Ratsprotokoll war Michael Hueber schon tot. Wegen der kleinen Kinder, liest man, lasse man der Baderin bis Weihnachten das Bad. In dieser Zeit solle sie sich nach einer Heirat umsehen und prüfen, ob ihr neuer Ehemann zum Badbetrieb tauglich sei. Wenn nicht, solle ihr oder ihm jeden Quatember aufgekündigt werden. ${ }^{501}$ Sie fand einen passenden Bader, nämlich Hans Püchler. Eine Nachricht aus dem Jahr I 546 bezeugt nämlich, dass dessen Frau Wandula die Witwe des Michael Hueber gewesen ist. ${ }^{502}$ Michel Hueber, dann seine Frau wurden zur I. und 2. Türkensteuer $5_{52} 9^{503}$ mit je 30 Kreuzern eingestuft. Damit lagen sie nur knapp unter dem Median von 36 Kreuzern. 
Abb. 67: Mann und Frau im Zuber mit Baderof; Miniatur aus "Li livres dou santé« des Aldobrandino da Siena, I3.Jh.

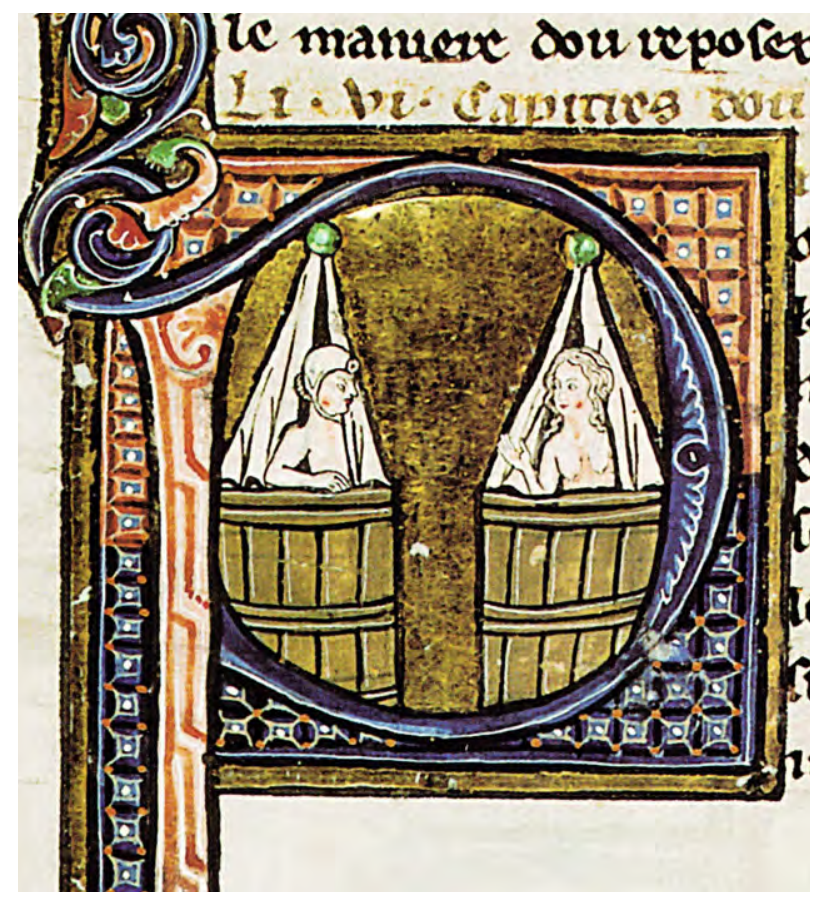

\subsubsection{Private Bäder}

Wenn der Rat I528 und I 529 Michael Hueber gebot, er solle dafür sorgen, dass samstags genügend Knechte zum Aufwarten der Badegäste zur Verfügung stünden, und ihm vorhielt, er selbst erscheine an den Badetagen nicht zum Arbeiten im Bad (s.o.), so ist das reine Scheinheiligkeit. Denn es waren gerade die Ratsherren und besseren Leute in der Stadt und Umgebung, welche den Bader und die Badknechte am Samstag für sich beanspruchten. Die Klagen über mangelnde Versorgung am Samstag müssen derart zugenommen haben, dass sie der Rat nicht mehr wie früher ignorieren konnte.

Im September I 523 nämlich hatte sich schon der Bäcker Michel Gartner mit hitzigen Worten unter anderem darüber beschwert, dass im Bad am Samstag, wenn der gemeine Mann baden gehe, »ain pöse pollucei« (Ordnung) gehalten werde. Die Knechte seien dann bei den Herren (= Rat) und dem gemeinen Mann werde nicht »ausgewart«. Der Rat lud Gartner vor, er musste für seine unbesonnenen Worte um Entschuldigung bitten, blieb aber dabei, dass alles, was er über den Mangel an Knechten im Samstagbad geredet habe, der Wahrheit entspreche. Weil sie die Herren bedienen müssten, könne dem 


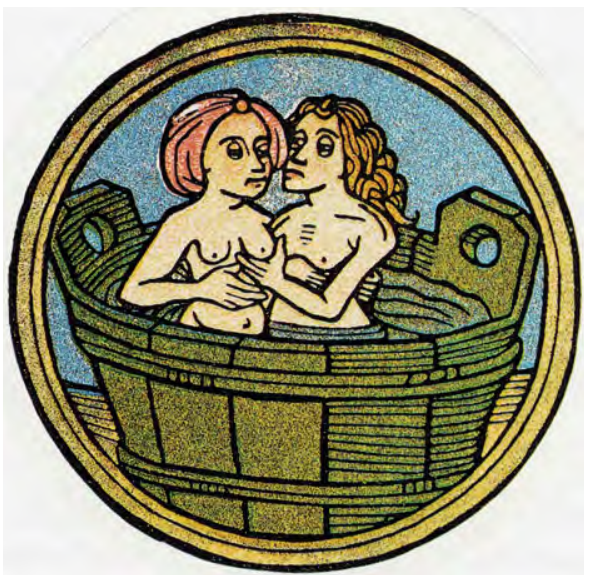

Abb. 68: Paar in einer Wanne; kolorierter

Titelholzschnitt eines Kalenders aus dem I6. Jh.

gemeinen Mann nicht aufgewartet werden. Das Ende vom Lied: Gartner wurde auf ein Tor geschafft und musste geloben, hinfort »ungegrünte wort « zu unterlassen. ${ }^{504}$

Wie begründet seine Worte waren, zeigte der Rat selbst, als er I 547 dem neuen Bader Matheus Paumgartner vorschrieb, er dürfe samstags keinem Herren oder anderen inner- und außerhalb der Stadt seine eigenen Knechte für ihr Bad überlassen oder gar sich selbst dafür hergeben. ${ }^{505}$ I 550 wiesen die Ratsherren den Badermeister Hans Fäler an, an Badetagen, besonders am Samstag, im Bad anwesend zu sein. ${ }^{506}$

Was schon früher über die Badezimmer im eigenen Haus in der frühen Neuzeit gesagt wurde, gilt auch hier. Kaum jemand besaß ein solches, schon gar nicht in einer Kleinstadt wie Rattenberg. Lediglich ein Mann wie der reiche, geadelte Hüttenmeister Ambrosi Mornauer von Lichtenwert, dessen großes Rattenberger Haus an die 20 Räume zählte, ${ }^{507}$ hätte sich ein eigenes Badezimmer leisten können ${ }^{508}$ oder sein Sohn Wolf Joseph, der dabei allerdings beim Rat aus Sicherheitsgründen auf Widerstand stieß. Als er im Juni ${ }_{5} 47$ in einem Turm des Zwingers ein Bad errichten wollte, wobei er die Schießlücke hätte vermauern und Fenster ausbrechen müssen, verweigerte der Rat die Zustimmung und ließ ihm anzeigen, vom Bau abzusehen. ${ }^{509}$ Sonst ist nur von der alten Silberbrennerin Ursula Khuen, einer flüchtigen Täuferin, bekannt, dass sie I 530 in Rattenberg eine Behausung mit Hofstatt, Garten, Bad und Stallung besaß. ${ }^{510}$ Wenn die Ratsherren die Bedienung der städtischen Badeknechte im eigenen Haus brauchten, wird es sich um ein Bad im Zuber, durch Baderof zum Schwitzbad gemacht, gehandelt haben. Die Badewanne wird wie üblich im Wohn- oder Schlafzimmer aufgestellt worden sein.

Die begüterten Rattenberger kauften sich gern einen Garten im Umkreis der Stadt, in dem oft ein typisches Bauernbadl stand. Die I 544 gestorbene Margret Marpeck, 
Tochter des Täuferführers Pilgram Marpeck und Ehefrau des Metzgers Jacob Stetner, besaß einen Garten mit Badhäusl, ${ }^{511}$ I 547 erwarb der Kaufmann Jeronime Arba, genannt Walch, vor der Stadt einen Garten samt darin stehendem Badl, ${ }^{512}$ I 548 verkaufte der Kupferschmied Simon Heiligmair einen Garten vor der Stadt mit Stadl und Stadlbad ${ }^{513}$ und im selben Jahr kaufte der Wirt Lienhart Sumer vom Wirt und Lädler Martin Arba einen Garten mit Stadl und Stadlbad. ${ }^{514}$

Die Herrschaften ließen sich, wenn sie im Zuber zu Hause oder im Stadlbad saßen, gern von kundigem Personal bedienen, das dann im Bad fehlte. Das fiel besonders schwer am Samstag ins Gewicht, dem beliebtesten Badetag. Den Badern und Badeknechten kann man aber nicht verargen, dass sie den Nebenverdienst suchten. Badgeld $^{515}$ und Sonderbehandlungen wie Haareschneiden, Kopfwaschen, Rasieren, Reiben mit Badequast, Massieren, Abgießen, Waschen, Aderlassen, Schröpfen brachten, abgesehen vom Schröpfen, nur wenige Vierer, also nicht eben viel. Vermutlich sind die Dienste außerhalb der städtischen Badstube, in Häusern oder Gärten, wesentlich großzügiger entlohnt worden, sonst hätten sich die Bader und ihre Knechte nicht so sehr danach gedrängt.

\subsubsection{Das Hochzeitsbad}

Als Michael Hueber Ende April I 524 zum neuen Stadtbader bestimmt wurde, trug ihm der Rat auf, sich in Kürze zu verheiraten. Der junge Mann ließ sich aber gehörig Zeit. Erst im Sommer 1527 lässt ein Eintrag im Rechnungsbuch des Augustinerklosters erkennen, dass er sich verehelicht hatte, vermutlich nicht lange vorher. Mit der Auszahlung seines Jahreslohns von fünf Gulden erhielt er nämlich zusätzlich I 4 Kreuzer »umb dem hochzeit bad.${ }^{516} \mathrm{Da}$ offensichtlich die Tatsache, dass im Rattenberger Badhaus Mai- und Hochzeitsbäder abgehalten wurden, bislang den heimischen Volkskundlern völlig entgangen ist ${ }^{517}$ - das scheint sogar für solche Bäder in ganz Tirol zu gelten -, sei hier etwas näher darauf eingegangen.

Das Hochzeitsbad, auch Brautbad genannt, fand an gewöhnlichen oder besonderen Badetagen, vor oder nach der Hochzeit statt. Das Bad nach der Hochzeit scheint feierlicher gewesen zu sein. Zum Bad begleiteten Männer den Bräutigam, Frauen und Mädchen die Braut. Ihre Zahl wurde beschränkt, in der Regel erlaubte man im I5. Jahrhundert der Braut und dem Bräutigam je zehn oder zwölf Begleiter. Man badete zusammen oder nach Geschlechtern getrennt.

Bei Adligen war der Brautzug zum Bad festlicher und unbeschränkter, wie die Hochzeit des Dietrich von Quitzow mit Elisabeth Schenck von Landsberg am 6. Juli I 394 in Berlin zeigt. Früh am Festtag zogen das Brautpaar und alle zur Hochzeit Geladenen in einem »festlich arrangiertem Zuge« zum Bad »auf dem Krögel«, dem ältesten Badhaus Berlins, voran die Stadtmusik mit Zinken, Schalmeien, Zimbel und Geige, begleitet von 




Abb. 69: Brautbad; Ausschnitt aus dem Kupferstich Darstellungen aus dem Leben einer Frau« des Wenzel Hollar [1607-1677].

der lärmenden Straßenjugend und Spaßmachern, die allerlei Allotria trieben. Alle badeten in den zwei Stuben des Badhauses, nahmen dort im Obergeschoss ein Mahl ein, kehrten danach ins Brauthaus zurück und darauf erfolgte erst der Kirchgang. ${ }^{518}$

Während des Badens oder danach wurde auch sonst wacker getrunken und gespeist, sogar getanzt, nicht immer in wünschenswerter Zucht. In Görlitz musste man I 434 den jungen Gesellen untersagen, wider alle guten Sitten in der Badekappe und »barschenckicht« zu tanzen. Wenn sie tanzen wollten, müssten sie Joppe und Hose anziehen. Das »unordentlich geseüffe« im Hochzeitsbad veranlasste die Obrigkeiten zum Eingreifen. Entweder wurden Essen, Trinken und Tanzen ganz verboten oder beschränkt. Augsburg erlaubte Mitte des I6. Jahrhunderts eine Zeche nach dem Brautbad, aber nur mit I6 Gästen. Görlitz gestattete 1476 nach dem Bad ein einfaches Mahl aus Käse, Brot, Obst mit Wein und Bier im Haus der Brautleute. Badgeld sollte nur der Braut und dem Hausgesinde des Bräutigams gezahlt werden (Nürnberg, Grünberg in Hessen). Der Bader und sein Personal erhielten Speis und Trank, was aber Gerolzhofen I 490 verbot.

Anlässlich eines Hochzeitsbades wurde Badewäsche (Handtücher, Badelaken, -kappen, -hemde, -kleider, Schleier, sogar Gürtel und Schuhe) verschenkt, so reichlich, dass die Zahl der Beschenkten begrenzt werden musste, letztlich auf Braut und Bräutigam, bisweilen noch auf engste Verwandte, manchmal nicht einmal auf diese. Da richtige Luxusartikel verschenkt wurden, setzten die Behörden eine Höchstgrenze für sie fest. 

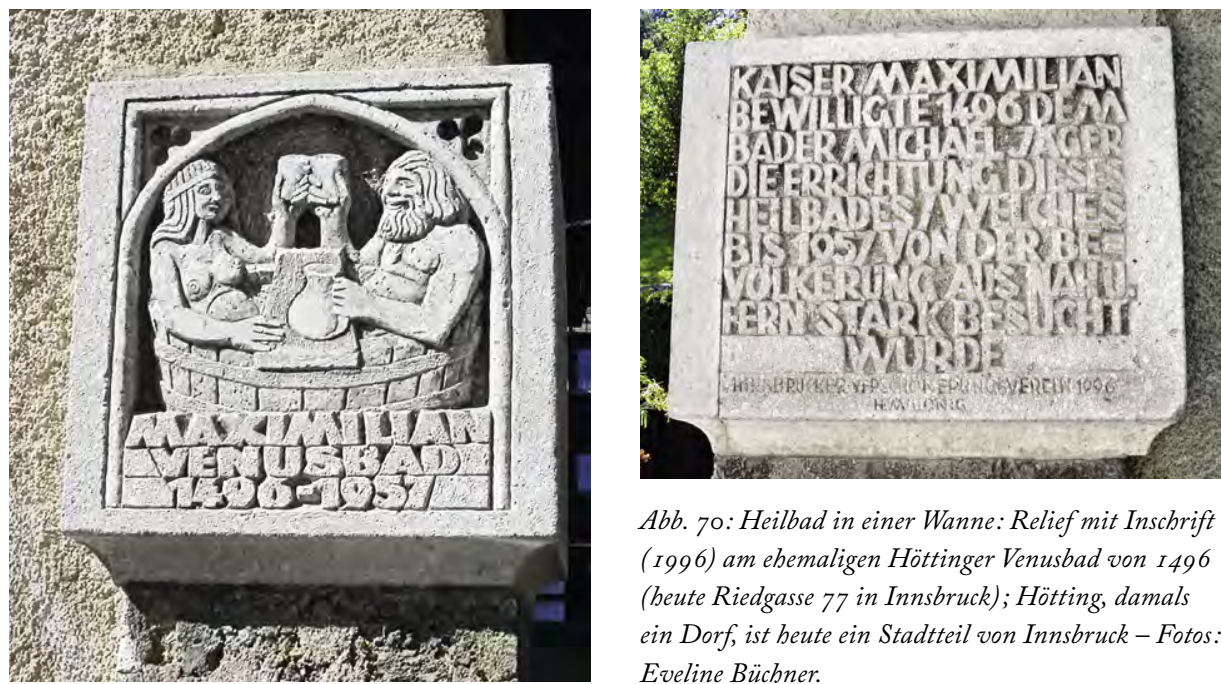

Abb. 7o: Heilbad in einer Wanne: Relief mit Inschrift (1996) am ehemaligen Höttinger Venusbad von 1496 (heute Riedgasse 77 in Innsbruck); Hötting, damals ein Dorf, ist heute ein Stadtteil von Innsbruck - Fotos: Eveline Büchner.

Wollte in Rostock eine Braut ihrem Bräutigam eine Badekappe verehren, dann durfte sie I 58 I nicht mehr als fünf Gulden kosten. Dazu durfte sie ihm noch zwei Kopftücher und einen Badebeutel überreichen. In Lübeck war es Ende des I 5 . Jahrhunderts nur der Braut erlaubt, ihrem Bräutigam leinene Kleider und eine Badekappe im Wert von acht Mark zu geben.

Während der Münchner Rat schon I405 die Hochzeitsbäder verboten haben soll, folgten andere Städte meist erst seit Mitte des I6. Jahrhunderts, ${ }^{519}$ Stolberg bereits I 526 . Im I 7. Jahrhundert verschwanden sie dann ganz. ${ }^{520}$

In welcher Weise Michael Hueber sein Hochzeitsbad gefeiert hat, kann man nicht sagen. Da ihm bei dieser Gelegenheit das Kloster einen kleinen Geldbetrag spendierte, andere vermutlich auch, hat er vielleicht die geladenen Gäste danach bewirtet. Möglicherweise hat er aber das Geld für das Brautbad seiner Frau verwendet. Dazu würde ein Brauch aus dem niederösterreichischen Rohr im Gebirge passen. »Während die Braut sich badete, schenkte der Brautvater Wein aus, der als Badewasser der Braut deklariert wurde ${ }^{521}$

\subsection{Hans Püchler}

Nachdem der Rat Wandula, der Witwe des verstorbenen Michael Hueber d. J., zwar das Bad bis Weihnachten I 529 gelassen, ihr aber gleichzeitig nahe gelegt hatte, sich rasch mit einem tüchtigen Bader zu verheiraten (s.o.), ließ sie sich anfangs etwas Zeit, 


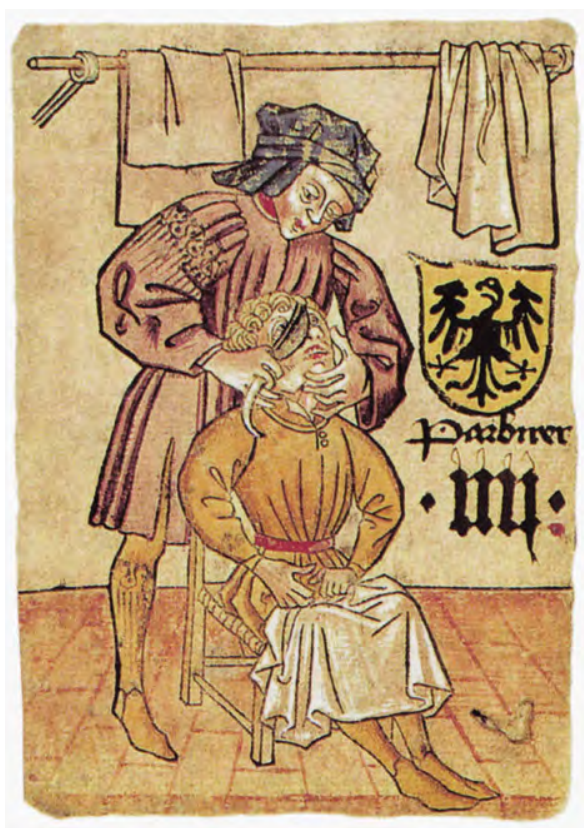

Abb. 7 I: Rasur durch einen Barbier; kolorierter Holzschnitt auf einer Karte des Hofämterspiels, um I460.

dann aber ging es Schlag auf Schlag. Am I. Januar I 530 heiratete sie Hans Püchler, ${ }^{522}$ am 6. Januar wurde er unter vierteljährlicher Kündigungsfrist zum künftigen Bader bestellt, am Tag darauf zum Inwohner aufgenommen, ${ }^{523}$ mit der Folge, dass man ihn bereits im Mai mit 30 Kreuzern zur 3. Türkensteuer ${ }^{524}$ veranlagte. Hans Püchler (Pichler) war schon I 529 als Klosterbader tätig, vermutlich im vierten Quartal. ${ }^{525}$ Fast bis zum Schluss wird er im Rechnungsbuch des Rattenberger Augustinerklosters, ${ }^{526}$ das 539 endet, als Bader des Konvents erfasst. Danach ist er es wohl bis zu seinem Tod geblieben, mögen auch Quellen über seine weitere Tätigkeit für die Mönche schweigen.

Für sie war er nicht bloß als Bader tätig, wenngleich das seine Hauptaufgabe war. I 529 badete er erkrankte Brüder, ${ }^{527}$ I 53 I ließ er die Mönche zur Ader ${ }^{528}{ }^{2} 538$ schuldete ihm zwar der Konvent über sechs Gulden für die Jahresprovision ( 5 Gld.), für das »hailen « von Bruder Michael und für das Scheren der ersten Tonsur zweier junger Mönche namens Emmeran und Johannes, doch machte ihm das Kloster eine Gegenrechnung von zwölf Gulden für Holzfuhren auf, so dass Püchler die Differenz bis auf einen Gulden, den er schuldig blieb, bezahlte. Außerdem musste ihm der Konvent noch fünf Klafter Holz fahren. ${ }^{529}$ Als der Prior 1536 Leistungen und Schulden des Baders bis Martini (I 535) gegeneinander aufrechnete, gewährte er ihm gnadenhalber einen Sold von sechs Gulden, jeder Badetag für die Brüder und ihre Knechte zu vier 
Kreuzern gerechnet. ${ }^{530}$ Zwei letzte Einträge über seine Tätigkeit als Klosterbader fallen in das Jahr $1538 .{ }^{531}$

Hans Püchler wurde von Jahr zu Jahr gegen den üblichen Sold von I6 Gulden zum Bader der Stadt weiterbestellt, wobei sich der Rat vorbehielt, ihm von Quatember zu Quatember den Dienst aufzukündigen. ${ }^{532}$ Bei der Verlängerung des Dienstes I 544 trug man ihm auf, sich um gute Knechte zu kümmern, besonders um einen, den man wegen des Bindens und Verarztens lobe (»berhüembt sey«), damit niemand »verwarlost« und dem Reichen wie Armen »treulichen gewart werde«. Sollte eine Seuche auftreten, müsse er auf seine Kosten einen Knecht halten, der die Infizierten pflege mit Aderlassen und allem anderen, was zur Heilung beitragen könne. Wenn er in einem solchen Fall den Rat um eine Kostenbeteiligung bitte, werde er sich nicht weigern. ${ }^{533}$ Es hat anscheinend Klagen über seine unfähigen Knechte gegeben, deren Lebenswandel zudem zu wünschen übrig ließ. Denn im selben Jahr warf der Rat Meister Hans vor, er habe seinem Knecht Matheus vier Wochen lang erlaubt, eine schwangere „Diern« im Bad zu halten und sie beieinander liegen lassen. Der Bader rechtfertigte sich damit, er habe nicht gewusst, ob sie verheiratet gewesen wären oder nicht. Der Rat entschied, Püchler zu bestrafen. ${ }^{534}$ Am ı o. Juni I 530 gestattete der Rat dem Bader, bis auf St. Bartlmetag (24. August) wöchentlich nur zwei Bäder, nämlich am Mittwoch und Samstag, zu halten. ${ }^{535} \mathrm{Ob}$ das ein erstes Zeichen nachlassenden Interesses am Baden war oder ob private Gründe Püchlers hinter der Beschränkung steckten, lässt sich nicht sagen.

Was seine wundärztliche Tätigkeit betrifft, ist wenig außerhalb der Klosterrechnungen bekannt geworden. So versorgte er I 54 I ein Kind im Spital. ${ }^{536}$ Vermutlich war es auch er, der 1538 die Schwester des Metzgers Stefan Schmerlinger, eine Pfründnerin im Spital, behandelte. ${ }^{537}$

Der Rat wachte eifersüchtig darüber, dass seine Rechte als Inhaber der niederen Gerichtsbarkeit nicht durch den Stadt- und Landrichter beschnitten wurden. Das bekam auch Hans Püchler zu spüren. Er hatte sich wegen einer Freveltat seines Bruders gegenüber dem Landrichter verbürgt, dass sich sein Bruder dem Richter wieder stellen werde. Das geschah aber nicht, im Gegenteil, der Bader gab dem Richter und Amtmann nur böse Worte. Der Richter fackelte nicht lange und führte ihn aufs Schloss, wo der Kerker war. Das verstieß gegen die Freiheiten der Stadt. Der Rat beschloss, weil sich der Bader an eine andere Obrigkeit gewandt und sein »hantgelobtes« Versprechen gebrochen habe, solle er zur Strafe auf ein Tor geschafft werden. Außerdem wurde Hans Püchler aufgefordert, seinen Bruder dem Richter zu stellen und in Zukunft keiner anderen Herrschaft mehr ein "gelüb « zu tun. ${ }^{538}$ Während des Einsitzens für einige Stunden auf dem Tor durfte der Bader darüber sinnieren, wie ungerecht es doch auf der Welt zugehe, falls er sich ungerecht behandelt fühlte. Schließlich hatte er ja schon auf dem Schloss eingesessen. 
Püchler fand ein trauriges Ende. Bei der Neubesetzung der Ämter zu Dreikönige I 545 verkündete der Rat, den Bader habe die "gewalt Gottes«, also ein Schlaganfall getroffen. Obwohl zu besorgen sei, dass er seinem Handwerk und Bad nicht mehr werde nachkommen können, werde man, weil er viele kleine unerzogene Kinder - es waren fünf - habe, bis zum nächsten Quatember abwarten, wie sich die Sache entwickle. Von einem neuen Meister, wie gebeten wurde, wolle man jetzt noch abstehen, doch solle er für taugliche und geschickte Knechte sorgen, damit es der Gemeinde an nichts fehle, ansonsten sei es »all wochen mit seinem Dienst vorbei. ${ }^{539}$

Die Dinge ließen sich aber gar nicht gut an. Als Ende Mai keine Hoffnung mehr bestand, dass der Bader Püchler jemals wieder sein Handwerk werde ausüben können, beschloss der Rat, sich heimlich ohne Wissen der großen Herren ${ }^{540}$ nach einem neuen tauglichen Bader umzusehen und Meister Hans das erst dann anzuzeigen, wenn der andere aufgenommen sei. Am r 9. Juni war es dann so weit. Meister Michel Schwegler, Barbier zu Schwaz, der am 8. Juni in der Gemeindeversammlung die meisten Stimmen erhalten hatte, wurde als neuer Bader Rattenbergs vom Rat bestätigt und aufgenommen. Er sollte angewiesen werden, die Fenster nach einem Bad bis zum nächsten Badetag offen zu halten. Hans Püchler musste zu Michaelis das Bad räumen. ${ }^{54}$ Seine Frau bekam noch für drei Quartale zwölf Gulden Sold. ${ }^{542}$

Michaelis erlebte Hans Püchler nicht mehr. Am I8. September erhielt seine Witwe ${ }^{543}$ einen Anweiser, ihre mit dem Verstorbenen erworbenen fünf Kinder (Hans, Simon, Katherina, Ursula und Magdalena) bekamen Vormunde. ${ }^{544}$ Offenbar besaß Püchler noch ein anderes Bad in Hallein, das er verpachtet hatte. Der Rattenberger Rat forderte seine Witwe im Interesse ihrer Kinder auf, sich bei der Halleiner Obrigkeit wegen der Rechtsgültigkeit des Kaufbriefs zu erkundigen und sich mit dem jetzigen Besitzer des Bades ins Einvernehmen zu setzen. Wandula Püchler wollte das Halleiner Bad gern kaufen, bat aber um ein Jahr Aufschub ab Datum des Kaufbriefs, weil sie vor der Aufteilung des Erbes keinen Kauf vornehmen könne. Außerdem ersuchte sie den Rat um Fürbitte bei den Herren in Hallein. Dieser Bitte wurde entsprochen, die Gewährung eines Aufschubs machte man davon abhängig, dass der Schlosser und Vormund Benedikt Melchior wegen der Ansprüche der Kinder und ihres Sohnes Michel ${ }^{545}$ zustimme. ${ }^{546}$ Offenbar war es eine verzwickte Angelegenheit.

Nachdem der Rat der alten Baderin im November geboten hatte, auf Jahr und Tag ihr Hab und Gut nicht zu verkaufen, kam es im Dezember zur Erbteilung. Die Witwe erhielt alle Güter ihres verstorbenen Mannes und das Bad zu Hallein. Dagegen musste sie ihre fünf Kinder bis zum vollendeten I6. Lebensjahr mit Speise und Trank, Bekleidung und Schuhwerk unterhalten, ihnen »zaf und zucht" (Pflege und Erziehung) erweisen. Die beiden Knaben erhielten jeder 25 Gulden und die Wehren ihres Vaters, die drei Töchter je 20 Gulden und ordentliches Bettgewand, wenn sich die Kinder verheirateten oder sonst etwas benötigten. Blieben sie nicht beim künftigen Ehemann 
der Witwe, durften sie die Gerhaben (Vormunde) auf Kosten der Mutter anderswo unterbringen. Zur Sicherstellung ihrer Kinder musste Wandula Püchler ihr ganzes Hab und Gut als Pfand einsetzen. ${ }^{547}$

Im Januar des nächsten Jahres kam es zu einem neuen Erbteilungsvertrag, nicht weil sich die Mutter Bedenkzeit ausgebeten hatte, ${ }^{548}$ sondern weil in der Zwischenzeit offenbar eines der Kinder gestorben war. Denn nun ist nur noch von vier Kindern die Rede. Es blieb so ziemlich alles gleich, doch statt bis zu einem Alter von I6 Jahren brauchte der Unterhalt nur bis zu dem Zeitpunkt gewährt werden, an dem die Kinder ihr Brot gewinnen konnten. Jedes der vier Kinder erhielt nun bei Heirat oder im Bedarfsfall 25 Gulden. Ein Zusatz betraf die Tochter Ursula. Da sie "tadlhäfftig “ ${ }^{549}$ war, musste sie, tot oder lebendig, gebührlich versorgt werden, doch sollte die Witwe nach dem Tod des Kindes nicht schuldig sein, jemandem etwas zu geben. Um die Ansprüche der Kinder hatte sich die »alte Baderin Wanndula» auf ihr Hab und Gut zu verschreiben, für die ıoo Gulden sogar auf neue Güter, falls sie künftig solche erwerben würde. ${ }^{550}$

In die Erbschaft fiel nicht ein Piesgarten ${ }^{551}$, der Wandula von ihrem »lieben vorigen Hauswirt«, dem ehemaligen Rattenberger Bader Michel Hueber, zugefallen und der mit einem Ewigzins von drei Kreuzern jährlich für die St. Virgilkirche belastet war. ${ }^{552}$ Ihn verkaufte sie ${ }_{5} 46$ an den Seiler Conrad Reichl, Bürger zu Rattenberg. ${ }^{553}$ Zum letzten Mal wird die »alte Baderin, Meister Hansen Pühlers seligen Witwe«, am 2. März I 547 in Rattenberg erwähnt, als es um einen Termin für die Abrechnung mit den Vormunden ihrer Kinder ging. ${ }^{554}$ Danach verschwindet sie aus den Quellen. Sie ist wohl nach Hallein gezogen, um dort das Bad zu übernehmen.

\subsubsection{Reiberin und Gewandhüterin}

In den bisherigen und folgenden Kapiteln über die Bader fällt auf, dass sie so oft vom Rat verlangen, die Reiberinnen und Gewandhüterinnen durch andere Frauen auf diesem Posten ersetzen zu dürfen. Pflichtversäumnisse wie mangelnder Fleiß ${ }^{555}$ oder übermäßiger Weingenuss, ${ }^{556}$ die Aufforderung, sich gebührlicher zu verhalten, ${ }^{557}$ können nicht der einzige Grund gewesen sein. Dann hätte man nicht wenige Bader und Badknechte entlassen müssen, denen der Rat dieselben Vorwürfe machte. Die Unlust der Bader über Reiberinnen und Gewandhüterinnen hing vermutlich mit den Aufgaben zusammen, die er ihnen über ihren Pflichtkreis hinaus aufhalsen wollte, ohne sie dafür zu bezahlen. Der Rat selbst brachte das $5_{5}$ I I zum Ausdruck, als er Meister Gabriel Freytag gestattete, die Reiberin zu entlassen und durch eine neue zu ersetzen, falls sie ihm nicht "zu gefallen dienen wurd uber das, so ir aufgeladen sei. $^{558}$ Was das denn war, wird nie gesagt, lässt sich aber erschließen, zumindest erahnen.

Wenn Bachmann schreibt ${ }^{559}$ : „Die Badreiberin musste mindestens alle I 4 Tage die Böden und Bänke reiben und das Badgeschirr sauber halten«, Stops ${ }^{560}$ das übernimmt 


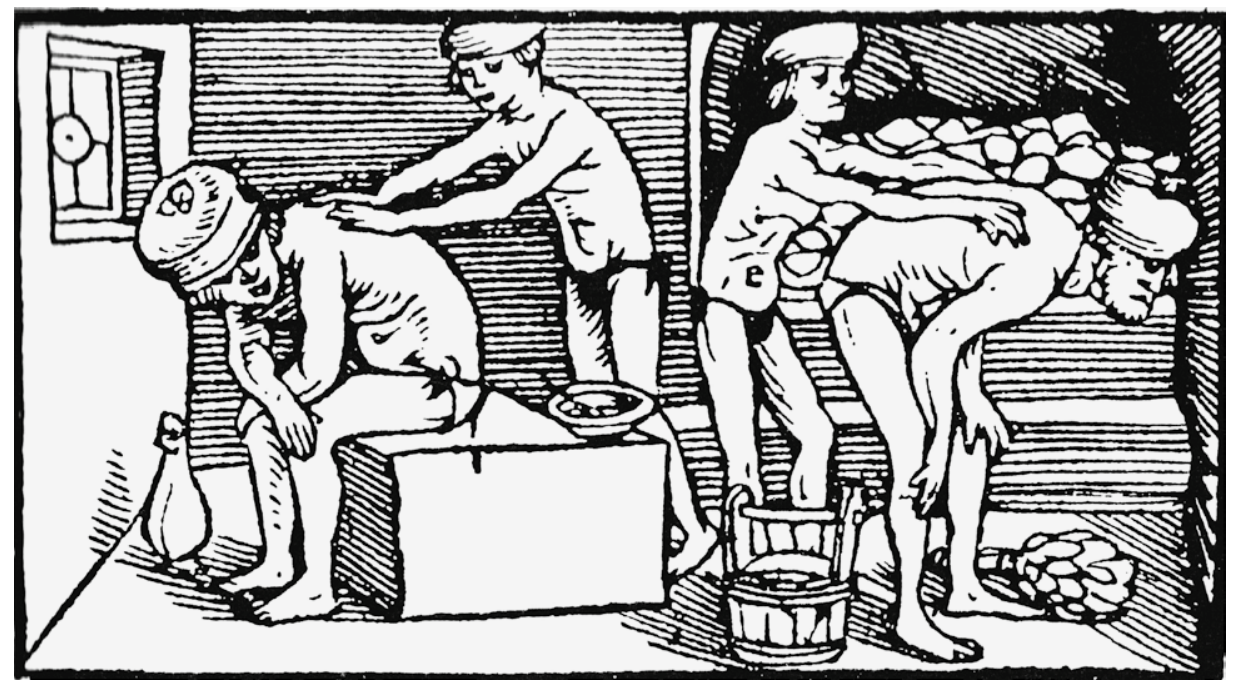

Abb. 72: Reiben (Massieren) vor und nach dem Bad; Holzschnitt aus Michael Heros "Schachtafelen der Gesuntheyt«, I533.

und erklärend hinzufügt, die Reiberin habe nicht die Aufgabe gehabt, die Körper der Badenden abzureiben, sondern die Badstuben zu reinigen und alles Gerät, von Trog, Zuber, Badschaffen angefangen, abzureiben und zu säubern, dann ist das einerseits blühender Unsinn, trifft aber andererseits den Kern der Sache, woran sich das Verhältnis des Baders zu den Reiberinnen und Gewandhüterinnen spießte. Schon ein Griff in eines der vielen Wörterbücher der deutschen Sprache zum Mittelalter, zur Neuzeit ${ }^{561}$ und zu den Dialekten verschiedener Landschaften hätte beide Autoren darüber belehrt, dass Reiberin früher nichts anderes bedeutet hat als »Badfrau«, dass das Wort keineswegs ein Synonym für »Raumpflegerin« war, die den Boden zu scheuern, zu reiben hatte. Eine bloß vierzehntägige Reinigung der Badstuben war und ist aus hygienischen Gründen undenkbar. Nach jedem Badetag, nach jedem Einheizen mussten die Stuben gelüftet, Boden, Bänke, Gläser (Fenster) und Handwerksgerät von Schmutz und Ruß befreit werden.

Die Reinigung oblag den Badknechten und Lehrjungen, wie z.B. die Ordnung der Innsbruck-Haller Baderbruderschaft von I 45 /6o deutlich herausstellt. Damals gab es Reiberinnen, die Mitglieder der Bruderschaft waren, doch erwähnen sie die Statuten nicht eigens, sondern nur unter dem Sammelbegriff »Schwestern«, und schreiben ihnen schon gar nicht die Säuberung der Stuben vor. ${ }^{562}$ Welche Aufgaben eine Reiberin in Rattenberg hatte, wird nie genau vom Rat definiert, nur einmal ziemlich verschwommen angegeben, und zwar unter Hans Püchler. 


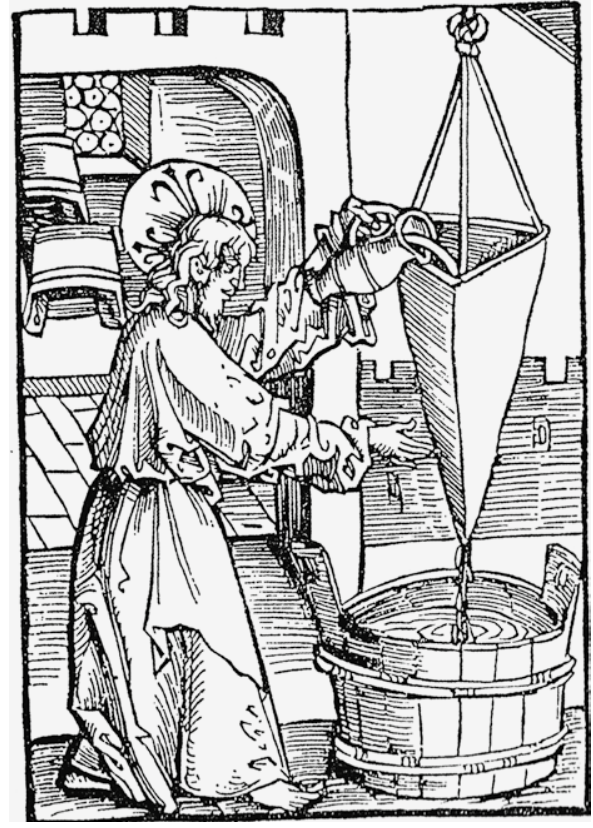

Abb. 73: Machen der Lauge; Holzschnitt aus Thomas Murners "Ein andechtig geistlich Badenfart«, I5 I4.



Abb. 74: Kopfwäsche; Holzschnitt aus Thomas

Murners "Ein andechtig geistlich Badenfart", I5 I4.

Er war I 544 mit seiner Reiberin, der Benediktin, übers Kreuz. Sie hatte gegen den Bader einen »unwillen«, er wollte sie loswerden. Der Rat gestattete ihr, zum nächsten Quatember (Michaelis) abzutreten. ${ }^{563}$ Bereits im September nahm die Stefan Reichlin das Reiberamt im Bad auf. Ihr schrieb der Rat vor: "Sie soll der Benedickhtin das geschirr abhänndln und den frawen vleissig warten und mit gueter laugen und anderer notturft versehen «. ${ }^{564}$ Unter der Aufwartung für die Frauen sind Übergießen, Abgießen, Waschen, mit dem Quast Reiben, Massieren, Fußbäder, Kopfwäsche, Kämmen, vielleicht auch Haareschneiden, Einreiben mit gebrannten Wässern oder ätherischen Ölen zu verstehen. Der Bader betrat die Frauenstube nur als Wundarzt, Aderlasser und Schröpfer. Zu dem Arbeitsgerät (Geschirr), das der Benediktin abgehandelt werden sollte, werden wohl Schaffe, Kübel, Quaste, Bimsstein zum Reiben, Lauge zum Abgießen und für die Kopfwäsche, Kamm, Schere, Badehüte oder -kappen, Handtücher, Badelaken, vielleicht auch Fläschchen und Tiegel für die Haut- und Körperpflege gehört haben. ${ }^{565}$

Die Reiberinnen hatten also genug zu tun und verdienten wenig. Sie wurden von Rat und Gemeinde angestellt, standen nicht wie die Badeknechte im Wochenlohn des Baders, sondern waren freiberuflich tätig. Nur von den Badbesucherinnen, die 
ihre Dienste in Anspruch nahmen, erhielten sie ein paar Vierer. Wenn dann ein Bader von ihnen die Reinigung der Badstuben verlangte, was nicht ihre Aufgabe war, warum hätten sie das kostenlos tun sollen? Denn darum ging es augenscheinlich bei allem Streit zwischen ihnen und den Meistern. Dass sie sich durchaus zum Putzen bereitfanden, wenn es bezahlt wurde, zeigte sich I544, als ihnen die Stadt das Waschen des Bodens in der Trinkstube mit 30 Kreuzern vergütete. ${ }^{566}$ Aber umsonst? Dann lieber noch als Wäscherin, Näherin, Spinnerin, Strickerin, Flickerin, Tagwerkerin tätig sein, das trug wenigstens einige Kreuzer ein. Das Problem der Badreinigung wurde offenbar dann akut, wenn der Bader keine Lehrjungen hatte, denen man Besen und Scheuerlappen in die Hand drücken konnte, und wenn sich die bezahlten Badeknechte - nicht selten nur faule, untaugliche Hilfskräfte - als Putzkräfte verweigerten.

Ähnlich lagen die Dinge für die Gewandhüterinnen, die wie die Reiberinnen besonders um jene weiblichen Gäste bemüht waren, die etwas springen ließen. I5 59 wurde der Gewandhüterin und der Reiberin im Bad vorgehalten, sie seien nicht fleißig, kümmerten sich nicht um die Armen, sondern nur um jene Frauen, die ihnen Wein spendierten. ${ }^{567}$

Die Reiberinnen in Rattenberg waren keine jungen Mädchen, sondern Frauen gesetzten Alters. So schrieb I 554 der Rat dem Bader Hans Fäler d. Ä. vor, er solle sich mit einer "guetn häuslichn matron « als Reiberin versehen. ${ }^{568}$ Sie kamen wie die Gewandhüterinnen aus Familien kleiner, nicht selten armer Handwerker, Krämer und städtischer Beamter. Die meisten von ihnen waren Witwen, denen der Rat mit dem bescheidenen Amt ein Nebeneinkommen verschaffen wollte. Das wird besonders deutlich im Jahr 1549, als die Stelle einer Gewandhüterin im Bad vakant geworden war. Es bewarben sich gleich sechs Frauen, nämlich »Sigmund Wachterin, Stindl Steyrerin, Benedictin, Gilg Peckhin, Sturm Kürschnerin und Melchiors Hausfrau«. Nach I4 Tagen Bedenkzeit entschieden sich Rat und Gemeinde auf Probe für die Sigmund Wachterin. Sie sollte einen Bürgen stellen. ${ }^{569}$

Nach zahlreichen Dokumenten im Rattenberger Stadtarchiv ${ }^{50}$ hatten die Ehemänner der sechs Bewerberinnen folgende Berufe. Barbaras kürzlich verstorbener Ehemann Sigmund Waldhueber hatte als Wächter und Torhüter in der Stadt gearbeitet, daneben noch als Tagwerker, Stind1 ${ }^{571}$ Steyrerin war vermutlich die Witwe Margreth des 1546 verstorbenen Krämers Augustin Schander, der auch das Amt eines Berggerichtsgeschworenen versehen hatte und wegen seines Beinamens wohl aus der Steiermark stammte. Mit der Benedictin ist die Frau des 1546 verstorbenen Futter- und Kornhändlers Benedict Oswald gemeint, ${ }^{572}$ der seit ${ }^{5} 544$ Wächter, Unterkäufel ${ }^{573}$ und Bettelrichter der Stadt gewesen war, während seine Frau zur selben Zeit das Amt einer Badreiberin ausgeübt hatte. Die Benedictin war so arm, dass ihr die Stadt ${ }_{547}$ Lebensmittel, ihrem »Püebl« I 55 I einen Rock schenkte. 


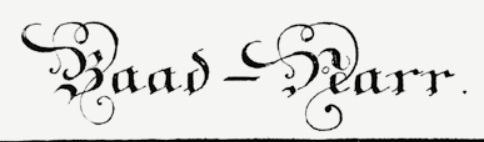

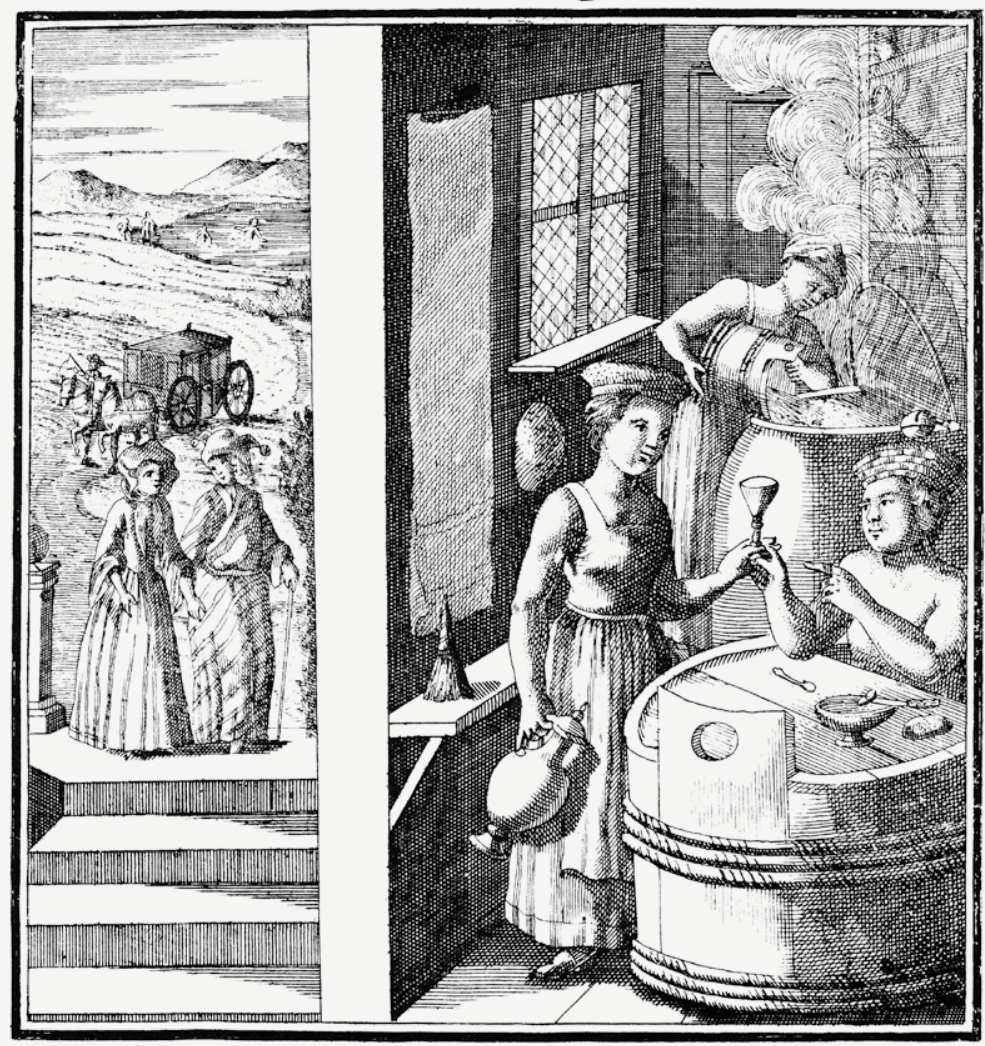

Dir bäder-Cur hat Sott gèchen.



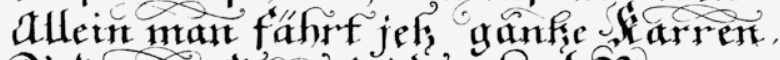
Dict angefillé mint farden Sorren. Die nut herfomment derentmegen,

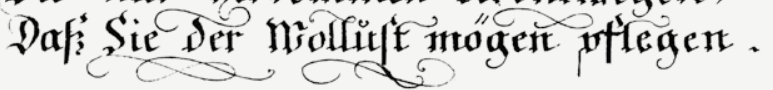

Abb. 75: Bade-Narr; Kupferstich von Johann Christoph Weigel in Abraham a Sancta Claras »Hundert Ausbündige Narren«, I7o9. 
Der Peckhin Ehemann Gilg Püchl, ein Bäcker, war I 528 als Täufer hingerichtet worden. ${ }^{574}$ Sie durfte noch einige Zeit einen Platz auf der Bäckerbank behalten. Potentia, die Witwe des I 546 verstorbenen Kürschners Marx Sturm, scheint unter den sechs Kandidatinnen die einzige gewesen zu sein, die über ein gewisses Vermögen verfügte. Nicht so gut ging es Katharina Melchior, der Witwe des jüngst verstorbenen Schlossers und begnadigten Täufers Benedict Melchior. Obgleich er Ratsgenosse war, scheint er ein dürftiges Erbe hinterlassen zu haben. Alles in allem genommen ergibt sich ein bedrückendes Bild verarmter Witwen von Rattenberger Bürgern und Inwohnern.

Dass die Witwe Waldhueber als Gewandhüterin einen Bürgen stellen musste, macht durchaus einen Sinn. Kam es nämlich zu einer Verwechslung oder einem Diebstahl der von einer Garderobiere in Verwahrung genommenen Kleidung und war dafür eine Gebühr bezahlt worden, musste sie den Schaden ersetzen, an bestimmten Orten auch der Bader, zumal wenn sie nicht zahlen konnte. ${ }^{575}$ Eine ähnliche Anordnung findet sich in Rattenberg. I 574 war Erhard Piechls, eines Bäckers, Witwe die Gewandhüterin im städtischen Bad. Der Rat warnte sie: Würde sie etwas an Kleidern und anderem, das sie bewachen solle, verlieren, müsse sie den Schaden ersetzen. ${ }^{576}$

\subsection{Michel Schwegler}

Er war ein Barbier aus Schwaz, wurde schon im Juni I 545, wie bereits vermerkt, zum neuen Bader bestellt und trat sein Amt zu Michaelis dieses Jahres an. ${ }^{577}$ Es sollten zwei Pachtbriefe ausgestellt werden, ${ }^{578}$ woraus sich eine Kurzfassung im Ratsprotokoll bei der Weiterbestellung zu Dreikönige I 546 findet. Danach lief der Vertrag von Quatember zu Quatember. Schwegler solle, heißt es, den Kessel nicht wie bisher überheizen, für längere Zeit einen Knecht halten, der sich auf das Aderlassen und Aderschlagen verstehe, und nicht jede Woche einen aufnehmen, woran seine Hausfrau schuldig sei. Er habe aufs Feuer zu achten und ein gut geheiztes Bad zu führen. Die Stellen am Ofen, wo das Feuer Schaden anrichten könnte, sollten in Kürze gemacht werden. ${ }^{579}$ Anscheinend hatte Schwegler als ehemaliger Barbier noch keine besondere Erfahrung mit Badstuben. Seine Frau ist schon die Dritte, die in den Rattenberger Quellen als eine Ehegattin erwähnt wird und sich in die Führung des Bades eingemischt hat. Vermutlich war auch noch mit anderen Meisterinnen im Bad nicht gut Kirschen essen, was mit den ständigen Wechsel der Badknechte, Reiberinnen und Gewandhüterinnen erklären könnte.

Am 7. Juli I 546 erhielt Schwegler das Inwohnerrecht ${ }^{580}$, bei der Weiterbestellung von Quatember zu Quatember am Dreikönigstag I 547 schärfte ihm der Rat erneut einige Pflichten ein. Er solle, heißt es, das Bad stärker heizen (»mer khenten«) lassen, auf saubere Pflege (»zaff») achten, gute Knechte halten, die Lehrbuben zu besserer "farcht ${ }^{581}$ und arbait « anhalten, als vergangenes Jahr geschehen ist, und fleißig auf das 
Feuer sehen. Sonst habe er alle Artikel des Pachtbriefs zu befolgen. Man werde ihm noch eine Stunde bestimmen, wie lange in der Nacht das Bad geöffnet bleiben solle. Seine Jahresprovision sei wieder 16 Gulden. ${ }^{582}$ Die Anweisungen von Rat und Gemeinde zeugen nicht gerade von großer Zufriedenheit mit der Betriebsführung durch den Bader, doch bald brauchte man sich deswegen keine Sorgen mehr machen. Das Problem erledigte sich von selbst. Bereits am I I. Februar nahm man ein neuen Bader und Wundarzt auf, weil Michel Schwegler gestorben war, ob an den Folgen eines Unglücksfalls oder an einer (Infektions-)Krankheit erfährt man nicht. Seiner Witwe wurde gnadenhalber noch ein volles Quartalsgeld von vier Gulden gewährt. ${ }^{583}$

\subsection{1 "Offner vergiffter Lufft"}

Nach Guarinoni verursachen Badhäuser den in ihrer Nachbarschaft wohnenden Menschen drei "gemeine Badschäden«. Zunächst einmal rinne das Schwenzwasser aus den Stuben, voll an Wust und Unrat, in anderes Wasser und verunreinige es stark, dann bestehe erhöhte Feuersgefahr und schließlich sei ein großes Übel

»der ungehewre und allenthalben außriechende Schweißdampff, so nicht inner dem Bad beschlossen, sonder von dem Wind in die Nachbarschafft herumb geführt unnd reichlich mitgetheilt wirdt, also daß, wo in einer Stadt der gemeinen Bäder zwo, drey oder mehr, die gantz Stadt von solchem Wust ohne alle Mühe mag berührt und der Lufft gefälscht werden [...] Der Geruch, so darauß kombt, der gibts menigklich zu erkennen, welcher auff ein gute Weite die Nasen der Fürüber- oder Herumbgehenden trifft «. ${ }^{584}$

Auch in Rattenberg dürfte in dieser Hinsicht nicht alles zum Besten gestanden sein. Dass der Rat, nachdem den alten Bader Hans Püchler der Schlag getroffen hatte, sich schon I 545 vor Antritt seines Nachfolgers Gedanken darüber machte, ihm vorzuschreiben, nicht immer das Wasser abzusperren, im Winter die Fenster nach dem Bad etliche Stunden geöffnet zu halten, ja sie überhaupt von einem Badtag auf den anderen offen zu lassen, stimmt schon nachdenklich. ${ }^{55}$ Bei dem Bader Matheus Paungartner, dem man noch I 547 ganz allgemein aufgetragen hatte, die Fenster von einem Badtag auf den anderen offen zu halten, damit die Stuben immer gut gelüftet seien, ${ }^{586}$ werden die Herren 549 deutlicher. Es werde geklagt, heißt es, das Bad rieche »saur und ÿbl«. Man wolle probieren, den Schaden zu beheben. Um ein Uhr nach Mitternacht werde man ins Bad gehen, es bis sechs Uhr morgens heizen, die Gläser (Fenster) und Tür öffnen und das Bad auf der Glut von sechs Uhr morgens an stehen lassen. Dann werde der Rauch vergehen und es ein gutes, süßes Bad werden. ${ }^{587}$

Da man nichts weiter über die Angelegenheit hört, mag der Versuch gelungen sein oder man hat sich auch später zeitweise mit üblem, säuerlichem Schweißgeruch abfin- 
den müssen. Ein Dreckhaufen beim Bad, den man I 579 wegräumen ließ, ${ }^{588}$ wird auch nicht gerade zur Luftverbesserung beigetragen haben.

\subsection{Matheus Paungartner}

Als er am I4. Februar I $547^{589}$ vom Rat zum neuen Wundarzt und Barbier aufgenommen wurde, ließ der Rat vom Stadtschreiber so genau seine Pflichten im Protokoll festhalten, dass man daran die einzelnen Artikel des Pachtbriefs erkennen kann. Es heißt: Paungartner ${ }^{590}$ solle gute, geschickte, taugliche Knechte beschäftigen, dreimal wöchentlich ein Bad halten und es gründlich heizen, von einem Badetag zum anderen die Fenster offen lassen, damit das Bad immer gut gelüftet sei. Er dürfe es nicht zulassen, dass samstags seine Knechte den Herren ${ }^{591}$ oder anderen Leuten inner- und außerhalb der Stadt in ihren Bädern aufwarten noch sich selbst zu einem solchen Dienst hergeben. Er habe jedermann, gleich ob arm oder reich, im Bad zu verarzten und allen Besuchern unverdrossen als Bader aufzuwarten. Es wird ihm aufgetragen, sorgsam aufs Feuer zu achten, den Badkessel nicht fahrlässig zu überheizen und dadurch zu verbrennen, auch in allen Stuben zu verhindern, dass man Fensterscheiben zerbreche. ${ }^{52}$

Dagegen gebühre ihm alle Quatember ein Sold von vier Gulden sowie nach altem Herkommen von jedem Bad- und Lassgeld. Der Witwe des verstorbenen Baders Schwegler solle er aus gutem Willen und Barmherzigkeit, nicht aus Gerechtigkeit vier Gulden überlassen und ihr nach Schätzung durch ehrbare Leute das Badzeug abkaufen. Gleichzeitig wurde Paungartner gegen eine Gebühr von vier Gulden zum Inwohner aufgenommen und aufgefordert, seinen Geburtsbrief nachzureichen. ${ }^{593}$

Bei der Ämterbesetzung zu Dreikönige I 548 wurde Meister Matheus weiterbestellt, die Bestimmungen über die Knechte und das Feuer wiederholte man und fügte hinzu, Paungartner solle das Bad zu rechter Zeit heizen und dafür sorgen, dass immer genug Wasser und gute Lauge vorrätig sei. Den Leuten aus der Gemeinde habe er bis um sieben Uhr im Bad aufzuwarten. Die Bänke seien sauber zu halten und müssten abgewaschen werden. Außerdem solle er mehr Badehüte halten. Seine Provision sei I 6 Gulden. Als in der Gemeindeversammlung Stimmen laut wurden, der Ofen sei »verderbt«, hatte Meister Matheus deswegen keine Klagen. ${ }^{594}$

Klagen hatten allerdings Rat und Gemeinde, als sie ihm im Jahr darauf erneut das Bad überließen. Zunächst hielt man ihm vor, er solle gute und tüchtige Knechte halten und nicht allein Buben (Lehrjungen) anstellen und außerdem ständig aufs Feuer achten, ${ }^{595}$ weil man bislang vorm und beim Bad $^{596}$ wenig Fleiß darauf verwendet habe. Er müsse die Stuben auskehren und putzen, Scheiter und Unsauberkeiten entfernen lassen. Das Bad sei zur rechten Zeit zu heizen. Dass es säuerlich und übel rieche, war eine allgemeine Klage. ${ }^{597}$ Man wünschte vom Bader, dass er jederzeit warmes Wasser und 
Abb. 76: Schienen eines gebrochenen Beines durch einen Wundarzt; Miniatur aus der Heidelberger Manesse-Handschrift, um 1320.

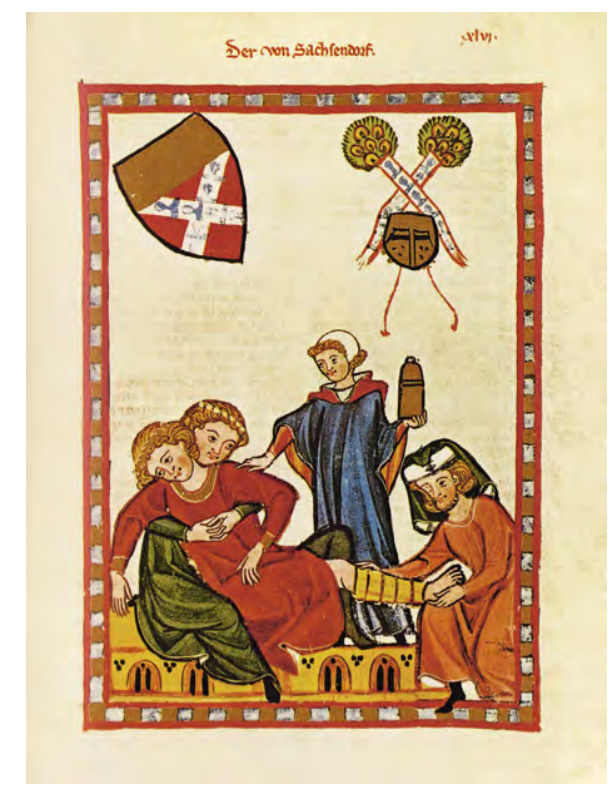

gute Lauge bereithalte, die Bänke abwaschen, das Bad am Boden abgießen (mit Wasser ausschwenzen), putzen lasse etc. »Schadhafte« Leute solle er im Bad nach hinten setzen. Über die Badestunden, wie lange man im Sommer und Winter baden lassen solle, konnte sich die Gemeinde nicht einigen. Es wurde nur allgemein festgehalten, die Hitze im Bad solle sich nach der Jahreszeit richten.

Was man von Meister Hans (Püchler) und anderen Badern verlangt habe, gelte auch für Meister Matheus. Trete eine gefährliche Krankheit der Pestilenz auf, was Gott verhüten möge, dürfe er mit einem Aderlasser (»Lässl«) nicht aus der Gemeinde weichen, sondern müsse mit Aderlass und anderem, was nötig wäre, die Kranken pflegen. Seine Jahresprovision bleibe bei I 6 Gulden. ${ }^{59}$

Paungartner hatte seinerseits auch Grund zum Klagen, nämlich über drei auswärtige Störer, die ihm ins Handwerk pfuschten. Der Rat versprach, über den Landrichter, notfalls über den Stadthauptmann, den Grafen von Liechtenstein, für Abhilfe zu sorgen. ${ }^{599}$ Zur Not hätte er sich wohl selbst gegen die Störer zu wehren gewusst, denn er scheint ein »schlagkräftiger« Mann gewesen zu sein. Meister Matheus wurde nämlich am 23. November 1548 vor den Rat geladen, weil er dem »Treybmaister « ${ }^{600}$ von Radfeld am Tag zuvor früh auf dem Kirchgang eine so kräftige Maulschelle gegeben hatte, dass der arme Kerl auf das Pflaster gefallen war. Der Rat vertrug beide Kontrahenten, die versprechen mussten, die Sache auf sich beruhen zu lassen, sich dafür nicht zu rächen, weder bei Wein noch bei Wasser. Meister Matheus wurde verurteilt, dem Treibmeister 
einen Gulden Schmerzensgeld, der Stadt einen Gulden Strafgeld zu zahlen und dazu noch auf dem Tor zu liegen. ${ }^{601}$

Über Paungartners Tätigkeit als Wundarzt gibt es einige verstreute Nachrichten. In der Erbauseinandersetzung nach seinem Tod kam zur Sprache, dass er, als er nach Schwaz gekommen war, bei einem Arzt namens Schweizer in Stellung gewesen sei. Als er damals einen Verwundeten zu behandeln gehabt hätte, habe er den Meister Hans Feyler zu sich genommen und den Verletzten geheilt. Bei dem halben Gulden Trinkgeld, den Meister Matheus erhalten hätte, habe seine Frau "zugeschlagen«, d.h. wohl, sich das Geld angeeignet. Feyler und Paungartner seien wie Blutsbrüder gewesen, Feyler (Fäler) habe auch den Paungartner »an ainem flus« (Rheuma?) geheilt. ${ }^{602}$

Man darf die Vorwürfe der Habgier an die Witwe und des geringen medizinischen Könnens an den verstorbenen Bader nicht überbewerten, schließlich ging es um einen Erbstreit. Paungartner konnte auch anders. So bewilligte ihm der Rat zwei Gulden Arztgeld, weil er den »Schaden« eines Knaben behandelt hatte, ${ }^{603}$ und ${ }_{5} 547$ erhielt er von der städtischen Bruderschaft auf Bitten des Bürgermeisters und anderer Bürger $4^{1 / 2}$ Gulden für das Verarzten der alten Arnbergerin. ${ }^{604}$

Sonst gibt es nichts über ihn zu berichten, da er früh gestorben ist. Nur noch ein eher nebensächliches Detail, das aber den damaligen Alltag widerspiegelt. $\mathrm{Zu}$ den ungebetenen Gästen gehören Mäuse. Sogar im Bad musste man sich dagegen wehren. Deshalb hat man 1547 in allen Gemächern des Bades die Mäuselöcher »verworffen«, d.h. mit Kalk verschlossen. ${ }^{605}$ Da das Bad am Inn lag, muss man sich fragen, ob es sich nicht um Wassermäuse (Wasserspitzmäuse oder Schermäuse) gehandelt haben könnte. Das Spital kaufte nämlich 1553 eine »wasser mauß fall «. ${ }^{606}$

Matheus Paungartner, der Ende März 549 noch lebte, wird einen Monat später als verstorben bezeichnet. Er war im Inn ertrunken, seine Leiche hatte man am 26. April noch nicht gefunden. Wie bereits früher erwähnt, ${ }^{607}$ hatte er an Syphilis gelitten und sich einer quälenden Schmierkur mit Quecksilber unterziehen müssen. Die Verhandlung über die Aufteilung seines Erbes bietet einen interessanten Einblick in die Vermögensverhältnisse und das Handwerkszeug eines Rattenberger Baders, Wundarztes und seiner Frau. Deshalb soll die Angelegenheit genauer betrachtet werden.

Die in Schwaz geschlossene Ehe von Matheus Paungartner und Margreth Maurer, Tochter des weiland Paul Maurer zu Vomp und verwitwete Hörman, blieb kinderlos. Deshalb erschienen als Erbberechtigte vor Bürgermeister und Rat die Witwe Margreth einerseits und drei Schwestern ${ }^{608}$ des verstorbenen Baders andererseits. Beide Parteien wurden durch einen Prokurator und andere vertreten. Der Prokurator Margreths machte für seine Mandantin folgende Ansprüche geltend:

250 Gulden Milch- und Krautgeld ${ }^{609}$ und anderes, das ihr verstorbener Mann Michl Hörman, genannt Vindler, zu Vomp ihr gelassen habe, 
40 Gulden Vermächtnis ihres ersten Mannes, ferner nach seinem Tod († I 535)

5o Gulden für Morgengabe und Betreuung, dazu I guter Gulden,

8o Pfund Flachs und gesponnenes Garn,

20 Gulden, geerbt von ihrem Bruder Bartlme Maurer,

Io Gulden, erlöst aus dem Verkauf von Kleidern, die sie von ihrer Schwester, verheiratet gewesen mit Bartlme Widman, geerbt habe; I Polster,

2 Kissen und die Leintücher, die jetzt im Inventar stünden, stammten auch von ihrer Schwester. ${ }^{610}$

Das alles habe sie in die Ehe mit Paungartner eingebracht und sie hoffe, man werde es auch ihr lassen. Im Inventar stehe ein Silberbecher auf drei Füßlein, gemacht aus "porttn " ${ }^{611}$ und Ringen. Der gehöre ebenso ihr wie das inventarisierte Schatzgeld (Spargeld) von 44 Gulden I7 Kreuzern in einem Zwillichsäckchen, ferner 8 Gulden I 3 Kreuzer in kleinen Münzen, die sich in einer Schachtel ihrer Truhe befänden. Das sei Geld, das ihr Leute geschenkt hätten, besonders Verwundete, die ihr Mann verarztet habe. Sie erwarte, das alles würde ihr bleiben.

Weiter begehre sie ihr Leibgewand und Bettzeug, worauf sie gelegen sei, Kleinode, Kleider, Kopfputz und was zu ihrem Leib gehöre, die zwei Truhen, ein Drittel der fahrenden Habe und die Hälfte dessen, was sie mit ihrem jetzt verstorbenen Mann erwirtschaftet habe, weil sie ihr Gut dazu hergegeben habe.

Die Gegenpartei stellte alle Forderungen, die nicht belegt werden könnten ${ }^{612}$ oder über den Witwenteil hinausgingen, den die Tiroler Landesordnung vorsehe, in Abrede. Der Prokurator Margreths beharrte auf ihren Ansprüchen und wies darauf hin, die Witwe habe sich nicht in ein gemachtes Nest gesetzt, sondern ihren Säckel für den gemeinsamen Haushalt aufgetan. Die Verwandten seien nur darauf aus, »die frau auf ainen schnittlein abzerichten«. Die andere Seite blieb bei ihrer Ablehnung und konterte mit einer süffisanten Frage. Wer wolle es wohl glauben, »das ain solche schone frau der selbign zeit ain solchen on als vermugen genomen solt haben?« Das war natürlich kein Argument. Wie viele vermögende schöne Frauen haben sich in einen Habenichts verliebt und ihn geheiratet, nicht selten sogar ausgehalten?

Obgleich die Witwe angab, sie sei »nun alt unnd mit alter schwachhait ihres leibs beladen«, könne »kainer arbait mer vor [...] sein«, überließ ihr der Rat nicht einmal ganz das in die Ehe eingebrachte Gut. Daneben erhielt sie noch den gesetzlich vorgeschriebenen Witwenteil und einige private Kleinigkeiten. Der Rat sprach ihr die eigene Bettstatt, Bettgewand mit allem Zubehör, ihr eigenes Leinen und Leibgewand, ihre Kleider, Kleinode, Kopfputz und -tücher, ihre eigene Truhe und aus dem Silbergeschirr den Silberbecher mit den drei Füßlein zu, ferner einen Schuldbrief Peter Säppls über I oo Gulden, ${ }^{613}$ die ihr vom ersten Ehemann verschriebenen 50 Gulden samt 
dem guten Gulden, weitere Ioo Gulden, die ihr mit der Zeit zu entrichten waren, ${ }^{614}$ den Sack und das Fässchen mit Flachs samt allem gesponnenen Garn, ein Drittel der fahrenden Habe, ausgenommen alles Werkzeug und die Arzneien. Die Einnahmen, die seit dem Tod ihres Mannes aus Bad und Aderlassen erzielt wurden, sollten ihr bleiben, doch musste sie davon die Knechte oder andere für diese Zeit bezahlen. Das vorhandene Brennholz durfte sie bis Quatember Pfingsten für Bad und Haus verheizen, vom übrig bleibenden Rest des Holzes erhielt sie ein Drittel. Gleichermaßen durften ihre Knechte alles, was zum Verarzten notwendig war, bis zu diesem Termin nehmen und brauchen, es sei zu frischen Wunden, Beinbrüchen oder anderem. Was sie nicht verwendeten, musste an Ort und Stelle bleiben. Was zum Badebetrieb nötig war wie Badewannen, Badeschaffe, Barbierbecken, Schröpfköpfe, Kännchen, Bademäntel, Schöpfer, Instrumente in der Scherbank und anderswo, wie man es auch heißt, durfte die Frau bis zum Pfingstquatember (1 2. Juni) nutzen. Wurde etwas verloren oder zerbrochen, musste der Schaden gutgemacht werden. Nach diesem Termin hatte sie »alln zeug und hausrat«, wie erwähnt, den Erben zuzustellen.

Alle andere Barschaft, Silbergeschirr, Männerschmuck und -kleidung fielen an die Erbinnen. Die im Inventar vermerkten und nicht angezeigten »Schulden«, ${ }^{615}$ die noch zur Sprache kommen könnten, standen ebenso ihnen allein zu wie Geld, Kleinode und anderes, das Meister Matheus bei sich habe, wenn man ihn finde. Hatte Meister Matheus in seinem Leben Schulden gemacht, mussten sie von den Erbinnen beglichen werden, ohne die Witwe zu belasten. Sollte dank Gottes Gnade Meister Matheus gefunden werden, hatten sie ihn auf ihre Kosten in geweihtem Erdreich zu bestatten. Alle Unkosten, die bisher aufgelaufen waren oder noch entstehen konnten (für Trauergottesdienst, Spenden, Almosen an die Armen, Vertragsausfertigung, Beschreibung des Inventars und was sich sonst gebührte), gingen zu Lasten der drei Schwestern. Siegel- und Schreibgeld, Entlohnung der Prokuratoren hatte jeder Teil für sich zu tragen. Beide Parteien erhielten je ein Exemplar des Erbvertrages. Außerhalb des Vertrages wurde vereinbart, dass beide Teile dem »Maydl«, das Paungartner erzogen hatte und von dem in der Verhandlung gesprochen worden war, eine angemessene Entschädigung (»erbrige ergetzligkait«) geben sollten. ${ }^{616}$

Die ausführlich geschilderte Erbauseinandersetzung hat gezeigt, dass das Rattenberger Bad für eine Kleinstadt zumindest unter Paungartner sehr ordentlich ausgestattet war. Der Wert der Arzneien wurde offensichtlich von den drei erbenden Schwestern so hoch veranschlagt, dass sie sich sogleich ausdrücklich das alleinige Zugriffsrecht darauf bestätigen ließen. Da vermutlich das meiste des Badgeschirrs, der Arzneien und der chirurgischen Instrumente mit dem Geld der vermögenden Frau Meisterin gekauft worden war, ist sie in dieser Hinsicht bei der Aufteilung zu kurz gekommen. Im Inventar des verstorbenen Baders vermisst man die Erwähnung von Büchern der Wundarznei, die von späteren Prüfungsgremien verlangt wurden. Offensichtlich war das zu 
Abb. 77: Schröpf-(links) und Lasseisen (rechts);

Holzschnitt aus Johann Dryanders "Artzenei Spiegel《, 1557 .

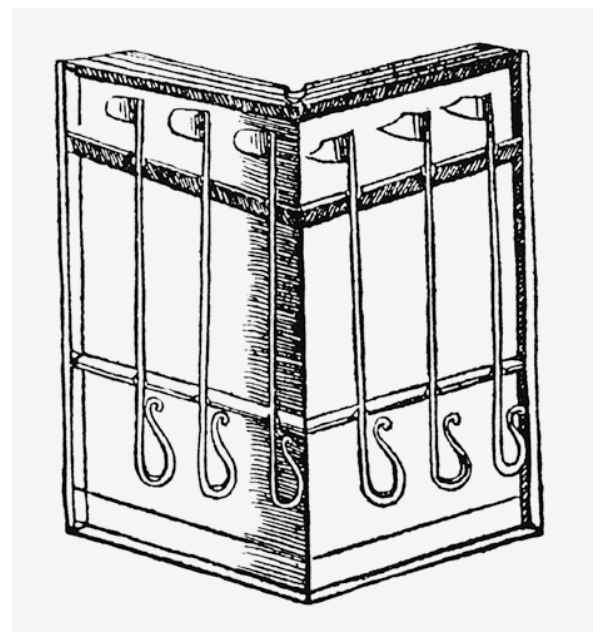

dieser Zeit noch keine Voraussetzung, um Wundarzt zu werden. Die Praxis stand noch im Vordergrund. ${ }^{617}$

Die Leiche Paungartners wurde gefunden oder angetrieben, er trug Geld bei sich, das hocherfreut Bürgermeister und Rat kassierten. Doch sie hatten die Rechnung ohne Utz Franntz gemacht. Er wandte sich im Namen seiner Frau und ihrer beiden Schwestern an die Innsbrucker Regierung, die prompt zu Gunsten der drei Erbinnen einschritt. Denn der Rat hatte in die landesfürstliche "Grundgerechtigkeit des Inns zu Rattenberg“ eingegriffen, wie es in einem Schriftverkehr (Mai/Juni I 549) der Regierung mit dem Hauptmann zu Rattenberg, dem Grafen Philipp von Liechtenstein, und dem Zöllner zu Rattenberg heißt. Die Grundruhr ${ }^{618}$ auf dem Wasser (Inn), ließ man den Grafen wissen, habe immer zum Zoll von Rattenberg gehört, sei vom Zöllner gefordert und mit der Kammer verrechnet worden. Dabei bleibe es. Der Graf solle den Zöllner nicht an der Ausübung dieses Rechtes hindern. ${ }^{619}$ Was das Geld »des ertrunckhnen Padmaisters zu Rattemberg Matheus Paunngartner« betraf, das bei ihm gefunden wurde, befahl die Regierung Marx Steger, dem Stadt- und Landrichter von Rattenberg, vom Rat das Geld einzufordern und es an die erwähnten Schwestern auszuhändigen. Die Stadt Rattenberg werde man entsprechend unterrichten. Der Rat gab klein bei und beschloss, dem Richter gegen eine Quittung das Geld zu übergeben. Denn es sei nun einmal so: Alles, was außerhalb des städtischen Burgfriedens geschehe, namentlich "was auf dem wasser verlustig wird, darin suecht di hoch obrigkhait iere gruntrecht «. In Zukunft werde man vorsichtiger handeln und begründeter vorgehen müssen, um darauf beharren zu können, dass kein Richter etwas mit einem Bürger zu schaffen habe. ${ }^{620}$ 
Von ihren Schwägerinnen, den drei Schwestern ihres verstorbenen Mannes ist Margreth Paungartner nicht in Unfrieden geschieden, zumindest nicht von der »Utz Franntz Schneiderin« (Waldpurga Paungartner). Ihr lieh Margreth gegen einen Schuldbrief 60 Gulden in bar. Dafür, wohl als Zinsen, sollte sie am kommenden Bartholomeitag (24. August) 30 Pfund Almschmalz erhalten. ${ }^{621}$ Mit dem Empfang von acht Gulden Sold für die ersten beiden Quatember des Jahres I $549^{622}$ war für Meister Matheus Paungartner selig und sie das Kapitel Rattenberg abgeschlossen. Die Witwe erscheint nie mehr in den Quellen der Stadt. Vermutlich ist sie in ihr Heimatdorf Vomp zurückgegangen.

\subsection{Hans Fäler d. Ä.}

Um die frei gewordene Stelle eines Baders und Wundarztes zu Rattenberg bewarben sich vier Männer, Michl Gasteiger »auf dem Ellend güetl«, ${ }^{623}$ Thoman Vierling von Kitzbühel, Hans Fäler, ${ }^{624}$ Wundarzt und Bader zu Vomp, und Geörg, Bader zu Hopfgarten. In einer Versammlung von Rat und Gemeinde am 30. April I 549 entschied man sich für Fäler, zunächst probeweise bis zu Dreikönige. Man gab ihm gleich einen kleinen Katalog an Vorschriften mit, nicht unbegründet, wie sich in der Folge zeigte.

Er solle sich gebührlich und gutwillig gegen jedermann, ob reich oder arm, betragen, heißt es, gute Knechte halten, auch solche von außerhalb der Stadt, solle einen Knecht mehr (als bisher) aufnehmen und das Bad gut versehen. Zudem wurde er verpflichtet, in Zeiten der Gefahr, bei Seuchen in der Stadt zu bleiben und nicht zu entfliehen, Inwohner zu werden, seinen Geburtsbrief beizubringen und am nächsten Quatember (Pfingsten) das Bad zu übernehmen. ${ }^{625}$ Binnen eines halben Jahres merkte die Stadt, wen sie sich da aufgehalst hatte. Die Vorhaltungen, die sie ihm bei der Weiterbestellung auf ein Jahr zu Dreikönige I 550 machte, sagen genug.

Er solle, verlangten Rat und Gemeinde, an Badtagen, besonders am Samstag, zu Hause bleiben, »die lotter puppn ruen laßn, sich nit überwein «, ${ }^{626}$ die »schadhaften« Leute nicht zuerst drannehmen, das schwere Fluchen unterlassen, sich gegen Ehefrau und Gesinde »gebührlicher, leydlicher weiß« benehmen, wie es einem Biedermann gezieme, das Holz nicht dort stapeln, wo die Wannen stünden, denn der Fußboden koste viel. ${ }^{627}$ Mit einem Wort: Er war ein widerlicher, fauler, liederlicher, trunksüchtiger Patron.

Sein ungutes Wesen hatte er schon in der Verhandlung um das Erbe des ertrunkenen Matheus Paungartner gezeigt, an der er als Rechtsbeistand teilgenommen hatte, nicht der Witwe, sondern der Gegenseite, der drei Schwestern Paungartners. Fäler wurde auch zweimal von ihrem Prokurator als Kronzeuge dafür aufgerufen, dass Paungartner in Schwaz kein besonders tüchtiger Wundarzt gewesen sei und dass die Witwe Margareth keineswegs, wie von der Gegenseite behauptet, so viel Gutes dem Meister 
Matheus getan hätte, als er »in der salbn gelegen« sei. ${ }^{628}$ Man kann nur rätseln, weshalb er sich so als Gegner der Witwe seines einstigen Blutsbruders aufführte. Hatten die drei Schwestern versprochen, ihm das Badgeschirr, die chirurgischen Instrumente und Arzneien, die sie ja geerbt hatten, zu einem günstigen Preis zu überlassen, wenn er ihre Interessen wahrnahm? War er ein von Margreth Paungartner verschmähter Liebhaber aus ihrer Jugendzeit, als sie eine sehr schöne Frau gewesen war? Schließlich stammte sie aus Vomp, war Fäler Bader in Vomp und liegt dieser Ort dicht bei Schwaz, wo Matheus Paungartner seinen Blutsbruder Fäler zur Wundarznei beigezogen hatte.

Die Zurechtweisung am Dreikönigstag hatte offensichtlich nichts gefruchtet. Schließlich riss dem Bürgermeister die Geduld. Am I 5. Juli I $55^{\circ}$ hat er den Bader Hans Fäler »überhoblt und wol capitlt« (kritisiert und abgekanzelt), trug der Stadtschreiber genüsslich ins Protokoll ein. Der Bürgermeister hielt ihm vor, dass er täglich mit seiner Hausfrau, seinen Knechten und Dienstboten poltere und schelte, nichts leide er an ihnen, obwohl er sich selbst nicht um das Bad kümmere, sondern es durch Buben versehen lasse, die er aufgenommen habe. Das sei man nicht gewohnt. Früher habe man gute Knechte gehabt und die wolle man wieder haben, damit das Bad nicht in Verruf komme. Er solle sich auch im Trinken mäßigen, denn aus der Trunkenheit erwachse aller Hader. Wolle er Besserung geloben, schön, wenn nicht, müsse er sich nach etwas anderem umsehen. ${ }^{629}$

Auch bei der Neubestellung zu Dreikönige I 55 I musste man ihm wieder ernstlich ins Gewissen reden. Wenn er sich für seine Person weiter im Bad säumig erzeige, sich nicht mit guten Knechten versehe, nicht besser das »ertznen« ausübe, werde man ihm jederzeit das Bad aufkündigen. Vor allem solle er das widerliche Gotteslästern und sein übles Benehmen gegen seine Hausgenossen unterlassen. Ein Bewerber um das Bad, der Badknecht Sigmund Pühlhueber, wurde noch abgewiesen. ${ }^{630}$

Ein Jahr später noch immer keine Besserung. Wieder wurde von Fäler verlangt, er solle tüchtige Knechte aufnehmen, die jedermann dienen wollten und die er so zu behandeln habe, dass sie bleiben. Er selbst solle fleißig im Verarzten sein und zu Ende bringen, was er angefangen habe. Er dürfe die Leute nicht ausnehmen und müsse Badbesucher, die eine gefährliche Krankheit wie die Franzosen hätten, abweisen. Er solle endlich sein Fluchen sein lassen, seine Knechte und andere mit ruhigen Worten davon abbringen. Das Bad sei zur rechten Zeit zu heizen, damit nicht immer so viel Rauch darin sei. Außerdem wurde ihm verboten, sich, wenn er sich betrunken hätte, unziemlich gegen Frau und Kinder zu benehmen. ${ }^{631} \mathrm{Zu}$ Dreikönige I 553 machte man es kurz. Fäler wurde zwar auf ein Jahr weiterbestellt, doch ihm zugleich angedroht, wenn er nicht seine ungeschickten Worte und das Trinken lasse, werde ihm der Dienst aufgekündigt werden. Der Sold bleibe bei I 6 Gulden wie früher. ${ }^{632}$

Bei der Ämterbesetzung I 554 hatte man die Geduld mit Fäler verloren. Sein Dienst wurde nur noch von Quatember zu Quatember verlängert, die Steuerfreiheit, um die 
er angesucht hatte, wurde ihm verweigert. ${ }^{633}$ Entrüstet kündigte er am r6. Februar das Bad auf, was nur zu gern angenommen wurde. Zum nächsten Quatember sollte er es räumen. Dann überlegte er es sich wieder anders, war bereit, die ihm auferlegte Steuer zu zahlen, woraufhin ihm der Rat das Bad zu den früheren Bedingungen, also mit Kündigung von Quatember zu Quatember, überließ. ${ }^{634} \mathrm{Ob}$ sich nun Fäler gebessert, der Rat resigniert oder Mitleid bekommen hat - schließlich war der Bader schon über 50 Jahre alt ${ }^{635}$-, in der Folge steht bei den jährlichen Ämterbesetzungen nur lakonisch »Bader: Hans Fäler«, ohne weiteren Kommentar. ${ }^{636}$ Erst I 566 und I 567 liest man wieder Zusätze: Zunächst heißt es, er solle einen Knecht, der zur Ader lassen könne, anstellen und den Tuesmwar im Bad unterbringen ( I 566), ${ }^{637}$ im Jahr darauf verlangte man von ihm, besonders auf seine Söhne aufzupassen, dass sie sich nicht »also füllen« und im Bad an der Scherbank fleißiger sind. ${ }^{638}$ Sie hatten offensichtlich zu gut vom Vater gelernt, was Trinken und Faulheit betraf.

Wohin das an Fäler gerügte Fluchen und Gotteslästern führen konnte, zeigt ein Vorfall aus dem Jahr I 553. Im Dezember verklagte ihn der städtische Vikar Georg von Rocca vor dem Rat, Meister Hans habe ihn einen Schelm und verlogenen Pfaffen gescholten. Der Geistliche glaubte, das sei nicht persönlich gemeint, sondern eine gezielte Gotteslästerung gewesen. Ein solches Schmähen der Ehre Gottes könne er nicht dulden. Fäler bestritt, Rocca einen Schelm genannt zu haben, gestand aber das Wort vom verlogenen Pfaffen ein. Dazu hätte der Priester selbst den Anlass gegeben. Ansonsten zweifle er nicht an seiner »frumckhait«. Meister Hans musste Abbitte leisten, der Rat vereinte beide gütlich. Der Streit war anscheinend über die Höhe der Behandlungskosten entstanden. Denn für Purgieren, Verarzten, Bad und anderes, was Fäler dem Vikar geleistet hatte, sollte nach dem Entscheid des Rates Herr Georg dem Bader drei Taler und seiner Hausfrau 36 Kreuzer geben. ${ }^{639}$

Eine grundsätzliche Gegnerschaft Fälers zu Klerus und Kirche wird man aus dieser Episode nicht herauslesen dürfen. Denn I 563 trug der Rat dem Frühmesser Wolfgang Antzinger und dem Bader auf, sich konzilianter gegen die Leute zu verhalten und nicht tropfnass aus dem Bad unters Volk zu gehen. Meister Hans solle überhaupt nicht in das Bad gehen. ${ }^{640}$ Offenbar verstanden sich die beiden gut.

Reiberinnen und Gewandhüterinnen werden unter Hans Fäler d. Ä.vom ersten Jahr seiner Amtszeit erwähnt, mit oder ohne Namen. ${ }^{641}$ Die alt bekannten Vorwürfe werden wieder erhoben: Sie sollen fleißiger sein ${ }^{642}$ und nicht so viel trinken. ${ }^{643}$

Ende I 562 brach im Bergbaugebiet um Schwaz eine Seuche aus, die sich zur größten des Landes im I6. Jahrhundert entwickelte, gebietsweise bis ${ }_{5} 66$ anhielt und auch ab ${ }_{5} 63$ Rattenberg ernstlich bedrohte. In Kitzbühel erlagen ihr allein vom Frühsommer bis Dezember ${ }_{5} 64$ an die 500 Menschen, von denen 3 I 8 namentlich bekannt sind. ${ }^{644} \mathrm{Da}$ die Seuche schon länger in Bayern wütete, erließ bereits im November I 562 die Innsbrucker Regierung einen Befehl an die Stadt Rattenberg, sich mit Priestern, 
Abb. 78: Aderlass; Miniatur aus einer Handschrift des I4. Jh.



Lässln und anderen Personen, die den Infizierten aufwarten sollten, zu versehen. Der Rat beauftragte Hans Fäler, sich um einen Lässl zu kümmern. Als es ihm nicht gelang, einen solchen aufzutreiben, erbot er sich, wenn eine schwere Krankheit einreißen sollte, selbst als Lässl der Gemeinde zur Verfügung zu stehen. Er werde dann seinen Haushalt und sein Gesinde verlassen und sich an einen Ort begeben, den ihm die Gemeinde bestimmen werde. ${ }^{645}$. Als im Sommer ${ }_{15} 63$ die Lage auch für Rattenberg kritisch wurde, erneuerte Meister Hans seine Bereitschaft, die Infizierten zur Ader zu lassen, falls die Seuche eindringe. Der Rat nahm ihn daraufhin zum Totenlässl auf und bestimmte ihm vom 3 I. August an ein Wartegeld von einen Gulden wöchentlich, das sich mit der ersten »Läß auf zwei Gulden 24 Kreuzer erhöhen sollte. ${ }^{646}$

Anscheinend benötigte man jedoch Meister Hans im eigenen Bad, denn am Dreikönigstag I 564 trug ihm der Rat auf, einen Knecht als Totenlässl für den Fall zu besorgen, dass das Sterben einreißen sollte. Fäller präsentierte Andre Kupferschmidt, einen Badknecht aus Ofen in Ungarn, der gegen ein wöchentliches Badgeld von 36 Kreuzern, das man später auf vier Pfund (= 48 Kreuzer) erhöhte, aufgenommen wurde. Fäller erbot sich, ihn zu verköstigen. Wenn die Seuche auftrete und der erste Aderlass vorgenommen werde, sollte Kupferschmidt zwei Gulden je Woche erhalten. Eine passende Herberge werde man ihm noch zuweisen, erklärte der Rat. ${ }^{647}$ Als die Seuche zu Beginn des Sommers in die Stadt eindrang, wurde dem Badknecht Andre als verordnetem To- 
tenlässl das Haus des Tischlers Peter Rixner zugewiesen, worin er sich eine bestimmte Zeit aufhalten sollte. Bett und Bettzeug erhielt er vom Spital, sein Lohn wurde auf zwei Gulden angehoben. ${ }^{648}$

Kupferschmidt als Totenlasser kostete die Stadt in einem Jahr 75 Gulden I 2 Kreuzer an Lohn. ${ }^{649}$ Dazu kamen noch Aufwendungen für Arzneien in der Höhe von I 2 $\frac{1}{2} 2$ Gulden, die man beim Apotheker in Schwaz besorgt und dem Totenlässl übergeben hatte. ${ }^{650} \mathrm{Da}$ sich der Mann aus Ungarn eine Weiterbestellung überlegte, erklärte im Januar I 565 Meister Hans, er werde einen Badeknecht als Totenlässl suchen. Sollte er keinen finden, werde er selbst diese Aufgabe übernehmen. Andre Kupferschmidt machte vor dem Abzug beim Rat noch Forderungen von 24 Gulden und einem Taler an verschiedene Personen oder ihre Erben für die Betreuung in der Infektionszeit geltend. ${ }^{651}$ Wie viele ihn schon für Sonderdienste bezahlt hatten, wird nicht gesagt. Totenlässl zu sein war ein lukratives Geschäft. Welcher Handwerker verdiente schon mehr als roo Gulden im Jahr? Doch wer wollte auch schon ein so lebensgefährliches Risiko auf sich nehmen? Die Seuche scheint zu Beginn ${ }_{5} 6_{5}$ in Rattenberg erloschen zu sein.

Eine wichtige Neuerung machte sich während Fälers Dienstjahren bemerkbar, nämlich die Verringerung der Badetage. Anfang Juli ${ }_{5} 56$ bat er den Rat, ihm in der Woche (mittwochs) den Badetag zu erlassen, wenn kein Feiertag sei. Damit er Holz spare, gestatteten ihm dies die Herren bis auf Laurenti (ro. August), doch solle er fleißiger sein und den Leuten besser aufwarten. ${ }^{652}$ Die Arbeit hatte er anscheinend noch immer nicht erfunden. Von einem Montag als Badetag ist nicht mehr die Rede. Die Begründung für die Bewilligung lässt erkennen, dass in Rattenberg die Brennholzpreise angezogen hatten. ${ }^{653} \mathrm{Um}$ den Bader zu unterstützen, war schon früher der Baumeister angewiesen worden, ihm Holz zu geben. ${ }^{654}$

Das Wochenbad bereitete Fäler nach wie vor Schwierigkeiten. I 564 suchte er erneut an, unter der Woche, und zwar Mittwochabend, nur dann ein Bad zu halten, wenn in dieser Woche ein Feiertag sei. Der Rat beschloss, wenn die Feiertage mitten in die Woche fielen, solle er das Bad halten. Geschehe das zwei Wochen nacheinander, dürfe er eines ausfallen lassen. ${ }^{655}$ Zwei Jahre später bat er überhaupt um die Einstellung des Wochenbades, weil niemand käme. Der Rat lehnte zunächst ab, aber versprach, nach Pfingsten sein Begehren zu überdenken. Man glaube, »es werde sich selbs einstellen «. ${ }^{656}$ Ein Jahr später begehrte der Bader erneut vom Rat, das Wochenbad einstellen zu dürfen. Wieder blieb es bei der Feiertagsregelung. Der Rat erlaubte ihm gnadenhalber, das Bad ausfallen zu lassen, sofern der Mittwoch, Donnerstag oder Freitag kein Feiertag sei. $^{657}$

Eingangs wurden die größten Pflichtversäumnisse erwähnt, die der Rat längere Zeit Meister Hans vorhielt. Darunter befand sich auch die Aufforderung, besser zu »ertznen«. Anscheinend hat er sich den Tadel zu Herzen genommen, wie einige wenige 
Abb. 79: Aderlassschnepper im Kästchen, I8. Jh.

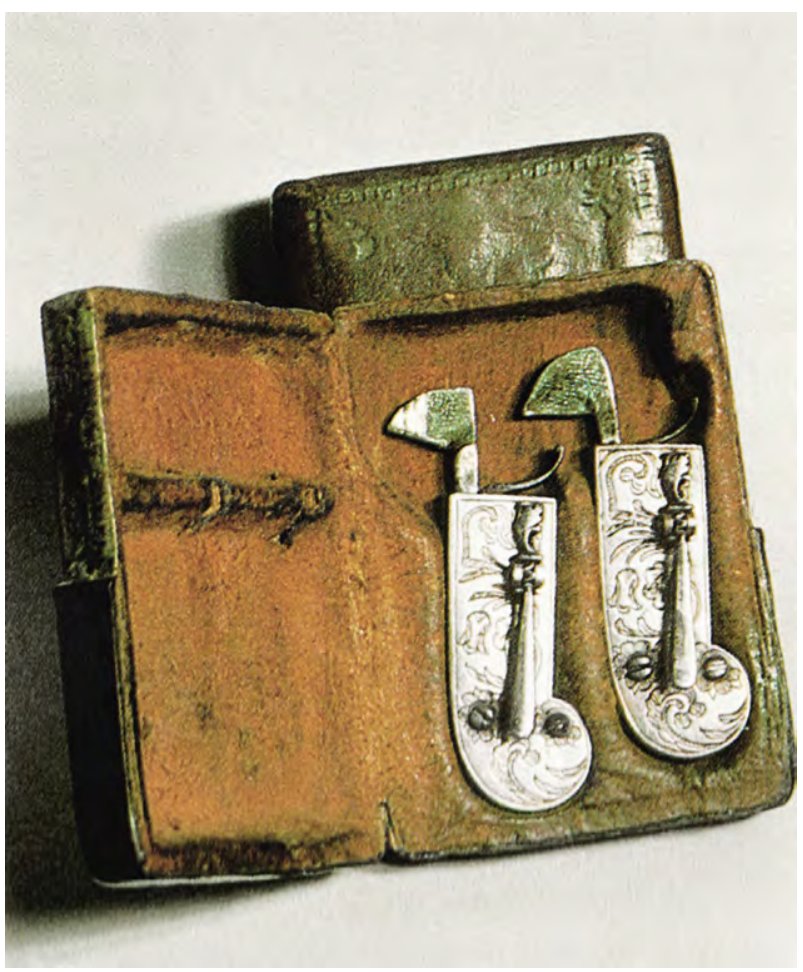

Zeugnisse öffentlicher Quellen (private fehlen) erkennen lassen. Nach dem oben angeführten Hinweis auf die erfolgreiche Behandlung des Rattenberger Vikars Georg von Rocca stößt man auf die Klage des Krämers Balthasar Simon gegen den Metzger und Wirt Stefan Merl wegen fahrlässiger Körperverletzung, Arztkosten und Schmerzensgeld. Passiert war Folgendes: Als Balthasar von der Lende eine Trage Salz in die Stadt trug, kam er an Merls Haus vorbei. Dessen Leute ließen gerade eine Tür herab, die ihnen aber aus den Seilen glitt, den Balthasar am Kopf traf und zu Boden warf. Hans Fäler, der ihn ärztlich versorgte, erklärte vor dem Rat, Balthasars Hirnschale sei »erschrickht«, gesprungen gewesen wie Glas, doch sei kein Knochen hervorgetreten. Der Rat sprach Fäler vier Gulden, Simon zehn Gulden zu, womit auch Zehrungskosten und eine Entschädigung für die Versäumung seiner Geschäfte eingeschlossen waren. Die Sache kam dann noch vor den Richter, der den Schadenersatz für Simon auf acht Gulden begrenzte und einschreiben ließ, der Bader wolle fünf Gulden haben. ${ }^{658}$

Viermal ist Hans Fäler in seiner Eigenschaft als Wundarzt in den Rattenberger Spitalrechnungen erfasst. I 55 I erhielt er für seine ärztliche Tätigkeit im Spital am Töch- 
terl des Fischers Wolfgang Taurstein, an einem Stummen und an den armen Leuten, die er verbunden hatte, vier Gulden 48 Kreuzer, I 557 bekam er seinen Arztlohn für die Behandlung von »Paungartners Dirndl«, also dem Mädchen (Magd) des Bäckers Hans Paungartner, dem der Spitalknecht Lentz den Arm abgeschlagen hatte, und ${ }_{5} 63$ und I 564 bestand seine Arbeit im Verbinden der armen, kranken Leute im Spital. ${ }^{659}$

Etwas undurchsichtig ist Fälers Klage gegen den Bäcker Bartlme Pettendorfer, der anscheinend bestimmte Kosten nicht allein tragen konnte oder wollte. Man habe seiner Schwester, als sie krank war, Wein »auf ainen Span«, ${ }^{600}$ d.h. auf Rechnung, vom Wirt Bernhard Ruedl zutragen lassen, der jetzt dafür mit vier Gulden I 6 Kreuzern bezahlt sein wolle. Der Rat teilte die Summe auf die Stadt- und Bergwerksbruderschaft, das Reichalmosen, Pettendorfer und Hans Fäler auf, der einen Gulden hergeben sollte. ${ }^{661}$ Wahrscheinlich war Folgendes geschehen: Fäler behandelte die kranke Schwester Pettendorfers und empfahl, ihr zur Stärkung Wein zu geben. Nun konnte Pettendorfer, dessen Armut notorisch war, ${ }^{662}$ nicht zahlen, weshalb sich der Wirt an Fäler hielt, der offenbar den Wein verordnet, vielleicht auch bestellt hatte. Der Rat war nun der Meinung, der Bader könne sich mit einem Gulden von seinem Honorar an der Bezahlung des Weins beteiligen.

Hans Fäler d. Ä. ist der einzige Rattenberger Bader, der nachweislich als Leichenbeschauer bei Tötungsdelikten tätig war. Bei der Erörterung der Trinkstube im Rattenberger Badhaus wurde schon auf den Tuchscherer Jörg Erber hingewiesen, den der Vikar Niclas Neuhauser erschossen hatte. Am I 8. Februar I 556 kam es im Beisein des Stadt- und Landrichters und anderer Personen zum Bahrrecht. Fäler beschaute den Leichnam Erbers, stellte kleinere Wunden, die jedoch nicht gefährlich und verbunden gewesen seien, fest und konzentrierte sich auf den einen tiefen Schuss mitten durch das Herz. Seiner Meinung nach war Erber an diesem Schuss gestorben, was alle Anwesenden bejahten. ${ }^{663}$

Wesentlich mehr Arbeit hatte der Rattenberger Bader im nächsten Jahr. Am 22. März I 557 versammelten sich in der Stube des Richters zwei Rattenberger Bürger, sieben Rattenberger Gerichtsmannen als Beisitzer, der Richter und noch andere Leute, darunter Caspar Scheiber, Bader zu Brixlegg, Cristan Puchinger, Arzt in der Wildschönau, und Hans Fäler, Bader zu Rattenberg, zum Bahrrecht, um in der Behausung des Erzknappen und Rattenberger Bürgers Jörg Hueber dessen Leiche zu beschauen. Er sollte durch einen Stich in die Wange beim Auge, den ihm der Rattenberger Bäcker Lamprecht Lechner zugefügt hatte, zu Tode gekommen sein. Die Leichenschau Huebers, der als »ain alte verlebte person« bezeichnet wurde, nahm Fäler vor.

Auf die Aufforderung des Richters hin erklärte der Bader unter Eid, die Wunde, die Hueber erhalten habe, sei nicht die Ursache seines Todes gewesen. Er hätte auch an den vielen anderen Krankheiten, unter denen er gelitten habe, nicht sterben müssen. Die ihm von Lechner zugefügte Wunde habe schon begonnen zu heilen, wäre in vier 
Abb. 8o: Bindfutter, d. h. Futteral für das Werkzeug eines Wundarztes (z. B. Messer, Brandeisen, Zahnzange, Verbandszeug, Salben); Holzschnitt aus Johann Dryanders "Artzenei Spiegel«, 1557.

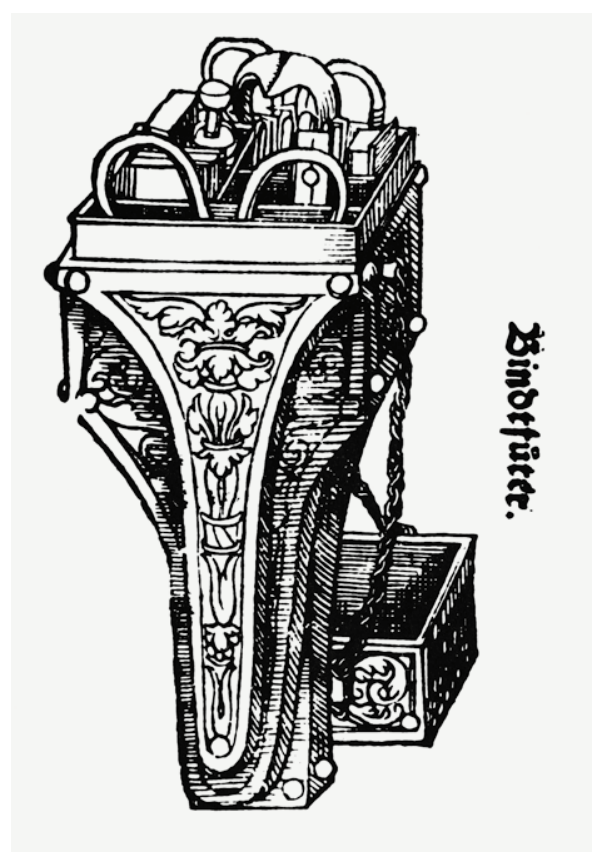

Tagen ganz ausgeheilt gewesen und hätte nicht mehr verbunden werden müssen. Seiner Ansicht nach habe Hueber »der gewalt Gottes«, der Schlag getroffen. Die beiden ärztlichen Kollegen schlossen sich Huebers Urteil an - auf den vermuteten Schlaganfall gingen sie nicht ein, woraufhin die sieben Beisitzer einhellig erkannten, Hueber sei nicht an dem zugefügten Stich in die Wange und an anderen bei ihm aufgetretenen Krankheiten gestorben. ${ }^{64}$ Meister Hans Fäler zeigte sich bei beiden Bahrrechten also durchaus als kompetent, um auch Positives über ihn zu erwähnen.

Eine weitere Nachricht zeigt ihn als Geber eines kleinen Kredits. Der verarmte Schneider Christof Staindl wurde I 562 ins Spital aufgenommen, wogegen er auf sein Hab und Gut verzichten musste. Davon sollten seine fünf Gläubiger, die zusammen 42 Gulden zu erhalten hatten, bezahlt werden. Unter ihnen war Hans Fäler. ${ }^{665}$ Der Anspruch von jedem der fünf kann nicht besonders hoch gewesen sein.

Bei der Ämterbesetzung am Dreikönigstag I 568 sagte Hans Fäler das Bad auf, weil er es wegen seines Alters nicht mehr versehen könne, und bat gleichzeitig, es seinem Sohn Hans zu übergeben. Hans Fäler d. J. wurde deshalb zum neuen Meister aufgenommen und ihm das Bad zu denselben Bedingungen wie seinem Vater überlassen. Er gelobte, was man von ihm forderte, nämlich fleißig zu sein und nicht absichtlich nachlässig zu werden. ${ }^{666}$ Hans d. Ä. dürfte in den nächsten Jahren gestorben sein. ${ }^{667}$ Denn im Juli I 572 erschienen Hans Fäler d. J. und sein Bruder Bernhard mit der Bitte vor 
dem Rat, er möge erlauben, dass Dolch und Siegelring, die Bernhard von seinem Vater geerbt hätte und die jetzt sein Gerhab verwahre, dem Hans ausgehändigt würden. ${ }^{668}$

\subsection{Hans Fäler d. J.}

Auf seine Bitte hin erteilte ihm der Rat gegen eine Gebühr von zwei Gulden und einer halben Pazeide (= ca. $3^{1 / 4}$ 1) Wein für die Herren das Inwohnerrecht. ${ }^{669}$ In jugendlichem Übermut schor der neue Meister einem gewissen Urban ein Kreuz auf den Kopf. Dem gefiel das gar nicht, dem Rat noch weniger, weshalb er Hans Fäler jr. zu einem Gulden Strafe und zum Einsitzen auf ein Tor verurteilte. ${ }^{670}$ Geschadet hat es dem jungen Mann nicht, denn er wurde zunächst klaglos von Jahr zu Jahr als Bader weiterbestellt. ${ }^{671}$ Das Dienstgeld war wie üblich I6 Gulden. ${ }^{672}$

Bei der Ämterbesetzung zu Dreikönige 1574 fanden Rat und Gemeinde so Einiges an ihm zu bemängeln. Er solle besser das Bad versehen, heißt es, künftig Vogeltennen und das Schießen meiden, gute Knechte halten, die »Miterbad « wie seit alters zurichten, eine stille Ordnung in Bad und Haus führen und Holz zum »Frauenstübl« hergeben. ${ }^{673}$ Dass es laut in der Badstube hergehen konnte, wird auch von anderen Orten erwähnt. Was wollte ein Bader dagegen machen. Das Frauenstübl bezieht sich auf den I 573 neu errichteten Anbau zur Frauengarderobe, wie bereits in anderem Zusammenhang erwähnt. Dass Hans Fäler sich weigerte, es mit seinem Holz beheizen zu lassen, hing mit den mehr und mehr steigenden Preisen für Brennholz zusammen. Deshalb suchte er immer wieder um die Erlaubnis an, das Bad am Mittwoch ausfallen lassen zu dürfen. Er verzeichnete beim Rat nur Teilerfolge. So wurde ihm im Januar I 572 auf seine Bitte hin gestattet, das Bad wegen der Kälte jeden zweiten Mittwoch geschlossen zu halten, ein Jahr später erlaubte ihm der Rat im Juni, bis auf Widerruf das Mitterbad einzustellen. ${ }^{674}$

Am 6. Januar I 575 durfte er sich wieder einige Vorwürfe anhören: Er solle sich des Weins enthalten, verlangte man, gute Knechte einstellen, das Mitterbad nicht ohne Bewilligung durch Bürgermeister und Rat ausfallen lassen, solle nicht "selbs« fortgehen oder so weite Reisen machen. ${ }^{675}$ Damit ist gemeint, dass er von solchen Reisen den Rat zu unterrichten und seine Zustimmung einzuholen hatte. Schließlich hatte er ja als Bader und Wundarzt Pflichten in der Stadt. Bei dem Bad am Mittwoch kam man ihm bald entgegen. Noch im Januar wurde ihm erlaubt, es bis Ostern nur alle I4 Tage zu halten, im März allerdings jede Woche. Nach Pfingsten durfte er es dann überhaupt einstellen. ${ }^{676}$

Während die Vertragsverlängerungen I 576, I 577, I 580 und I 58 I klaglos über die Bühne gingen, ${ }^{677}$ hieß es bei der Wiederbestellung 1578 , er solle die »schadhaften« Leute nicht neben und unter die anderen setzen, kein Pflaster oder sonstige Unsauberkeit im Bad auf den Boden werfen und liegen lassen, das Brunnenbecken sauber halten 


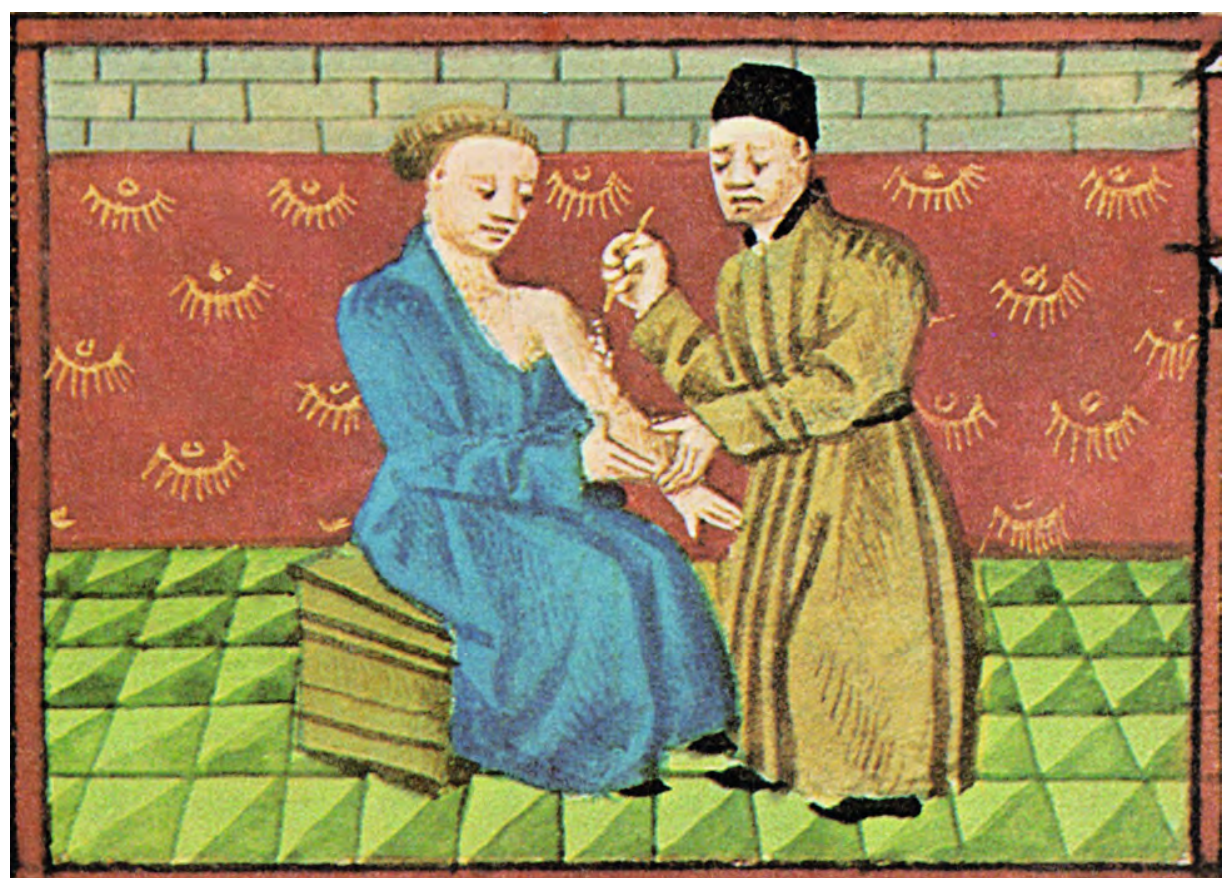

Abb. 8I: Behandlung von Furunkeln; Miniatur aus einer französischen Übersetzung von "De proprietatibus rerum « des Bartholomäus Anglicus, I5. Jh.

und niemandem gestatten, sich darin zu waschen, auch solle »er sich etlicher schäden, so ime zu hailen nit gebüren, keineswegs nit unnderfahen oder annemen ${ }^{678}$ : Fäler sollte also nicht in die Befugnisse der Ärzte eingreifen.

Damit sind fremde Ärzte, nicht etwa ein Stadtarzt zu Rattenberg gemeint. Den gab es hier immer noch nicht. Die Rattenberger Ratsprotokolle des Untersuchungszeitraums erwähnen nie einen eigenen Arzt. Dr. Johannes Kuefner, ein Enkel des Rattenberger Brauers Peter Kuefner, hat nach Ausweis der Quellen nie in Rattenberg praktiziert. ${ }^{679}$ Er studierte Medizin in Mainz und vermutlich Bologna, kehrte nach Abschluss seines Studiums um I 535 nach Rattenberg zurück, war von I 538 bis I 543 Stadtarzt in Hall und ging dann außer Landes, wo er sich hauptsächlich als medizinischer Schriftsteller betätigte. I 553/54 verliert sich seine Spur in Italien und Frankreich. ${ }^{680}$

Benötigte man in Rattenberg einen studierten Arzt (»Bucharzt«), musste man sich nach außerhalb wenden. ${ }^{61}$ Werden die Rechnungen des dortigen Augustinerklosters genauer, erfährt man auch den Wohnsitz des nächsten Arztes, nämlich Schwaz. Ihn konsultierten die Mönche, bei ihm oder beim Schwazer Apotheker holten sie sich auch die nötigen Arzneien. ${ }^{62}$ Einen eigenen Apotheker stellte Rattenberg erst I 566 ein. Nachdem 


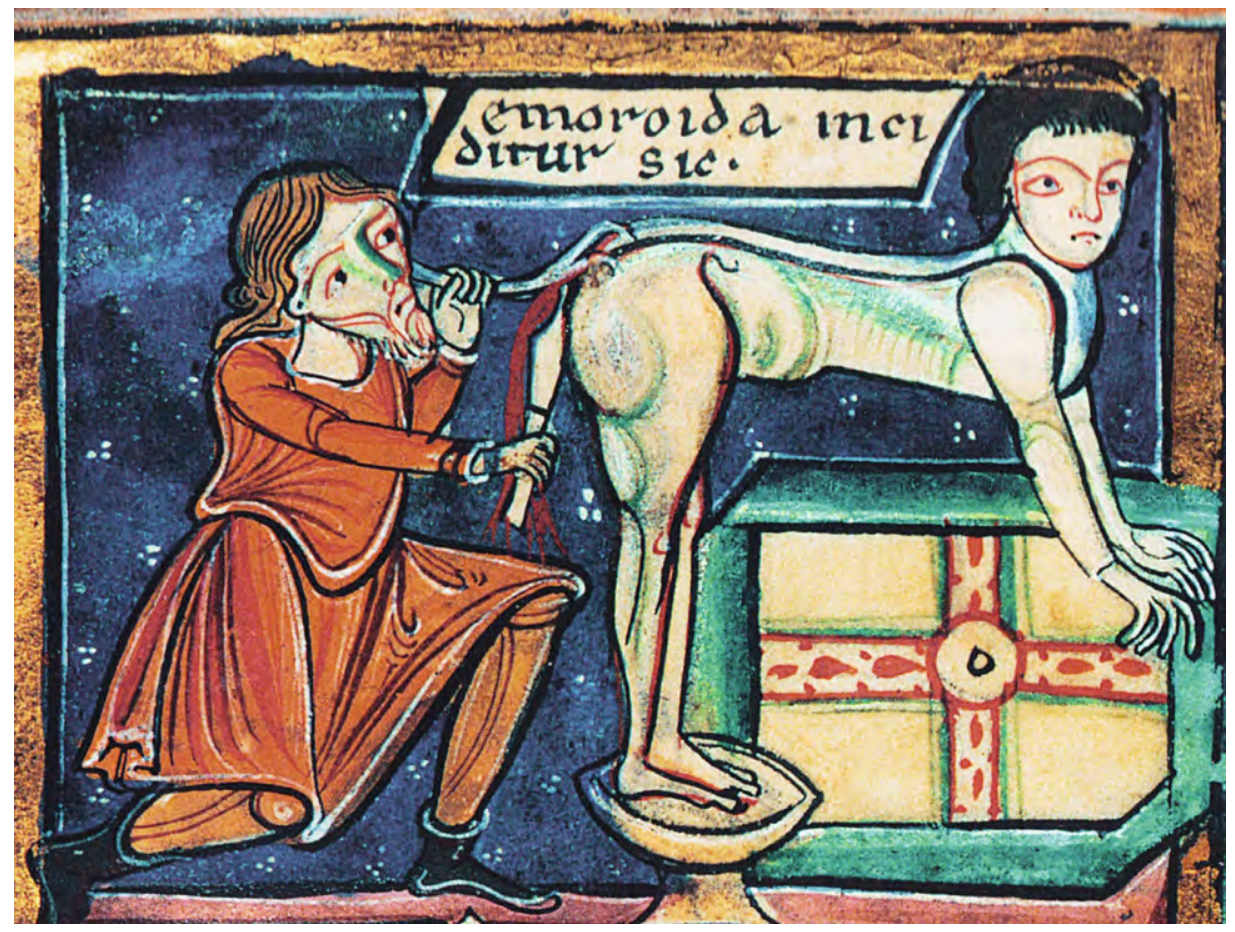

Abb. 82: Wundarzt schneidet mit einem Skalpell Hämorrhoiden aus; Miniatur aus einer englischen Handschrift, Ende I2. Jh.

Hans Baptista Frölich (Frelich) die nötigen Unterlagen beigebracht hatte, erhielt er am 25. Februar 1566 vom Rat das Bürgerrecht. ${ }^{683}$ Allerdings scheint Frölich weniger mit Arzneien und Heilmitteln, als mit anderen Waren seinen Verdienst gefunden zu haben. So schuldete er 1566 einer Kaufmannswitwe 230 Gulden für Waren im »Spetzgerladen«, ${ }^{684}$ machte er der Stadt 1567 acht Windlichter und lieferte ihr 450 Nägel. ${ }^{685}$

Wenn alle Hausmittel nicht gewirkt hatten, dürften Erkrankte in der Stadt Hans Fäler und andere seiner Berufsgenossen auch in solchen Fällen um Hilfe gebeten haben, die nicht zur Wundarznei gehörten, sondern in die Kompetenz akademisch gebildeter Mediziner fielen. ${ }^{686}$ Wer wollte denn gleich immer zum Herrn Doktor nach Schwaz (ca. I7 km entfernt) gehen, reiten, fahren oder schicken, zumal sein Honorar ziemlich sicher höher gewesen ist als das des heimischen Wundarztes? Also versuchte man es zunächst mit ihm, anscheinend mit Erfolg, sonst hätte der Rat Hans Fäler nicht nur wegen seiner Übergriffe in fremde Zuständigkeiten zurechtgewiesen, sondern auch seine misslungenen Kuren angeprangert. Wer ihn angeschwärzt hat, Neider in Rattenberg oder der Doktor in Schwaz, erfährt man nicht. 




Abb. 83: Badende Männer und Frauen in einem Bassin mit Brunnen; Miniatur von Jörg Glockendon d. J. in einem Brevier, $1542 / 44$.

Als Hans Fäler bei der Weiterbestellung zu Dreikönige I 579 um eine Lohnaufbesserung wegen der gestiegenen Holzpreise bat, musste ihn die Stadt wegen allerlei sonstiger Verpflichtungen abschlägig bescheiden. ${ }^{687}$

Mit den Gewandhüterinnen und Reiberinnen, die während seiner Amtszeit mehrfach in den Protokollen aufscheinen, scheint er keine Schwierigkeiten gehabt zu haben. Es waren wieder Hausfrauen bzw. Witwen verarmter Handwerker. ${ }^{688}$ Der Rat allerdings hatte hin und wieder schon etwas an den Matronen zu bemängeln. Es sind die altbekannten Vorwürfe, wenn 574 die Pockhin Reiberin und Pichlin Gewandhüterin ermahnt wurden, fleißiger als bisher zu sein und sich gebührlicher zu verhalten, sonst seien sie auf der Stelle ihren Posten los, ${ }^{689}$ wenn man 1575 diese Warnung an die Pockhin wiederholte, ${ }^{690}$ wenn man 1576 die neue Reiberin, die alte Plaicknerin, anwies, fleißig zu sein und nicht zu viel Wein zu trinken. ${ }^{691}$

Obwohl Hans Fäler d. J. auch ein Wundarzt war, finden sich keine Einträge zu seiner medizinischen Tätigkeit, sehr wohl aber zu seinem anstößigen Verhalten. Bei einer Hochzeit, die am 2 I. Januar 575 im Haus des Wirtes und Bürgermeisters Georg Kremer stattfand, benahm er sich ganz »schimpflich« und gebrauchte ungebührliche Worte gegen den Herrn Hauptmann. Er wurde am nächsten Tag wegen groben Unfugs auf einen Turm geschafft und Anfang Februar mit zwei Gulden bestraft. Außerdem musste er dem Rat geloben, in Zukunft ungebührliche Worte gegen den Hauptmann und die Seinigen zu unterlassen. ${ }^{62}$ Auch das scheint er von seinem Vater gelernt zu haben.

Die folgende Angelegenheit beruhte auf einer irrigen Annahme Fälers. I 579 erschien Michel Weingarter, Badermeister zu Schwaz, vor dem Rattenberger Rat und beschuldigte Meister Hans, er habe ihn zu Unrecht in einem Schreiben an das Bader- und Barbierhandwerk zu Schwaz der Ehren bescholten. Fäler entschuldigte sich und erklärte die Sache wie folgt. Vor ungefähr acht Jahren, als Weingarter bei ihm Lehrjunge 




Abb. 84: Rattenberg; kolorierter Stablstich von Friedrich Würthle, 1852.

des Baderhandwerks gewesen sei, wären ihm etliche Scheren, Schermesser und dergleichen abhanden gekommen. Im Glauben, Weingarter sei irgendwie in den Diebstahl verwickelt gewesen, habe er nach Schwaz geschrieben. Er habe sich geirrt und bezichtige weder Weingarter noch einen anderen Lehrjungen und Bader, die damals bei ihm gearbeitet hätten, des Diebstahls. Der Rat konnte beide Parteien gütlich vereinigen. ${ }^{693}$ Man kann ziemlich sicher sein, dass wirklich sein damaliges Personal das Handwerkszeug gestohlen hat. Außer Badergesellen und -lehrjungen hätte es niemand in dieser Menge nötig gehabt. Fälers Pech war nur, er konnte den Diebstahl nicht beweisen.

Meister Hans Fäler jr. ist im Sommer I58 I gestorben. Am I 8. August erschienen die erbberechtigten Parteien oder ihre Vertreter vor dem Rat. Auf der einen Seite stand Barbara Frannck, die Witwe weiland Hans Fälers, auf der anderen standen seine fünf Schwestern ${ }^{694}$ oder ihre Nachkommen. Von Bernhard, seinem Bruder, ist nicht die Rede. Er war offensichtlich schon tot, die Ehe des Baders war kinderlos geblieben. Als Barbara das Testament ihres verstorbenen Mannes verlesen lassen wollte, wies sie der Rat darauf hin, dass sie Bürgschaft für die vorhandenen Schulden und 3 I Gulden leisten müsse, wofür Hans Fäler seinerzeit Bürge geworden sei. Die Witwe verzichtete 


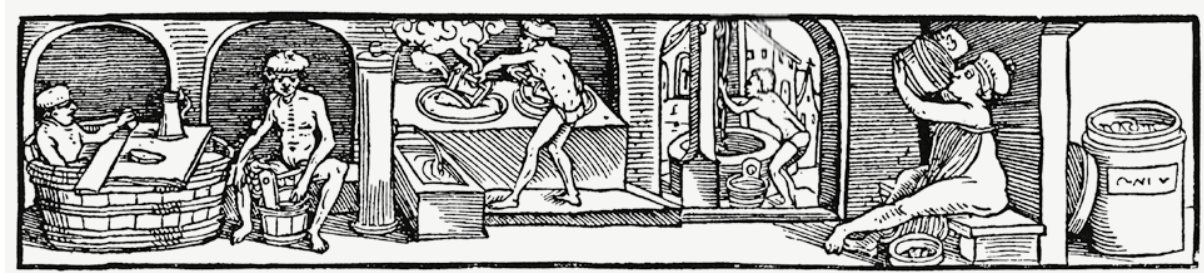

Abb. 85: Badeszenen (Essen und Trinken in der Badewanne, Waschbütte, Laufbrunnen, Warmwasserkessel, Ziebbrunnen, Abgießen); Holzschnitt aus Michael Heros »Schachtafelen der Gesuntheyt«, I533.

daraufhin auf das Testament und wollte bei ihren »wittiblichen Sprüchen«, d.h. ihren Ansprüchen als Witwe nach Landesrecht bleiben, weil das von ihrem Mann hinterlassene Vermögen »klain und schlecht« sei und es ihr deshalb schwerfallen würde, Bürgschaft für alles Geschuldete zu leisten. Beiden Parteien wurde Bedenkzeit gewährt, den Verwandten des Verstorbenen sollten Inventar und Testament zur Einsicht zugestellt werden. ${ }^{695}$

Am r. September kam es zur Erbteilung. Der Witwe Barbara Frannck wurde das gesamte Hab und Gut ihres Mannes zugesprochen. Über alle Gelder musste sie Rechenschaft ablegen, auch hatte sie alle Unkosten zu tragen. Die fünf Schwestern bzw. ihre Nachkommen bekamen dagegen zusammen 20 Gulden, jede vier. Zwei Schwestern sollten binnen eines Monats, die anderen drei in Jahr und Tag mit den vier Gulden zufrieden gestellt werden. ${ }^{696}$ In der Tat, ein äußerst dürftiges Erbe, wenn da nicht das ganze Handwerkszeug eines Baders und Wundarztes der Witwe geblieben wäre, das sie natürlich geschickt zu ihrer Versorgung einsetzte.

Als neuer Bader war zunächst Wolf Fueß, Barbier zu Schwaz, vorgesehen. Nach seiner Absage beauftragte der Rat die Fälerin, bis auf weiteren Bescheid wie bisher das Bad fleißig zu betreiben. ${ }^{697}$ Es erschienen bald neue Bewerber um die vakante Stelle eines Rattenberger Baders, insgesamt sechs: Christof Ruetz, Barbier zu Innsbruck, Sigmund Fuchs zu Zell im Zillertal, Chosman Mann zu Aibling, ein Bader zu Schwaz, Georg Leutner zu Rattenberg und Hans Luechner, Sohn des einstigen Rattenberger Spitalpächters Georg Luechner. Der Rat entschied sich für Hans Luechner, der das Handwerk bei Hans Fäler selig gelernt, sich bei ihm gut aufgeführt hatte und acht Jahre auf dem Handwerk gewandert war. Wenn Luechner, dem man eine gute Badverwaltung zutraute, ${ }^{698}$ seinen Geburtsbrief beibringen und sich verheiraten werde, wollte ihn der Rat zum Bader aufnehmen. ${ }^{699}$ Einen Monat später legte Luechner, der inzwischen Fälers Witwe geheiratet hatte, seinen Geburts- und Lehrbrief vor und wurde daraufhin vom Rat zu einem Bader und Inwohner aufgenommen. ${ }^{700}$ 
Damit endet die Studie über Bad, Bader und Badeleben zu Rattenberg. Mochte auch I630 vom Badhaus geschrieben stehen: »alles paufällig und gleichsam allerdings von neuen zuerpauen vonnethen «, so stand das Bad anscheinend noch Anfang des I8. Jahrhunderts in Betrieb, vermutlich nur mit einem Badetag (Samstag) je Woche, und ist erst in der zweiten Hälfte des I8. Jahrhunderts geschlossen worden. Das Badhaus geriet in der Folge in private Hände, wurde zu einem Gasthaus, Café, zu einer Schlosserei umgestaltet und beherbergte einige Zeit eine physiotherapeutische Praxis. ${ }^{701}$ Der heutige Eigentümer baut derzeit das Bad zu einem Wohnhaus um und sucht dabei möglichst viel von der alten Bausubstanz zu erhalten. 


\section{Zusammenfassung}



tädtische Bäder gab es in Tirol seit dem I 3. Jahrhundert, das in Rattenberg entstand um I 400. Das Rattenberger Bad, mit I 6 mal I 4,90 m gar nicht so

klein, kann durchaus als Beispiel für andere Bäder dienen, die im Spätmittelalter errichtet wurden. Unten im Haus befanden sich die Baderäume (je eine Stube für Männer und Frauen, Vorraum mit Garderoben, hinten der Heizraum mit Knechtskammer), im Obergeschoss lagen die Wohnung des Baders und die Trinkstube für die Badegäste. Zwar war und ist Rattenberg nur eine Kleinstadt, doch zeigten die Bäder in mittleren und größeren Städten keine andere Struktur, konnten vielleicht in dem einen oder anderen Fall größer und komfortabler gewesen sein, etwa durch einen eigenen Ruheraum mit Liegen. So gut wie alle Bäder, auch Rattenberg, sind in erster Linie als Schwitzbäder erbaut worden, doch bot man auch Wannen zum Sitzbad, verfeinert mit Heilkräutern, an.

Dass in Rattenberg ständig Balken (Durchzüge), Polsterholz und Dielen des Fußbodens sowie die Vertäfelung der Wände erneuert werden mussten, verwundert nicht. Wasser, Hitze und Dampf setzten ihnen halt dauernd zu. Mehr erstaunt, dass auch der Badeofen häufig repariert, nicht selten abgerissen und neu errichtet werden musste. Die städtischen Rechnungen über Fuhren von Sand, Kalk, Steinen, Schamottesteinen, Ziegeln, über Maurer- und Hilfsarbeiterlöhne geben reichlich Zeugnis davon. Vermutlich musste man zu oft den Ofen überheizen, um genug Wärme in den beiden Badstuben zu erzielen. Das vertrug er dann nicht. Wenn Jahr für Jahr zahllose Fensterscheiben zu Bruch gingen und ersetzt werden mussten, kann es sich nur um gewöhnliches Flachglas gehandelt haben. Butzenscheiben, die es z.B. in der Trinkstube gab, sind nicht so leicht zerbrechlich. Wie in vielen anderen Orten hat man auch in Rattenberg dem Badepersonal im r6. Jahrhundert das mühsame Herbeischleppen des Wassers dadurch erspart, dass man in die Badestuben eine Wasserleitung mit Brunnenbecken legte.

Da es für Rattenberg im I6. Jahrhundert weder Chroniken, Reiseberichte noch private Zeugnisse (Memoiren, Tagebücher) gibt, ist man auf vereinzelte Hinweise zum Badeleben in offiziellen und kirchlichen Quellen angewiesen. Danach pflegten die Bewohner der Stadt wie anderswo bisweilen leicht geschürzt ins Bad und nass aus dem Bad zu eilen, meist trugen die Frauen in der Dampfstube eine "Badehr« (Badehemd), die Männer eine »Bruch«(Badehose), beide Geschlechter einen Badehut aus Stroh. Man erfreute sich an Mai- und Hochzeitsbädern, war es gewohnt, auf der Trinkstube des Badhauses zu speisen und zu trinken, ja der Becher kreiste schon in den Schwitzstuben, nicht nur beim Bader und seinem Personal. Wie überall wird es auch in Ratten- 
berg in den Badstuben laut und fröhlich, aber nicht unziemlich hergegangen sein. Sie waren eben beliebte gesellschaftliche Treffpunkte, neben aller Hygiene, Heilbehandlung, Regeneration, Körperpflege und -reinigung, der man sich dort unterzog.

Handwerker und Knappen, die in Hall und höchstwahrscheinlich auch in Rattenberg das Gros der Badbesucher stellten (dazu kamen noch Hüttenarbeiter und Dorfbewohner aus der Umgegend, auch Gesinde, Krämer und einige Kaufleute der Stadt), sorgten dafür, dass ihr Bad nicht im I6. Jahrhundert wie in so vielen anderen Städten unterging, sondern bis ins I 8 . Jahrhundert bestand, allerdings beschränkt auf einen Badetag je Woche. Der Zulauf zu den Kur-, Thermal- und Wildbädern, das Meiden der Schwitzstuben und das Bevorzugen des Wannenbades im eigenen Haus, wenn man überhaupt noch badete, erfasste nicht in großem Maße das einfache Volk in den kleinen Städten. Es hielt an seinem Dampfbad fest, ließ sich nicht wie die feinen Leute von den Behauptungen der Ärzte irre machen, in die durch Dampf geöffneten Poren könnten allerlei Krankheiten eindringen und deshalb seien Schwitzbäder zu unterlassen, Kaltbäder zu bevorzugen. Die Mode »trockener« Toilette der Höflinge mit Abreiben, Abwischen, Parfümieren, häufig gewechselter weißer Leibwäsche konnte das Volk sowieso nicht mitmachen. Eigene Badezimmer waren noch äußerst selten und gehören erst seit dem Ersten Weltkrieg zum Standard bürgerlicher Wohnungen.

Sexuelle Freizügigkeiten, die sich so oft in den Miniaturen von burgundischen Luxusbädern, den heutigen Massagesalons vergleichbar, finden, lassen sich in Rattenberg nicht, in anderen deutschen Bädern dieser Zeit kaum nachweisen. Die jungen und reiferen Männer in der Stadt am Inn dürften dazu auch wenig Lust verspürt haben, waren hier doch die Reiberinnen, die Badfrauen gesetzte Matronen, keine jungen liebreizenden Bademägde. Es scheint überhaupt, dass die meisten lasziven Badeszenen, von denen man liest, nur der ausschweifenden Phantasie mancher Schriftsteller entsprungen sind. Um I 800 allerdings, als mondäne Badeschiffe, türkische, chinesische, maurische Bäder für ein extravagantes Publikum in Mode waren, kann man mit mehr Sinneslust in solchen Bädern rechnen.

Die Bader hatten keinen angesehenen Status in der Gesellschaft, weder in Rattenberg, wo sie in der Regel nur das Inwohnerrecht erhielten, noch vielfach anderswo. Als Inwohner konnten sie nicht über die Versammlungen der Bürgergemeinde aktiv die Stadtpolitik mitgestalten, geschweige denn Ratsherrnstellen einnehmen. Die Geschichte der Bader in Rattenberg, soweit sie sich für das I6. Jahrhundert rekonstruieren ließ, ist die Geschichte kleiner Leute. Allerdings zählte man die Bader im Süden des Reiches nicht wie in Teilen des Nordens zu den unehrlichen Berufen. Der reine Badebetrieb mit Reiben, Übergießen, Massieren, Waschen, Abgießen war ein Pfennig-, in Tirol Vierergeschäft und trug nicht viel ein. Aderlassen und Schröpfen brachten mehr, noch einträglicher war die Wundarznei, die sich am Ort mit dem Baderberuf verband. Da Rattenberg damals noch keinen eigenen Arzt hatte, behandelten anscheinend 
hier einige Bader/Wundärzte Krankheiten, für die nur studierte Mediziner zuständig waren. Das als Bader, Wundarzt und Barbier mit Badediensten, Schröpfen, Aderlassen, Kopfwaschen, Haarschnitt, Rasieren, Wundbehandlung usw. erzielte Einkommen reichte aus, um sich und die eigene Familie über die Runden zu bringen, aber nicht, um ein Vermögen zu erwerben. Das zeigte sich deutlich beim Erbe, das sie ihrer Witwe und ihren Kindern hinterließen. Es war durchweg bescheiden, ja ärmlich. Ein einziger Rattenberger Bader (Matheus Paungartner) lebte in gesicherten finanziellen Verhältnissen, doch auch nur wegen des Vermögens, das seine Frau in die Ehe eingebracht hatte. Hätte der Rattenberger Rat nicht den Witwen das wertvolle Bader- und Chirurgenhandwerkszeug ihrer verstorbenen Männer überlassen, sie wären an den Bettelstab gekommen, zumal sie auch die Wohnung im Badhaus räumen mussten. So konnten ihnen Badewannen, Schaffe, Barbierbecken, Lasseisen, Schröpfköpfe, Scheren, Schermesser, chirurgische Instrumente, Verbandszeug, Pflaster, Arzneien usw. manchmal zum willkommenen Heiratsgut für die Ehe mit einem neuen Bader dienen.

Um ihre Einkünfte, die häufig durch Störer vom Lande geschmälert wurden, zu steigern, übten die Bader schon einmal einen Nebenerwerb (Hersteller von Seife und Badehüten, Messer- und Scherenschleifer, Kaminkehrer, Glaser usw.) aus. Das lässt sich für Rattenberg nicht nachweisen. Allerdings suchten zwei Bader hier ihre Lebensumstände dadurch zu verbessern, dass sie neben dem Rattenberger Bad noch ein zweites hielten, Gabriel Freytag in Brixen, Hans Püchler in Hallein.

Der Ruf der Bader litt nicht selten daran, dass sie nicht fleißig und sorgfältig genug arbeiteten, zu viel tranken, mit Frau, Gesinde und Badepersonal grob umsprangen. Häufig wurde beanstandet, dass sie nicht auf die Sauberkeit in den Badstuben achteten, zu spät oder unzureichend einheizten und zu wenig lüfteten, was zu argen Geruchsbelästigungen führte. Als Knechte zogen die Bader häufig ungelernte und wenig taugliche Kräfte heran, was zu Protesten unter den Badbesuchern und zum Einschreiten der Obrigkeit führte. Ein anderer Missbrauch, um Kosten zu sparen, war, vermehrt Lehrjungen zur Bedienung in den Badstuben heranzuziehen. Die Reiberinnen und Gewandhüterinnen wurden in Rattenberg vom Rat angestellt. Er gab diese Posten älteren Frauen, meist Witwen armer oder verarmter Handwerker, Krämer und städtischer Bediensteter, um ihnen ein, wenn auch geringes Einkommen zu verschaffen.

Trotz des Rückgangs des Badbesuchs stellten sich I 58 I in Rattenberg sechs Bewerber um die vakante Bader- und Wundarztstelle vor, ein Zeichen, dass es dabei noch immer etwas zu verdienen gab. Es war ein gefährlicher Beruf. Nur wenige Bader erreichten ein hohes Alter. Von zehn untersuchten Badern der Stadt am Inn waren nur zwei über längere Zeit, d.h. ungefähr 25 Jahre als Bader und Wundarzt in Rattenberg (Michael Hueber d. Ä.) oder in Vomp und Rattenberg (Hans Fäler d. Ä.) tätig, aber gleich drei starben hier nach nur fünf (Michael Hueber d. J.), zwei (Matheus Paungartner) oder anderthalb Jahren (Michel Schwegler) Berufsausübung. Sie hatten sich ver- 
mutlich im Bad oder als Wundarzt mit einem Krankheitserreger infiziert, der zum Tod führte. Der ertrunkene Matheus Paungartner litt an Syphilis. Die Maßnahme, Leute mit Hautkrankheiten, offenen und schwärenden Wunden vom Bad auszuschließen oder im Bad nach hinten zu setzen, half nicht immer. Die Lebenserwartung der Bader dürfte auch in anderen Städten nicht sehr hoch gewesen sein.

Nur Michael Hueber d. J. und Hans Fäler d. J. folgten ihren gleichnamigen Vätern als Bader zu Rattenberg nach, Hueber nicht direkt, da er beim Tod seines Vaters noch ein Kind war. Die Berufsvererbung, zumindest am Ort, war also damals unter den Rattenberger Badern nicht üblich.

Nach Lehre, Gesellen- und Wanderzeit bewarben sich die meist fremden Bader beim Rattenberger Rat um das vakant gewordene Amt eines Baders und Wundarztes in der Stadt und wurden von den Herren bei Eignung gegen einen Jahressold von I6 Gulden angestellt. Der Vertrag mit ihnen wurde alljährlich bei der allgemeinen Ämterbestellung am Dreikönigstag verlängert, falls nicht ein Bader und Wundarzt wegen Unfähigkeit oder ungebührlichen Betragens entlassen wurde. Eine Meisterprüfung für Bader und Wundärzte war in Tirol während des I6. Jahrhunderts noch nicht üblich.

Die detaillierte Studie zu Rattenberg ist in eine Geschichte des Badewesens eingebettet, die von den Dampf- und Wannenbädern des Mittelalters bis zu den Volksbädern und Volksbrausebädern des I9. Jahrhunderts reicht. Darin kommen auch Kur-, Heil-, Thermal-, Mineral- und Wildbäder, Badeschiffe, Flussbadeanstalten, Seebäder und orientalische Bäder ebenso zur Sprache wie die wechselnden Ansichten der Mediziner über Hygiene und Körperpflege, über Nutzen und Schädlichkeit von Wasser und Baden. 


\section{Anmerkungen}

1 Birgit Tuchen, Öffentliche Badhäuser in Deutschland und der Schweiz im Mittelalter und der Frühen Neuzeit [Dissertation Heidelberg 1999]. Petersberg 2003 (163 Abb.). Wer ein reich bebildertes Buch zum Thema der vorliegenden Studie sucht, sei nachdrücklich auf folgendes Werk verwiesen: Martin Widmann und Christoph Mörgeli, Bader und Wundarzt. Medizinisches Handwerk in vergangenen Tagen (Zürich 1998). Das Buch ist stark gegliedert und enthält viele Farbabbildungen in ausgezeichneter Qualität, zu denen mehr oder weniger ausführliche Texte gründliche Informationen bieten.

2 Allerdings ergibt sich bei genauerem Zusehen ein Ungleichgewicht, was die Größe der behandelten Städte in diesem Raum betrifft. Nimmt man z.B. den Literaturanhang zu Beutter, Badstuben, 340-347 her, so stellt man fest, dass es sich nach Isenmanns (Stadt, 31) Klassifizierung fast nur um Studien zu größeren (Nürnberg, Ulm, Augsburg) und mittleren Städten (Zürich, Bern, Basel, Luzern, Nördlingen, Schwäbisch Hall, Schwäbisch Gmünd, Freiburg i. Br., Dinkelsbühl, Memmingen, Ravensburg) handelt. Lediglich drei Abhandlungen in der Liste beziehen sich auf Kleinstädte (Windsheim, Eberbach, Wangen). Die Darstellungen fallen jedoch alle für das 16. Jh. mangels Quellen sehr dürftig aus. Alle drei genannten Orte waren im Untersuchungszeitraum ungefähr doppelt so groß wie Rattenberg, das zur Zeit seiner Blüte (1. Hälfte des 16. Jh.) nur rund 900 Einwohner zählte. Eine eingehende Untersuchung über das Badewesen einer mittleren Kleinstadt, die in der Größe mit Rattenberg zu vergleichen wäre, liegt meines Wissens überhaupt noch nicht vor, zumindest nicht für das 16. Jh.

3 Diesem Bad widmeten sich in jüngster Zeit gleich zwei Hochschulschriften: Barbara Huber, Badewesen und Badereisen im späten Mittelalter und in der frühen Neuzeit. Bad Maistatt im Pustertal. Dipl. Arb. Univ. Innsbruck 2000 (historisch) und Albert Kopfsguter, Bad Maistatt in der Bäderregion Hochpustertal. Dipl. Arb. Univ. Innsbruck 2005 (besonders zu Kurbetrieb, Baubestand, Lage).

4 So lautet das umfangreiche, informative Kapitel (S. 153-260) in seinem Buch »Von Apothekern, Ärzten, Badern und Hebammen. Zur Geschichte des Gesundheitswesens der Stadt Hall in Tirol« (Hall i. T. 1996). Darin werden auch ausführlich die vier städtischen Bäder (beim Spital, beim Ölkopf, auf dem Graben, in der Fassergasse) behandelt (S. 214-260). Hermine Reinstadlers Diplomarbeit »Badewesen und Bader im Spätmittelalter und zu Beginn der Neuzeit« (Univ. Innsbruck 1991) geht nicht näher auf die städtischen Bäder Tirols ein. Soeben (März 2013) ist eine kleine Studie von Meinrad Pizzinini (Das Lienzer »Failbad«. Ein untergegangenes Geschichtsdenkmal, Der Schlern 87, 3 [2013] 41-52) zum Lienzer Stadtbad erschienen, das erstmals 1460 erwähnt wird, aber weiter zurückreichen dürfte. Zum Badhaus gehörten ein Garten und weitere landwirtschaftliche Gründe. Besondere Beachtung verdient der Vertrag der Stadt mit dem Bader Christoph Püchler (Pichler) aus dem Jahr 1565 (S. 48).

5 Hans Bachmann, Stadtbad und Bader im alten Rattenberg. Beilage zum »Tiroler Grenzboten« 76 (1952) Nr. 51-52, S. 12 u. 77 (1953) Nr. 1, S. 8, übernommen von Köfler, Häuserbuch (s.u.), S. 260-262.

6 Friedrich Stops, Rattenberg. Chronik der alten Stadt am Inn, Thaur ${ }^{2} 1981$, S. 115-120.

7 Die Ratschlagbücher, die zur Hauptsache Protokolle der Ratssitzungen und gelegentlicher Gemeindeversammlungen und nur in geringem Maße Stadtbücher sind, setzen 1506 ein und fehlen zwischen 1514 und 1523 und wieder zwischen 1532 und 1544.

8 Von den 106 Baumeisterrechnungen zwischen 1476 und 1581 sind nur 30, also nicht einmal ein Drittel, 
erhalten. Vor 1476 existiert keine Raitung des Baumeisters, ab 1478 bis 1515 nur ein Heft (1508), von 1526 bis 1537 fehlen alle Hefte.

9 KIAR Codex 71: Raitbuch 1482-1523, Codex 70: Raitbuch 1523-1539.

10 Guarinonius, Grewel, 898 u. 947.

11 Von ihren Benutzern erwähnt er eigens »alle Handwercker, alle starcke Arbeiter, in sonderheit bey uns hie zu land alle Knappen, so die gantz Wochen mit unaußsprechlicher Mühe unnd unauffhörlichen Schmertzen deß gantzen Leibs, mit Anspannung aller ihrer Kräfften das härte Ertzt auß dem Bürg hawen" (Guarinoni, Grewel, 946). Zu Dr. Hippolyt Guarinoni Vgl. man Moser, Apotheker, 42-56 und besonders Jürgen Bücking, Kultur und Gesellschaft in Tirol um 1600. Des Hippolytus Guarinonius "Grewel der Verwüstung Menschlichen Geschlechts« (1610) als kulturgeschichtliche Quelle des frühen 17. Jahrhunderts (Histor. Studien 401), Lübeck 1968 (für das Badewesen allerdings kaum ergiebig).

12 Als älteste im Reich wird jene zu Fulda genannt, die unter Abt Marquard (1150-1168) errichtet wurde (Martin, Badewesen, 210).

13 Jaritz, Bad, 1331-1332; Tuchen, Badhäuser, 20-22, 36; Kiby, Badekultur, 34; Reutter, Badestuben, 63.

14 Hähnel, Stube, 73.

15 Ladurner, Chronik, 208; Hähnel, 73.

16 Moser, Apotheker, 214.

17 Haidacher, Bevölkerungsgeschichte, 122; Stolz, Geschichtskunde, 315-316; Widmoser, Badhäuser, 111; Hähnel, 76-77.

18 Hye, Bundesland Tirol, 143 u. 159.

19 Büchner, Bauen, 78 u. 84. Der hier zu 1478 und 1483 vermerkte Meister Peter, Bader, ist 1484 gestorben (ebenda, 88).

20 Hähnel, 74.

21 TLA Urkunde II 8539 (1487 Jan. 8, als Zeuge erwähnt: Meister Lienhart, Bader zu Bruneck).

22 Jaritz, 1332; Martin, 113.

23 Stolz, 316; Widmoser, 111. Als gemeine Bäder in Tiroler Dörfern erwähnt Hähnel (74-76) für das 16. Jahrhundert noch folgende Orte: Innichen (um 1500), Herrschaft Kropfsberg (16. Jh.), Marling (16. Jh.), Rinn und Tulfes (1547), Rum (1540), Schenna (1591), Steinach (um 1530). Die Badestube in Tramin, die jährlich sechs Mark in das Amt Kurtatsch zinste, brannte 1506 bis auf die Grundmauern ab. Der bisherige Bader Mathes Rorer war bereit, das Bad auf eigene Kosten wieder aufzubauen, wogegen die Kammer ihm versprach, er brauche die nächsten fünf Jahre keinen Zins und danach nur einen ermäßigten von jährlich einer Mark und zwei Pfund zahlen (TLA EuB 1506, 220, 452-452').

24 Stolz und Widmoser, ebenda. Die Badstuben wurden häufig auch als Flachsdarren benutzt (Hähnel, 72). 25 Martin, 113-114; Tuchen, 23. Wohl im Gefolge der Tiroler Feuerordnung von 1609 kämpfte auch hier die Regierung gegen die Privatbadstuben, aber vergeblich (Hähnel, 72 u. 76). In der Schweiz suchte man den städtischen Bader vor ländlicher Konkurrenz zu schützen. So beschloss 1471 Luzern, alle Badstuben, die innerhalb einer Meile von der Stadt lagen, bis auf je eine in Russwyl und Eschenbach abzuschaffen.. Alle, die außerhalb einer Meile von Luzern bestanden, durften bleiben, doch wurde die Errichtung neuer untersagt (Zehnder, Volkskundliches, 569-570).

26 Vgl. zu Württemberg Fritz, Badstuben, 11-35.

27 Tuchen, 25-26; Widmann/Mörgeli, Bader, 26-31 (Baden im Kloster).

28 Dies ist allerdings im Jahr 2000 gelungen, als man auf Burg Schlössel (Rheinland-Pfalz) ein hölzernes Badehaus des späten 11. Jahrhunderts mit Heizungsanlage, Wärmekanal und Kamin freilegen konnte (Böhme, Badestuben, 72).

29 Martin, 159; Zappert, Badewesen, 67 mit Anm. 167. 
30 Waren es zunächst Holzröhren, so ging man bald zu Bleirohren für die Wasserleitung über (vgl. Vetter, Eberbach, 54).

31 Tuchen, 36-41, 106-111; Martin, 168-170; Jaritz, 1332. An der Verschmutzung konnten aber auch die Bader selbst schuld sein. 1384 musste dem Klosterneuburger Bader der Stube in der Hundskehle Niklas Herbst verboten werden, Schutt, Mist, Asche, Steine und anderen Unflat in den Mühlbach zu entsorgen, weil dadurch der Mühlbetrieb des Stiftes geschädigt wurde. Bei den Steinen dürfte es sich um solche aus dem Ofen im Schwitzbad gehandelt haben, die durch das vielfache Übergießen zersprungen waren (Mazakarini, Badstuben, 58-59).

32 Tuchen, 42-45. Über die Bauweise von Bädern unterrichten auch ausführlich Matthias Bitz (Badewesen in Südwestdeutschland 1550-1840. Zum Wandel von Gesellschaft und Architektur « [Wiss. Schriften im Wiss. Verlag Dr. Schulz-Kirchner, Reihe 9, 108]. Idstein 1989) und Johannes Cramer (Badhäuser - ein städtischer Bautyp, in: Hausbau im Mittelalter, hg.v. Konrad Bedal, Bd. 2 [Jahrbuch für Hausforschung. Sonderband], Sobernheim-Bad Windsheim 1985, 9-58). Da aber Birgit Tuchen beider Erkenntnisse in ihr Buch »Öffentliche Badhäuser" eingearbeitet hat, wurde darauf verzichtet, sie eigens zu zitieren.

33 Tuchen, Badhäuser, 48-50. Es gab anscheinend für angesehene Leute besondere Bänke (Martin, Badewesen, 178).

34 Guarinonius, Grewel, 949; Flamm, Bader, 17-18.

35 Tuchen, 50-56, 69-75; Vetter, Eberbach, 39; Widmann/Mörgeli, Bader, 42-45.

36 Tuchen, 56-58.

37 Tuchen, 65-69, 212.

38 Tuchen, 59-64.

39 Tuchen, $75-78,81-85$.

40 Tuchen, 91-92, 112-122.

41 Tuchen, 30, 48, 93-95, 100-101, 135; Martin, Badewesen, 157, 171.

42 Vgl. dazu Bonneville, Bad, 9-14.

43 Schon im altindischen Atharvaveda heißt es: "Die Wasser heilen wahrhaftig, verjagen jede Krankheit und heilen alles Leid« (Kiby, Badekultur, 6).

44 Martin, 180-182; Stolz; Handwerke, 101-102. Strömten viele Menschen zu einer großen, länger dauernden Veranstaltung herbei, dann machten auch die Bader und Scherer gute Geschäfte. Ulrich von Richental will 310 »scherer, bader, schrepfer und söllich, die uß und in luffend«, auf dem Konstanzer Konzil (1414-1418) gezählt haben (Richental, Chronik, 169).

45 Peters, Arzt, 35.

46 Tuchen, 35; Stolz, 102; Martin, 177-179. Binding (Baubetrieb, 146-150) weist darauf hin, dass die Gesellen im Bauhandwerk jeden oder jeden zweiten Samstag ein Badgeld erhielten, das sich auf ein Fünftel bis ein Zehntel eines Tagelohns belief. Fürs 15. Jahrhundert nennt er die Städte Prag, Budweis, Regensburg, Freiburg, Wien, Krems, Straßburg, Nürnberg. In Hamburg und Aachen bekamen die Gesellen neben dem Badgeld auch ein wöchentliches Biergeld.

47 Tuchen, 35; Stolz, 103; Martin, 188-195; Zappert, Badewesen, 51-58.

48 Tuchen, 29-30; Martin, 182-183.

49 Tuchen, 29; Martin, 144-146; Zappert, 73-74; Vetter, Eberbach, 23; Widmann/Mörgeli, Bader, 50-52; Himmelsbach, Badstuben, 31.

50 Guarinonius, Grewel, 948; vgl. Flamm, Bader, 15-16; schleussig = zerschlissen, Dieher = Tücher, Füssen offen $=$ barfuß, Niderwad $=$ Unter - , Badehose. Mit der nicht genannten Stadt ist Hall gemeint.

51 Seifried Helbling, 115-116 (Text III).

52 König Pippin soll nur mit Schuhen und Hemd bekleidet und sein Schwert in der Hand das Bad zu Aachen aufgesucht haben. Eine Handschrift des Sachsenspiegels zeigt einen Mann, der in ein Badelaken 
gehüllt das Bad verlässt. Als 1490 die Augsburger zum Kampf auszogen und einige von ihnen lange Badehemde trugen, schien das dem Chronisten so, als ob sie ins Bad gehen wollten. Der Bader zu Hildesheim musste im Mittelalter darauf achten, dass niemand nackt über die Straße ging. Mancherorts in der Schweiz schritt man im Bademantel über die Gasse zur Badestube (Martin, 147 u. Zappert, 76 mit Anm. 196). Andere Quellen des Mittelalters wollen auch wissen, dass manche Leute ganz nackt zum Bad eilten (Beutter, Badestuben, 63).

53 Nach Hektor Ammann gab es Ende des Mittelalters ungefähr 4000 deutsche Städte. Davon waren ca. 94,5\% Klein- und Kleinststädte mit bis zu 2000 Einwohnern, wenig über 8 ha groß, oft darunter (Isenmann, Stadt, 31).

54 Stops, Rattenberg, 96. Um 1530, als der Bergbau noch blühte, war die Stadt dichter besiedelt. Nach den drei Türkensteuerlisten von 1529 und 1530 (erhalten in StAR Schuber 61) zu urteilen und unter Einbeziehung der Personen, die als nicht steuerpflichtig darin fehlen (städtische und fürstliche Beamte, drei Weltgeistliche, Augustinerkloster, Schlossbewohner, Spitalsinsassen, alle mit ihrem Gesinde), darf man davon ausgehen, dass damals 850 bis 900 Menschen in Rattenberg lebten.

55 Nach dem Maßstab des Stadtgrundrisses bei Köfler, Häuserbuch.

56 StAR RS 9, 213.

57 Der Geistliche muss ziemlich abgehärtet gewesen sein, denn der Eintrag erfolgte zum 17. Dezember. Die Rüge an Hans Fäler bestand sinngemäß darin, dass er sich gefälligst um die Badbesucher kümmern und sich nicht zum Frühmesser auf die Schwitzbank setzen sollte.

58 Zappert, 75; Martin, 147; Vetter, Eberbach, 23.

59 Himmelsbach, Badstuben, 22.

60 Schon der Ritter im Seifried Helbling ließ sich vom Knecht das Badehemd nachtragen (Seifried Helbling, 116: "Nim mîn badhemd mit dir!«). Auch Marktbesucher, Reisende, Bauern aus umliegenden Dörfern werden kaum im Badehemd erschienen sein (Tuchen, 98).

61 Besser Gestellte besaßen davon mehrere. Eine Haller Bürgerin hinterließ 1476 drei Badehemden (Moser, Urkunden, Nr. 361), 1669 fanden sich in der Verlassenschaft der Jungfrau Elisabetha Zollerin in Zürich »16 Hemder und Bad-Ehren, 32 Hembder und Bad-Lacken, item Bad-Ehren« (Martin, 168). Die Badehr zu tragen machte die Aargauer Badeordnung von 1506 zur Pflicht. Zu diesem und anderen Geboten der zeitgenössischen Obrigkeiten, um die Schicklichkeit und Sittlichkeit in den Bädern zu wahren, vgl. Wiemers, Unschuld, 91-92. Sein ganzer Aufsatz (S. 81-97) ist eine interessante Studie zur Frage von Nacktheit und Scham, von unschuldigem und lasterhaftem Badevergnügen in Bildern der Renaissance, sowohl in den Augen der damaligen Künstler als auch in den Augen heutiger Betrachter. Ein Badehemd konnte schon auch einmal anderen Zwecken dienen. Als 1414 das märkische Schloss Golzow von Herzog Rudolf von Sachsen belagert wurde und sein Verteidiger Wichard von Rochow es nicht mehr halten konnte, bat er, einen Strick um den Hals, und die Frauen in weißen Badekitteln, um Gnade (Fontane, Wanderungen III, 54-55).

62 Duerr, Nacktheit, 43; Martin, 232.

63 Tuchen, Wangen, 12-13; Zappert, 74-78; Martin, 105, 146-147; Widmann/Mörgeli, Bader, 53-57; Flamm, Bader, 14.

64 Ruß hatte aber auch sein Gutes. Man kratzte im Dampfbad Ruß, Schweiß und Ö1 von den Wänden, mischte sie, manchmal mit Kot, zu einer Salbe, dem »Badstuben-Wust« (lat. strigmenta balneorum), der gegen Geschwüre, Warzen, Nieren- und Hüftleiden usw. helfen sollte (Rauch, Wellness, 15, 36-37).

65 Tuchen, Badhäuser, 31.

66 Wenn 1570 und 1602 zwei verschiedene Haller Bader 40 bzw. 38 Badeschaffe besaßen (Moser, Apotheker, 181, 218, 250), kann man daraus nicht auf die Besucherzahl an einem Tag schließen, weil die Schaffe von mehreren Personen nacheinander benutzt wurden. 1598 zählte das Bad zu Gräfenberg (Bayern) 
samstags 140-160, mittwochs 40-60 Gäste (Tuchen, 26). Die 40-er Zahl für Kübel oder Schaffe galt auch in anderen Bädern, z. B. in Eberbach (1628) und in Wangen (1589) (Tuchen, 24, 115).

67 Tuchen, Badhäuser, 30-32; Zappert, 78-80; Martin, 163-165.

68 Guarinonius, Grewel 901 u. 1945; vgl. Martin, 162 u. Flamm, Bader, 14. Anscheinend war nicht einmal ein Wasserbad ungefährlich. 1669 wurde ein Mann in einer Badestube zu Winterthur, der, vom Wein berauscht, eingenickt war, so "versotten« (verbrüht), dass er noch am selben Abend starb (Martin, ebenda).

69 Martin, 162. Dass Dampfbäder nicht nur heute, sondern auch schon früher kriminelle Energien weckten, behauptet der Stricker (1. Hälfte des 13. Jh.). In seiner Verserzählung »Der Pfaffe Amis« sperrt ein Arzt einen Edelsteinhändler, der angeblich unter Wahnvorstellungen leidet, in ein Schwitzbad ein und erhitzt es so sehr, dass er ihn beinahe "verprunnen« (verbrüht) hätte (Der Stricker, Amis, 120-123).

70 Tuchen, 32 u. 84; Martin, 171; Vetter, 23-24.

71 Guarinonius, Grewel, 946.

72 Hähnel, Stube, 74.

73 Martin, 176-177.

74 Moser, Apotheker, 181, 218 u. 250. Auch anderswo scheint die Zahl der Wannen nicht viel größer gewesen zu sein. Das Bad St. Vivien zu Paris z.B. enthielt 1380 sechs Badewannen, drei Ruhebetten und mehrere Bettdecken (Vigarello,Wasser, 32).

75 Martin, 109.

76 Bonneville, Bad, 73.

77 Martin, 152, 154, 155; Baader, Badewesen, 1341. Sehr merkwürdig waren die sogenannten Brotbäder in der Schweiz, womit man vor allem Rheumatismus und Gicht behandelte. Es waren Schwitzstuben direkt über dem Ofen einer Bäckerei, die ihre Hitze durch ein Loch in dem Boden empfingen (Martin, 112-113). Seltener kam es vor, dass arme Leute nach dem Herausziehen des Brotes direkt im Backofen schwitzten (Martin, 126-127).

78 Genannt werden Kamille, Baldrian, Feldkümmel, Schafgarbe, Rosmarin, Lavendel, Pfefferminze, Heublume, Hanf, Holunder, Steinklee (Kř́žek, Kulturgeschichte, 80; Bonneville, 34; Kiby, Badekultur, 44).

79 Baader, 1341.

80 Pictorius, Badenfahrtbüchlein, 23-24 u. Martin, 129.

81 Vgl. Schwäbisches Wörterbuch 3 (1911) 1797.

82 Martin, 236, 278. Als Frauenbad könnte man auch das erstmals 1460 erwähnte Wildbad Rotenbrunn (Sellrain) bezeichnen. Sein eisenhaltiges Quellwasser galt als heilkräftig und wurde seit dem 16. Jahrhundert besonders von adligen Damen, bürgerlichen Frauen und Mädchen geschätzt (Klaar, Alt-Innsbruck, 35-39).

83 Straganz, Beiträge, 20, 27, 40, 41, 46-48, 73 u. ö; Tersch, Selbstzeugnisse, 260. Auch der Innsbrucker Pfarrer Johannes Marchstainer († 1618) trank zur Linderung der Gicht Holzwasser oder einen Sud aus Chinawurzel (Tersch, 459-460).

84 Ryff regte an, im Sommer die Badewanne im Garten aufzustellen (Martin, 106).

851403 kaufte Margarethe von Flandern $40 \mathrm{~m}$ toille bourgeoise (gewöhnliche Leinwand), um damit zwei Badezuber zu verhängen (Camesasca, Geschichte, 390).

86 Martin, 107-108, 123-126, 206; Kiby, 34 u. 36; Bonneville, 72-73. Hölzerne Schwitzkästen traten bald neben die Wannen mit Baderof (Martin, 124, 126, 128).

87 Baum, Bader, 1339.

88 Wenn dies Verb auch die Wundarznei betrifft, dann könnte damit das Anlegen eines übers Kreuz geflochtenen Verbandes, eines Kreuz-, Druck-, Streckverbandes o.ä., gemeint sein. Da es sich um die Pflichten der Badeknechte handelt, dürfte sich der Ausdruck kaum auf das Flechten von Haar nach der Kopfwäsche beziehen. Das wäre ja Aufgabe der Reiberinnen in der Frauenstube, der Bademägde oder -frauen, gewesen. 
89 Hier sind Fensterscheiben, Fenster gemeint, nicht Schröpfköpfe, Tiegel, Becher aus Glas.

90 Für Ordnung und Sauberkeit im Haus sorgen.

91 TLMF FB 2994 (nicht paginiert); vgl. Moser, Apotheker, 17-18. Die Innsbruck-Haller Bruderschaft war kurzlebig und beschränkte sich seit ca. 1470 nur noch auf Hall. Anscheinend sorgten die vier gemeinen Bäder der Stadt, weitere zwei Bader- bzw. Barbiermeister zu Hall sowie die Bader und ihr Personal aus den umliegenden Dörfern (die Ordnung von 1450/60 spricht von Meistern und Gesellen »in der gegent«) schon allein für genügend Mitglieder (Moser, 18, 154).

92 Der Artikelbrief der Hildesheimer Bader von 1623 ließ jedoch schon einen Knaben im Alter von zehn Jahren als Lehrjungen eines Baders zu (Bähre, Balsam, 29).

93 Die Chirurgie war im Reich jahrhundertelang keine akademische Disziplin. Sie wurde hier nicht von studierten Ärzten, sondern von stationären Handwerkern oder fahrenden Heilern (darunter viele Quacksalber und Scharlatane) ausgeübt.

94 Es konnte auch mehr sein. Hans Luechner, der 1581 das Amt eines Baders in Rattenberg übernahm, war nach eigener Aussage acht Jahre »auf dem Handwerk« gewandert (StAR RS 14, 253).

95 Moser, 154-155; Peters, Arzt, 36; Kraft, Helfer, 8-9.

96 Von der Pflicht zu einem Universitätsstudium der Chirurgie war immer noch nicht die Rede. Eine Chirurgenvereinigung, die in Konkurrenz zur Schulmedizin trat, wie die Pariser "Confrérie en l'église St-Cosme et Damien« von 1379 (mit Vorgängerin seit der Mitte des 13. Jahrhunderts) bestand im Reich auch nicht (Seidler, Collège, 16). Hier fristete die Chirurgie an den Universitäten des 18.Jh. ein Schattendasein, wurde eigentlich nur geduldet. Erst im 19. Jahrhundert erreichte sie in Deutschland den Rang eines vollwertigen medizinischen Universitätsfaches. Bestrebungen, Wundärzte durch eine Medizinische Fakultät prüfen zu lassen, gab es schon früh im Reich, aber sie scheiterten regelmäßig an den Scherern/Wundärzten und dem städtischen Rat, der ihnen entgegenkam und stets zwischen Universität und Handwerkschirurgen vermittelte. Der Stiftungsbrief Erzherzog Albrechts VI. von Österreich von 1457 für die Universität Freiburg sah ein solches Examen vor, doch bis ins 18. Jahrhundert änderte sich nichts, zumal der Rat die Entscheidung über die Zulassung eines Handwerkers, was damals ein Wundarzt war, nicht aus der Hand geben wollte (Himmelsbach, Badstuben, 58-61: »Wir setzen auch und wellen, das kein wundartzat, scherer oder ander, in was stats der sy, lib artzny triben, er sy dann bewert von der facultet der artznie und zugelassen von den meister derselben facultet« [59]).

$97 \mathrm{Kraft}$, ebenda.

98 Moser, 156. Nach der Hildesheimer Ordnung von 1487/88 handelte es sich bei den drei Pflastern um je ein Emplastrum fuscum, attractivum glaucum und canum (ein schwarz-braunes, ein Zug- und ein graues Pflaster) mit Zutaten aus Olivenöl, Bleiglätte, Bienenwachs, Baumharz, Talg vom Ziegenbock, Weihrauch, Myrrhe, Mastix, Terpentin und Zinkoxyd, deren Wirkung kaum beurteilt werden kann. Deutlicher ist schon das Hildesheimer Amtsmeisterbuch von 1566, das von einem Beinbruchpflaster, einem Beulen- oder auch Geschwulstpflaster und einem Stichpflaster spricht, die ein Kandidat 1567 herstellen musste (Bähre, Balsam, 54-59).

99 Tuchen, Badhäuser, 24 u. 115-116; Martin, Badewesen, 120-121; Moser, Apotheker, 182 u. 218 (Inventare zweier Haller Bader und Wundärzte von 1570 u. 1602).

100 Vgl. Tuchen, 24 u. Baum, Bader, 1339.

101 Křížek, Kulturgeschichte, 105.

102 Einige Abbildungen dazu bei Widmann/Mörgeli, Bader, 72-75.

103 Schäfer, Toilette, 232; Beutter, Badestuben, 66; Widmann/Mörgeli, 76.

104 Rauch, Wellness, 24.

105 Tuchen, Badhäuser, 33; Tuchen, Wangen, 8; Martin, 70, 73-74; Beutter, 66. 
106 Wenn in der heutigen Medizin der Aderlass angewendet wird, zapft man dabei, je nach Alter, Konstitution und Gesundheitszustand des Patienten, 250 bis $800 \mathrm{ml} \mathrm{ab} \mathrm{(Jütte,} \mathrm{Ärzte,} \mathrm{72-73).}$

107 Tuchen, Badhäuser, 33-34, 112-114; Tuchen, Wangen, 8-9; Jütte, Ärzte, 71-73; Martin, 77-79; Stolz, Handwerke, 86-88; Widmann/Mörgeli, 96-111; Himmelsbach, Badstuben, 30-31 (er unterrichtet auch über das Ansetzen von Blutegeln).

108 Tuchen, Badhäuser, 34; Moser, 178; Peters, Arzt, 35; Stolz, 88; Seidl, Bader, 73; Widmann/Mörgeli, Bader, 86-95.

109 Tuchen, 34.

110 Martin, 180; Bonneville, Bad, 36.

111 Rauch, Wellness, 56-57; Beutter, Badestuben, 67; Widmann/Mörgeli, 118-122.

112 Martin, 197. Alle Einkünfte aus dem Bad und der Wundarznei reichten aber bloß aus, dass die Bader nach ihrem Vermögen in der Regel nur der unteren Mittelschicht einer Stadt zuzurechnen waren, in Schwäbisch Hall ebenso (Reutter, Badestuben, 68) wie in Rattenberg (s.u.).

113 Martin, 178; vgl. Zappert, Badewesen, 158-159 (mit weiteren Beispielen für verschiedene Städte).

114 Vetter, Eberbach, 51.

115 Zappert, 159

116 Dort hatten in der zweiten Hälfte des 15. Jahrhunderts die Steinmetz-, Maurer- und Zimmergesellen wöchentlich zu ihrem Lohn zwei bis drei Pfennige Badgeld erhalten, die Bauhilfsarbeiter nur einen bis zwei Pfennige (Dirlmeier, Untersuchungen, 151, 153, 160, 162).

117 Martin, 197-198; Zappert, 159-160.

118 Hähnel, Stube, 74. Zwar entsprach ein Vierer nach der Tiroler Währung (1 Pfund $=12$ Kreuzer $=60$ Vierer $=240$ Pfennig) vier Pfennig, doch ergab das keinen höheren Wert als ein Pfennig in der Pfund/ Schilling-Währung (1 Pfund = 8 oder 12 Schilling = 240 Pfennig). Denn ein solches Pfund galt so viel wie ein Gulden (bis Anfang des 16. Jh. sogar noch etwas mehr), während erst fünf Tiroler Pfund einem Gulden gleichgesetzt wurden.

119 Salzer, Brennendes Thema, bes. 29.

120 Tuchen, 24-25; Stolz, 74-75; Martin, 68-69; Peters, 36 u. 38.

121 Moser, 220.

122 Zappert, 110-111; Martin, 68; Tuchen, 24 u. 41; Jankrift, Brände, 97-99.

123 Peters, 52.

124 Tuchen, 25; Zappert, 133-135; Jütte, Bader, 93-103.

125 So Martin, 84.

126 Martin, 178.

127 TLMF FB 2994. 1346 erlaubten Ammann, Rat und Gemeinde zu Ulm dem städtischen Badepersonal (Badhütern, Reibern und Schröpfern), gleich ob Mann oder Frau, eine Gemeinschaft (Bruderschaft) zu bilden und eine gemeinsame Kasse zu errichten, aus der zahlende Mitglieder im Krankheitsfall oder für das Begräbnis unterstützt werden sollten. In der damals erlassenen Ordnung betrafen weitere Punkte Hochzeit, Taufe, Hochämter, Verbot des Spielens in der Weinschenke und Diebstahl, der zur Entlassung aus dem Dienst und zum Ausschluss aus dem Handwerk führen sollte (Gustav Veesenmeyer [Hg.], Ulmisches Urkundenbuch, Bd. 2, 1: 1315-1356, Ulm 1898, Nr. 291).

128 Tuchen, 31.

129 TLMF FB 2994.

130 Binding, Baubetrieb 298; Büchner, Bauen, S. 70, 86, 93, 108, 114, 121.

131 Tuchen, 31. Bald ergriff man Maßnahmen gegen notorische Diebe. Stahl ein Geselle, bevor er wegzog, seinem Meister Geld oder Werkzeug, so wurde ihm 1679 in Hildesheim »nachgeschrieben«, d.h. man teilte den benachbarten Zünften sein Vergehen mit (Bähre, Balsam, 31). 
132 Tuchen, ebenda.

133 Rüthing, Höxter, 209-210.

134 Tuchen, ebenda.

135 Martin, 166-167; Duerr, Nacktheit, 45-46.

136 Tuchen, 24.

137 Duerr, 361, Anm. 19.

138 Guarinonius, Grewel, 949.

139 Martin, 166.

140 Tuchen, 99 u. 102.

141 Z. B. Martin, 182 (Baden im Aargau), 235 (Leuk) u. 273; Bonneville, Bad, 37; Kř́̌žek, Kulturgeschichte, S. 86 Abb. 51.

142 Bonneville, 35 u. Kř́žzek, S. 86, Abb. 49.

143 Bachfischer, Musikanten, 184; Kiby, Badekultur, 40.

144 Martin, S. 185 Abb. 88.

145 Guarinonius, Grewel, 900; Sträuble = Schmalzgebäck. Vgl. Widmann/Mörgeli, Bader, 36-39 (einige Abbildungen zum Speisen und Trinken im Bad).

146 Ebenda, 944-945; nach der Bauß = nach Herzenslust. Vg1. Moser, Apotheker, 181.

147 Voigt, Briefe, 120 (lat. Text). Auf den folgenden Seiten macht Costabilis noch weitere wenig schmeichelhafte Bemerkungen über die Ess- und besonders Trunksucht der Deutschen.

148 Natürlich kam auch so etwas vor, wie die Gebote zur Beschränkung des Glückspiels in Bädern zeigen oder die Kölner Verfügung, die Bader dürften nach elf Uhr abends keine Trinkgelage mehr in ihren Stuben halten und niemanden dort übernachten lassen (Baum, Bader, 1339).

149 In Florenz erlaubte man den Männern nicht, im Bad zu speisen und zu trinken, weil man die üble Gewohnheit von Huren kannte, sich zu solchen Gelagen einzustellen (Duerr, Nacktheit, S. 365 Anm. 58).

150 Vetter, Eberbach, 24 u. 40. Birgit Tuchen (Badhäuser, 98-103) wertet Stuben in den Obergeschossen, die nicht zum Wohnbereich der Bader gehörten, als Umkleide- und Ruheräume. Es ist zu fragen, ob nicht einige von ihnen aufgrund der gediegenen Ausstattung Trinkstuben waren.

151 Wenn, wie oben erwähnt, 1660 der Stadtrat dem Haller Bader Jakob Mayr die Bitte abschlug, in seinem Bad »auch« Bier ausschenken zu dürfen (Moser, Apotheker, 220), darf man annehmen, dass er seinen Gästen schon Wein kredenzte. Kaiser Ferdinand III. erlaubte 1651 ausdrücklich allen Meistern des Badehandwerks im Viertel unter dem Manhartsberg (Weinviertel), jedem »Baadmann, der es begeret, ein halb Wein« im Badhaus zu reichen (Flamm, Bader, 18). In Hildesheim war man übrigens nicht so kleinlich wie in Hall in der Vergabe von Schankkonzessionen. Dort durfte schon 1386 Hinrik der Stover (Bader) Bier in seiner Badestube ausschenken (Bähre, Balsam, 14).

152 Guarinonius, Grewel, 949-950; zwagen = waschen, Üppigkeit = Wollust.

153 Zappert, Badewesen, 132-133. In Italien soll es zur Zeit der Renaissance nur sehr wenige Bader gegeben haben, die nicht ihre Kammern für Schäferstündchen mit den Bademägden vermietet hätten (Duerr, Nacktheit, S. 363 Anm. 46).

154 Martin, Badewesen, 90.

155 Duerr, 55 ; »buoben« hier im Sinne von Zuhältern.

156 Duerr, 49-52; Rossiaud, Venus, 13-14 (nach ihm gab es in Avignon sechs, in Lyon sieben und in Dijon ebenfalls sieben » Badepuffs«).

157 Spufford, Handel, 155.

158 Duerr, 51-52.

159 Martin, 85-86; Duerr, 52-53. 
160 Martin, 85.

161 Martin, 85, 86, 89, 90; Duerr, 54; Zappert, 133.

162 Freiburg i. Br. hatte zwölf Bäder. Nur ein einziges Mal wird berichtet, dass sich in ihnen Huren aufhielten: 1615 beschloss der Rat, eine Haussuchung bei Thoman Hauser vorzunehmen, weil sich in seinem Schwabsbad »zwo Schnueren« befinden sollten (Himmelsbach, Badstuben, 86). »Schnur« hat hier nicht die Bedeutung von Schwiegertochter, sondern von Dirne, Hure, meretrix.

163 Moser, Apotheker, 181.

164 Auch Bachmann (Stadtbad, 8) verneint, dass es im Rattenberger Bad zu "Ausgelassenheit und Zuchtlosigkeit « gekommen ist.

165 Martin (89) weist darauf hin, dass man überhaupt auf keinem Bild weibliche Bedienung im Männerbad sehen kann.

166 Das hat auch Birgit Tuchen (Wangen, 9) schon vor Jahren betont.

167 Vgl. Duerr, 46-50.

168 Wird nur ein nacktes Paar in einem Zuber, mit oder ohne Baderof, abgebildet, kann man sicher sein, dass es meist um das Baden im häuslichen Bereich geht.

$169 \mathrm{Zu}$ finden etwa bei Duerr, 48; Kiby, Badekultur, 45; Bonneville, Bad, 35; McKendrick, Reviving, 75; Reddig, Bader, 118; Rossiaud, Venus, 45, Luz, Bad, Abb. 12 usw.

170 McKendrick, 74 (»It is not an undistorted peek through the keyhole at medieval life«.), 264-274.

171 Bonneville, Bad, 40.

172 Martin, Badewesen, 232-234; Luz, Bad, 67-69; Thomas Hohmann u. Georg Kreuzer, Heinrich von Langenstein, Die deutsche Literatur des Mittelalters - Verfasserlexikon 3 ( $\left.^{2} 1981\right) 771$.

173 Martin, 231.

174 In deutscher Übersetzung z.B. bei Martin, 239-245 zu finden.

175 Sander, Bader, 917; Martin, Badewesen, 210-211. In Frankreich zeigte sich dieselbe Entwicklung. Dijon verlor sein letztes der vier Badehäuser um die Mitte des 16. Jahrhunderts, in Beauvais, Angers und Sens gab es Ende des 17. Jahrhunderts keine öffentlichen Bäder mehr (Vigarello, Wasser, 32).

176 Z. B. hatte Nürnberg zur Zeit des Hans Sachs 13 gemeine Badstuben, 1792 waren es immer noch zehn und dazu ein Gesundbrunnen, das Wildbad (Martin, 211)

177 Martin, 213; Tuchen, 27.

178 Tuchen, Badhäuser, 27; Martin, 213-214.

179 Moser, Apotheker, 225, 247, 252-253, 260.

180 Tuchen, 29; Bonneville, Bad, 41; Sander, 918.

181 Tuchen, 26-27; Sander, 918; Pictorius, Badenfahrtbüchlein, 7 (Vorwort von Udo Becker).

182 Als Beispiel sollen die Preise zu Rattenberg in Zehnjahreszyklen herangezogen werden. Ein Klafter Brennholz Fichte kostete 1510-1520: 36 Kreuzer, 1550-1560: 42 kr., 1570-1580: 441/2 kr., 1590-1600: 64,6 kr., 1600-1610: 76,08 kr. Für einen Klafter Brennholz Buche zahlte man 1510-1520: 39,32 Kreuzer, 1550-1560: 46 kr., 1570-1580: 49,89 kr., 1590-1600: 79,84 kr., 1600-1610: 106,28 kr. (Schmelzer, Preise, 296 u. 301). Nach der Tiroler Landesordnung von 1573 entsprach ein Holzklafter 6,084 $\mathrm{m}^{3}$ (ebenda, 37). Die Badstube im Dorf Renningen (bei Stuttgart) verschlang im Jahr 1567 an die 30 Klafter (ca. 100 Raummeter) Brennholz, dazu noch viel Reisig (Fritz, Badstuben, Anm. 30 auf S. 15). Der Holzbedarf der Bäder war also enorm.

183 Martin, 213; Sander, 918.

184 Tuchen, 28-29; Martin, 204-205.

185 Zusammenstellung aus vielen Einträgen in den Ratsprotokollen und Rechnungen der Stadt zu den betreffenden Jahren.

186 Pictorius, 7 (Vorwort von Udo Becker). 
187 Tuchen, 27.

188 Vgl. Kiby, Badekultur, 74, 81; Bonneville, Bad, 74, 76, 80. Beide nennen noch weitere Beispiele für Badezimmer von Königen, Fürsten, Adligen, Päpsten wie der Sforza in Mailand, der Gonzaga in Mantua, der Este in Ferrara, der Montefeltre in Urbino, Karls V. und Franz' I. von Frankreich, Philipps von Kleve usw.

189 Voigt, Berichte, 168; vgl. Dengel, Beschreibung, 226 (lat. Text) u. 231 (dt. Übersetzung); Moser, Apotheker, 16.

190 In das Marmorbad des Kasseler Schlosses ist z.B. nie eine Wasserleitung gelegt worden (Pape, Puder, 94).

191 Böhme, Badestuben, 72.

192 Vigarello, Wasser, 36.

193 Ebenda, 35.

194 Martin, 116-117; Kiby, 81; Schmidt/Dirlmeier, Geschichte, 311; Fouquet, Annäherungen, 469-470: Tucher reichte ein Bad nicht. Er ließ sich ein zweites in seinem Garten anlegen (ebenda, 470). Bäder während des Sommers im Garten oder im Freien waren nicht selten (Bonneville, 76-77; Martin, 116).

195 Tuchen, 27.

196 Bonneville, 73-74, 90, 92-93.

197 Jütte, Ärzte, 68; Fouquet, 470-471. Die Stadt Görlitz beschränkte 1440 und 1476 das Baden im eigenen Haus aus anderen Gründen auf die Hausbewohner, um nämlich die Einkünfte des öffentlichen Badhauses nicht zu schmälern (Tuchen, 27).

198 Fouquet, 471.

199 Wischermann, Mythen, 432.

200 Bonneville, 100-104.

201 Kramer, Beginn, 93.

202 Sparsame Leute allerdings nicht. Kaiser Wilhelm I. scheute die Kosten für den Einbau eines Bades mit heißem Wasser im Berliner Schloss. Er begnügte sich damit, einmal wöchentlich in einem wasserdichten Ledersack, den man über ein Gestell gezogen hatte, zu baden (Christopher Clark, Preußen. Aufstieg und Niedergang 1600-1947, München 2007, 671).

203 Wischermann, 432; Corbin, Pesthauch, 232 u. 239; Vigarello, 255-259; Bonneville, 65, 96, 107.

204 Vier bis sechs Stunden in einem Mineralbad waren nicht ungewöhnlich (Zappert, Badewesen, 126). Guarinoni (Grewel, 901) empfahl, ein Schwitzbad nicht zu oft und nicht länger als eine halbe Stunde zu nehmen.

205 Zappert, 124-125; Pictorius, Badenfahrtbüchlein, 17.

206 Baader, Badewesen, 1340; Kiby, 30-31. Das Bad der hl. Elisabeth bestand darin, dass sie sich den Fuß nass machte (Kiby, 30).

207 Pictorius, 17; Baader, 1340.

208 Camesasca, Geschichte, 390;. Kiby, 57, Pape, Puder, 98 u. Vigarello, 22 (Behauptung des Medizinschriftstellers Théophraste Renaudot, 1655).

209 Vigarello, 11, 17-22; Kiby, 56; Bonneville, 82.

210 Eckart, Hygiene, 737-738.

211 Naphy, Baden, 915.

212 Kiby, 82.

213 Pape, Puder, 94.

214 Tagebuch des Grafen Wolrad von Waldeck, 278. Es ist zu hoffen, dass Herr von Buswy mit »unsere« die niederdeutschen Frauen und nicht die Damen des kaiserlichen Hofes gemeint hat.

215 Tuchen, Badhäuser, 27-28; Baader, 1340; Vigarello, 19; Kiby, 57. 
216 Rauch, Wellness, 54. Hier sei auf ein neues Werk über die Kurbäder hingewiesen: Pius Kaufmann, Gesellschaft im Bad. Die Entwicklung der Badefahrten und der »Naturbäder« im Gebiet der Schweiz und im angrenzenden südwestdeutschen Raum (1300-1610), Zürich 2009. Der Autor behandelt besonders die Therme Pfäfers, die seit dem 14. Jahrhundert aufgesucht wurde. Durch seinen methodischen Ansatz, Medizin-, Sozial-, Wirtschafts- und Herrschaftsgeschichte zu kombinieren, gelingt es dem Autor, interessante Zusammenhänge aufzudecken und zu neuen Erkenntnissen zu kommen.

217 Tuchen, 28.

218 TLA Urkunde II 7031 (1470 Nov. 8). Eduard Widmoser (Südtirol A-Z, Bd. 4 [O-Z], InnsbruckMünchen 1995, 205) lässt das Bad Schgums, das 1928 abbrannte, erstmals 1555 erwähnt sein. Das Datum ist entsprechend zu korrigieren.

219 Vigarello, 11, 26-28, 59-60; Bonneville, 82; Camesasca, Bad, 390 u. 392; Eckart, Hygiene, 738.

220 Vigarello, 75; Bonneville, 80, 82.

221 adstringierend $=$ das Gewebe zusammenziehend.

222 Bonneville, 40-41; Martin, 40-45.

223 J. G. Krünitz, Oekonomische Encyklopädie 3 (²1782) 411-413; Martin, 45-46; Bonneville, 43-44; Kramer, 91-93.

224 Seledec u.a., Baden, 20-23; Ganster, Bäderstadt, 67. Wesentlich detaillierter und genauer ist die Beschreibung, die damals der Reiseschriftsteller Friedrich Nicolai von dem durch Pascal Joseph Ferro auf eigene Kosten errichteten »Badeschiff « lieferte. Es heißt: »Hinter dem Augarten sind die 1780 [richtig: 1781] von Herrn Doktor Ferro angelegten Bäder in der Donau eine sehr nützliche Anstalt. Es sind zwischen zwei großen Kähnen, die vor Anker liegen, etwa acht verschlossenen Zellern [d.h. Kabinen], von Brettern gebaut. In denselben findet sich ein Kanapee, Spiegel, Anziehtisch, leinerner Schlafrock und so weiter. Man steigt in das Bad auf Stufen hinunter. Es besteht aus einem breiten Boden, auf welchem man steht oder sitzt, und das nach der Höhe der Donau höher oder tiefer gemacht werden kann. An den Seiten ist alles rund herum vergittert, so dass die Donau hindurchrauscht. Die Zellen sind so angelegt, dass das Wasser aus einem Bade nicht auf das andere schießen kann. Ein Bad kostet 40 Kreuzer (Eder, Bade- und Schwimmkultur, 110). Bei einem solchen Preis blieb das Baden im Fluss ein exklusives Vergnügen der Bessergestellten. Kaiser Joseph II. soll manchmal unauffällig das Ferrobad besucht haben (Eder, 109).

225 Eckart, Bäder, 923-924; Keller, Bäderstadt, 926-928; Martin, 62-63; Bonneville, 42 u. 47.

226 Bonneville, 42; Corbin, Pesthauch, 233-236.

227 Corbin, 235-236.

228 Bonneville, 46, 50-54; Tuchen, 29.

229 Martin, 47.

230 Martin, 215-216.

231 Bonneville, 57-58; Kramer, 96-97. Eine kombinierte Körper- und Wäschewaschanstalt wurde 1855 in Wien mit dem »Leopoldstätter Bad« errichtet (Eder, Bade- und Schwimmkultur, 151).

232 Bonneville, 58; Küthe, Powder-room, 108-111. Das »Erste Wiener Volksbrausebad« wurde am 22. Dezember 1887 in der Mondscheingasse eröffnet. Weitere Volksbrausebäder folgten rasch in anderen Stadtteilen (Eder, 151).

233 Dafür spräche auch, dass auf der Ostseite des Dachstuhls vom Bad die Mauer zum Turm auf dem Brückentor durchbrochen wurde. Der Durchlass könnte aus der Zeit um 1416 herrühren.

234 Wenn im Folgenden von der Ost-, Süd-, West- und Nordseite des Bades gesprochen wird, muss man wissen, dass es sich hierbei um eine Vereinfachung in Bezug auf die Himmelsrichtungen handelt. In Wirklichkeit erstreckt sich die Breite des Hauses $(14,90 \mathrm{~m})$ von Nordost nach Südwest und die Länge $(16,00$ m) von Nordwest nach Südost (vgl. den Häuserplan bei Stops, Rattenberg, Vorsatz). 
235 Stops,115; Kogler, Rattenberg, 29 u. 101.

236 Nach der Baumeisterraitung von 1581 (StAR BM 1581, 33’: 1 Fuder Schindeln zum Badhaus) müsste es mit Schindeln gedeckt gewesen sein, doch zeigt die Miniatur Rattenbergs im Schwazer Bergbuch von 1556 das Bad und alle anderen Häuser mit einem roten Ziegeldach. Das dürfte wohl auf künstlerische Freiheit zurückzuführen sein. Denn 1551 steht das Dachdecken des Bades, vermutlich mit Schindeln, unter den Ausgaben für Zimmerleute (StAR BM 1551, 7'), 1568 ebenfalls (StAR BM 1568, 14' u. 38), 1525 wurde das Bad gedeckt (StAR BM 1525, 14), und schon 1476 heißt es von zwei Zimmerleuten, dass sie "auf dem tach gemacht « haben, d.h. wohl Schindeln ausgetauscht haben (StAR BM 1476, 9').

237 Ammann, Kunstdenkmäler, 634; Köfler, Häuserbuch, 260. Der moderne Eingang befindet sich an der Innseite, mit einer Stiege in das Obergeschoss.

238 StAR BM 1547, 25. Damals wurden der Kamin und das Badhaus zum "verrechen«, d.h. um Bauarbeiten auszuführen, eingerüstet und zwei Fuder Schiefersteine (wohl: Schieferplatten) herangeschafft. Der Kamin wurde gewölbt (ebenda, 9, 18, 22', 25). - Da umfangreiche bauliche Veränderungen im Badhaus stattgefunden haben (zeitweise enthielt es vier Kleinwohnungen, die Badestube der Männer war eine Zeit lang die Praxis einer Physiotherapeutin, wo einst der westliche Teil des Vorhäusls und die Frauenstube waren, befinden sich jetzt drei große Garagen usw.), ist die folgende Beschreibung nur als provisorisch anzusehen. Erst eine eingehende Bauuntersuchung dürfte für mehr Klarheit sorgen. Dass ich überhaupt so viele Bemerkungen zum Baubestand machen kann, habe ich dem jetzigen Eigentümer des Hauses, Herrn Michael Unterrainer, zu verdanken, der mich in entgegenkommender Weise anderthalb Stunden durch das Haus (es wird gerade renoviert) geführt und mir geduldig zahlreiche Fragen beantwortet hat. Ihm sei an dieser Stelle nochmals herzlichst gedankt.

239 Nach einer Beschreibung von 1775 (Köfler, 263 u. Bachmann, Stadtbad, 8).

240 StAR BM 1476, 8. Sie war wohl ursprünglich, wie noch 1610 in den Bädern zu Hall, aus Holz, vgl. Guarinonius, Grewel, 949: „hültzene dinne Wänd« zwischen Männer- und Frauenstube.

241 StAR RS 13, 13'; vgl. Bachmann, 11; Stops, Rattenberg, 117; Köfler, 260. Die Baumeisterraitung für dieses Jahr ist leider nicht erhalten.

242 Köfler, 263: „Ebenerdig: 1 Holzgwölbm und 1 ruinirtes Badhaus«.

243 Bachmann (a.a.O.) irrt, wenn er meint, das Rattenberger Bad sei ein reines Schwitzbad gewesen. Er kann zwar behaupten:«Die Badenden saßen nicht in Wannen, von solchen ist niemals die Rede«, doch trifft genau das Gegenteil zu. 1523 heißt es, es solle »das vorheusl im pad zum Mayen pad« hergerichtet werden (StAR BM 1523, 9'), 1541 wird das »vorheusl, da die wannen sten«, erwähnt (StAR BM 1541, 4') und 1550 ermahnte der Rat den Bader, kein Holz dort zu lagern, wo die Wannen stehen, denn der Boden koste viel (StAR RS 6, 3). Die Wannen waren aus Lärchenholz (Stops, Chronik, 48).

244 Nach freundlicher Auskunft von Herrn Unterrainer hat die Männerstube noch einen Pfeiler, die in der Frauenstube sind durch den Umbau in Garagen verschwunden. Die Pfeiler im Bad wurden 1556 untermauert (StAR BM 1556, 12'). Die Sockel hatten wohl unter der Feuchtigkeit gelitten. Beide Stuben zeigen ebenfalls ein Kreuzrippengewölbe. Einige Gewölbe im Bad wurden 1538 repariert (StAR BM 1538, 16), welche, erfährt man nicht.

245 Ein Fenster im Vorhäusl wurde 1523 »ausgemacht» (fertig gestellt) und verputzt (StAR BM 1523, 17). Dabei half ein Tagelöhner 4플 Tage (ebenda, 14: Sigmund Weinprenner hat "mörter zum vorheusl im pad gekocht, zuetragen und zugeholffen, was not ist gewesen«.) Bei den damaligen Arbeiten im Vorhäusl wurden auch 300 Bretternägel verschlagen (ebenda, 22).

246 In der Karwoche 1547 fanden umfängliche Reparaturarbeiten im Vorhäusl statt. Es wurden Laden (Dielen) gehobelt, ein Polsterholz (Dielenträger) und darauf ein neuer Boden gelegt, die Tür gerichtet, ein neues Gestell gemacht und eben auch die Rinne ausgehackt (StAR BM 1547, 6). 
247 StAR RS 1, 98'.

248 Das Gitter wird sich nicht über die ganze Länge der Stuben erstreckt, sondern vom Ofen weg höchstens bis zur ersten Gewölbe tragenden, eingemauerten Säule erstreckt haben. Zieht man von der Gesamtlänge des Hauses $(16 \mathrm{~m})$ die Breite des Vorhäusls, der hinteren Knechtskammer (s.u.), beider dicken Außenmauern (davon eine gut $1 \mathrm{~m}$ ) und beider Innenmauern (Vorhäusl/Stube und Stube/ Knechtskammer) ab, so dürften beide Badestuben 7 bis $7 \frac{1}{2} \mathrm{~m}$ lang gewesen sein.

249 Das Wort wird von den Baumeistern auch im engeren Sinne für die Männerstube verwendet, für das Frauenbad begegnet bisweilen der Ausdruck »hintere Stube«.

250 StAR BM 1477, 12 u. 14; BM 1541, 7’; BM 1551, 9.1703 war er bereits durch einen steinernen Brunnengrant ersetzt (Kö̈ler, Häuserbuch, 262).

251 Martin, Badewesen, 89; Tuchen, Badhäuser, 300; Kiby, Badekultur, 38.

252 Tuchen, 75-78.

253 StAR BM 1547, 8: »luckh«(Luke) = Verschluss, Deckel.

254 StAR BM 1477, 9-9': Maurer arbeiten am Kessel im Bad, der zudem mit Bretternägeln beschlagen wird; BM 1521, 23; BM 1523, 10; BM 1539, 13'; BM 1542, 8, 18', 22, 26; BM 1547, 8 u. 25 : ein Hafner setzt im Bad die zwei Kupferkessel um; BM 1551, 7 u. 8: im Männerbad wird eine neue Rinne zum Kessel gemacht; BM 1568, 17, 18', 22', 34, 36.

255 Stops, Rattenberg, 115.

256 Wenn sonst das Vorhäusl gemeint ist, was aber selten vorkommt, wird es ausdrücklich als solches bezeichnet. Man schreibt dann nicht allgemein vom Bad.

257 S. Anm. 245.

258 StAR BM 1579, 21.

259 Stops, 117; Bachmann, 11; Köfler, 260. Alle drei Autoren haben den Hinweis darauf einem Rechnungseintrag des Baumeisters zur Osterwoche 1476 entnommen: »Item viij kr umb häckl in das pad, da man dy hüett an hengt“ (StAR BM 1476, 4').

260 Vgl. Anm. 234.

261 StAR BM 1508, 13’: fünf Fuder Feuersteine; BM 1553, 48: Feuersteine aus dem Zillertal; BM 1547, 20: 220 Ziegelstein; BM 1581, 33: zwei Fuder Ziegel

262 Baumaßnahmen am Ofen: StAR BM 1476, 4, 7', 9'; BM 1477, 14'; BM 1508, 13'; BM 1524, 14; BM 1538, 16; BM 1547, 14', 19', 20, 22', 28; BM 1551, 9', 10, 14'; BM 1568, 19, 26', 29, 29', 34, 36, 38; BM 1572, 12, 13'; BM 1579, 19', 21, 23', 28', 29, 40; BM 1580, 14', 15', 23'; BM 1581, 26, 32', 33, 33', 37'.

263 StAR BM 1476, 9': Die Badeknechte, die den Badeofen gewölbt haben, erhalten acht Kreuzer

264 Vgl. Bachmann, Stadtbad, 12.

265 StAR BM 1477, 14. Sie erhielten auch nur ein Pfund Berner (= 12 Kreuzer) als Lohn. Das entsprach nicht einmal einem vollen Tagessatz. Damals lag z.B. der Tageslohn für einen Zimmermann bei acht Kreuzern (StAR BM 1476, 8). Ein ähnlicher Eintrag wegen einer neuen Mauer beim Badeofen findet sich 1551 (StAR BM 1551, 14').

266 StAR BM 1547, 28: Der Krämer Walthauser Simon, genannt Pair, erhielt zwei Kreuzer für Kerzen, die zum neuen Badeofen verbrannt wurden.

267 StAR RS 6, 114.

268 Der oben (vgl. Anm. 236) zu 1510 genannte Kachelofen kann nicht der Badeofen gewesen sein. In rund 50 Belegen zwischen 1476 und 1581, die den Ofen betreffen (Reparatur, Neubau), werden alle möglichen Baustoffe genannt, aber nicht ein einziges Mal Kacheln. Einen Kachelofen jedoch besaß vermutlich die Trinkstube (s.u.).

269 Tuchen, Badhäuser, 75-78 u. 84-87.

2701547 erhielt der Tischler Peter Rixner 24 Kreuzer für zwei Fensterrahmen und Bretter zu einer Kam- 
mer im Bad (StAR BM 1547, 25). Ob es sich um den Heizraum, der auch als Knechtskammer diente, handelte oder um eine Kammer in der Wohnung des Baders kann ebenso wenig gesagt werden wie, ob sich nur die Bretter auf die Kammer beziehen.

271 Freundliche Mitteilung von Herrn Unterrainer.

272 StAR RS 7, 32', 33', 48, 96.

273 Tuchen, 87-91.

274 Als man 1547 das Bad hinten mit Schiefersteinen versah, wurde gleichzeitig der Kamin gewölbt (vgl. Anm. 208). Der Kamin wird noch einmal zwei Jahre später erwähnt, als man nach der Feuerschau dem Bader Matheus Paungartner große Nachlässigkeit im Hinblick auf den Kamin vorhielt (StAR RS 5, 85 : 1549 März 29).

275 StAR BM 1523, 9.

276 Ebenda, 22: Bretternägel für die Kammer im Bad; StAR BM 1547, 25 : Bretter für eine Kammer im Bad.

277 StAR BM 1551, 4'.

278 StAR Raitbuch 1514-1529, 275': Der Schlossermeister Benedikt Melchior erhält für ein Blech (30 Pfund schwer) vor dem Badofen und für Nägel einen Gulden 31 Kreuzer (zu 1526). Da das Blech ein beträchtliches Gewicht hatte, ist anzunehmen, dass es ziemlich groß war und nicht nur den Boden vor dem Ofen, sondern auch vor den Brennkammern der Warmwasserkessel bedeckte. StAR BM 1547, 4: einen Schild vor dem Ofen im Bad gemacht; ebenda, 23: einen Teil von 100 Bretternägeln für den Schild im Bad verbraucht.

279 Abgesehen von den zwei Hinweisen auf Ziegel im Zusammenhang mit dem Ofenbau (vgl. Anm. 231) werden sie nur noch einmal erwähnt. StAR BM 1551,13': die Ziegelmauer unter den Bänken gemacht. Damit war die Wand zwischen dem Vorhäusl und den Badstuben gemeint, die heute noch deutlich Ziegel zeigt.

280 Tuchen, 65.

281 StAR BM 1477, 11': Zwei Maurer zogen einen Tag den Estrich im Bad auf, einer hat ihn dann "gar geschlagen« (planiert); StAR 1547, 28: Die Ederin hat fünf Fuder Sand fürs Bad und für den Estrich im Pfarrhof geworfen. Sand benötigte man nicht nur beim Ofenbau, sondern er diente auch zum Auffüllen des Bodens, wenn er sich unter den Dielen gesenkt hatte. Vgl. StAR BM 1508, 14: vier Fuder Sand in die Frauenstube.

282 Köfler, Aspekte, 13.

283 Stops, Rattenberg, 116.

284 Freundliche Mitteilung von Herrn Unterrainer.

285 Vgl. Tuchen, 65.

286 Sie konnten aus Holz oder Stein sein, in Rattenberg wurden sie eingemauert. StAR BM 1551, 6': im

Männerbad einen neuen Boden und eine neue Rinne gelegt; 8: eine neue Rinne zum Kessel im Männerbad gemacht; 11: im Bad einen neuen Boden und eine neue Rinne gemacht; 13': im Männerbad die Rinne wieder eingemauert.

287 Stops, Rattenberg, 116; Stops, Chronik, 48.

288 Als der Rat im Mai 1575 den Stadtzimmermeister und den Baumeister aufforderte, den Boden im Männerbad zu besichtigen, ihn »auf[zu]schraufen« und nach ihrem Urteil einen Durchzug einzubringen, geschah das angesichts des schlechten Zustands des alten Bodens, so dass zu besorgen sei, er werde ganz einfallen (StAR RS 13, 122).

289 StAR BM 1476, 2', 3, 8, 9'; BM 1477, 9, 12-14' (Die Maurer und Zimmerleute erhielten ein Viertel Wein, weil sie in der Nacht gearbeitet hatten. Dazu waren auch Kerzen gekauft worden); BM 1523, 9 , 10', 22; BM 1524, 7; BM 1525, 11, 12; BM 1541, 7'; BM 1545, 27; BM 1547, 4, 8', 9, 23', 25', 26, 28; 
BM 1551, 4', 6', 7 (Hier liest man, dass der Boden im »Vailpad«, d.h. im öffentlichen, gegen Entgelt benutzbaren Bad gelegt worden sei. Der Ausdruck Feilbad begegnet sonst nicht in Rattenberg.), 9', 10, 11; BM 1579, 13, 38'; BM 1580, 9'.

290 StAR BM 1476, 4, 8; BM 1477, 9; BM 1523, 10’; BM 1542, 22; BM 1547, 8, 8', 9, 29'; BM 1579, 17, 22.

291 StAR RS 4, 63.

292 Die Höhe im Vorhäusl beträgt bis zu $2 \mathrm{~m}$, in den Stuben dahinter, die auf demselben Bodenniveau lagen, ist sie gleich gewesen. Von diesen 2 m muss man noch die Höhe des einstigen Dielenbodens abziehen.

293 Tuchen, 48-49.

294 StAR BM 1524, 7: im Bad »ain laspanckh gemacht«; BM 1541, 4’: »auf dem padt in der frawen stuben ain newe laspannckh gemacht«; BM 1547, 8': wieder eine Lassbank in der Frauenstube gemacht; ebenda, 28': Röhren unter der Scherbank; BM 1556, 17: Scheiben im Bad bei der Scherbank eingesetzt.

2951549 schrieb der Rat Meister Matheus Paumgartner, dem Bader, bei der Wiederbestellung unter anderem vor, er solle »schadhafte (mit Krankheiten behaftete) Leute nach hinten setzen (StAR RS 5, 52).

296 Die Zeugnisse dafür sind dürftig (StAR BM 1547, 6: ein neues Gestell gemacht, 25’: Bretternägel für ein Gestell verbraucht), doch ist nicht daran zu zweifeln, dass es genügend Regale im Männer- wie Frauenbad gegeben hat. Wo die Baumeisterrechnungen nur allgemein vom Ankauf von Brettern und Nägeln fürs Bad und von Zimmermannsarbeiten sprechen, ist davon auszugehen, dass ein Teil davon auch Gestelle betraf. Hierher dürfte ebenfalls der Ankauf von Stangen für das Bad gehört haben (StAR BM 1476, 2').

297 Tuchen, 56.

298 Ebenda.

299 StAR BM 1547, 22. Dazu wurden zwei Yhrn (je ca. 78 1) Kalk verbraucht (ebenda, 25'). Damals wurde auch der Boden im Vorhäusl gerichtet (ebenda, 25').

300 Doch das Ausweißen der Kirche mit Kalk zu vermerken, fühlte man sich durchaus bemüßigt (StAR BM 1580, 23').

301 So schon Bachmann, 12 und Köfler, Häuserbuch, 236.

302 Tuchen, 78; vgl. StAR BM 1477, 12: Kauf von 400 »klamperen« und 250 Bretternägeln; ebenda, 9: den Kessel mit Nägeln beschlagen.

303 StAR BM 1523, 10; BM 1551, 7 u. 13'.

304 StAR BM 1476, 4'. Auf diese Stelle bezieht sich schon Bachmann, 12.

305 Dafür spricht folgender Eintrag in der Baumeisterrechnung von 1572. Der Tischler Wolfgang Piechl fertigte sechs neue Fensterrahmen für das Bad an, der Glaser Paul Deisenseer setzte in sie Gläser (Scheiben) ein, der Schlosser Georg Rautner beschlug vier Rahmen, lieferte Reibl (Fensterwirbel) und machte sechs eiserne Stängl zu zwei Rahmen (StAR BM 1572, 18'-19).

306 StAR BM 1476, 1'.

307 Tuchen, 61.

308 Lerner, Geschichte, 25

309 Lerner, 70, 78, 83; 71-76: Mondglas und Butzenscheibe (eine kleine, runde, in der Mitte verdickte Glasscheibe). Die einzelnen Stücke wurden mit Bleiruten zu Fenstern zusammengefügt. Die grünliche Färbung rührt vom Eisenoxyd im Quarzsand her.

310 Die Glaser Ambrosi vom Hof und Jörg Tobler waren auch Maler (StAR Rechnung Ratmberg 15071513, 129 [zu 1513: vom Hof] u. 141 [zu 1513: Tobler], Paul Deisenseer betätigte sich zudem als Spengler (StAR BM 1579, 40). Hans Hoflach war vom Rat mit der "charhuet« beauftragt, d.h. er beaufsichtigte die städtischen Brunnen, die von der Bevölkerung immer wieder verschmutzt wurden, weil 
sie unsauberes Zeug, z.B. Gemüse, darin wusch (StAR RS 4, 184 ; char, chor, kar, kor = Gefäß, Becken, hier: Brunnenbecken).

311 Lerner, 40, 138-141.

312 Bei den nachfolgenden Belegen ist zu bedenken, dass nicht immer geklärt werden kann, ob die Rahmen und Glasscheiben im Bad (Männer-, Frauenstube) oder »auf« dem Bad, d.h. im Obergeschoss in der Trinkstube oder Wohnung des Baders eingesetzt, repariert oder erneuert wurden. StAR BM 1477, 14; BM 1508, 12 (zehn Scheiben eingesetzt, Lohn zehn Groschen = Kreuzer) u. 13'; Rechnung Ratmberg 1507-1513, 141 (zu 1513); BM 1523, 10' u. 24; BM 1525, 19; BM 1539, 13'; BM 1545, 26 ' (sieben Scheiben eingesetzt, Lohn sieben Kreuzer); BM 1547, 23 (sechs Kreuzer für das Küchenfenster im Bad, das der Wind eingestoßen hat) u. 25 (Gläser eingesetzt, der Tischler Peter Rixner macht zwei Fensterrahmen); RS 5, 57' (zu 1549); BM 1551, 15’; BM 1555, 19' (Gläser ausgebessert, der Tischler Rixner macht vier Rahmen); BM 1556, 17, 17', 18; BM 1562, 22, 23'; BM 1568, 38; BM 1579, 40 u. 42 (der Tischler Püechl macht neue Rahmen); BM 1580, 20', 21', 25; BM 1581, 41. Wenn der Glaser 1477 für 65 Kreuzer und 1513 für 80 Kreuzer Gläser im Bad gemacht hat und das Einsetzen einer Scheibe 1508 und 1545 je einen Kreuzer kostete, müssen demnach 1477 und 1513 viele Scheiben zerbrochen gewesen sein, vermutlich als Folge eines Sturms.

313 Die Hütten, die gewöhnliches Glas erzeugten, lagen wegen des enormen Holzverbrauchs im Wald und zogen weiter, war einmal der Wald abgeholzt. Unter Waldglas verstand man besonders das grünliche Glas aus dem Schwarzwald. Die Herstellung der grünen Butzenscheiben war relativ einfach, Fenster aus zusammengesetzten Butzenscheiben im Bleifeld beherrschten bald den Markt (Lerner, 78). In Heidelberg kostete 1579 eine gewöhnliche Scheibe drei Pfennig, eine Waldscheibe zwei Pfennig, das Einsetzen einer Raute drei Pfennig (Lerner, 146).

314 Egg, Werkleute, 148.

315 Lerner, 76.

316 StAR BM 1539, 15.

317 StAR BM 1564,19. Nach dem bezahlten Preis von zwei Gulden 24 Kreuzern dürfte es sich um bessere Fenster oder Fensterflügel gehandelt haben, vielleicht für die Trinkstube.

318 Stops, Rattenberg, 115-117.

319 Es wurde übrigens vom Torhüter des Brückentors mitbewacht (StAR RS 2, 51: zu 1513).

320 StAR Rechnung Ratmberg 1507-1513, 124. Als zwei Jahre früher ein Fasser der Stadt »zwen prunn eimer« lieferte (StAR RR 1511,14'), dürfte auch schon der Ziehbrunnen gemeint gewesen sein, auch wenn er nicht ausdrücklich genannt wird.

321 StAR BM 1515, 15’: der Schlosser Benedikt Melchior wird für seine Arbeit am Brunnen beim Bad bezahlt.

322 StAR RS 5, 4'u. 14.

323 Er erwarb 1524 das Inwohner-, 1526 das Bürgerrecht zu Rattenberg, war ein Wirt, mehrmaliger Ratsherr und von 1536 bis 1545 Stadt- und Landrichter zu Rattenberg. Nach seinem Tod (1556) bewohnte sein Sohn Erhard, Faktor des Ferdinand von Völs, später landesfürstlicher Zollverwalter zu Rattenberg, das Haus in der Stadt (Angaben nach vielen Dokumenten im Stadtarchiv).

324 StAR RS 7, 134' u. 135'. 1556 wurde der Ziehbrunnen mit einem "gätter« (Gitter) abgedeckt (StAR BM 1556, 16').

325 StAR BM 1568, 14.

326 Eine genauere Zeitangabe ist nicht möglich. Den Bau einer wichtigen und kostspieligen Wasserleitung ins Bad hätte nur der Rat beschließen können, doch die Ratsprotokolle zwischen 1532 und 1544 fehlen, und aus dieser Zeit sind bis 1541 nur zwei Baumeisterrechnungen $(1538,1539)$ erhalten. Sie sagen nichts über Ziehbrunnen, Brunnenbecken und Röhren aus. 
327 StAR BM 1541, 7'. Das Umhüllen mit Filz diente dem Frostschutz. Vg1. BM 1523, 11': Die Brunnensäulen in der Stadt wurden vor der "gefrüer« (Frost) mit Mist »vermacht« (umgeben). Weil der Ausbau der Röhren im Bad Wassermangel verursachte, wurden zeitweise zwei Wasserträger beschäftigt (StAR BM 1541, 8').

328 StAR RS 4, 63.

329 Nach den Baumeisterrechnungen dieser und späterer Zeit gab es damals drei städtische Laufbrunnen, den alten Stadtbrunnen am Markt, einen zweiten vor dem Haus des Vikars (Pfarrhof), einen dritten vor Geislers Haus. Ein weiterer Laufbrunnen stand im Hof des Klosters (Büchner, Einzug, 102). Hinzu kam noch der Ziehbrunnen beim Härrer.

330 StAR BM 1547, 7', 9' 13, 14', 28'. Demnach befand sich wohl auch das Brunnenbecken bei der Scherbank, also hinten - vom Ofen aus gesehen - bei der Eingangstür.

331 StAR 1547, 23' u. BM 1572, 12'. Sie wurden mit »Mieß« (Moos) abgedichtet (StAR BM 1579, 40).

332 StAR RS 7, 152.

333 Caspar Geisler, genannt Inzinger, war Wirt, Ratsherr und Bürgermeister (1536) von Rattenberg. Nach seinem Tod (1544) folgten ihm als Wirt seine Söhne Hans († 1549) und Sebastian nach (lt. Dokumenten im Stadtarchiv).

334 StAR BM 1568, 12'; BM 1572, 7', 12; 13', : Holz für das Brunnenbecken; 15'-16: Besichtigung des Brunnens im Bad.

335 StAR BM 1579, 7', 17, 19', 22.

336 Möglicherweise ist es der alte oder ein neuer Härrerbrunnen, von dem die Brunnensäule im Männerbad gespeist wurde, vgl. StAR BM 1579, 8': die Brunnensäule im Bad »bey dem obern Härrerprunnen« gesetzt.

337 Damit könnte allerdings auch die Trinkstube auf dem Rathaus gemeint sein.

338 StAR BM 1544, 14'. Er wollte zunächst "gwandthuterin" schreiben, verbesserte sich aber dann auf »Reiberin« und vergaß, das ganze Wort davor zu tilgen. Mit Stefflin ist die Frau des Stefan Reichl, eines Frätschlers (Lebensmittelhändlers), gemeint. Sie war vom Rat am 10. September 1544 zum nächsten Quatember als Badreiberin aufgenommen worden und hatte die alte Reiberin, Benediktin, genannt, ersetzt (StAR RS 4, 43'). Die Benediktin war die Frau Benedikt Oswalds, damals Wächter der Stadt (ebenda, 3). Da beide Frauen im Bad tätig waren, wird es sich um die Trinkstube des Bades, nicht um die auf dem Rathaus gehandelt haben. Um die Reinigung des Rathauses hätte sich die Frau des Stadtschreibers kümmern müssen, die dafür vom Rat bezahlt wurde.

339 In allen Rechnungen ist dies der einzige Beleg für eine solche den Reiberinnen aufgetragene Arbeit.

340 Dabei scheuten sie sich nicht, Lasstafeln, die die richtige Zeit zum Aderlassen angaben, und einen Badschwamm auf Kosten der Stadt zu kaufen (StAR Raitbuch Rattenberg 1514-1529, 15 [1514], 63 [1516], 175 [1523]).

341 Zur ganzen Geschichte vgl. Büchner, Mord (2008-2009).

342 TLA Verfachbuch Rattenberg 50/5 (1552-1556) 154'.

343 Die im Streit erlittenen kleineren Kopfwunden ließ sich Erber im Bad verbinden (Büchner, 82).

344 In der Regel verweist »im Bad« auf das Erdgeschoss, »auf dem Bad« auf das Obergeschoss.

345 StAR BM 1538, 7. Hier steht versehentlich »im pad«. Es hätte »auf dem Bad« heißen müssen.

346 StAR BM 1568, 38. Auch der zu 1510 erwähnte Kachelofen (vgl. Anm. 239) dürfte sich auf die Trinkstube bezogen haben. Möglicherweise betrafen Hinweise, die lediglich allgemein von einer Reparatur oder Erneuerung eines Fensters, des Bodens, der Vertäfelung in der Stube sprachen, in dem einen oder anderen Fall auch den Gesellschaftsraum.

347 StAR BM 1547, 6.

348 StAR BM 1572, 11'. 3 Werkschuh = ca. $1 \mathrm{~m}$, Leitkauf = Trunk bei Abschluss eines Vertrages, um ihm Rechtskraft zu verleihen, oft nur noch eine Art Trinkgeld. 
349 StAR BM 1581, 36 u. 37.

350 Vgl. Anm. 266.

351 StAR BM 1523, 25. Das »wildfeur« betraf den Werkstadl des Wirtes, Metzgers und Viehhändlers Michel Hupfauf (ebenda, 23).

352 StAR BM 1547, 22; BM 1551, 6’ u. 7.

353 Vgl. Anm. 233.

354 Diese Summe wurde als Badgeld seit ca. 1506, (nach der Auszahlung zu urteilen) ständig seit 1509 von der Einwohnerschaft eingehoben, vgl. StAR RR 1506, 4': eingenommenes Badgeld acht Mark acht Pfund. Davor mag der Sold für den Bader geringer gewesen sein, denn z.B. 1487 wurden nur 13 Gulden drei Pfund Badgeld unter den Einnahmen der Stadt verbucht (RR 1487, 4). Man wird nach 1506 die Einwohner nicht mit einem höheren Badgeld belastet haben. Doch genau lässt sich das nicht erheben, weil seitdem nur eine Summe für eingenommenes Bad- und Wachtgeld in den Rechnungen erscheint (z.B. RR 1509, 3: 28 Mark Bad- und Wachtgeld, RR 1511, 4: 31 Mark, RR 1516, 4': 64 Gulden, RR 1528, 7: 60 Gulden, RR 1542, 11': 61 Gulden).

$355 \mathrm{Zwar}$ war die Aufnahmegebühr für Inwohner deutlich geringer als für Bürger, doch unterlagen sie gewissen Beschränkungen, namentlich in Handel und Gewerbe. Inwohner waren nicht Mitglied der Gemeindeversammlung, sie durften kein Tuch ausschneiden, keinen Wein schenken, kein Wachs ausschlagen, kein Eisen verkaufen, kein ungesottenes Garn kaufen usw. (Kogler, Rattenberg, 39 mit Anm. 187; StAR RS 1, 48 u. Vorsatz: Inwohnereid).

356 Martin, Badewesen, 96.

357 TLMF FB 2994: Ordnung der Baderbruderschaft zu Innsbruck (nicht paginiert). Der Eintrag wurde getilgt.

358 Genannt werden, sofern Ortsangaben stehen, nur Heinrich Angstwurm, Bader zu Zirl, Cristan Künig vom Filß (Vils), Oswald Kueperger von Prutz. Vielleicht ist noch Lienhart Frisch(er), »knecht des Michel pader sun von Lens«, hierher zu setzen, da im genannten Ort Lans vermutet wird (Gaisböck, Zünfte, 146).

359 Füssen, München, Augsburg, Kempten, Landsberg, Weilheim, Straubing, Tegernsee, Memmingen, Regensburg, Berchtesgaden.

360 Auf dem Siegel der Rattenberger Bergwerksbruderschaft von 1473 liest man in der Umschrift: Rotenberg (vgl. die Abb. bei Mutschlechner, Erzbergbau, 39).

361 Bachmann, Stadtbad, 12.

362 Scherper, schörper $=$ einfaches Messer, kleines Küchenmesser $($ Josef Schatz, Wörterbuch der Tiroler Mundarten 2 [1956] 520).

363 TLA Hs. 218: Register der »Wänndl« [Strafen, Bußen] des Rattenberger Bergrichters Caspar von Pirchach 1470/1471, 9.

364 KlAR Codex 71, 140, 146', 150', 159, 175', 181, 194', 211'

365 Ebenda, 211' u. 254. Sonderleistungen wurden anscheinend extra vergütet. Als 1500 der Provinzial Kloster und Konvent visitierte, nahm er einen Bader, wohl Freytag, in Anspruch. Dieser erhielt 6 Kreuzer (ebenda, 226).

366 Ebenda, 261.

367 Ebenda, 278'.

368 Ebenda, 14'.

369 Ebenda, 131; gemeiner Tod = Epidemie, Seuche, Viehseuche.

370 Deshalb sah sich auch das Kloster gezwungen, auswärtige Hilfe in Anspruch zu nehmen, wenn es einmal eine Arznei oder einen Arzt benötigte. So besorgte es sich 1526 zur Zeit einer Seuche Medizin um neun Gulden vom Arzt Georg Klein zu Schwaz (K1AR Codex 70, 47, 49’), beschäftigte 1530 einen 
Arzt und einen Wundarzt (ebenda, 85, 85'), 1531 einen Arzt wegen eines Steines (ebenda, 101) und ließ 1531 und 1534 Medizin aus Schwaz holen (ebenda, 106, 125').

371 Wie üblich wurde die Rossarznei von Hufschmieden versehen. So behandelte z.B. der Rattenberger Schmied Gall Ganser 1521 ein krankes Pferd (»equum morbidum«) des Klosters (KlAR Codex 71, 419), 1529 war es der Schmied Cristan Pürgl, der für das »ertznen« eines braunen Rosses im Spital vier Pfund acht Kreuzer erhielt (StAR Spital Raitung 1529, 14').

372 K1AR Codex 71, 289'.

373 StAR RS 1, 35'.

374 KlAR Codex 71, 292': „Dedi balneatrici Michaelis de balneando per annum 14 Pfd.«

375 Ebenda, 294'

376 KlAR Codex 71, 355' (1514). Abrechnung mit Meister Conrad, »unserem« Bader. Er soll jährlich vom Konvent fünf Gulden und einen Star gewöhnliche Gerste als Lohn erhalten; 138 (1518): Der Badermeister Conrad erhält seine Jahresprovision von fünf Gulden und zwei Star Gerste.

377 Ebenda, 312 (1509): Der Bader Wendl erhält zehn Kreuzer, dann nochmals 15 Kreuzer fürs Rasieren; ebenda, 45' (1526): Der Bader Cuntz erhält scht Kreuzer für Weizen und noch einen Gulden, »ut cicius veniat ad nos tempore (infirmitatis) pestis«. Es handelt sich wohl um Kuntz Stolz aus Kramsach, den die Stadt während der Seuche als Totenlässl beschäftigte (s.u.). K1AR Codex 70, 122 (1533): ein Barbier aus Fügen.

378 Das Badezimmer im Kloster scheint sehr ordentlich ausgestattet gewesen zu sein. 1506 kaufte man eine neue Badewanne (K1AR Codex 71, 172), 1509 machte der Kupferschmied Egidius eine Kupferwanne fürs Bad - in der damaligen Zeit ein Luxus - und führte die Röhren vom Braukessel ins Bad (ebenda, 318), 1525 renovierten Zimmerleute das Bad (K1AR Codex 70, 35'), 1526 wurden drei Badehüte gekauft (ebenda, 38').

3791536 wird ausdrücklich bei der Abrechnung mit dem Baders betont, dass man ihn für alle Arbeiten bezahle, »es sey in seinem pad oder in dem convent« (ebenda, III').

380 Es gab noch andere als nur solche im Kloster. 1538 war z.B. im Rattenberger Spital der Bader Jörg aus Jenbach tätig, der neben Zehrungskosten und Trinkgeld zwölf Gulden Arztlohn erhielt (StAR Spital Raitung 1538, 5', 6-7', 9-10'). 1555 begegnet im Landgericht Rattenberg ein Bader namens Caspar, der vorgeladen wurde (StAR RR 1555, 23').

381 Kogler, Rattenberg, 74.

382 StAR RS 5, 57' u. 79'.

383 StAR RS 9, 23'.

384 StAR RR 1564, 27’ u. RR 1565, 5.

385 StAR RS 5, 96'.

386 StAR RS 1, 89.

387 StAR RS 2, 28' (Osterwoche 1512).

388 StAR RS 3, 137.

389 Ichenhausen (LK Günzburg).

390 StAR RS 8, 31, 68-69'.

391 Die Jahresrechnung und Baumeisterrechnung der Stadt für 1508 fehlen, ein Journal des Kämmerers begnügt sich für 1508 mit pauschalen Angaben zu einigen Ausgabeposten und geht kaum ins Detail. Die Ratsprotokolle für 1508 und 1509 sind unergiebig.

392 KlAR Codex 71, 309.

393 Ebenda, 314; 1 Star = 31,7 1. Vor Vertragsabschluss hatte der Badermeister schon im März zehn Kreuzer fürs Baden erhalten (ebenda, 310').

394 Ebenda, 320 u. 322'. 
395 Ebenda, 326’.

396 StAR RS 1, 86, 98, 142'.

397 Ebenda, 85 u. 87’.

398 StAR Rechnung Ratmberg 1507-1513, 35’, 48 u. 59' (1509), 79 (1510).

399 Jetzt erfährt man, dass Katharina Hueber die Tochter eines Rattenberger Bürgers gewesen ist.

400 Wenn die Redensart nicht bloß »von Kopf bis Fuß, ganz und gar« meint (vgl. Grimms Dt. Wörterbuch 11,3 [1936] 1448), könnte man sie auch räumlich im Sinne von »in der Trinkstube oben und in den Badstuben unten« auslegen.

401 StAR RS 2, 72.

402 Ebenda, 79'.

403 StAR Raitbuch Rattenberg 1514-1529, 15 (nur zwölf Gulden für drei Quatember 1514), 35 (1515), 63 (1516), 93 (1518), 130' (1519).

404 StAR RR 1521, 4'. Er wird hier das einzige Mal mit seinem Familiennamen »Heinrich Perchtold, Pader«, genannt. Da ihn sonst aber die Quellen nur als Meister Heinrich oder Heinrich Öttinger bezeichnen, wurde diese Benennung von mir beibehalten. Öttinger ist eine Herkunftsbezeichnung. Er stammt wohl aus dem nahen Alt- oder Neuötting in Bayern.

405 Z.B. StAR RS 3, 19' (1523).

406 Da die Ratsprotokolle für beide Jahre fehlen, lässt sich darüber nichts Genaueres aussagen.

407 StAR RR 1521, 24'-25 (Jacob erhielt 3 Gld. 20 Kr., die Diwoldin 1 Gld. 30 Kr.). Eigene Totenlässl für die Kranken in Seuchenzeiten anzustellen war auch anderswo üblich, z.B. 1564 in Kitzbühel, als wieder einmal die pestis herrschte (Kostenzer, Gesundheitswesen, 391, 392, 433).

408 K1AR Codex 71, $367^{\prime}$ u. 368 (1515), 375 (1516), 382 (1517), 396 (1519), 406’ (1520), 419 (1521), 429’ (1522), 435 (1523)

409 K1AR Codex 71, 98' (1517, ein Star Weizen), 106 u. 107 (1519, 33 bzw. 20 Klafter Holz; hier wird der kleine Johannes als Öttingers Knecht erwähnt); Codex 70, 15 (1523: der Klosterknecht Peter liefert dem Prior 32 Kr. Fuhrlohn von der Baderin ab).

410 K1AR Codex 71, 396 (1519: der Bader erhält sechs Pfund wegen einer Stummen und wegen eines Jünglings, ob fürs Baden oder Verarzten wird nicht gesagt), 436 (1523: der Bader rasiert den Pater Provinzial und den Distriktsvikar, die zur Visitation im Kloster waren); Codex 70, 12 (1523: als der Prior in Geschäften des Klosters das Bad aufsuchte, rasierte ihn der Bader zweimal).

411 K1AR Codex 71, 416'.

412 Ebenda, 117'.

413 StAR RS 3, 22'; sein Dienst war ihm noch am 1. März 1523 verlängert worden, mit dem Befehl, den Knecht Khuntz zu behalten (ebenda, 10’).

414 Ebenda, 30'-31.

415 StAR Raitbuch Rattenberg 1514-1529, 218, 219, 241, 242.

416 StAR BM 1523, 25.

417 Das ist im Hinblick auf Jacob Rasp gesagt.

418 StAR RS 3, 169' (1529 Januar 22). 1551 hört man noch einmal von Heinrich Öttingers Nachkommen. Einem Enkel von ihm stellte der Rat für seine Schwester Margrete eine Urkunde aus, die einen Erbfall aus dem Jahr 1540 betraf (StAR RS 6, 127).

419 Im Anlageregister wurden 175 Bürger und Inwohner erfasst. Der nicht aussagekräftige Durchschnittswert der Steuer betrug einen Gulden 32 Kreuzer (einige wenige bezahlten hohe Beiträge), der Median lag nur bei 36 Kreuzern. Diesen erreichten Öttingers Erben nicht. Sie zählten zu jenen 25 Einwohnern, die je zwölf Kreuzer entrichten sollten. Unter ihnen lagen nur noch sieben mit je sechs Kreuzern (StAR Schuber 61: Steuerwesen 1528-1726, 1. Anlageregister zur Türkensteuer vom 23. Februar 1529). Bei 
zwei weiteren Vorschreibungen 1529 und 1530 wurden Öttingers Erben wieder nur mit je zwölf Kreuzern eingestuft (ebenda, 2. Anlageregister vom 1. Oktober 1529, 3. Anlageregister vom 23. Mai 1530).

420 StAR RS 3, 32' u. 36'-37.

421 StAR BM 1523, 9'.

422 Martin, Badewesen, 10-20 u. ders., Frühlingsbäder, 812-818. Spätere Autoren wie Baader (Badewesen, 1340-1341) und Kiby (Badekultur, 59) stützen sich bei ihren kurzen Anmerkungen zum Maibad auf Martin. Vgl. Widmann/Mörgeli, Bader, 65-67 (einige Bilder zum Maibad).

423 Martin, 18.

424 KlAR Codex 71, 211' (1496 Mai 13, Randvermerk: "Maister Gabriel ist angestanden«).

42518 Pfund Berner entsprachen in der damaligen Tiroler Währung 216 Kreuzern (1 Mark = 10 Pfund, 1 Gulden = 5 Pfund, 1 Pfund = 12 Kreuzer). Das Fahren eines Fuders Brennholz wurde vom Kloster auf zweieinhalb Kreuzer veranschlagt (s.u.), Ein Fuder entsprach der Ladung eines zweispännigen Wagens (vgl. Grimms Deutsches Wörterbuch 4, 1, 1 [1878] 364). Der Knecht der Mönche transportierte demnach ca. 861/2 Wagenlasten für Freytag. Noch beeindruckender ist die Zahl in der Abrechnung von 1513 (s.u.). Damals wurden dem Bader sechs Mark und acht Pfund (= 816 Kreuzer) für Holzfuhren in 23/4 Jahren gegen seinen Lohn aufgerechnet. Falls nicht entgegen dem Wortlaut des Rechnungsbuches noch andere Schulden des Baders gegenüber dem Kloster in dieser Summe enthalten sind, müsste der Knecht für ihn insgesamt 326 Fuder Brennholz, d.h. 1181/2 in einem Jahr gefahren haben, eine erstaunliche, möglicherweise zu hohe Zahl. Wie dem auch sei, der Brennholzbedarf des Bades, wenn es drei Tage in der Woche geöffnet hatte, war sehr hoch.

426 Ebenda, 254. Bei den Grundstücken handelte es sich um die Wiese Sporenpeunt, den Acker Percherin und das Mencklin-Gärtchen (ebenda, 34', 36, 37' einige Zinsangaben). Zudem hatte Freytag vom Kloster noch das Payrin-Gärtchen, für das er nichts zahlte (ebenda, 77’: »nichil recepi«).

427 KlAR Codex 71, 348'.

428 StAR Rechnung Ratmberg 1507-1513, 96 (1511), 124 (1512); Raitbuch Rattenberg 1514-1529, 14 (1514).

429 StAR Rechnung Ratmberg 1507-1513, 89.

430 Ebenda, 124 (1512).

431 StAR RS 1, 130' (1511: Der Bäcker Sebastian Plaickner hatte den Hans Paumgartner, ebenfalls einen Bäcker, verwundet. Der Rat erlegte dem Plaickner als Strafe auf, dem Paumgartner wegen »lem und leibschaden« 32 Gulden in vier Raten und dem Bader Gabriel, »der oberürten scheden zu ertzneyen«, 7 Gulden in drei Raten zu zahlen).

432 Ebenda, 134

433 StAR RS 2, 51; vgl. Kogler, Rattenberg, 136.

434 StAR RS 1, 121' (1511); RS 2, 32 (1512) u. 39' (1512).

435 Es war das obere Bad in Brixen, das 1533 sein Sohn Hans innehatte (Mader, Häusergeschichte, 86).

436 StAR RS 2, 72.

437 Ebenda, 79'.

438 StAR Raitbuch Rattenberg 1514-1529, 14.

439 StAR RS 2, 88.

440 Moser, Apotheker, 250.

441 Dass noch im 17. Jahrhundert schreibunkundige Bader wirkten, zeigt eine Urkunde aus dem Jahr 1633, worin vom Meister Georg Schweikhardt, Bürger und Bader zu Neumarkt in der Steiermark, gesagt wird, er verstünde sich nicht aufs Schreiben. Trotzdem war er aber geschickt genug, einem verwundeten Soldaten eine Bleikugel von anderthalb Lot aus der linken Achsel zu schneiden. Der Soldat wurde wieder gesund und blieb schmerzfrei (Hölzl, Gemeindearchive, Nr. 21/304). 
442 TLA Embieten und Befelch 1514, 204 (März 24).

443 Guarinonius, Grewel, 945 : Der eine bringt »ein gute batzete, feiste Rauden, der ander ein guten dürren Aussatz, der dritt etwan ein junge Frantzosen, der vierdt fein geschmeidige Schlier.»

444 Winkle, Kulturgeschichte, 35 (über die Lepra im Mittelalter und in der Neuzeit: 15 ff.); Jankrift, Gott, 119-140 (hier: 121); Reddig, Bader, 77.

445 Zur Krätze (Skabies) Vgl. Winkle, 1050-1066.

446 Winkle, 548 (über die Syphilis in der Neuzeit: 541 ff.); Jankrift, 106-108; Reddig, 102-103.

447 Reddig, 103-104; Jankrift, 107.

448 Winkle, 551 u. 553.

449 Reddig, 104.

450 Tuchen, Badhäuser, 28 u. 117; Martin, Badewesen, 207-208; Winkle, 549.

451 Martin, 199-200, 208.

452 Winkle, 549.

453 Jankrift, 106.

$454 \mathrm{Da}$ dies Wort in den Quellen Badbesucher bezeichnet, die einen offensichtlichen Leibschaden wie blutende Wunden, eitrige Geschwüre, übel riechende Ausflüsse, zerkratzte Haut, Borken, Schorf usw., also im Allgemeinen Hautkrankheiten hatten, wird eine Übersetzung mit »krank« vermieden. Leute, die an Gallen-, Nieren- Blasensteinen, an Kopf-, Leib-, Hals-, Brust-, Magen-, Gelenk-, Rücken-, Knieschmerzen o.ä. litten, sind sicher nicht damit gemeint. Deren Schaden war nicht sichtbar.

455 StAR RS 2, 51.

456 StAR RS 5, 52 (dass er sie "hin hinter setz«).

457 StAR RS 6, 3.

458 StAR RS 13, 259'; vgl. Bachmann, Stadtbad, 8 u. Stops, Rattenberg, 118.

459 KlAR Codex 71, 429: "[...] non fui ausus intrare estuarium causa infirmitatis mee«. Er verrechnete nunmehr 1522 die Kosten des Rasierens in drei Jahren. Frater Topf ist Anfang November 1523 gestorben (K1AR Codex 70, 8').

460 Ebenda, 427’: »Item feci mederi mutam nostram de morbo gallico, dedi medico mesner de Meren causa medendi« 7 Pfd. Berner (1522 Febr. 16).

461 StAR RS 3, 56.

462 StAR RS 5, 92'-93.

463 Ebenda, 94. Dagegen spricht allerdings, dass Paungartners Leiche, als man sie gefunden hatte, Geld bei sich trug. Welcher Mann springt schon mit anscheinend beträchtlichem Geld ins Wasser und begeht Selbstmord, es sei denn, er hasst seine Frau und künftige Witwe und will ihr schaden.

464 Reddig, 103.

465 StAR RS 6, 181.

466 StAR RS 3, 36'-37 u. 38. Die Bestellung wurde am Dreikönigstag 1524 wiederholt (ebenda, 50).

467 Die Formulierung legt nahe, dass es außer diesen beiden noch andere Knechte im Bad gegeben hat. In einer Kleinstadt wie Rattenberg könnten das höchstens noch ein Dritter gewesen sein, mehr hätte sich hier ein Bader kaum leisten können.

468 Ebenda, 53'u. Bachmann, Stadtbad, 8.

469 Ebenda, 56-56'; vgl. Stops, Rattenberg, 118.

470 Ebenda, 64'; StAR Raitbuch Rattenberg 1514-1529, 217' -218.

471 K1AR Codex 70, 23 (Lohn: drei Gulden vier Kreuzer).

472 Er hat sich demnach jenseits des Inns sein Brennholz besorgt, vermutlich in der Hagau, im Brandenberger Tal oder in Steinberg am Rofan, wo in Wäldern viel Holz geschlagen wurde, besonders für die Hüttenwerke in und bei Brixlegg. 
473 StAR RS 3, 59'.

474 Moser, Apotheker, 153.

475 TLA Parteibuch 5 (1534-1536) XCII-XCII’ (1534 Sept. 22: Hans Kenntler wird hier als »Schnytt Artzt« bezeichnet).

476 TLA Parteibuch 7 (1539-1540) 41' (1539 April 18).

477 StAR RS 3, 56'; Bachmann, Stadtbad, 8. Er erklärt irrigerweise die zwei Väter als Vater und Großvater. In Wirklichkeit sind der Vater Michael Hueber d.Ä. und der Stiefvater Heinrich Öttinger gemeint.

478 StAR RS 3, 70.

479 Ebenda, 144.

480 Ebenda, 116 (1526).

481 StAR Raitbuch Rattenberg 1514-1529, 274', 275' (1526), 290' (1527); RR 1528, 21.

482 StAR RS 3, 137. Ihr verstorbener Mann ist vermutlich ein Schiffer gewesen (vgl. StAR BM 1477, 8).

483 StAR Raitbuch Rattenberg 1514-1529, 289': Die Stadt zahlte dem Bader Michel die Hälfte der Kosten (1 Gld. $46 \mathrm{Kr}$.) »von wegen der aczung des holczknechts, den der kübl schmalcz von Smäntzen abgestössen« (1527 März 22). "Atzung« ist hier wohl als Pflegekosten zu verstehen. »Schmäntz« (= Schmatzer) war der Spitzname des Frätschlers (Lebensmittelhändlers) Hans Kagrer.

484 StAR RS 3, 138 (1527 Okt. 18); Bachmann, 8; Stops, 118.

485 Ebenda, 113'. Zuvor (113) hatte man schon auf Wartegeld zwei Frauen ausgewählt, die den Kranken aufwarten, die Toten einnähen und begraben sollten..

486 Ebenda, 124 (1527 Februar 5: 20 Kreuzer Wartegeld wöchentlich); 149 (1528 Jan. 17: Wochenlohn von einem Gulden auf 20 Kreuzer Wartegeld herabgesetzt). Der Stadt kam der Totenlässl ziemlich teuer zu stehen. 1526 erhielt Stolz 18 Gulden (StAR Raitbuch Rattenberg 1514-1529, 274-275'), 1527 waren es 14 Gulden 20 Kreuzer (ebenda, 292-292').

487 Ebenda, 137.

488 KlAR Codex 70, 45’: „Dem Cuntz pader 8 kr. um weicz plus 1 flo., ut cicius veniat ad nos tempore infirmitatis pestis «; florenus = Gulden.

489 KlAR Codex 70, 45' (1526 Okt. 5, für das vergangene Jahr), 67 (1527), 68' (91/2 Pfund, wohl für zusätzliche Leistung) u. 70' (1528)

490 Ebenda, 34 (1525: Hueber erhielt nur sieben Pfund als Baderlohn, »cetera sunt defalcata pro Stephano pfragner«. Anscheinend haben die Augustiner seine Schulden beim Pfragner (Lebensmittelhändler) Stephan Reichl beglichen. Für den Prediger, den er vermutlich rasiert hat, erhielt Meister Michael damals noch 20 Kreuzer.

491 Nach der Auswertung der Einträge im Rechnungsbuch für 1529 (K1AR Codex 70, 75' ff.).

492 Ebenda, 47.

493 Ebenda, 61', 64', 65.

494 Ebenda, 81'

495 Ebenda, 73.

496 Ebenda, 48 (1529).

497 Mecenseffy, Täufer, Nr. 106. Die Ratsprotokolle Rattenbergs für 1528 und 1529 hüllen sich über die Täufer in der Stadt in Schweigen. Keine Einträge.

498 Ebenda, Nr. 127. Vgl. Stops, 83: Dass Hueber, den Henker vor Augen, »in einer furchtbaren seelischen Verfassung« dem Richter Täufer genannt und damit eine »verheerende Kettenreaktion« ausgelöst hat, wie Stops meint, ist pure Erfindung. Der Bader hat augenscheinlich nie an einer Täuferversammlung teilgenommen und konnte deshalb auch nicht die Namen von Teilnehmern angeben.

499 StAR RS 3, 169.

500 Ebenda, 175. 
501 Ebenda, 179' (1529 Sept. 12). Nach Stops (Rattenberg, 116) wurde vom Rat 1529 der Bader Jacob Mörschweger aus dem Salzburgischen angestellt, doch machte er sich bald mit einem weiblichen Badegast davon. Das Ratsprotokoll weiß nichts davon. Für ihn ist als Badermeister im Jahr 1529 kein Platz, es sei denn, er war lediglich ein Badknecht.

502 TLA Verfachbuch Rattenberg 50/2 (1546-1547) 29'-30.

503 Vgl. Anm. 408 .

504 StAR RS 3, 37'.

505 StAR RS 4, 163'.

506 StAR RS 6, 3.

507 Inama-Sternegg, Nachlassinventar, 41.

$508 \mathrm{Ob}$ er eins hatte, weiß man nicht.

509 StAR RS 4, 174. Zwei Wochen später (am 30. Juni) allerdings war der Rat bereit, ihm zu gestatten, an seinem Haus ein Badl zu machen, falls der junge Herr Bürger werden und bürgerliche Pflichten übernehmen wolle (StAR RS 4,176). Wolf Joseph wollte anscheinend nicht. Denn soviel man weiß, wurde er nicht Bürger, kam es nicht zu einem Bad an seinem Haus. Die Reinlichkeit wurde seinen Privilegien als Adliger und fürstlicher Beamter (Silberbrenner, Urbarrichter) geopfert, fast nach dem Motto: Lieber etwas schmutzig als ein Bürger.

510 Mecenseffy, Täufer, Nr. 620. Mecenseffy behauptet ständig (z.B. S. 422 Anm. 7, ihr folgen Stops, 84 und andere), Ursula sei die Witwe des gerichteten Täufers Caspar Khuen gewesen. Das ist barer Unsinn. Er ist 1526 gestorben, als es in Tirol noch keine Täufer gab. Am 23. Februar 1526 erhielten die sieben Kinder des Caspar Khuen selig Vormunde (StAR RS 3, 101'), am 14. März 1526 schloss seine Witwe Ursula einen Erbvertrag mit Caspar Khuens selig Kindern (ebenda, 104'-105), auf Ursulas Bitte um Unterstützung hin, weil ihr verstorbener Mann an die 40 Jahre den Fürsten als Silberbrenner gedient habe, gewährte ihr die Kammer am 9. September 1527 ein Gnadgeld von 24 Kreuzern wöchentlich (TLA Geschäft von Hof 1527, 47 u. 299; Missiven an Hof 1527, 83-83'), sicher nicht, wenn sie damals schon eine Täuferin gewesen wäre.

511 StAR RS 4, 47.

512 TLA Verfachbuch Rattenberg 50/1 (1546-1547) 109'-110.

513 Ebenda 50/4 (1548-1549) 65-66.

514 Ebenda, 66-67.

515 Man könnte meinen, weil die Bürger und Inwohner Rattenbergs schon die 16 Gulden Jahreslohn für den Bader aufgebracht haben, hätten sie wenigstens freien Eintritt gehabt. Doch dem war nicht so. 1547 bei der Bestellung eines neuen Baders heißt es ausdrücklich im Pachtbrief, er erhalte alle Quatember vier Gulden und dazu von jedem Bad- und Lassgeld, wie üblich und altes Herkommen sei (StAR RS 4, 163'). 516 K1AR Codex 70, 61'.

517 Auch frühe Nachweise für das Pflugziehen und Auftreten Maskierter zur Fastnachtszeit in Rattenberg sind vermutlich bislang unbekannt geblieben, weshalb sie hier angeführt werden sollen: K1AR Codex 70, 427': »Dedi juculatoribus aratri 2 kr.» (1522 Febr. 28) und ebenda: „Fuerunt juculatores mascerati, dedi eis 6 kr.«(1522 Febr. 24).

518 Nach alten Quellen berichtet von Theodor Fontane, Wanderungen III, 26-27, 1121 (Quellen) u. 1124 (Anm. 26).

519 Z. B. Stadtrecht Überlingen 1559: »Soll das Hochzeitsbad genzlich abgethon ... sein« (Schwäbisches Wörterbuch 3 [1911] 1720).

520 Martin, Badewesen, 184-187; van Dülmen, Kultur, 146 u. 148 (er stützt sich auf Martin). Hochzeitsbäder in württembergischen Dörfern sind für Dagersheim (1473) und Neuhausen an der Erms (1536) nachgewiesen (Fritz, Badstuben, Anm. 93 auf S. 28). 
521 Bayerisch-österreichisches Wörterbuch I: Österreich, Bd. 1 (1976) 72.

522 KlAR Codex 70, 83: »In nupciis balneatoris« verauslagt sieben Pfund Berner.

523 StAR RS 3, 186'u. 187': Aufnahmegebühr ein Gulden.

524 Vgl. Anm. 388.

525 KlAR Codex 70, 93: „Feci racionem mit dem Hans pader de anno vicesimo nono et tricesimo, dedi illi 2 florenos 3 Pfd. perner 4 kr und 2 ster Rogkn um 1 flo. propter balneum conventus, cetera sundt (!) defalcata in labore vecture (vermutlich Holzfuhren).

526 Es starb 1556 aus, konnte 1570 wieder mit Patres besetzt werden, doch blieb die Zahl der Konventualen gering (zwei bis drei) und außerdem drohte lange Zeit der wirtschaftliche Ruin (Angerer,Kloster, 159-160).

527 K1AR Codex 70, 81': Lohn 5 Pfd.

528 Ebenda, 106.

529 Ebenda, 90. Weitere (Holz-)Fuhren bezahlt: ebenda, 51 (1530), 56 (1531), 67(1533; dagegen schuldete ihm der Konvent noch vier Gld. $12 \mathrm{Kr}$.).

530 Ebenda, III': »Als offt wir paden, es sey in seinem pad oder in dem convent, so geben wir vur uns als und als den knechten all pad tag 4 kr., facit piß Invocavit [5.März 1536] 16 Patzen«; 1 Batzen $=4$ Kreuzer.

531 Ebenda, XXIX': zwei Pfund Berner an den Bader für das Scheren zweier Knaben; XXXII (1. Adventssonntag): drei Gulden anteiliger Lohn.

532 StAR RS 3, 201 (1531) u. 212' (1532); RR 1533, 18 u. 19; RR 1535, 17; RR 1540, 21'; RR 1542, 20; RR 1543, 21'.

533 StAR RS 4, 2'.

534 Ebenda, 47.

535 StAR RS 3, 195'.

536 StAR Spital Raitung 1541, 9': Um ein Kind zu »ertznen«, erhält Meister Hans, Bader, einen Gulden.

537 StAR Spital Raitung 1538, 12': Der Schwester »anndnigt [Antlitz, Gesicht] zu ertznen« 3 Gulden, Arznei 4 kr., ein neuer Tiegel für die Arznei 6 kr. Als Empfänger der Zahlung steht in der Rechnung Lienhart Püchler. Der Vorname ist wohl nur ein Versehen des Schreibers. Denn Lienhart Püchler war ein Zimmermann und Holzmeister und wird kaum als Wundarzt tätig gewesen sein.

538 StAR RS 3, 216 (1532 April 29).

539 StAR RS 4, 60'.

540 Wer das sein soll wird nicht gesagt. Vermutlich waren der Hauptmann von Rattenberg, Graf Christoph Philipp von Liechtenstein, und der geadelte Hüttenmeister von Rattenberg, Ambrosi Mornauer von Liechtenwert, gemeint. An beide Herren pflegten sich Rattenberger Einwohner zu wenden, wenn sie sich vom Rat unrecht behandelt fühlten.

541 StAR RS 4, 77, 77', 79', 81.

542 StAR RR 1545, 24'. Die Zahlung erfolgte nach Püchlers Tod.

543 Sie wird hier vom Rat irrtümlich Benigna genannt, ihr richtiger Name war Wandula.

544 StAR RS 4, 88'.

545 Bei ihm dürfte es sich um einen Sohn aus Wandulas erste Ehe mit Michael Hueber d.J. handeln.

546 StAR RS 4, 91.

547 Ebenda, 94' (1545 Dez. 18). Da sich der Stiefvater der Witwe um die Hälfte verbürgen wollte, sollte sie beim Abzug nur die Hälfte der Fahrnis in Rattenberg zurücklassen oder sich um alles verbürgen (ebenda).

548 Ebenda.

549 Mit einem Gebrechen behaftet, behindert.

550 StAR RS 4, 112'. 
551 Obst-, Gemüsegarten.

552 In der Abrechnung für 1544 (StAR St. Virgilien Kirche Raittung 1544, 3) steht, Hans Pichler, Bader, hat von seinem Garten drei Kreuzer bezahlt. Das ist natürlich falsch. Der Garten gehörte Wandula.

553 TLA Verfachbuch Rattenberg 50/2 (1546-1547) 29'-30 (1546 März 2). „Wandula« wird hier als »yeczt jünngstlich maister Hannsen Püchlers, paders und bürgers zu Ratenberg, seligen gelassne wittib« bezeichnet. Dass Püchler auch das Bürgerrecht erworben hat ist sonst nicht überliefert, aber gut möglich, weil die Ratsprotokolle zwischen 1532 und 1544 und auch viele Rechnungen aus dieser Zeit fehlen.

554 StAR RS 4, 164'.

555 Z.B. StAR RS 7, 205' (1555); RS 13, 43' (1574).

556 Z.B. StAR RS 11, 1'(1567); RS 13, 157 (1576).

557 StAR RS 13, 43' u. 98 (1574 u. 1575).

558 StAR RS 1, 121'.

559 Stadtbad, 8.

560 Rattenberg, 117-119.

561 Z. B. Grimms Dt. Wörterbuch 8 (1893) 567, Abschnitt 3f (reiben im Bad) u. 571 (Reiberin).

562 TLMF FB 2994 Ordnung der Baderbruderschaft zu Innsbruck und Hall von 1450/60. Reiberinnen als Mitglied, z.B. »Chlara, des Hanns Schroman Weib«, Reiberin im Untern Bad von Innsbruck.

563 StAR RS 4, 40' (1544 Agust 29).

564 Ebenda, 43' (1544 Sept. 10).

565 Vgl. zu den Aufgaben einer Reiberin Tuchen, Badhäuser, 31.

566 StAR RS 4, 14 .

567 StAR RS 8, 170'.

568 StAR RS 7,114.

569 StAR RS 5, 133'-134 (1549 Sept. 7) u. 137' (1549 Sept. 20).

570 Sie hier einzeln anzuführen würde zu weit gehen.

571 Ein Kurzname für Augustin.

572 Er betätigte sich vor allem im Fürkauf, im Aufkaufen von Korn zum Weiterverkauf, war nur ein kleiner Getreidehändler.

573 Zwischenhändler, Makler im Auftrag der Stadt (vgl. Grimms Dt. Wörterbuch 11,3 [1936] 1633-1634).

574 Mecenseffy, Täufer, Nr. 170, 176 B, 206. Sie nennt ihn irrigerweise Kuchlpeck oder Kuechlpeck, obgleich in den Originaldokumenten der Innsbrucker Regierung richtig Gilg Püechl steht.

575 Martin, Badewesen, 148.

576 StAR RS 13, 43'- 44.

577 StAR RR 1545, 24': „Die vierdt [quottember] Maister Micheln Schwegler« mit vier Gulden bezahlt.

578 StAR RS 4, 81.

579 Ebenda, 109'.

580 Ebenda, 128': Aufnahmegebühr zwei Gulden.

581 Hier ist weniger an Gottesfurcht als an Ehrerbietung, an gutes Benehmen gegenüber den Badegästen zu denken.

582 Ebenda, 157'. Die Öffnungszeit wurde auf sechs Uhr nachts begrenzt. Danach solle er niemanden mehr baden lassen (ebenda, 159: 1547 Januar 10).

583 StAR RS 4, 163-164 u. RR 1547, 18.

584 Guarinonius, Grewel, 945 u. 947. Auch in anderen Städten als Hall verursachten Bäder Umweltprobleme, um es modern zu sagen. Als 1580 der Bader Caspar Greupp neben dem Kitzbüheler Spital ein neues Bad zu errichten begann, protestierten die Anwohner und die anderen beiden Bader der Stadt dagegen und ersuchten den Rat um Einstellung des Baus. Der Rat entsprach der Bitte mit der Be- 
gründung, das Schmutzwasser des Bades würde über die Landstraße rinnen und bei den Leuten Ekel erregen. Das mochte wohl stimmen, doch der eigentliche Grund lag tiefer. In Wirklichkeit wollten die Inhaber der beiden existierenden Kitzbüheler Bäder keinen Konkurrenten haben (Kostenzer, Gesundheitswesen, 433-434). Auch in Württemberg ekelte man sich vor der grausigen Brühe aus schmutzigem Badewasser, Blut und Operationsabfällen, die von Badern in Flüsse und Bäche geleitet wurden. 1366 musste z.B. dem Gmünder Badestubenbesitzer untersagt werden, den Mühlbach mit Blut und Dreck zu verunreinigen (Fritz, Badstuben, 17 mit Anm. 40). Vgl. oben in der Anm. 22 den Hinweis auf den Unrat, den ein Klosterneuburger Bader 1384 in einen Bach entsorgte.

585 StAR RS 4, 71'u. 79.

586 Ebenda, 163 '.

587 StAR RS 5, 52 u. 57.

588 BM 1579, 8'.

589 Deswegen erhielt er 1547 nur eine Provision von zwölf Gulden für drei Quatember, vier Gulden musste er für den ersten Quatember der Schweglerin überlassen (StAR RR 1547, 18).

590 Sein Name wird meist so geschrieben, seltener Paunngartner, Paumgartner, Baungartner oder Baugartner.

591 Damit sind die Ratsherren gemeint.

592 Als 1549 alle Gläser (Fensterscheiben) im Bad gemacht worden waren, vermerkte dazu der Rat im Protokoll, zu gegebener Zeit müsse der Bader unbeschädigte Fenster zurückgeben (StAR RS 5, 57').

593 StAR RS 4, 163'-164. Am 15. Juli legte er eine Urkunde über seine eheliche Geburt und dass er sich zu Schwaz ehrbar verhalten habe, vor und zahlte gleichzeitig die Aufnahmegebühr von vier Gulden (ebenda, 182').

594 StAR RS 5, 3'.

595 Bei der Feuerbeschau Ende März 1549 wurde eine große Nachlässigkeit hinsichtlich des Kamins im Bad festgestellt (ebenda, 85).

596 Ein Feuer, das während des Badens brannte, kann sich nur auf den Warmwasserkessel beziehen.

597 Wie man diesem Übelstand zu Leibe rückte, s .o. Anm. 554.

598 StAR RS 5, 52 (1549 Januar 2).

599 Ebenda, 57 ' u. 79 '.

600 Der Treibmeister leitete die Trennung des Bleis vom Silber im Treibofen.

601 Ebenda, 44'.

602 Ebenda, 93.

603 Ebenda, 39 (1548 Okt. 12).

604 StAR Raitung der Bruderschaft der Stadt und des ganzen Bergwerks 1547, 10. Ihr Mann Hans Ärnberger, ein Bäcker, damals nach eigener Auskunft ungefähr 84 Jahre alt, lebte in einem Kämmerl des Spitals (StAR RS 4, 128' u. TLA Verfachbuch Rattenberg 50/3 [1546-1552], 4).

605 StAR BM 1547, 12', 17', 24.

606 StAR Spital Raitung 1552-1553, 30'(1553 Dez. 20).

607 Vgl. den Text zu den Anm. 453-455.

608 Nämlich Appolonia Baungartnerin von Leipheim, Barbara Baungartnerin zu Augsburg und Waldpurga Baungartnerin, verheiratet mit dem Schneidermeister Utz Franntz von Schwaz. Erwähnt wird auch noch ein Matheus Schmidt, Weber und Bürger zu Augsburg, als Schwager der Margreth (vg1. StAR RS 5, 100). Er dürfte der Ehemann der Barbara Baungartnerin gewesen sein.

609 Zwar hatte der Bergsegen in Schwaz schon seinen Höhepunkt überschritten, doch arbeiteten immer noch Tausende von Knappen in den Revieren um Schwaz und Rattenberg, so dass sich der Verkauf von Milch und Kraut an die Bergleute und ihre Familien nach wie vor lohnte, zumal damals Milchbrei und Kraut ständig auf den Tisch einfacher Leute standen. 
610 In der Vertragsurkunde wird noch davon gesprochen, dass sie von ihrem Vater geerbt hat, ohne dies im Einzelnen anzuführen.

611 Borte (hier) = silberbesticktes Schmuckband oder silberbeschlagener Gürtel.

612 Zum Glück konnte sie einen Spruchbrief des Freundsberger Landrichters Sigmund Kapeller vom 8. September 1535 vorlegen, worin genau angeführt war, was ihr der Richter nach dem Tod ihres ersten Mannes zugewiesen hatte.

613 Der Schuldbrief vom 8. Juli 1548 ist als Eintrag im Gerichtsbuch erhalten. Danach verpfändeten Peter Säppl »zu Hauß auf dem pach im Moserthal« und seine Frau Magdalena dem Meister Matheus Baugartner gegen eine Schuld von 100 Gulden samt allfälligen Zinsen ihr halbes Gut auf dem Bach zu Hauß (TLA Verfachbuch Rattenberg 50/4 [1548-1549] 84'-85').

614 Die 250 Gulden sollten wohl den Betrag des Spruchbriefs von 1535 ergeben.

615 D .h. Forderungen an (Geld-)Schuldner.

616 StAR RS 5, 90-94 (1549 April 26) und Urkunde Nr. 232 (1549 April 27). Die obige Darstellung hält sich an die acht Seiten über die Verhandlungen und den Erbvertrag vor dem Rat. Die am nächsten Tag ausgestellte Vertragsurkunde hat im Wesentlichen dieselben Bestimmungen wie das Ratsprotokoll, geht aber bisweilen mehr ins Detail und wurde in solchen Fällen ergänzend herangezogen. Sie enthält noch einen genaueren Passus über das alleinige Verfügungsrecht der Erben über die Arzneien. Was die Witwe davon entbehren könne, dürften sie sofort an sich nehmen oder von ihr verlangen, es wegzuschließen.

617 Der Haller Bader und Wundarzt Melchior Schlögl besaß 1570 schon acht Bücher, darunter Hans von Gersdorffs »Feldbuch der Wundarznei«, sein späterer Haller Kollege Hans Feichtmayr hinterließ 1602 gar eine Bibliothek von 28 Büchern, meist Arznei- und Kräuterbücher (Moser, Apotheker, 218 u. 250).

618 Die Grundruhr war das »Recht auf Aneignung von Gegenständen, die durch Unfall auf dem Wasser herrenlos geworden waren «. Nach dem Verbot durch die Carolina (1532) lebte es in der milderen Form des Bergelohns fort (Lieberich, Grundruhr, 1753). Bayern und Tirol hatten 1425 gegenseitig auf die Ausübung der Grundruhr auf Isar und Inn verzichtet, weil das »der Arbeit auf dem Wasser schädlich sei« (Stolz, Zollwesen, 230, 237). Für eigene Untertanen wollte die Innsbrucker Regierung anscheinend davon nichts wissen.

619 TLA Embieten und Befelch 1549 [= Kammer-Kopialbuch 216] 227-227’: Mai 4. Als einen Monat später ein Schiff mit Kupferfässern an der Brücke zu Rattenberg unterging, wies die Regierung den Zöllner zu Rattenberg an, die Grundruhr auf dem Wasser für diesen und künftige Fälle geltend zu machen und mit der Kammer zu verrechnen (ebenda, 285 : Juni 3).

620 StAR RS 5, 114' (1549 Juni 15); TLA Parteibuch 12 (1549) 59 (Juni 6), 61'-62 (Juni 12). Der Rat nennt hier (114') und schon in der Vertragsurkunde Paungartner einen Bürger der Stadt. Die Ratsprotokolle sind für die Zeit, in der er Bader zu Rattenberg war, vollständig erhalten. Danach hat er nur das Inwohner-, nie das Bürgerecht bekommen. Offensichtlich benutzte der Rat den gehobenen Status des Baders als Argument bei der Regierung.

621 StAR RS 5, 116 (Juni 16).

622 StAR RR 1549, 19 (Dezember 19).

623 Elend ist ein Ortsteil von Voldöpp.

624 Das ist die häufigste Schreibweise seines Namens, ansonsten begegnet dafür auch Fäller, Väller, Feiler, Feyler.

625 StAR RS 5, 96'. Im Juni wurde er Inwohner, der Geburtsbrief war bis Jacobi (25. Juli) nachzureichen, dann wolle man sich seiner annehmen, ließ der Rat verlauten (ebenda, 115').

626 Lotterpuppe $=$ Dirne, überweinen $=$ zu viel Wein trinken.

627 StAR RS 6, 3.

628 StAR RS 5, 90’ u. 93. 
629 Ebenda, 58.

630 Ebenda, 98.

631 Ebenda, 181.

632 StAR RS 7, 6. Die Zahlungen der 16 Gulden sind mehrfach nachzuweisen. StAR RR 1549, 19 (acht Gulden für zwei Quatember und weitere acht Gulden, damit »er di pad dester stattlichen warm mach«); RR 1552, 22; RR 1554, 20'; RR 1557, 18; RR 1564, 16'; RR 1566, 15; RR 1567, 24.

633 StAR RS 7,114.

634 Ebenda, 120'-121.

635 Als er 1552 eine Zeugenaussage zum Testament einer verstorbenen Bäckersfrau, die kürzlich noch bei ihm gebadet hatte, machte, gab er sein Alter mit ungefähr 50 Jahren an (TLA Verfachbuch Rattenberg 50/5 [1552-1556] 18'-19: 1552 Sept. 10).

636 StAR RS 7, 205’ (1555); RS 8, 5’ (1556), 63’ (1557), 115' (1558), 169' (1559); RS 9, 6 (1560), 54' (1561), 108 (1562), 169' (1563); RS 10, 4 (1564), 57’ (1565).

637 StAR RS 10, 123'. Zwei Jahre zuvor hatte der Rat mit Meister Fäler ausgemacht, dass er Simon Tuesmwar nicht mehr zum "Zwagen« (Waschen) heranziehen werde (ebenda, 22'). Anscheinend hatte der Bader ihn inzwischen entlassen.

638 StAR RS 11, 1'.

639 STAR RS 7, 106-106'.

640 StAR RS 9, 213.

641 StAR RS 5, 134 u. 137' (1549: Sigmund Waldhueberin, Gewandhüterin); RS 6, 182 (1552: Reiberin); RS 7, 6 (1553: Steffanin, Reiberin) u. 114' (1554: Der Bader soll sich mit einer "guetn häuslichn matron« als Reiberin versehen.); RS 10, 123' (1566: Regina Pockhin soll vom Bader statt der Stefflin zur Reiberin aufgenommen werden.) u. 191 (1566: Die Badreiberin Stefflin erhält auf ihre Bitte hin zwölf Kreuzer wöchentlich aus der Bruderschaft).

642 StAR RS 7, 205' (1555: Reiberin); RS 8, 170' (1559: Gewandhüterin und Reiberin sind gar nicht fleißig, kümmern sich nicht um die Armen, sondern nur um die Frauen, die ihnen Wein spendieren.).

643 StAR RS 11, 1' (1567: Der Bader soll verhindern, dass die Reiberin im Frauenbad, »die zutzeiten auch vol weins sei«, nicht mehr so viel trinkt.).

644 Schretter, Seuchen, 46-47.

645 StAR RS 9, 158'u. 159 (1562 Nov. 13 u. 18.

646 Ebenda, 195' u. 201'.

647 StAR RS 10, 4 u. 22'.

648 Ebenda, 31-31' (1564 Juni 14).

649 StAR RR 1564, 22 (für die Zeit 10. Januar 1564 bis 12. Januar 1565).

650 Ebenda, 24'.

651 Ebenda, 59, 60, 66'.

652 StAR RS 8, 33'.

$653 \mathrm{Vgl}$. Anm. 171.

654 StAR RS 7, 87’: Der Baumeister solle dafür sorgen, dass man das Bad früh heize und die Glut ausgehen lasse. Außerdem solle er dem Bader noch weitere zwei Klafter Holz geben (1553 Sept. 19). Die Formulierung weist darauf hin, dass er bereits schon Holz erhalten hatte, und zwar vier Klafter am 8. April (ebenda, 33': Zum Heizen sollte man lange Stücke nehmen.). Die Stadt konnte in dieser Hinsicht großzügig sein, besaß sie doch drei von einem Waldmeister verwaltete Wälder, am Stadtberg, in Rettengschöß und im Brandenberger Tal (StAR RR 1552, 22).

655 StAR RS 10, 22'.

656 Ebenda, 153-153'. 
657 StAR RS 11, 39.

658 StAR RS 7, 257, 258'-259 (1555 Okt. 12 u. 25) u. Verfachbuch Rattenberg 1553-1560 (ausnahmsweise nicht im TLA sondern im StAR, Schuber 172), 162-162' (1555 Nov. 7).

659 StAR Spital Raitung 1551, 25' (Der Bader habe mit den Spitalsinsassen viel Mühe und Arbeit gehabt, wird hinzugefügt); Spital Raitung 1556/57, 18' (zu 1557); Spital Raitung 1562/65, 33 (1563) u. 34' (1564).

660 Span = eigtl. Kerbholz, auf dem durch Einschneiden von Kerben Schulden oder Leistungen eingetragen wurden (Grimms Dt. Wörterbuch 10,1 [1905] 1864).

661 StAR RS 8, 136 (1558 Juni 3).

662 Als 1555 sechs Bäcker bestraft wurden, weil sie zu kleine Brötchen gebacken hatten, mussten vier von ihnen einen bzw. zwei Gulden Strafe zahlen, zwei, darunter Bartlme Pettendorffer, kamen mit dem Einsitzen auf dem Tor davon, »angesehen der beider armuet« (StAR RS 7, 261').

663 Büchner, Mord, 26. Die kleinen Wunden am Kopf, die nicht »painschrotig« waren, also nicht bis auf die Knochen gingen, hatte der Erschossene im Verlauf der Handgreiflichkeiten mit dem Vikar erlitten und waren von den Badknechten Hanns Memle und Lienhart Auer versorgt worden (TLA Verfachbuch Rattenberg 50/5 [1552-1556] 160). Bereits sechs Jahre früher war Fäler als Sachverständiger vom Rat hinzugezogen worden, als es um die Beurteilung des Unfalltodes einer Schusterfrau ging (StAR RS 6, 44: 1550 Mai 28).

664 StAR Verfachbuch Rattenberg 1553-1560, 220-223.

665 StAR RS 9, 154-154'.

666 StAR RS 12, 2'.

667 Als 1570 der hochbetagte, ungefähr 80-jährige Rattenberger Schmied Jeronime Schwaiger einen Vertrag mit seinen elf (!) Stiefkindern über ihr mütterliches Gut schloss, zog er den Bader Hans Fäler, seinen Schwiegersohn, als Beistand heran (StAR RS 12, 144'-145': 1570 Februar 4). Damals lebte folglich der alte Bader noch.

668 Ebenda, 236'-237: Der Bitte wurde entsprochen, doch mussten sich Hans Fäler d.J. und seine Frau Bernhard um eine frühere Schuld und diesen Dolch verschreiben und sich verpflichten, ohne Zustimmung von Bürgermeister und Rat nichts herzugeben.

669 StAR RS 12, 2' (1568 Mai 4).

670 Ebenda, 50 (1568 Sept. 13).

671 Ebenda, 176' (1571) u. 216' (1572); RS 13, 2 (1573).

672 Z.B. StAR RR 1573, 15'.

673 StAR RS 13, 41

674 StAR RS 12, 176' u. 233.

675 StAR RS 13, 97.

676 Ebenda, 102 u. 111'.

677 Ebenda, 155 (1576) u. 197 (1577); RS 14, 103 (1580) u. 189'(1581). Es heißt nur lakonisch: Bader bzw. Bader und Wundarzt: Hans Fäler.

678 StAR RS 13, 259'-260; vgl. Bachmann, Stadtbad, 12 u. 8; Stops, Rattenberg 117.

679 Die Rattenberger Raitungen für 1535 und 1536 sind überliefert. Sie enthalten ebenso wenig einen Sold für Dr. Johannes Kuefner wie die vorhergehenden und nachfolgenden Stadtrechnungen für irgendeinen andern fest angestellten Arzt. Die Hefte für 1534 und 1537 bis 1539 fehlen.

680 Vgl. zu ihm Büchner, Bier, 40-45. 1531, als Kuefner noch Student der Medizin war, vermerkte er in der Einleitung zu seiner Übersetzung der acht Bücher des Celsus, es gebe in Rattenberg keinen Arzt (Kostenzer, Cuefner, 19).

681 KlAR Codex 70, 85: „dedi ainem wundarzt 32 kr, dedi dem doctor 3 kr« (1530) u. 101: einen Gulden 
für einen Arzt »der stain halben« (1531); StAR Spital Raitung 1541, 10: ein fremder Arzt heilt einen Buben vom Grind.

682 KlAR Codex 70, 47: sechs Gulden »doctori in Swacz« für Medizin in der Seuchenzeit (1526); 49': drei Gulden für Doktor Georg Klain zu Schwaz (1526); 106: der Bauknecht des Kloster wurde um Medizin nach Schwaz geschickt (1531); 94: "fui in Schwatz pei dem doctor vnd apoteger vmb etlich remedia« (1539). Codex 71, 377’'drei Gulden »doctori et medico Ambrosio in Schwaz« (1516); 402: Bezahlung an den Apotheker in Schwaz (1519). Solange die Stadt keinen eigenen Apotheker hatte, gingen ihre Einwohner auch zum Schwazer Apotheker um Arzneien (StAR RR 1564, 24').

683 StAR RS 10, 114 u. 138-138'. Bereits 1568 war Frölich Angehöriger des äußeren Rates (RS 12, 1).

684 StAR RS 10, 127'-128.

685 StAR RR 1567, 32 u. StAR BM 1567, 28-28'.

686 Das geschah auch anderswo. In Kitzbühel, das ebenfalls lange Zeit keinen Arzt hatte, praktizierten die Wundärzte auch als Internisten (Kostenzer, Gesundheitswesen, 428). Allerdings wird der Umfang der inneren Krankheiten, die nur von studierten Medizinern behandelt werden durften, nie so richtig beschrieben. Wenn die Hildesheimer Barbierordnung von 1680/81 unter inneren Krankheiten »Fieber, Hauptweh, Magenschwachheiten undt wie sie Nahmen haben mögen« (Bähre, Balsam, 26) versteht, sind das sehr dehnbare Begriffe.

687 StAR RS 14, 31.

688 Gewandhüterin: Erhard Piechls Witwe StAR RS Konzeptbuch 1572, 26; RS 13, 42, 43', 44 (1574), 98 (1575), 259 (1578); RS 14, 32 (1579), 105 (1580), 190' (1581). Reiberinnen: Hans Pocks Hausfrau StAR RS 12, 176' (1571); RS 13, 43' (1574), 98 (1575), 157 (1576); die alte Plaicknerin RS 12, 157 (1576), 198 (1577), 259 (1578); RS 14, 32 (1579), 104' (1580), 190' (1581). Hans Pock und Erhard Piechl waren Bäcker, Jörg Plaickner ein Kürschner.

689 StAR RS 13, 43': Der Gewandhüterin wurde noch angedroht, sollte sie Kleidung und anderes, was sie im Bad zu bewachen habe, verlieren, müsste sie es ersetzen.

690 Ebenda, 98.

691 Ebenda, 157.

692 Ebenda, 102 u. 103'.

693 StAR RS 14, 33-33' (1579 Januar 16).

694 Nur eine der fünf Fälerinnen verheiratete sich nicht im näheren Umkreis, nämlich Margareth, die den Augsburger Bader Lucas Raiser heiratete, während Elisabeth die Ehefrau des Hans Staudacher, Schneiders zu Hall, die verstorbene Afra die des Rattenberger Badknechts Simon Tuesmwar, die verstorbene Eva die des Rattenberger Erzknappen Matheus Mayer wurde und es von Anna nur heißt, sie sei verheiratet und wohne zu »Prug (Bruck am Ziller).

695 StAR RS 14, 239-241.

696 Ebenda, 244'-245.

697 Ebenda, 246'-247 (1581 Sept. 15).

698 Die Hoffnungen waren wohl zu hoch geschraubt, denn 1588 kritisierte der Rat an Luechner, dass »er zu den schäden und arzneien wenig hail, glückh oder genad« habe und dass er entlassen werde, wenn er nicht fleißiger sei (Bachmann, Stadtbad, 12). Luechner müssen also einige Kuren misslungen sein.

699 Ebenda, 252'-253 (1581 Okt. 6).

700 Ebenda, 258' (1581 Nov. 10).

701 Köfler, Häuserbuch, 262-265 u. Stops, Rattenberg, 117-119. 


\section{Sigeln}

BM Baumeister Raitung Rattenberg

K1AR Klosterarchiv (Archiv des Augustinerklosters) Rattenberg

LexMA Lexikon des Mittelalters

RR Rattenberger Raitung

RS Ratschlagbuch (Ratsprotokoll) Rattenberg

StAR Stadtarchiv Rattenberg

TLA Tiroler Landesarchiv Innsbruck

TLMF Tiroler Landesmuseum Ferdinandeum Innsbruck 


\section{Archivalien}

Tiroler Landesarchiv Innsbruck

Kopialbücher

Embieten und Befelch I 506, I 5 I 4, I 549

Geschäft von Hof ${ }_{5} 527$

Missiven an Hof 1527

Parteibuch 5 (I 534-I 536), 7 (I 539 -I 540), I 2 (I 549)

Verfachbuch Rattenberg 5o/I (I 546-I 547), 50/2 (I 546-I 547), 50/3 (I 546-I $55_{2}$ ), 50/4



Urkunde II 703 I, II 8539

Handschrift 2 I 8: Register der Wänndl des Rattenberger Bergrichters Caspar von Pirchach $1470 / 7$ I

Tiroler Landesmuseum Ferdinandeum Innsbruck

FB 2994: Ordnung der Baderbruderschaft zu Innsbruck und Hall (ca. I 450/60)

Klosterarchiv Rattenberg (im TLA)

Codex 70: Raitbuch I 523-I 539

Codex 7r: Raitbuch I 482-I 523

Stadtarchiv Rattenberg (im TLA)

Ratschlagbücher: I (I 506-I 5 I I), 2 (I 509-I 5 I 4), 3 (I 523 -I 532), 4 (I 544-I 547), 5

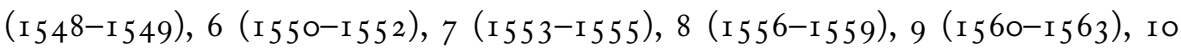

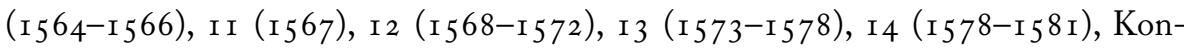
zeptbuch 1572

Rechnung gemeiner Stat Ratmberg I 507-I 5 I 3

Raitbuch der Stadt Rattenberg I 5 I 4-I 529

Rattenberger Raitung I 487, I 506, I 509, I 5 I I, I 5 I6, I 52 I, I 528 , I 533 , I 535, I 540 , I 542 , I 543 , I 545 , I 549 , I 552 , I 554 , I 555 , I 557 , I 564 , I 565 , I 567

Baumeister Raitung I 476, I 477, I 508, I 5 I 5 , I 52 I, I 523 , I 524 , I 525 , I 528 , I 538 , I 539 , I 54 I, I 542 , I 544 , I 545 , I 547 , I 55 I, I 555 , I 556 , I 562 , I 564 , I 568 , I 572 , I 579 , I 580 , I 58 I

Spital Raitung I 529, I 538, I 54 I, I 55 I, I 556/57, I 562/65, I 573

St. Virgilien Kirche Raitung I 544

Raitung der Bruderschaft der Stadt und des ganzen Bergwerks I 547 
Steuerwesen I 528-I 726: I., 2. und 3. Türkensteuerregister I 5 29/30 Urkunde Nr. 232 


\section{Quellen und Literatur}

Ammann, Gert u.a. (Bearb.): Die Kunstdenkmäler Österreichs. Tirol (Dehio-Handbuch. Die Kunstdenkmäler Österreichs. [Neue Serie]). Wien 1980.

Angerer, Anton: Das Kloster der Augustiner Eremiten von Rattenberg, in: Festschrift zur Wiedereröffnung der Stadtpfarrkirche zum hl. Virgil in Rattenberg, hg.v. Pfarramt Rattenberg/Tirol, Rattenberg I983, I 54-1 83.

BAADER, Gerhard: Badewesen, LexMA I (I980 I340-I34I.

Bachfischer, Margit: Musikanten, Gaukler und Vaganten. Spielmannskunst im Mittelalter. Augsburg 1998.

Bachmann, Hans: Stadtbad und Bader im alten Rattenberg, Beilage zu "Tiroler Grenzbote" 76 (1 952 ) Nr. 5 I-52, S. I 2 u. 77 (I 953) Nr. I, S. 8.

Badewonnen. Gestern - heute - morgen. Hg. v. Hansgrohe. Köln r 993.

BäHRE, Ludolf: Balsam, Bocksblut und Barbiere - Von Badern, Barbieren, Wundärzten und Chirurgen in Hildesheim, Hildesheimer Jahrbuch für Stadt und Stift Hildesheim 78 (2006) I I -72 .

BAum, Hans-Peter: Bader, LexMA i (I980) I339.

Beut ter, Herta: Die öffentlichen Badestuben in der Reichsstadt Hall, in: Ärzte, Bader und Barbiere. Die medizinische Versorgung vom Mittelalter bis zum Ende des Alten Reichs. Ausstellung I 4. Mai bis I 8. September 20 I I im Hällisch-Fränkischen Museum Schwäbisch Hall, 8. Oktober 20 I I bis 22. Januar 20 I 2 im Heimatmuseum der Stadt Tuttlingen. Katalog von Herta Beutter u.a., Schwäbisch Hall 20 I I , 60-77 und Katalog.

Binding, Günther: Baubetrieb im Mittelalter. Darmstadt 1993.

Böнme, Horst Wolfgang: Badestuben, in: H.W. Böhme u.a. (Hg.), Wörterbuch der Burgen, Schlösser und Festungen, Stuttgart 2004, 72.

Bonneville, Françoise de: Das Buch vom Bad (Collection Rolf Heyne). München ${ }^{2} 2002$.

Büchner, Robert: Bauen zum Lobe Gottes und zum Heil der Seele. Der Neubau der St. Johanneskirche zu Lienz im I 5. Jahrhundert (mit einer Edition des Rechnungsbuches I467-I49I) (Medium Aevum Quotidianum. Sonderbd. I7). Krems 2006.

Büchner, Robert: Bier, Brauer und Wirte im Unterinntal, besonders in Rattenberg (I 474-I600), Der Schlern 87, Io (2013) 24-I I 5.

Büchner, Robert: Ein Mord vor dem Pfarrhof zu Rattenberg anno i 556 und das Streben des Rates nach Kirchenregiment, Tiroler Heimatblätter 83 (2008) 78-83 u. $84(2009) 26-3$ I. 
Büchner, Robert: Fürstlicher Einzug in eine Kleinstadt: Ferdinand I. in Rattenberg I 5 23/24, Tiroler Heimatblätter 79 (2004) 95-I 07.

Camesasca, Ettore (Hg.): Geschichte des Hauses. Berlin I986.

Corbin, Alain: Pesthauch und Blütenduft. Eine Geschichte des Geruchs (Fischer Taschenbuch 4402). Frankfurt/M. I988.

Dengel, Ignaz Philipp: Eine Beschreibung Tirols aus dem Jahre I47 I, Veröffentlichungen des Museum Ferdinandeum I 2 (1932) $207-232$.

Dirlmeier, Ulf: Untersuchungen zu Einkommensverhältnissen und Lebenshaltungskosten in oberdeutschen Städten des Spätmittelalters (Mitte I4. bis Anfang I6. Jahrhundert) (Abhandlungen der Heidelberger Akademie der Wissenschaften. Philos.hist. Klasse, Jg. I978, I). Heidelberg 1978.

Duerr, Hans Peter: Nacktheit und Scham (H.P. Duerr, Der Mythos vom Zivilisationsprozess I). Frankfurt/M. ${ }^{2}$ I 988.

Dülmen, Richard van: Kultur und Alltag in der Frühen Neuzeit, Bd. I : Das Haus und seine Menschen, I6. - I8. Jh. München I 990.

EскаRт, Wolfgang U.: Medizinische Bäder, Enzyklopädie der Neuzeit I (2005) 92 I-926.

Eска т, Wolfgang U.: Hygiene, Enzyklopädie der Neuzeit 5 (2007) 736-74 I.

Eder, Ernst Gerhard: Bade- und Schwimmkultur in Wien. Sozialhistorische und kulturanthropologische Untersuchungen (Kulturstudien 25). Wien etc. I 995 .

EGG, Erich u.a.: Von allerley Werkleuten und Gewerben. Eine Bildgeschichte der Tiroler Wirtschaft. Innsbruck etc. 1976.

Flamm, Heinz: Bader - Wundarzt - Medicus, in: Bader - Wundarzt - Medicus. Heilkunst in Klosterneuburg. Hg. v. Heinz Flamm u. Karl Mazakarini (Menschen und Häuser in Klosterneuburg), Klosterneuburg 1996, 7-40.

Fontane, Theodor: Wanderungen durch die Mark Brandenburg, Bd. 3. Hg. v. Helmuth Nürnberger. München 2006.

Fouquet, Gerhard: »Annäherungen«. Große Städte - Kleine Häuser. Wohnen und Lebensformen der Menschen im ausgehenden Mittelalter (circa I470-I600), in: Geschichte des Wohnens, Bd. 2, 347-501.

Fritz, Eberhard: Badstuben im Konstitutionsprozess der ländlichen Gemeinde in Südwestdeutschland an der Wende zur Frühen Neuzeit, Zeitschrift für Württembergische Landesgeschichte 65 (2006) I I-35.

Gaisв ӧск, Agathe: Zur Geschichte der Zünfte in Tirol, vor allem in Innsbruck, Tiroler Heimat NF 7-8 (1934/35) i I 7-r 82.

Ganster, Ingrid: Bäderstadt Wien im Wandel der Zeit, Studien zur Wiener Geschichte = Jahrbuch des Vereins für Geschichte der Stadt Wien 66 (2010) 63-86.

Geschichte des Wohnens, Bd. 2 : 500-1800. Hausen, Wohnen, Residieren. Hg. v. Ulf Dirlmeier. Stuttgart r 998; Bd. 3: r800-г9 18. Das bürgerliche Zeitalter. Hg. v. Jürgen Reulecke. Stuttgart i 997. 
Guarinonius, Hippolytus: Die Grewel der Verwüstung Menschlichen Geschlechts. Hg. v. Elmar Locher (Reihe Reprint). Bozen I994 (Reprograph. Nachdruck der Ausgabe Ingolstadt I 6ro).

Hähnel, Joachim: Stube. Wort- und sachgeschichtliche Beiträge zur historischen Hausforschung (Schriften der Volkskundlichen Kommission des Landschaftsverbandes Westfalen-Lippe 2 I). Münster/W. I975.

Haidacher, Christoph: Zur Bevölkerungsgeschichte von Innsbruck im Mittelalter und in der beginnenden Neuzeit (Veröffentlichungen des Innsbrucker Stadtarchivs NF I 5 ). Innsbruck I 984.

Himmelsbach, Iso: „Von wegen der Badstuben ...«Zur Geschichte des Freiburger Badewesens von I 300 bis I 800 (Alltag \& Provinz Io). Freiburg i. Br. 2000.

Hölzl, Sebastian: Die Gemeinde-, Markt- und Stadtarchive des Bezirkes Kufstein samt Schlossarchiv Matzen (Tiroler Geschichtsquellen 46). Innsbruck 2002.

Hye, Franz-Heinz: Die Städte Tirols, r. Teil: Bundesland Tirol (Österreichische Städtebuch $5, \mathrm{I})$. Wien I980.

Inama-Sternegg, Hanns: Das Nachlassinventar des Ambros Mornauer von Lichtenwert I 5 50, in: Festgabe für Erich Egg zum 65. Geburtstag, Red.: Gert Ammann, Innsbruck I 985, 39-59.

Isenmann, Eberhard: Die Deutsche Stadt im Spätmittelalter I $250-$ I 500 . Stadtgestalt, Recht, Stadtregiment, Kirche, Gesellschaft, Wirtschaft (UTB für Wissenschaft. Große Reihe). Stuttgart i988.

Jankrift, Kay Peter: Brände, Stürme, Hungersnöte. Katastrophen in der mittelalterlichen Lebenswelt. Ostfildern 2003.

Jankrift, Kay Peter: Mit Gott und schwarzer Magie. Medizin im Mittelalter. Stuttgart 2005 .

Jaritz, Gerhard: Bad, Mittelalter, LexMA i (i 990) I 33 I-I333.

Jütтe, Robert: Ärzte, Heiler und Patienten. Medizinischer Alltag in der frühen Neuzeit. München, Zürich I 99 I.

Jütте, Robert: Bader, Barbiere und Hebammen. Heilkundige als Randgruppen?, in: Bernd-Ulrich Hergemöller (Hg.), Randgruppen der spätmittelalterlichen Gesellschaft, Warendorf ${ }^{2}$ I 994, 89-г 20.

Keıl, Gundolf: Bader (Heilkunde), LexMA I (i 980) I 340.

Keller, Katrin: Bäderstadt, Enzyklopädie der Neuzeit I (2005) 926-928.

Kıву, Ulrika: Die Badekultur, ein Vergnügen der Menschheit seit der Antike, in: Badewonnen, 6-90.

KLA A R, Karl: Alt-Innsbruck und seine Umgebung. Bd. 2 : Umgebung. Innsbruck I 940. Köfler, Werner: Baugeschichtliche Aspekte Rattenbergs, Tiroler Heimatblätter 50 (I975) 5-I 7. 
Köfler, Werner: Häuserbuch von Rattenberg (г767-r96r). 2 Bde. Diss. Innsbruck I964.

Kogler, Ferdinand: Recht und Verfassung der Stadt Rattenberg im Mittelalter (Schriftenreihe zur bayerischen Landesgeschichte I). München I 929.

Kostenzer, Otto: Dr. Johannes Cuefner aus Rattenberg (Biographische Notiz), Tiroler Heimatblätter 46 ( 1 97 I) i 8-20.

Kostenzer, Otto: Gesundheitswesen in Kitzbühel, in: Stadtbuch Kitzbühel, Bd. 4, Kitzbühel I 97 I, 389-520.

Kraft, Josef: Die Helfer der Kranken auf dem Lande in älterer Zeit (vornehmlich im Gerichte Landeck), Tiroler Heimat NF 2 (r929) 5-36.

Kramer, Klaus: Beginn eines neuen Hygienebewusstseins, in: Badewonnen, 9 I-ı oo.

Kren, Thomas u. McKendrick, Scot: Illuminating the Renaissance. The Triumph of Flemish Manuscript Painting in Europe. Exhibition Los Angeles and London 2003-2004 (Texts and Catalogue). Los Angeles, London 2003.

Ǩ̌ížEK, Vladimir: Kulturgeschichte des Heilbades. Leipzig, Stuttgart I 990.

Küthe, Erich: Vom »Powder-room« zum »Erlebnisbad«, in: Badewonnen, Io I-ı68.

Ladurner, Justinian: Chronik von Bozen i 844. Hg. u. bearb. v. Bruno Klammer. Bozen 1982 .

Lerner, Franz: Geschichte des Deutschen Glaserhandwerks. Schorndorf ${ }^{2}$ I 98 I.

Luz, Wilhelm August: Das Büchlein vom Bad. Berlin-Grunewald I 958.

Martin, Alfred: Deutsches Badewesen in vergangenen Tagen. Jena i 906. Nachdr. München I 989 .

Mazaka RINi, Karl: Die öffentlichen Badstuben in Klosterneuburg, in: Bader - Wundarzt - Medicus. Heilkunst in Klosterneuburg. Hg. v. Heinz Flamm u. Karl Mazakarini (Menschen und Häuser in Klosterneuburg), Klosterneuburg r 996, 47-69.

Mecenseffy, Grete (Bearb.): Quellen zur Geschichte der Täufer I3: Österreich, 2. Teil (Quellen und Forschungen zur Reformationsgeschichte 4 I). Gütersloh I 972.

McKendrick, Scot: Reviving the Past: Illustrated Manuscripts of Secular Vernacular Texts, I 467-I 500, in: Kren u. McKendrick, Illuminating, 59-78.

Moser, Heinz: Von Apothekern, Ärzten, Badern und Hebammen. Zur Geschichte des Gesundheitswesens der Stadt Hall in Tirol. Hall i.T. I 996.

Moser, Heinz: Die Urkunden der Pfarre Hall in Tirol i 28 I- 7 80 (Tiroler Geschichtsquellen 39). Innsbruck I 998.

Mutschlechner, Georg: Erzbergbau und Bergwesen im Berggericht Rattenberg. Alpbach etc. I984.

Naphy, William: Baden, Enzyklopädie der Neuzeit i (2005) 9I4-9 I 5.

PA Pe, Reinhild: Puder, Pomade, Parfüm oder: Katzenwäsche im Barock, in: Geschichten der Reinlichkeit. Vom römischen Bad zum Waschsalon, hg. v. Angela Delille und Andrea Grohn, Frankfurt a. Main i 986, 93-гоo. 
Peters, Hermann: Der Arzt und die Heilkunst in alten Zeiten. 4. Auflage = Fotomechan. Nachdruck der I 900 erschienenen Erstausgabe. Düsseldorf, Köln I 973.

Pictorius, Georgius: Badenfahrtbüchlein. Wie und wo man richtig badet. Ein kommentierter, übersetzter und mit zeitgenössischen Bildern versehener Nachdruck des Werkes von D. Georgius Pictorius aus dem Jahr I 560 (Vorwort: Udo Becker). Freiburg i.Br. etc. I 980.

Pizzinini, Meinrad: Das Lienzer »Failbad«. Ein untergegangenes Geschichtsdenkmal, Der Schlern 87, 3 (2013) 4I-52.

Rauch, Margot: Wellness um I 500 : Die Badstube der Philippine Welser, in: Splash!, I0-67.

Reddig, Wolfgang F.: Bader, Medicus und Weise Frau. Wege und Erfolge der mittelalterlichen Heilkunst. München 2000.

Richental Ulrich: Chronik des Konstanzer Konzils I4I4-I4I8, eingeleitet u. hg. v. Thomas Martin Buck (Konstanzer Geschichts- u. Rechtsquellen 4I). Ostfildern ${ }^{2} 2011$.

Rossiaud, Jacques: Dame Venus. Prostitution im Mittelalter. München I989.

Rüthing, Heinrich: Höxter um I500. Analyse einer Stadtgesellschaft (Studien und Quellen zur westfälischen Geschichte 22). Paderborn 1986.

Salzer, Ronald: Ein brennendes Thema: Der Destillierhelmfund in der ehemaligen Badestube von Zwettl-Niederösterreich und die Rolle der Destillation im Mittelalter und in der Frühen Neuzeit, Medium Aevum Quotidianum 6r (2010) 27-55.

SAnder, Sabine: Bader, Enzyklopädie der Neuzeit i (2005) 9I 6-92 I.

Schäfer, Michael: (All)tägliche Toilette: Vom Kamm bis zum Zahnstocher - Körperpflege im Mittelalter und in der frühen Neuzeit, Concilium medii aevi I 2 (2009) $225^{-250 .}$

Schmelzer, Matthias: Geschichte der Preise und Löhne in Rattenberg vom Ende des I 5. bis in die 2. Hälfte des I 9. Jahrhunderts. 2 Bde. Diss. Innsbruck 1972.

Schmidt, Fritz u. Dirlmeier, Ulf: Geschichte des Wohnens im Spätmittelalter, in: Geschichte des Wohnens, Bd.2, 229-346.

SEIdL, Katharina: Vom Bader zum Zahnbrecher: Das Bad als Ort der Gesundheit, in: Splash!, 70-I07.

Seidler, Eduard: Collège de St-Come, LexMA 3 (i986) 36-37.

Seifried Helbling. Hg. u. erklärt von Joseph Seemüller. Halle a.d.Saale i 886.

SEledec, Wilhelm u.a.: Baden und Bäder in Wien. Wien r 987.

Spufford, Peter: Handel, Macht und Reichtum. Kaufleute im Mittelalter. Stuttgart 2004 .

Splash! Das Bad der Philippine Welser. Eine Ausstellung des Kunsthistorischen Museums Wien im Schloss Ambras, Innsbruck, 30. März bis 30. Juni 20 r 2. [Katalog]. Hg. v. Sabine Haag. Wien 2012. 
Stolz, Otto: Geschichte des Zollwesens, Verkehrs und Handels in Tirol und Vorarlberg von den Anfängen bis ins 20. Jahrhundert (Schlern-Schriften ro8). Innsbruck I953.

Stolz, Otto: Geschichtskunde der Gewässer Tirols (Schlern-Schriften 32). Innsbruck 1936 .

Stolz, Susanna: Die Handwerke des Körpers. Bader, Barbier, Perückenmacher, Friseur. Marburg I 992.

Stops, Friedrich: Die Chronik der alten Stadt Rattenberg. Rattenberg I95 I.

Stops, Friedrich: Rattenberg. Chronik der alten Stadt am Inn. Thaur ${ }^{2}$ I 98 I .

Straganz, Max: Beiträge zur Geschichte Tirols II: Die Autobiographie des Frhrn. Jakob v. Boimont zu Pairsberg (I 527 - 5 8 I), Programm des k.k. Obergymnasiums der Franziskaner in Hall i 895-r 896, Innsbruck r 896, I-ro5.

Der Stricker: Der Pfaffe Amis. Mittelhochdeutsch/Neuhochdeutsch. Nach der Heidelberger Handschrift cpg 34 I hg., übers.u. kommentiert von Michael Schilling (Reclams Universal-Bibliothek 658). Stuttgart 2007.

Tageвuch des Grafen Wolrad von Waldeck. Reisebuch zum Augsburger Reichstag I 548. Übers. v. Gerhard Koppe, historisch bearb. v. Ursula Machoczek (Monographia Hassiae 22). Kassel 1998.

Tersch, Harald: Österreichische Selbstzeugnisse des Spätmittelalters und der Frühen Neuzeit (1 400-I650). Wien etc. I 998.

Tuchen, Birgit: Öffentliche Badhäuser in Deutschland und der Schweiz im Mittelalter und der Frühen Neuzeit. Petersberg 2003.

Tuchen, Birgit: »... wolher ins bad reich und arm ...«. Die »Obere Badstube« zu Wangen im Allgäu. Archäologie-Museum (Archäolog. Informationen aus BadenWürttemberg 26). Stuttgart I 994 .

Vetter, Roland: Das Alte Badhaus zu Eberbach. Von der spätmittelalterlichen Badstube zum Hotel-Restaurant. Heidelberg I 990.

Vigarello, Georges: Wasser und Seife, Puder und Parfüm. Geschichte der Körperhygiene seit dem Mittelalter. Frankfurt/M., New York 1988.

Voigt, Klaus: Italienische Berichte aus dem spätmittelalterlichen Deutschland. Von Francesco Petrarca zu Andrea de' Franceschi (I333-1492) (Kieler Histor. Studien I7). Stuttgart I973.

Voigt, Klaus: Die Briefe Antonio de' Costabilis und Cesare Mauros von der Gesandtschaft Ferraras zu König Maximilian I. (I 507/08), Römische historische Mitteilungen I 3 (r97 I) 80-136.

Widmann, Martin u. Mörgeli, Christoph: Bader und Wundarzt. Medizinisches Handwerk in vergangenen Tagen. Zürich 1998.

Widmoser, Eduard: Südtirol A-Z. 4 Bde. Innsbruck, München r982-r 995. Bd. I (I 982 ) I I I : Badhäuser u. Badstuben, Bd. 4 (I 995) 205 : Schgums. 
Wiemers, Michael: Zwischen Unschuld und Laster - zum Bild des Badens in der Renaissance, in: Rüdiger Fikentscher, Badekulturen in Europa (mdv aktuell 6), Halle/S. 20I0, 8 I-97.

Winkle, Stefan: Kulturgeschichte der Seuchen. Frechen 2000.

Wischermann, Clemens: Mythen, Macht und Mängel: Der deutsche Wohnungsmarkt im Urbanisierungsprozess, in: Geschichte des Wohnens, Bd. 3, 333-502.

Zappert, Georg: Über das Badewesen mittelalterlicher und späterer Zeit, Archiv für Kunde österreichischer Geschichts-Quellen 2 I (I 859) I-I66.

Zennder, Leo: Volkskundliches in der älteren schweizerischen Chronistik (Schriften der Schweizer. Gesellschaft für Volkskunde 60). Basel r 976. 


\section{Register}

(Zu häufig vorkommende Begriffe wie Bad, Bader, Badestube, Badhaus, Rattenberg, Tirol wurden nicht erfasst.)

\section{a) Orte}

Aachen 145

Aargau 45, 150

Aibling 137

Allensbach 46

Altötting 162

Altprags 7

Angers 151

Antwerpen 41

Auer 9

Augsburg 17, 50, 106, 143, 160, 169

Avignon 41, 150

Baden (Aargau) 45, 150

Baden-Baden 49, 58

Bad Pyrmont 58

Bamberg 22, 30

Basel 42, 143

Bayern 10, 66, 82, 87, 126, 146, 162, 170

Beauvais 151

Berchtesgaden 90,160

Berlin 63, 105

Bern 143

Besançon 40

Böhmen 40

Bologna 133

Bormio 23

Bozen 9

Brabant 55

Brandenberger Tal 164, 171

Brennerbad 7

Breslau 42

Brighton 58

Brixen 9, 88, 93, 141, 163

Brixlegg 85, 86, 97, 130, 164

Bruck am Ziller 173
Brügge 41, 44

Bruneck 9, 144

Brünn 42

Budweis 145

Burgund 40, 43, 44, 51

Capua 44

Chemnitz 63

Chur 7

Dagersheim 166

Deal 58

Deutschland $11,42,46,50,55,58,62,64,90,143$, 148

Dijon 40, 150, 151

Dinkelsbühl 143

Doberan 58

Eberbach 7,37, 40,143, 145-147, 149, 150

Elend 170

England 40, 58

Eschenbach 144

Esslingen 31

Ferrara 38, 152

Florenz 49, 150

Frankfurt am Main 46, 58, 75, 98

Frankreich 40, 50, 54, 58, 133, 151, 152

Freiberg (Sachsen) 30, 34

Freiburg i. Br. 143, 145, 148, 151

Fügen 161

Fulda 144

Fürth 63

Füssen 17, 145, 160 
Gerolzhofen 106

Golzow 146

Görlitz 106, 152

Göttingen 75

Gräfenberg 146

Grünberg (Hessen) 106

Hagau 102, 164

Hall (Tirol) 7, 9, 10, 13, 18, 22, 25, 26, 32, 42, 48, $49,66,75,99,133,140,143,145,148,150,154$, 168,173

Hallein 110, 111, 141

Hamburg 63, 145

Hannover 63,75

Häring 7

Harwich 58

Hasegg 49

Haus (Mosertal) 170

Heidelberg 143, 158

Hessen 106

Hildesheim 146, 148, 149, 150, 173

Hopfgarten 124

Hötting 107

Höxter 36, 150, 181, 185

Ichenhausen 86,161

Ingolstadt 66

Innichen 7,144

Innsbruck 9, 21, 25, 34, 35, 82, 102, 107, 112, 137 , $143,147,148,160,168$

Italien $56,133,150$

Jena 7,50

Jenbach 161

Kaltern 22, 31

Karlsbad 58

Kassel 152

Kempten 160

Kirchbichl 25

Kitzbühel 9,124, 126, 162,173

Klausen 9, 22, 31

Klosterneuburg 145, 169

Köln 50,150

Konstanz 42

Kramsach 76, 85, 86, 100, 161
Krems 145

Kropfsberg 144

Kufstein 9

Kulmbach 7

Kurtatsch 144

Laas 56

Landsberg 105,160

Lans 160

Leipheim 169

Leipzig 46, 63

Leukerbad 55

Lienz 9

Lille 41

Liverpool 63

London 41, 63

Lübeck 107, 144

Luzern 42,143, 144

Lyon 41,150

Mâcon 40

Magdeburg 63

Mailand 152

Mainz 9, 133

Maistatt 7,143

Mannheim 58

Mantua 152

Margate 58

Marling 144

Mehrn 86, 97, 164

Memmingen 143, 160

Meran 9

Montpellier 41

Mosbach (Baden) 30

München 152, 153, 160

Münster (b. Rattenberg) 88

Nals 23

Neuhausen an der Erms 166

Neumarkt (Steiermark) 163

Neuötting 162

Nevers 40

Niederlande 40

Norderney 58

Nördlingen 143

Nürnberg 9, 25, 75, 96, 106, 143, 145, 151 
Ofen (Ungarn) 127

Österreich 9, 32, 40, 148, 167

Paris 9, 41, 52, 58, 59, 64, 147

Pfäfers 153

Philadelphia 54

Plombières 53

Prag 145

Prutz 160

Radfeld 85,119

Ravensburg 143

Regensburg 145, 160

Reith 85

Renningen 151

Rettengschöß 171

Rinn 144

Rohr im Gebirge (NÖ) 107

Rostock 107

Rotenbrunn 147

Rudolstadt 55

Rügenwalde 58

Rum 144

Russwyl 144

San Gimignano 48

Schenna 144

Schgums 56, 153

Schlössel 144

Schwaben 76, 82

Schwäbisch Gmünd 143, 169

Schwäbisch Hall 9, 143, 149

Schwanburg 23

Schwarzwald 158

Schwaz 88, 90, 110, 116, 120, 124-126, 128, 133-137, 160, 161, 169, 173

Schweiz 9, 16, 82, 90, 96, 143, 144, 146, 147, 153

Sellrain 147

Sens 151

Southwark 41

Speyer 46

Steinach 144

Steinberg am Rofan 164

Sterzing 9
St-Germain-en-Laye 58

Stolberg 107

Straßburg 37, 42, 145

Straubing 160

Stuttgart 31, 151

Tegernsee 160

Toulouse 41, 49

Tramin 144

Travemünde 58

Trient 56

Tschengls 56

Tulfes 144

Ulm 7, 9, 32, 143, 149

Ungarn 127, 128

Urbino 152

Versailles 49

Vils 160

Vinschgau 56

Voldöpp 170

Vomp 120, 124, 125, 141

Vorarlberg 82

Wallis 55

Wangen 143, 146-149, 151

Wangerooge 58

Weilheim 87, 160

Wien 3, 30, 46, 58, 75, 145, 153

Wiesbaden 20, 45, 58

Wildschönau 130

Wimpfen 7

Winchester 41

Windsheim 143, 145

Winterthur 7,147

Württemberg 11, 144, 169

Würzburg 9, 32

Zell im Zillertal 137

Zirl 160

Zürich 143, 146, 153

Zwettl 32 


\section{b) Personen}

Albrecht VI., Erzherzog von Österreich 148

Aldegrever, Heinrich 14

Aldobrandino da Siena 103

Alembert, Jean Le Rond d' 59

Allendorf, Philipp 19

Ambrosi Dr., Arzt 173

Amman, Jost 27, 85, 98

Andreoli, Giorgio de Pietro (Maestro Giorgio da

Gubbio) 54

Angst, Bartlme 102

Angstwurm, Heinrich 160

Anton von Burgund, der »Große Bastard « 43, 44, 51

Antzinger, Wolfgang 18, 126

Arba, Jeronime, gen. Walch 105

Arba, Martin 105

Ärnberger, Hans 169

Arnbergerin 120

Arnald von Villanova 23

Ässinger, Cristof 74

Auer, Lienhard 172

Augustinus, hl. 52

Bachmann, Hanns 111

Barbara, Gewandhüterin 83

Bartholomaeus Anglicus 133

Bartisch, Georg 15

Baungartner (Paungartner), Appollonia 169

Baungartner (Paungartner), Barbara 169

Baungartner (Paungartner), Waldpurga, verh. Franntz 169

Beham, Hans Sebald 10, 68, 69

Benedikt, hl. 52

Bernhard, Klosterknecht 100

Bock, Hans d. A. 55

Boimont zu Pairsberg, Jakob Frhr. von 23

Brunschwig, Hieronymus 27

Buswy, Herr von 55, 152

Casanova, Giacomo Girolamo 44

Caspar, Bader 161

Clemens VII., Papst 48

Conrad, Bader 161

Costabilis, Antonio de' 38
Cramer, Johannes 38

Deisenseer, Paul 157

Diderot, Denis 58, 59

Diwoldin 89, 162

Drinker, Elizabeth 54

Drinker, Henry 54

Dryander, Johann 123, 131

Dürer, Albrecht 97

Eberl, Jorig 90

Eberstein, Johann von 45

Ederin 156

Elisabeth, hl. 152

Emmeran, Augustinernovize 108

Erasmus von Rotterdam 95

Erber, Barbara 78, 79

Erber, Jörg 78, 79, 130, 159

Fäler, Afra 173

Fäler, Anna 173

Fäler, Bernhard 131, 136, 172

Fäler, Elisabeth 173

Fäler, Eva 173

Fäler (Fäller, Väller, Feiler, Feyler) Hans d. Ä. 18, $86,96,97,104,114,120,124-132,141,146$, 170-172

Fäler, Hans d. J. 16, 131-137, 142, 172

Feichtmayr, Hans 170

Ferdinand III., Kaiser 150

Ferro, Pascal Joseph 153

Fieger, Siegmund 90, 98

Filippuccio, Memmo di 48

Frannck, Barbara, verw. Fäler 136, 137

Franntz, Utz 123, 124, 169

Franz I., König von Frankreich 54, 152

Freytag, Gabriel 68, 76, 83, 88, 89, 92-94, 96, 111, $141,160,162,163$

Freytag, Hans 163

Friedländer, Michael 61

Fries, Lorenz 57

Frisch(er), Lienhart 160

Frölich (Frelich), Hans Baptista 134, 173

Fuchs, Sigmund 137 
Fuchs von Fuchsberg, Christoph 98

Fueß, Wolf 137

Fugger 50

Ganser, Gall 161

Gartner, Michel 103, 104

Gasteiger, Michel 124

Gebhart, Johann 87

Geigenfeindt, Wolf 74

Geisler, Caspar, gen. Inzinger 77, 159

Geisler, Hans 159

Geisler, Sebastian 159

Geörg, Bader 124

Gersdorff, Hans von 94, 170

Gerung, Matthias 39

Gesner, Konrad 53

Glockendon, Jörg d. J. 135

Goethe, Johann Wolfgang von 50

Graf, Hans 99

Greupp, Caspar 168

Guarinoni, Hippolyt 9, 13, 16-20, 22, 37, 38, 40, $94,117,144,145,147,150,152,154,164,168$

Hannibal 54

Hänsl, Badknecht 102

Härrer, Erhard 158

Härrer, Martin 76.158, 159

Hausen, Peter von 33

Hauser, Fritz 88

Hauser, Thoman 151

Heiligmair, Simon 105

Heinrich IV., König von Frankreich 58

Heinrich von Langenstein 45, 151

Helbling, Seifried 18, 146

Heldt, Sigmund 34

Herbst, Niklas 145

Hero, Michael 112, 137

Heypacher, Rudolf 80

Hieronymus, hl. 52, 62

Hinrik der Stover (der Bader) 150

Höchstetter, Ambrosius 50

Hof, Ambrosi vom 157

Hoflach, Hans 157

Hollar, Wenzel 106

Holtzmann, Peter 100

Holtzmannin 100
Hörmann, Michl, gen. Vindler 120, 121

Hueber, Jörg 130, 131

Hueber, Katharina 84, 87, 99, 161, 162

Hueber, Mich(a)el d. Ä. 83, 84, 90, 100, 111, 141, 165

Hueber, Mich(a)el d. J. 84, 89, 90, 99-103, 105, $107,110,111,141,142,165,167$

Hueber, Veronica 90

Hufeland, Christoph Wilhelm 61

Hupfauf, Michel 81, 160

Hutten, Ulrich von 40, 95

Jacob, Bader 89, 162

Jakob von Warte 11

Johannes, Augustinernovize 108

Johannes, Badknecht 162

Johannes de Sacrobosco 91

Jörg, Bader 161

Joseph II., Kaiser 153

Kagrer, Hans, gen. Schmäntz 165

Kapeller, Sigmund 170

Karg, Hans 82, 83

Karl V., König von Frankreich 152

Karl der Kühne, Herzog von Burgund 44, 50

Karnejew, Efim 62

Kastenbauer (Agricola), Dr. Stefan 89

Kentler, Hans 90, 97-99, 165

Khuen, Caspar 166

Khuen, Ursula 104, 166

Klein (Klain), Georg 160, 173

Kolber, Jörg 10, 79

Konrad von Ammenhausen 26, 72

Kräl, Gilg (Egidius), Kupferschmied 161

Kremer, Georg 135

Kripp, Richard 87

Kuefner, Peter 133

Kuefner, Dr. Johannes 133, 172

Kueperger, Oswald 160

Künig, Cristan 160

Kunz, Badknecht 162

Kupferschmidt, Andre 127, 128

Kyeser, Konrad 12

Lavoisier, Antoine Laurent de 61

Lechner, Lamprecht 130, 131 
Lentz, Spitalknecht 130

Leutner, Georg 137

Liechtenstein, Balthasar von 56

Liechtenstein, Christoph Philipp Graf von 85, 86, 98, 102, 119, 123, 167

Liechtenstein, Paul von, Frhr. zu Castelcorn 86, 88

Liechtenstein, Philipp Graf von 123

Lienhart, Bader 144

Lochgrueber, Jakob 25, 26

Ludwig VII., der Bärtige, Herzog von BayernIngolstadt 66

Ludwig XIV., König von Frankreich 49, 55, 58

Luechner, Barbara, verw. Fäler 137

Luechner, Georg 137

Luechner, Hans 137, 148, 173

Mann, Chosman 137

Marchstainer, Johannes 147

Margarete, Königin von Navarra 54

Margarethe von Flandern 147

Marlet, Jean Henri 65

Marpeck, Margret 105

Marpeck, Pilgram 105

Marquard, Abt zu Fulda 144

Martin, Alfred 7

Matheus, Bader 88

Matheus, Badknecht 109

Maurer, Bartlme 121

Maurer, Margreth 120

Maurer, Paul 120

Maximilian I., Kaiser 38, 86

Mayer, Matheus 173

Mayr, Jakob 32, 150

Meister des Anton von Burgund 43, 44, 51

Meister der Wenzelsbibel 36

Melchior, Benedikt 110, 156, 158

Melchior, Katharina 114, 116

Memle, Hans 172

Merl, Stefan 129

Mornauer von Lichtenwert, Ambrosi 104, 167

Mornauer von Lichtenwert, Wolf Joseph 104, 166

Mörschweger, Jacob 166

Moser, Heinz 7, 42

Moser, Sigmund 76

Mössler, Ludwig 48

Murner, Thomas 23, 113
Neuhauser, Niclas 78, 79, 130

Nicolai, Friedrich 153

Niccoli, Niccolò 45

Oswald, Benedikt 114, 159

Oswald, Benediktin 113,114, 159

Öttinger, Anna 89, 90

Öttinger, Apollonia 89,90

Öttinger, Heinrich (eigtl. Heinrich Perchtold) 81, $84,87-90,92,93,162,163,165$

Öttinger, Katharina, verw. Hueber 84, 87, 89, 90 , 99

Öttinger, Margreth 89, 90162

Paracelsus 56, 98

Patrizzi, Agostino 49

Paungartner (Baungartner), Hans 130, 163

Paungartner (Baungartner), Margreth, verw. Hörmann 97, 120-125

Paungartner (Baungartner), Matheus 76, 85, 96, 97, 104, 117-125, 141, 142, 157, 164, 169170

Paungartner (Baungartner), Waldpurga 124

Peter, Bader 144

Peter, Klosterknecht 162

Petrarca, Francesco 25

Pettendorfer, Bartlme 130, 172

Pfeiffer, Achaci 85, 86

Philipp II., Markgraf von Baden 49

Philipp der Gute, Herzog von Burgund 44, 49, 55

Philipp von Kleve 152

Pictorius, Georg 23, 147, 151, 152

Piechl, Erhard 116, 173

Piechl, Wolfgang 157

Pippin, fränkischer König 145

Pirchach, Caspar von 160

Plaickner, Jörg 173

Plaickner, Sebastian 163

Plaicknerin (die alte Plaicknerin) 135, 173

Plank, Hans 83

Pock, Hans 173

Pockhin, Regina 135, 171, 173

Poggio Bracciolini, Gianfrancesco 45

Poitevin, Jean-Jacques 58

Puchinger, Cristan 130

Püchl, Gilg 116, 168

Püchl (Gilg Peckhin) 114, 116, 135 
Püchler, Hans 102, 107-113, 117, 119, 141, 167, 168

Püchler, Hans d. J. 110, 111

Püchler, Katharina 110, 111

Püchler, Lienhart 167

Püchler, Magdalena 110, 111

Püchler, Simon 110, 111

Püchler, Ursula 110, 111

Püchler, Wandula, verw. Hueber 102, 107, 108, 110, 111, 167, 168

Püechl, Tischler 158

Pühlhueber, Sigmund 125

Pürgl, Cristan 161

Quitzow, Dietrich von 105

Raiser, Lucas 173

Ranndek, Johannes d. Ä. und d. J. 83, 84

Rasp, Jacob 90, 162

Rautner, Georg 157

Reichl, Conrad 111

Reichl, Stefan 113, 159, 165

Reichlin, Stefanin 78, 113, 159, 171

Renaudot, Théophraste 152

Richental, Ulrich von 145

Rixner, Peter 128, 155, 158

Rocca, Georg von 126, 129

Rochow, Wichard von 146

Roland von Parma 31

Rorer, Mathes 144

Rudolf, Herzog von Sachsen 146

Ruedl, Bernhard 130

Ruetz, Christof 137

Rüm(e)1 von Liechtenstein, Anthoni 88

Ryff, Walter Hermann 22, 23, 40, 73, 92, 147

Saint-Ursin, Dr. Marie de 62

Sancta Clara, Abraham a 115

Säppl, Magdalena 170

Säppl, Peter 121, 170

Savonarola, Giovanni Michele 40

Schander, Augustin 114

Schander, Margreth (Stindl Steyerin) 114

Scheiber, Caspar 130

Schekl, Hans 83

Schelhamer, Dr. 63
Schenck von Landsberg, Elisabeth 105, 106

Schick, Alexander 86

Schick, Stefan 85, 86

Schlögl, Melchior 94, 170

Schmerlinger, Stefan 109

Schmied (Schmidt), Matheus 86, 87, 169

Schneider, Andreas 87

Schromann, Clara 168

Schromann, Hans 168

Schwaiger, Jeronime 172

Schwegler, Michel 110,116-118, 141, 168

Schweglerin 169

Schweikhardt, Georg 163

Schweizer, Arzt 120

Sigmund, Erherzog von Österreich 56

Simon, Balthasar (Walthauser), gen. Pair 129, 155

Solis, Virgil 14

Staindl, Christof 131

Staudacher, Hans 173

Steber, Bartholomaeus 96

Stefan, Badknecht 92

Steger, Marx 123

Stetner, Jacob 105

Stolz, Kuntz (Conrad) 86, 100, 161, 165

Stops, Friedrich 7, 69, 72, 76, 111, 143, 146, 153$156,158,164-166,172$

Sturm, Marx 116

Sturm, Potentia 114, 116

Sumer, Lienhard 105

Susruta 28

Taurstein, Wolfgang 130

Tobler, Jörg 157

Todeschini-Piccolomini, Francesco (Pius III.) 49

Topf, Wolfgang 96, 97, 164

Torrella, Gaspar 96

Tuchen, Birgit 7, 38, 72, 143

Tucher, Anton 50,152

Tuesmwar, Simon 126, 171, 173

Ulsen, Theoderich (Dietrich) 97

Ursula, Klostermagd 97

Valerius Maximus 41, 43, 44, 51

Vierling, Thoman 124

Vischer, Hans 77 
Völs, Ferdinand Frhr. von 158

Voltaire (François-Marie Arouet) 58

Waldeck, Wolrad Graf von 55, 152

Waldhueber, Barbara (Sigmund Wachterin) 114, 116,171

Waldhueber, Sigmund, Wächter 114

Weigel, Johann Christoph 115

Weingartner, Michel 135, 136

Weinprenner, Sigmund 154

Weinsberg, Hermann 50

Wendl, Bader 161

\section{c) Sachen}

Abgießen 14, 28, 105, 113, 137, 140

Abreiben, Reiben 19, 21, 22, 28, 31, 34, 69, 101, 105, 112, 113; vgl. Massieren

Abtritt 13, 79, 80

Abziehstube 15, 20, 66, 67; vgl. Garderobe, Umkleideraum

Aderlass 15, 27-29, 31, 33, 34, 47, 72, 73, 75, 82, $83,86,87,89,96,100,105,108,109,113,116$, $119,122,126,127,140,141,149,157$

Arbeiter (als Badegäste) 22, 66, 140

Arzneien 27, 30, 94, 100, 122, 125, 128, 134, 141, $160,167,170,173$

Arznei- und Kräuterbücher 27, 170

Arzt 52, 54-56, 58, 61, 84, 96, 133, 160, 161, 172, 173

Aufguss 22

Augustinerkloster,-mönche 8, 83, 84, 87, 89, 92, $96,99,100,102,105,107-109,133,159-167$, 172,173

Aussatz (Lepra) 93, 94, 164

Badebekleidung 15, 20

Badebordell, Bordell 37, 38, 40-45, 140, 150

Badefrau 28, 36, 37, 78, 82, 112, 140, 147; vgl. Bademagd, Reiberein

Badehr (Badehemd, -kittel) 17, 18, 20, 21, 34, 37, $58,106,139,146$

Badehut, -kappe, -mütze 19, 20, 32, 34, 36, 68, 69, $106,107,113,118,139,155,161$
Wertinger, Hans 21

Wetin, Jacob 86

Wetin, Ursula 86, 87

Widmann, Bartlme 121

Wilhelm I., Kaiser 152

Wilhelm von Hirsau 52

Wimpfeling, Jacob 96

Wolf, Franz 60

Würthle, Friedrich 136

Zierler, Thoman 86

Zoller(in), Elisabeth 146

Badejunge, -lehrling 16, 25, 32, 78, 97-100, 112, $114,116,118,125,136,141,148$

Badekessel s. Kessel

Bad(e)knecht 13,16, 20, 24, 25, 27, 28, 31-37, 70, $71,73,78,82,84,86,89,93,98-101,103-105$, $109,111,112,114,118,122,124,125,132,136$, $141,147,155$

Badelaken, -tuch 20,27, 36, 50, 68, 73, 106, 113, 145,146

Bademagd 20, 27, 28, 30, 33, 34, 36, 37, 41-43, 69, $101,140,147$

Bademantel 20,27, 50, 68, 122, 146

Badeofen s. Ofen

Badequast, -wedel 16, 19, 20, 29,36, 69, 70,105, 113

Baderbruderschaft, -zunft 24, 25, 34, 35, 112, 148, $149,160,168$

Baderof 24, 47, 48, 90, 103, 104, 147, 151

Badeschaff s. Schaff

Badeschiff 58, 59, 61, 140,142, 153

Badetage 16, 27, 46, 82, 99, 109, 118, 128, 132, $138,140,163$

Badewanne, -zuber 27, 50-52, 104, 137, 161; vgl. Wanne, Zuber

Badezimmer 16, 24, 47, 50-52, 58, 64, 104, 140, 152,161

Badgeld 16, 28, 30, 31, 105, 106, 145, 149, 160, 166

Badgeschirr, -zeug 27, 89, 92, 93, 111, 113, 118, 122,125 
Bänke 13, 15, 20, 27, 68, 70, 73, 75, 79, 82, 112, $118,119,145,156$

Barbier, Bartscherer 25-28, 33, 82, 85-87, 90, 100, 110, 116, 118, 140, 145, 148, 161

Bauern (als Badegäste) 66, 140, 146

Bauernbadl (Badhäusl, Stadlbad) 7, 66, 104, 105

Beamte (als Badegäste) 16

Becken 12, 27, 36, 68, 73, 74, 82, 122, 141

Bildung 93, 94, 122, 123, 163, 170

Bindfutter 72, 74. 131

Blutegel 149

Brautbad s. Hochzeitsbad

Brennkammer 13, 71

Brennholz, Holz 27, 34, 46, 68, 70, 81, 88, 89, 92, $94,99,102,108,122,124,128,132,135,151$, $159,162-164,167,171$

Brotbad 147

Bruch (Badehose) 20, 21, 34, 37, 139

Brunnen, Laufbrunnen 12, 32, 70, 76, 77, 137, 157-159

Brunnenbecken 27, 73, 76-78, 132, 139, 158, 159

Bürger (als Badegäste) 19, 22, 31, 66, 140

Butzenscheiben 14, 75, 76, 139, 157, 158

Chirurg, Chirurgie 7, 25, 26, 30, 32, 148

chirurgische Instrumente $27,30,36,68,73,82$, $122,125,141$

Dampfbad 8, 11, 41, 46, 48, 52, 54, 57, 62, 140, 147; vgl. Schwitzbad

Diebstahl (der Kleidung, des Handwerkszeugs) 19, 20, 36, 37, 136, 149, 173

Dielen 14, 20, 72, 73, 75, 139, 154

Dienstboten, Gesinde 16, 30-32, 87, 124, 125, 140,146

Duftbad 23, 24

Duschbad, -kabine 54, 64

Eimer 27, 32, 36, 76; vgl. Kübel

Eintrittspreis s. Preis

Eisenbad, -quelle 56,147

Essen und Trinken im Bad 16, 38, 40, 43, 70, 78, $80,83,90,91,106,139,150$

Fenster, Fensterrahmen, -scheiben 14, 67, 70, 73, $75,76,110,118,139,148,154,157-159,169$
Feuerordnung (Tiroler von 1609) 144

Feuersgefahr, Feuerbekämpfung 12, 32, 116-118, 169

Fließgewässer 12, 14

Flussbadeanstalten 58,62, 142

Frauenbad 23, 58, 60, 63, 147

Frauenstube 10, 12, 13, 20, 37, 42, 66, 67, 69, 70, $73,75,77,113,132,139,147,154-158,171$

Fußbad 27, 51, 62, 101, 113

Garderobe 15, 19, 81, 132, 139; vgl. Abziehstube, Umkleideraum

gebrannte Wässer 27, 32, 113

Gefährlichkeit des Wassers und Badens 52, 54, 57, $62,140,142$

Geruchsbelästigung 74,117, 118, 141

Gesellen (als Badegäste) 16

Geselligkeit 16, 38, 42, 61, 78, 140

Gewandhüterin 36, 37, 82, 83, 93, 111-114, 116, $126,135,141,149,159,171,173$

Gitter 13, 20, 68, 92, 155, 158

Glas (Flach- und Waldglas) 14, 75, 76, 139, 157, 158

Haarschnitt 15, 28, 30, 35, 73, 87, 105, 113, 141

Handtuch 58, 63, 64, 66, 73, 106, 113

Handwerker (als Badegäste) 16, 19, 22, 30, 140

Hautkrankheiten 30, 94, 96, 97, 142, 164

Heilbad 22, 23, 55, 64

Heißluftbad 11, 19

Heizen, Heizraum 11, 16, 27, 30, 34, 66, 70, 71, $81,82,116,118,125,139,141,144,171$

Heubad 7

Hochzeitsbad 8, 38, 105-107, 139, 166

Holzkämmerl 81,89

Holzwasser 23

Huren, Dirnen 40-45, 96, 124, 150, 151, 170

Hygiene 16, 22, 40, 52, 56, 140, 142

Infektionskrankheiten 47, 52, 94-96, 100, 127

Kabinen 58, 59, 63

Kachelofen 11, 15, 19, 68, 71, 79, 155, 159

Kaltbad 7, 55, 56, 58, 140

Kämmen s. Haarschnitt, Kopfwäsche 
Kessel 11, 14, 26, 68, 69, 71, 74, 81, 82, 92, 116,

$$
118,137,155,156,161,169
$$

Kinder 17, 19, 30, 31, 61, 109, 110

Klistier 24, 26, 30

Knappen (als Badegäste) 19, 22, 66, 140

Knechtskammer 71, 72, 81, 139, 156

Kopfwäsche 15, 19, 21, 28, 35, 69, 73, 75, 105, 113, 141,147

Körperpflege 16, 22, 30, 35, 61, 113, 140, 142

Kranke, Krankheiten (allgemein) 82, 93-97, 100, 102, 108, 119, 124, 125, 127, 132, 134, $140,157,164,165$

Krätze 94, 164

Kräuterbad 23, 24, 90, 139, 147

Kübel 27, 36, 76, 113, 147; vgl. Eimer

Kuppelofen 12

Kurbad 7, 16, 38, 44, 45, 56, 64, 140, 142, 153

Lanzette 28, 36

Lasseisen 28, 36, 68, 73, 82, 100, 101, 123, 141

Lasskalender, -tafel, -zettel 28, 159

Lauge 22, 27, 28, 73, 113, 118, 119

Lehrzeit 25

Leibwäsche 57,140

Leichenbeschau, Leichenwäsche 32, 130

Lepra s. Aussatz

Lohn (Wochenlohn) 34-37

Lüften $14,27,75,82,112,117,118,141$

Maibad 8, 90-92, 105, 139

Männerstube (Männerbad) 12, 13, 42, 58, 63, 66, $67,69,72,73,75,77,78,139,154-159$

Massieren 11, 22, 28, 69, 105, 112, 113, 140

medizinische Bäder (zur Vorbeugung und Hei-

lung) $16,22-24,52,55-57,62,78,90$

Meisterprüfung, -stück 25, 26, 142, 148

Messer- und Scherenschleifen 32

Mietwanne (Leihwanne) 50

Milchbad 23

Mineralbad 7,16, 52, 55, 142, 152

Mundhygiene 30, 35, 57

nackt, halbnackt ins Bad 12,17-19, 37, 106, 139, 146

Nebenverdienst $31,32,40,141$
Ofen $9,11,13,26,32,68,70,71,74,81,82,118$, $139,155,156$

Öffnungszeiten 16, 27, 82, 117-119, 168

Ohrlöffelchen 35

Öl(bad) 27, 113

Pest 46, 54, 95, 119

Pflaster 25, 26, 73, 102, 141, 148

Pfründner 87, 109

Pinzette 28

Podagra (Gicht) 23, 25, 52, 56, 147

Preis 22, 27, 29-31

private Bäder 38, 47-52, 99, 100, 103-105, 140, $144,151,152,166$

Quast s. Badequast

Quecksilbersalbe 94-97, 120

Rasieren 15, 28, 35, 73, 96, 105, 108, 141

Rasiermesser s. Schermesser

Rauchgas 14, 16, 71, 117, 125

Regeneration 16, 22, 52, 62, 78, 140

Reiber, Reiberin 36, 37, 42, 78, 82, 93, 100, 111-116, 126, 135, 140, 141, 147, 149, 159, 168, 171,173

Rinne 14, 67, 72, 154-156

Röhren(leitung) 12, 68, 77, 78, 145, 157-159, 161; vgl. Wasserleitung

Ruhebett 15, 16, 27, 40, 67, 139, 147

Ruß 20,112, 146

Salbe $25,26,73,102,146,131$

Sauberkeit 27, 28, 56, 57, 78, 82, 112, 116, 118, $119,141,148$

Sauerbrunnen 7

Schaff 20, 27, 32, 34, 36, 68, 73, 82, 89, 94, 112, 113, 122, 141, 146, 147

Schenkelbad s. Teilbad

Scherbank, -sessel 15, 27, 73, 77, 122, 126, 157, 159

Scherer s. Barbier

Schermesser 27, 28, 36, 82, 96, 100, 136, 141

Schmutz(wasser) 12, 14, 72, 117, 145, 168, 169

Schnepper 28, 36, 129

Schönheitspflege 30,61

Schröpfen 19, 21, 27-29, 33, 34, 36, 73, 75, 82, $105,113,140,141,145,149$ 
Schröpfeisen, -köpfe 15, 27, 29, 31, 36, 68, 70, 73, $74,82,87,101,122,123,141,148$

Schurz 37

Schwamm 22, 52, 159

Schwitzbad, Schweißbad 9-11, 14-16, 20, 22, 24, $28,30,38,40,46,52,57.63,68.73,87,104,139$ 140, 147, 154; vgl. Dampfbad

Schwitzbänke s. Bänke

Seebad 7,58, 142

Seelbad 16

Seife 22, 28, 32, 52, 63, 64

Seuche 24, 30, 46, 47, 89, 100, 102, 109, 119, 124, $126,127,160,161$

Sitzbad 9, 62, 139

Sole- und Schwefelbad, -quelle 55, 56

Spital 8, 47, 109, 120, 129, 130, 146, 161, 169, 172

Steine (erhitzte) 9, 13, 21, 22, 24, 70, 145

Störer (auswärtige Bader) 84-87, 93, 119, 141

Strohhut 21, 32, 139

Syphilis (Franzosen) 47, 54, 94-98, 120, 125, 142, 164

Täfelung 14, 69, 73-75, 79, 139, 159

Teilbad 27,62

Thermalbad 7, 9, 23, 38, 44, 45, 49, 52, 53, 55, 56, $58,64,140,142$

Totenlässl 30, 47, 86, 89, 100, 119, 127, 128, 161, 162,165

Trennwand (Schidwand) 13, 66, 68

Trinkstube 8, 38-40, 78-80, 83, 114, 139, 150, 155, $158,159,162$

trockene Toilette 57,140

Trog 14, 26, 68, 92, 112, 155

Trunksucht 32, 38, 82, 111, 124-126, 132, 135, $141,150,170,171$

Übergießen 20, 23, 28, 34, 56, 113, 140
Umkleideraum 15, 66, 67, 69, 150; vgl. Abziehstube, Garderobe

Unehrlichkeit 32,33, 140

Unfleiß (mangelnder Fleiß) 102, 111, 114, 124126, 128, 135, 141, 171

Unsauberkeit s. Schmutz

Unzucht 33, 37, 38, 40-45

Verbandszeug, Verbinden 25, 27, 34, 73, 82, 109, 130, 141, 147

Vieh-, Rossarznei 84, 161

Volksbad 63, 142

Volksbrausebad 63, 64, 142, 153

Vollbad 9, 14, 61

Vorhäusl (Vorbad) 14, 15, 66-69, 74, 90, 91, 139, 154-157

Wanne, Wannenbad 8, 10,11, 14, 16, 19, 22, 27, $30,38,46,47,50,63,64,67-69,82,87,90,94$, $122,124,139-141,147,154,161$

Warmwasserkessel s. Kessel

Wäsche(anstalt) 10, 63, 153

Wasserleitung 12, 27, 69, 77, 139, 152, 158; vgl. Röhrenleitung

Weinbad 23

Werkzeug (eines Baders) 35, 36, 68, 82, 94, 112, $122,137,141$

Wildbad 7, 38, 39, 44, 45, 55-57, 140, 142, 151

Wundarznei $15,30,34,35,73,75,83,86-88,92$, $96,100,109,113,118-121,125,126,128,129$, $133,134,140,141,149,163,165,167,172,173$

Zahnpflege 29, 30

Ziegel 14, 24, 72, 80, 139, 156

Ziehbrunnen 12, 76, 92, 137, 158, 159

Zuber 9, 24, 27, 32, 38, 46, 50, 89, 91-93, 103-105, $112,147,151$

Zungenschaber 30,35 


\section{Bildnachweis}

Abraham a Sancta Clara, Centi-Folium stultorum in Quarto oder Hundert Ausbündige Narren (I709): Abb. 75

Ärzte, Bader und Barbiere. Die medizinische Versorgung vom Mittelalter bis zum Ende des Alten Reichs. Katalog [der gleichnamigen Ausstellung in Schwäbisch Hall und Tuttlingen 201I/I2] von Herta Beutter u.a. (20II): Abb. 6, I0, 21, 22, 26, 5 I, $52,53,66$

Margit Bachfischer, Musikanten, Gaukler und Vaganten (r 998): Abb. 60

Badewonnen. Gestern-heute-morgen. Hg. v. Hansgrohe (1993): Abb. 5, 37, 38, 39, 43, 44, 45, 47, 49,

Robert Bartlett, Die Welt des Mittelalter (200r): Abb. 54

Françoise Bonneville, Das Buch vom Bad (2002): Abb. 30, 31, 33, 34, 40, 46, 68

Eveline Büchner: Abb. 48, 50, 70

Franz Caramelle u.a., Sankt Notburga (1996): Abb. 56

Hans Dollinger ( $\mathrm{Hg}$.), Hexen, Mönche, Rittertum. Das große Buch vom Mittelalter (2009): Abb. 3, 6I

Handbuch und Führer zum Keramikmuseum Schloss Obernzell ( ${ }^{2}$ I983): Abb. 8

Kay Peter Jankrift, Mit Gott und schwarzer Magie. Medizin im Mittelalter (2005): Abb. I 8, 57, 62, 63, 82

Peter Murray Jones, Heilkunst des Mittelalters in illustrierten Handschriften (I 999): Abb. 20, 59, 67

Kitti Jurina, Vom Quacksalber zum Doctor Medicinae (1985): Abb. 80

Karl-S. Kramer, Bauern, Handwerker und Bürger im Schachzabelbuch. Mittelalterliche Ständegliederung nach Jacobus de Cessolis (I 995): Abb. I 5

Thomas Kren u. Scot McKendrick, Illuminating the Renaissance (2003): Abb. 29

Vladimir Kř́žek, Kulturgeschichte des Heilbades (1990): Abb. 19, 27, 28, 36

»Kurzweil viel ohn' Maß und Ziel«. Alltag und Festtag auf den Augsburger Monatsbildern der Renaissance (1 994): Abb. 7

Alfred Martin, Deutsches Badewesen in vergangenen Tagen ( ( go6): Abb. 9, 35, 65, 69, 85

Ulrich Merkl, Buchmalerei in Bayern in der ersten Hälfte des I6. Jahrhunderts (I 999): Abb. 83

Hermann Peters, Der Arzt und die Heilkunst in der deutschen Vergangenheit (I 900): Abb. I3, I7

Franciscus Petrarca, Von der Artzney bayder Glück, des guten und widerwertigen (I 532 ): Abb. I 4 
Georgius Pictorius, Badenfartbüchlein (1560, Nachdr. 1980): Abb. г 2, 72, 77

Wolfgang F. Reddig, Bader, Medicus und Weise Frau (2000): Abb. 4, 24, 64, 7 1 , 76, 78 , Wilhelm Seledec u.a., Baden und Bäder in Wien (1987): Abb. 4 I, 42

Splash! Das Bad der Philippine Welser. Eine Ausstellung des Kunsthistorischen $\mathrm{Mu}-$ seums Wien im Schloss Ambras, Innsbruck, 30. März bis 30. Juni 20 r 2. Katalog hg. v. Sabine Haag (201 2): Abb. I I, 23

Susanna Stolz, Die Handwerke des Körpers (I 992): Abb. 2

Tiroler Landesmuseum Ferdinandeum Innsbruck: Abb. I, 55

Richard Toellner, Illustrierte Geschichte der Medizin, Bd. 3 ( I 986): Abb. 8 I

Birgit Tuchen, Öffentliche Badhäuser in Deutschland und der Schweiz im Mittelalter und der frühen Neuzeit (2003): Abb. 73, 74

Roland Vetter, Das Alte Badhaus zu Eberbach (r 990): Abb. 79

Wenzelsbibel. König Wenzels Prachthandschrift der deutschen Bibel, erläutert v. Horst Appuhn, Bd. 8 (I990): Abb. 25

Friedrich Würthle, Malerische Ansichten von Süd- und Nordtirol (I 852 ): Abb. 84 


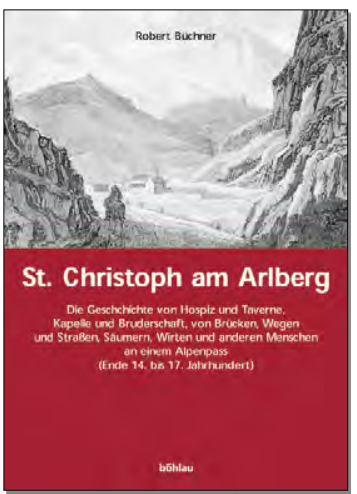

ROBERT BÜCHNER

ST. CHRISTOPH AM ARLBERG

DIE GESCHICHTE VON HOSPIZ UND TAVERNE, KAPELLE UND BRUDERSCHAFT, VON BRÜCKEN, WEGEN UND STRASSEN, SÄUMERN, WIRTEN UND ANDEREN MENSCHEN AN EINEM ALPENPASS (ENDE DES 14. BIS MITTE DES 17. JAHRHUNDERTS)

Die bislang vorliegenden Studien über St. Christoph am Arlberg sind im Wesentlichen eine Geschichte der dortigen Bruderschaft, ergänzt durch einige Aufsätze zur Verkehrsgeschichte. Nun wird, gestützt auf umfangreiches neues Quellenmaterial, noch einmal die Geschichte des Hospizes und der Kapelle seit 1386 aufgerollt und entscheidend korrigiert. Wichtigstes Ergebnis ist der Nachweis, dass die Bruderschaft zu St. Christoph reine Fiktion, eine Erfindung geschäftstüchtiger Almosensammler und Wirte war. Vor allem aber handelt das Buch von jenen Menschen, die am und vom Arlberg lebten oder ihn überquerten. Seit Ende des 15. Jahrhunderts bis in die Zeit Kaiser Josefs II. führte nur ein Saumweg über den Arlberg, und der Verkehr wurde von Säumern aus Vorarlberg und der Schweiz bestimmt, die Schmalz nach Innsbruck und Hall brachten und von dort Salz zurücktransportierten. Daneben kommen Bergführer, Vieh- und Salzhändler, Bergleute, Postboten, Soldaten, Pilger, Reisende, Kaufleute, fahrendes Volk, Gesindel u.a. zu Wort. Für sie war der Arlberg Station oder Mittelpunkt ihres Lebens und sie hatten gelernt, sich an die raue Natur im Hochgebirge anzupassen.

2005. VIII, 523 S. 4 S/W- U. 12 FARB. ABB. $170 \times 240$ MM

ISBN 978-3-205-77282-8

BÖHLAU VERLAG, WIESINGERSTRASSE I, A-IOIO WIEN, T: + 43 I 33024 27-O INFO@BOEHLAU-VERLAG.COM, WWW.BOEHLAU-VERLAG.COM | WIEN KÖLN WEIMAR 

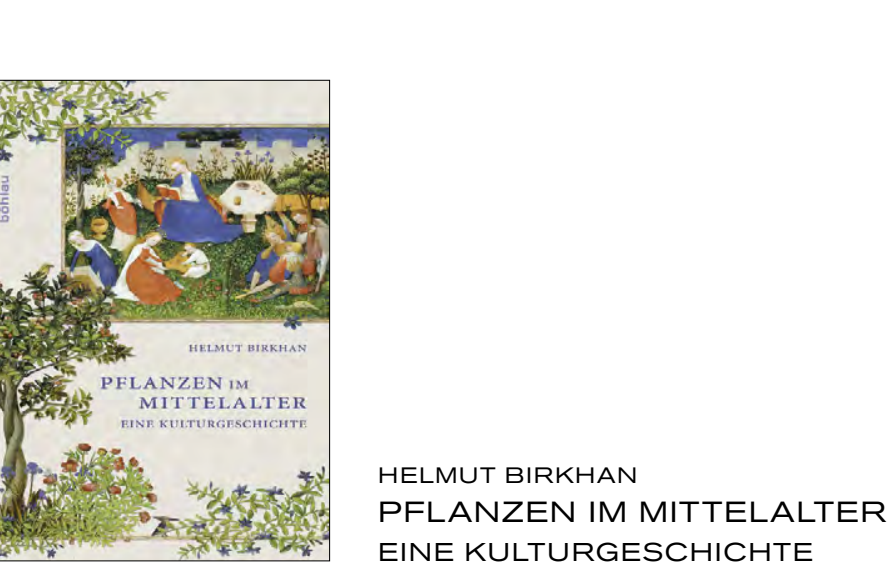

Helmut Birkhan begleitet die Leser in die Welt des Mittelalters, in der die Beziehungen zwischen Pflanzen und Menschen eine besondere Bedeutung hatten. Sein Buch stellt dar, was die Menschen damals über vertraute und weniger vertraute Pflanzen dachten, wofür sie diese verwendeten und welche Wirkung sie sich von den Gewächsen versprachen. „Pflanzen im Mittelalter“ ist eine kulturgeschichtliche Zeitreise und kenntnisreich geschriebene Darstellung.

2012. 310 S. 14 S/W-ABB. GB. 135 × 210 MM. | ISBN 978-3-205-78788-4

BÖHLAU VERLAG, WIESINGERSTRASSE I, IOIO WIEN. T : + 43 (o) I 33024 27-O INFO@BOEHLAU-VERLAG.COM, Www.BOEHLAU-VERLAG.COM | WIEN KÖLN WEIMAR 


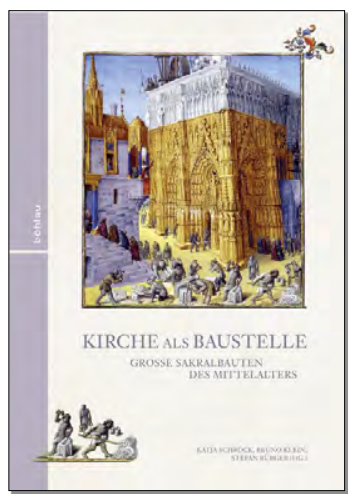

KATJA SCHRÖCK, BRUNO KLEIN,

STEFAN BÜRGER (HG.)

\section{KIRCHE ALS BAUSTELLE}

GROSSE SAKRALBAUTEN

DES MITTELALTERS

Wer sich heute große mittelalterliche Kirchen in den alten Städten Europas anschaut, sieht zumeist nur das künstlerische Resultat, ohne die schwierige Entstehungsgeschichte dieser Monumente zu bedenken. Die Bauherren lösten mit ihrem Bauauftrag stets Prozesse aus, die sie in vielerlei Hinsicht nicht überblicken konnten: Weder ließ sich die zeitliche Dauer abschätzen noch die endgültige künstlerische Gestalt. Vor allem aber vermochten sie die potenzielle soziale Dynamik eines solchen Projektes nicht zu kalkulieren, da solche großen Bauvorhaben das Engagement zahlreicher Personen und Gruppen erforderten. Dabei konnte jeder Stifter und Förderer versuchen, seine soziale Stellung und politische Position zu stabilisieren oder zu verändern. Dass diese Aktivitäten als Teil der baukünstlerischen Qualität zu verstehen sind, wird im vorliegenden Band systematisch und anhand zahlreicher Einzelfälle dargestellt.

2013. 428 S. 134 S/W-ABB. GB. $178 \times 260$ MM | ISBN 978-3-412-20976-6

BÖHLAU VERLAG, URSULAPLATZ I, D-50668 KÖLN, T:+49 22I 9I3 90-O INFO@BOEHLAU-VERLAG.COM, wWw.BOEHLAU-VERLAG.COM | WIEN KÖLN WEIMAR 


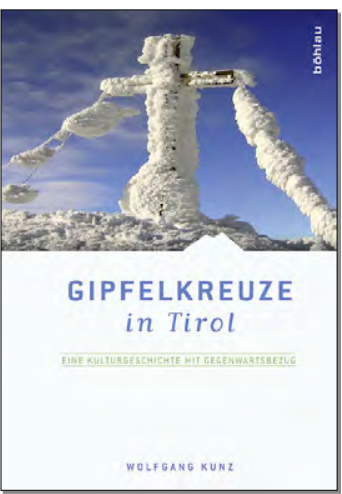

WOLFGANG KUNZ

GIPFELKREUZE IN TIROL

EINE KULTURGESCHICHTE MIT GEGENWARTSBEZUG

Gipfelkreuze sind Symbole des christlichen Glaubens und markieren die höchsten Punkte der Berge. Als Zeichen kollektiver oder individueller religiöser Handlungen ermöglichen sie uns Einblicke in die Glaubenswelten der Menschen. Wer stellt überhaupt Gipfelkreuze auf? Und warum tun das die Menschen? Wie passt dieses Phänomen in eine Zeit der Säkularisierung? Als jüngste kulturell-religiöse Erscheinung auf den Gipfeln werden heute an den Kreuzen immer öfter buddhistische Gebetsfahnen befestigt; ja selbst die Ablehnung von Gipfelkreuzaufstellungen ist ein nicht zu übersehendes Begleitphänomen. Auf alle diese Fragen suchte der Autor Antworten und lädt den interessierten Leser ein, diese kulturellen Aspekte einer Naturlandschaft kennenzulernen.

2012. 262 S. 16 FARB. ABB. GB. $135 \times 210$ MM | ISBN 978-3-205-78727-3

BÖHLAU VERLAG, WIESINGERSTRASSE I, A-IOIO WIEN, T: + 43 I 33024 27-O INFO@BOEHLAU-VERLAG.COM, Www.BOEHLAU-VERLAG.COM | WIEN KÖLN WEIMAR 
Seit dem Mittelalter dienten Schwitzstuben und Wannen in den städtischen Bädern Alt und Jung zur Körper- und Gesundheitspflege, doch man eilte auch zu geselligem Beisammensein ins Bad. Dort gingen Bader, Badeknechte und -frauen den Gästen mit verschiedenen Hilfeleistungen zur Hand (Kopfwaschen, Rasieren, Aderlass, Schröpfen), die Wundarznei blieb dem Meister vorbehalten. Für 100 Jahre (1480-1580) wird das Badeleben in einer Kleinstadt wie Rattenberg vor Augen geführt. 